The author(s) shown below used Federal funds provided by the U.S. Department of Justice and prepared the following final report:

Document Title: Explaining the Prevalence, Context, and Consequences of Dual Arrest in Intimate Partner Cases

Author(s): $\quad$ David Hirschel ; Eve Buzawa ; April Pattavina ; Don Faggiani ; Melissa Reuland

Document No.: 218355

Date Received: May 2007

Award Number: $\quad$ 2001-WT-BX-0501

This report has not been published by the U.S. Department of Justice. To provide better customer service, NCJRS has made this Federallyfunded grant final report available electronically in addition to traditional paper copies.

Opinions or points of view expressed are those of the author(s) and do not necessarily reflect the official position or policies of the U.S. Department of Justice. 


\title{
Explaining the Prevalence, Context, and Consequences of Dual Arrest in Intimate Partner Cases
}

\author{
David Hirschel \\ Eve Buzawa \\ April Pattavina \\ Don Faggiani \\ Melissa Reuland
}

\section{Final Report submitted to The U.S. Department of Justice April, 2007}

This project was supported by Grant No. 2001-WT-BX-0501 awarded by the National Institute of Justice, Office of Justice Programs, U.S. Department of Justice. Points of view in this document are those of the authors and do not necessarily represent the official position or policies of the U.S. Department of Justice. 


\section{ACKNOWLEDGEMENTS}

This study was implemented and completed with the expertise and contributions of many people. We gratefully acknowledge the assistance and input we received from the following.

\section{Local Police, Court, and Victim Service Agencies}

It would not have been possible to carry out this project without the help of many people in the local criminal justice and allied service agencies who provided us with access to the data we required and helped us understand the context in which their agencies operate. To maintain their confidentiality, we are not able to name all of the chiefs and sheriffs, records and information systems supervisors and clerks, domestic violence program coordinators and counselors, police command staff, and domestic violence police officers and deputies who contributed their time and expertise to this project. We are very thankful for their assistance.

\section{State Agencies}

Individuals at the state level were likewise highly instrumental in assisting us to obtain data we required to carry out this project and interpreting the meaning of those data. In particular, we would like to acknowledge the contributions of Dave, Gary, Lisa, and Stan in Connecticut and Tom and Ed in Virginia.

\section{Research Staff, University of Massachusetts Lowell}

Throughout the project we were ably assisted by many talented students at the University of Massachusetts Lowell. Angela Vey was our sole go-to person in the early days of the project and set the standard of excellence we began to expect from all our research staff. In turn, she was succeeded by Helen Bentley, Tiana Platz, and Meaghan Shaw all of whom all of whom demonstrated excellent supervisory skills and ensured that the contributions that they made to this report were of the finest quality. Jeremy Fowler and Matt Geoffroy had prime responsibility for the computerization of the various forms of data we acquired. Their diligent work is highly appreciated. Also gratefully acknowledged are the contributions of Lisa Iannacci, Lolita Desousa, Kristin Sparacello, Eulalie Barraford, Julie Sabourin, Pat Dos Santos, and Tom Scheller.

\section{Police Executive Research Forum}

We at the University of Massachusetts at Lowell are indebted to our partner, the Police Executive Research Forum, its Executive Director Chuck Wexler and PERF's members around the country for their steadfast support and involvement in this research.

\section{National Institute of Justice}

Dr. Angela Moore Parmley, our Project Manager, was an excellent sounding board for the various issues that arose during the course of this project. From the project's inception to its completion she provided us with excellent feedback and highly constructive and helpful suggestions. We greatly appreciate all of her assistance. We would also like to acknowledge the helpful suggestions we received from the reviewers of the initial draft of this report.

Our work is the better as the result of the assistance we have received from all of those we have mentioned and those whom we have inadvertently failed to mention. We are deeply indebted to all of you. 


\begin{abstract}
This Department of Justice funded project provides the first large-scale examination of the police response to intimate partner violence and of the practice known as "dual arrest.” A “dual arrest” occurs when the police arrest both parties involved in an incident. The current research addresses deficiencies in prior research through a two-stage data collection process. In Phase I, we examined all assault and intimidation cases in the year 2000 National Incident-Based Reporting System (NIBRS). This database contains 577,862 police records from 2,819 police departments in 19 states. Using this database and additional information on state law, we investigated the circumstances in which police arrest one of the parties, arrest both parties, and arrest no one in intimate partner, other domestic, acquaintance, and stranger cases. Based on our findings in Phase I, we selected 25 police departments in four states for more intensive examination of domestic violence cases. We conducted on-site visits, examined police records and documents, and conducted interviews. We also followed cases through the court system, and checked for subsequent re-offending. In addition, we surveyed police departments in five states in order to investigate the interrelationships among statutory frameworks, departmental policies, and actual arrests rates.
\end{abstract}

Arrests for domestic violence in states with mandatory arrest laws and preferred arrest laws were significantly higher than those for departments in discretionary states. These higher arrest rates were observed in acquaintance and stranger cases as well, revealing an apparent spillover effect. Factors significantly increasing the likelihood of arrest include offense seriousness, presence of a minor, and offender race. In Phase I analyses location of the incident (in a residence versus elsewhere) was also significantly associated with likelihood of arrest. In Phase II, however, this variable was replaced by whether the offender had remained on the scene.

The overall dual arrest rate was 1.3\%. Dual arrest rates were higher for intimate partner (1.9\%) and other domestics (1.5\%) than for acquaintance $(1.0 \%)$ and stranger $(0.8 \%)$ cases. The existence of mandatory arrest laws (but not preferred arrest laws) significantly increased the likelihood of dual arrest. Dual arrest was significantly more likely to occur in cases involving same sex couples as opposed to heterosexual couples.

Although the existence of a mandatory or preferred warrantless arrest law increased the likelihood of arrest, prosecutorial decision-making and court outcome indicate that cases in states with mandatory warrantless arrest provisions are more likely not to end up in conviction than cases that take place in states with discretionary arrest laws.

Seriousness of the current offense, injury, the offender's criminal history and offender race are all significantly associated with the likelihood of conviction. Determinants of reoffending include prior record, the involvement of alcohol or drugs in the presenting incident, and offender sex with males being more likely than females to reoffend. The policy implications of these results are discussed. 


\section{Executive Summary}

In an effort to combat intimate partner violence, state laws governing police warrantless arrest powers in domestic violence cases have been greatly expanded over the past thirty years. All states have increased police authority by empowering the police to make warrantless arrests in cases of domestic violence and by increasing both the scope of relationships as well as the acts covered under these statutes. Current research indicates that the passage of these mandatory and preferred arrest domestic violence laws has resulted in an increased likelihood of arrest in cases of domestic violence.

This research also suggests the increased arrest rate is in part attributable to a disproportionate increase in arrests for females either as a single offender or as part of what is known as a "dual arrest,” the situation that arises when both parties involved in an incident are arrested. These studies are, however, for the most part limited by their use of a single department, departments in a single state, and/or the size and composition of their sample. In addition, there are a number of important victim, incident, and offender variables that are not considered in the analyses.

\section{Project Goal}

The goal of this project is to overcome these limitations by examining the prevalence, context, and consequences of dual arrest in intimate partner violence cases in a broader context. First, we compare dual arrest in intimate partner cases with its use in other non-intimate partner domestic and non-domestic (acquaintance and stranger) cases. Examining dual arrest in intimate partner cases without reference to what is occurring in these other situations poses the risk of concluding that dual arrests constitute a problem that is unique to intimate partner 
violence. Second, we investigate numerous incident-specific factors and determine their association with officers' decisions to make no arrest, a single arrest, or a dual arrest.

\section{Data Collection Strategy}

Data for the project were collected in two phases. In Phase I, we examined all assault and intimidation cases in the year 2000 National Incident-Based Reporting System (NIBRS) database to investigate the extent to which dual arrest is occurring nationwide, the relationship between incident and offender characteristics, and the effect of state laws on police handling of these cases for all relationship types.

Because the NIBRS dataset only contains a limited number of incident-specific variables that may help explain divergent arrest practices, in Phase II, we collected more detailed information on a subset of NIBRS cases from 25 police departments of varying sizes across four states. This phase of the study was restricted to intimate partner and other domestic violence cases. Additional data were collected for these cases to evaluate court case outcomes and subsequent re-offending. This phase also included an assessment of how closely department policy reflected state law in a larger sample of agencies within five states.

\section{Prior Research and State Law}

Prior research examining the impact of domestic violence legislation has revealed several unintended consequences, including increases in both single and dual arrests of women. In order to obtain an understanding of the legal parameters that may help account for the wide range of arrests rates noted in the literature, project investigators examined variations in individual state law guidelines that dictate police practices in executing warrantless arrest for domestic violence.

In 2000, the year on which this study focuses, there were, including the District of Columbia, 23 states with mandatory arrest provisions, six states with preferred arrest provisions, 
and 22 states with discretionary arrest provisions. These arrest provisions varied both with regard to the circumstances in which an arrest was mandated or preferred (all crimes, only felonies, violation of a restraining order) and the types of relationships those arrest provisions were designed to cover. Primary aggressor laws, which seek to reduce dual arrests by guiding officers to determine the "real” offender, were determined to exist in 24 states.

\section{Phase I Data Collection and Findings}

Sample. Phase I of the study used data from the National Incident Based Reporting System (NIBRS). To focus on the most frequent offenses, and to broaden the context of our examination of dual arrest, the NIBRS dataset examined in this study included all assault and intimidation cases reported to the NIBRS in the calendar year 2000 regardless of relationship type. To identify dual arrest cases, we used a multi-step process to select those incidents where the "victim was offender" code was used in combination with one of several codes that defined the actual relationship between the offender and the victim.

A total of 2,819 contributing jurisdictions in 19 states generated a total of 577,862 incidents of aggravated assault, simple assault, and intimidation in the calendar year 2000 NIBRS dataset. In these 577,862 incidents there were 650,849 victims, 622,258 offenders, and 235,690 arrests. Because the primary focus of the study is on assessing the police response to incidents, the incident was chosen as the primary unit of analysis.

Analysis Strategy. We used Hierarchical Generalized Linear Modeling (HGLM) as the statistical technique for these analyses, with the incident as level one and the agency as level two. The independent variables used to assess arrest practices were legal context (as indicated in state domestic violence warrantless arrest laws); agency characteristics (such as the number of officers per 1000 population, female to male officer ratio, and the total number of assault, simple 
assault and intimidation cases reported in the jurisdiction); victim and offender demographics (including age, sex and race); and incident characteristics (such as offense seriousness, use of weapon, injury, and incident location).

Findings: Arrest practices. A total of 213,598 (37.0\%) of the 577,862 assault and intimidation incidents to which the police responded resulted in arrest. This number comprises 206,370 (35.7\%) incidents in which the police made one or more arrests and 7,228 (1.3\%) situations in which the responding officers arrested both of the involved parties. Arrest rates were higher for intimate partner (49.9\%) and other domestic violence cases (44.5\%) than for cases involving acquaintances (29.1\%) and strangers (35\%). Dual arrest rates also were higher for intimate partner (1.9\%) and other domestics (1.5\%) than for acquaintance $(1.0 \%)$ and stranger $(0.8 \%)$ cases. Factors influencing theses variations in arrest rates were examined next.

Findings: Impact of domestic violence legislation on arrest practices. HGLM analysis revealed that mandatory and preferred arrest laws are having the intended effect of producing higher domestic violence arrest rates in these states compared to states with discretionary arrest laws. In mandatory arrest states, with other factors held constant, the odds of arrest in intimate partner incidents increase by $97 \%$ compared to discretionary arrest states. In preferred arrest states the increase is even higher: about $177 \%$. These higher arrest rates are observed not only in intimate partner and other domestic violence cases, but in acquaintance and stranger cases as well, revealing an apparent spillover effect.

In addition, while the overall dual arrest rates were low (1.3\%), the existence of a mandatory arrest law significantly increased the likelihood of dual arrest for all three of the relationship categories (intimate partner, other domestic, and acquaintance) examined. Thus, this study provides support for the hypothesis that mandatory arrest laws produce higher rates of dual 
arrest in a range of relationship types. The existence of a preferred arrest law did not, however, produce a similarly significant impact on the likelihood of dual arrest.

Findings: Impact of incident and victim/offender characteristics on arrest practices. The key incident-level variables in analyses affecting the arrest decision are those relating to offense seriousness and location, with offenses occurring in residences more likely to result in arrest than those taking place in public. Offender race had a significant effect on the response to intimate partner cases with arrest more likely if the offender was white.

In these analyses, sex had no significant effect on the response to intimate partner or stranger cases. Thus, no support is provided by these analyses for the hypothesis that the increase in the number of female arrests in intimate partner violence cases can be attributed to their disproportionate arrest rate for minor offenses. However, the fact that males and females are equally likely to be arrested may be evidence of an increase in female arrests, if in the past males were more likely to be arrested.

Findings: Impact of victim and offender gender on arrest practices.

Further analysis of the interrelationship between the sex of both the victim and the offender revealed that although the police were equally likely to resolve cases involving both heterosexual and same sex intimate partner couples by making an arrest, cases involving same sex intimate partner couples were substantially more likely to result in the arrest of both parties. Specifically, $26.1 \%$ of the female same sex cases and $27.3 \%$ of the male same sex cases resulted in the arrest of both of the involved parties compared to $0.8 \%$ of the cases with male offenders and female victims and 3.0\% of the cases with female offenders and male victims.

Although dual arrests were about equally likely in female and male same sex aggravated and simple assault cases, dual arrests were twice as likely to occur in intimidation cases 
involving female same sex couples as they were in cases involving male same sex couples. In addition, though in general arrest was more likely if the incident took place in a home or residence, cases involving same sex female victims were marginally more likely to result in arrest if the incident took place outside of the home or residence. Thus, same sex female couples who were involved in incidents that took place outside the home were more likely to be arrested than any of the other victim-offender sex categories.

With regard to heterosexual couples our analyses provided two findings that expanded on what we had found so far. First, the likelihood of dual arrest was about three times greater for cases with male victims and female offenders than for cases with female victims and male offenders. Second, while arrest was less likely in cases involving minority couples, incidents with a minority female victim and a male offender were particularly likely not to result in an arrest.

\section{Phase II Data Collection and Findings}

In Phase II, which focuses only on intimate partner and other domestic cases, the NIBRS dataset was supplemented by the addition of numerous variables from several different sources to explain more fully the divergent practices we observed in arrest patterns. First, we assessed the agency's domestic violence policy as it relates both to the state statute and to that agency's arrest practices. Second, we added detailed incident-level variables not contained in NIBRS to understand their contribution to arrest patterns. These variables included: whether the offender was on the scene when the police arrived, who reported the incident, the exact nature of injuries suffered by the involved parties, victim and offender substance use, offender demeanor, and presence of children. During this phase, data were also collected on court case processing and 
criminal histories to determine the likelihood of conviction in the current case and subsequent offending.

Findings: Policy Analysis. In order to account for some of the unexplained variation found to exist among police departments, we examined the interrelationships among statutory frameworks (e.g. mandatory, preferred, or discretionary arrest), departmental policies, and actual arrests rates. We requested domestic violence policies for the year 2000 from a sample of 479 police departments in five states and obtained responses from 282 (59\%) of the departments.

In exploring the extent to which agency policy varied from statutory arrest requirements, we found that the overwhelming majority of agencies in states with a mandatory arrest law also have mandatory arrest policies in place. As expected, the less predictable results were for agencies in preferred and discretionary arrest states, with the general trend being to have a stricter arrest policy than required by state law, (e.g. a police department in a discretionary arrest state reporting that it has a preferred or mandatory arrest policy).

Whether a department had a mandatory arrest policy according to statute or departmental policy was found to have no effect on arrest practices. Likewise little difference was found for departments defined as having discretionary policies. However, departments that had a preferred arrest policy according to state law tended to have higher arrest rates than departments that defined themselves as preferred arrest departments in their department policies.

Over two-fifths (44.1\%) of the agencies in states without primary aggressor laws had policies with mandates to identify primary aggressors and specific instruction as to their identification. While it may be premature to attribute the lower dual arrest rates in these jurisdictions to the existence of these policies, it is to be noted that these agencies reported a dual arrest rate in intimate partner violence cases that was equal to that reported by agencies in states 
with primary aggressor laws and less than a quarter of the dual arrest rate observed in jurisdictions that operated in states without primary aggressor laws and did not provide primary aggressor instruction.

Findings: Incident-Level Variables. During Phase II, we also collected detailed information from a sample of cases taken from select police departments within four states (Idaho, Tennessee, Virginia and Connecticut) representing the three types of warrantless arrest statutes (mandatory, preferred, and discretionary). To maximize the relevance of our findings and policy implications for other police departments nationwide, we selected, in each of the four states, two medium to large jurisdictions that varied from each other in potential dual arrest, actual dual arrest, and overall arrest rates to serve as core sites. We then selected at least one additional satellite police jurisdiction located near each of the two core jurisdictions selected in each state. A total of 8 core sites and 17 satellite sites were included in this phase. For each of the core and satellite sites, we selected all of the jurisdiction's dual arrest cases and randomly selected a total of 220 single and no arrest cases.

Phase II results contribute substantially to our understanding of the police response to domestic violence. First, while Phase I findings indicated that arrest was more likely if the incident took place in a residence as opposed to somewhere else, Phase II analysis showed that location of the incident no longer exerted a significant impact on the likelihood of arrest. A new variable, offender on the scene, appears to have taken its place. If the offender remained on the scene, he/she was nearly four times more likely to be arrested than if he/she left the scene. As in our Phase I analyses, arrest was more likely in intimate partner than in other domestic cases and if the offender was white. Other new variables that manifested a significant positive effect on 
the likelihood of arrest were: victim injury, presence of minors, and whether the incident took place in a core city.

Most of these variables also impacted the likelihood of dual arrests. Dual arrests were more likely to occur in intimate partner cases and in core cities as opposed to satellite jurisdictions. The responding officers were also more likely to effect dual arrests if the offender remained on the scene. However, they were less likely to make dual arrests if they were aware of the offender having a prior history of violence and if the offender was white.

Sex also appears to affect the likelihood of dual arrest. When the primary aggressor is male, the other party is less likely to be arrested. Since most of the incidents in this study involved parties of the opposite sex, this could be taken as evidence that, for a variety of reasons, the police are adopting a more lenient attitude toward females.

Findings: Court processing of domestic violence cases. In addition to investigating the factors that impact the decision to arrest, we followed domestic violence cases in which the police had made an arrest through the criminal justice system to determine the likelihood of prosecution and conviction, and the factors that affect the probability that the offender will be prosecuted and convicted. We also examined the sentences that were imposed on those convicted of domestic violence offenses.

The sample for this and the next aspect of the project comprises all Phase II cases from the states of Connecticut, Idaho, and Virginia $(\mathrm{N}=3,202)$. Concerns about the quality of data in Tennessee led to the omission of cases from that state.

When we examined the police decision to arrest, we saw that the existence of a mandatory or preferred warrantless arrest law increased the likelihood that the police would make an arrest. The analysis of prosecutorial decision-making and court outcome indicates that 
at this stage of the criminal justice process the reverse occurs. Cases in states with mandatory warrantless arrest provisions were more likely not to end up in conviction than cases that took place in states with discretionary arrest laws. Thus, it appears that prosecutors in mandatory arrest states may be compensating for the increase in caseload generated by the higher number of police arrests by dismissing more cases.

Measures of the seriousness of the current offense and the offender's criminal history are significantly associated with the likelihood of conviction. If injury was inflicted the case is about one and a half times more likely to end up in conviction.

Whites were thirty percent more likely than minorities not to have the case result in conviction, which is inconsistent with what we saw at the police stage. Thus, while white offenders were more likely to be arrested, they were less likely to be convicted than minority offenders. This is a significant issue that merits further investigation.

Consistent with our previous finding that the police were more likely to arrest in intimate partner violence cases, our analysis of the court processing of cases shows that conviction is more likely to occur in intimate partner than in other domestic cases. This may be an indication that there is a system wide inclination to treat intimate partner violence cases more seriously. This is, however, an issue that requires further investigation.

Findings: Rearrest. The final issue examined in this report concerns the impact of police intervention on the likelihood of rearrest. Of particular concern is whether there is a differential impact on males and females who are arrested for domestic violence offenses, particularly those who are arrested as part of a dual arrest. All offenders and victims in the 3,202 cases were tracked through either the state or local record system to see if they were rearrested after the 
incident that brought them into the year 2000 NIBRS dataset. The minimum follow up period was three years, the maximum just over five years.

The results of this analysis are consistent with prior research that shows that prior behavior is the most significant predictor of subsequent behavior. Offenders with prior arrest records for any offense were over seven times more likely than those without prior records to be rearrested. Being arrested or cited for the incident that brought the case into the sample was not, however, a significant predictor of subsequent arrest. Nor was being convicted for that incident. For many of these offenders the current case was just one in a series of arrests.

The involvement of alcohol or drugs in the incident was, however, a significant predictor of subsequent arrest. This finding would appear to highlight the recognized interrelationship between alcohol/drug use and battering, and the need for offenders to receive treatment for both problems.

Being male was also a significant predictor of rearrest. It is uncertain to what extent this finding is an indication of the intractability of the male psyche or is the result of other factors such as the lack of availability of, referral to, and successful usage of treatment options.

\section{Policy Implications}

These results should be reassuring to those legislators and community members who supported the creation of mandatory arrest laws to improve the consistency and severity with which police treat domestic violence. However, in addition to increasing the overall arrest rates, these laws also produce higher dual arrest rates. Those who sought to provide officers with somewhat greater decision-making authority, by enacting preferred arrest laws, will be pleased that these laws appear to mitigate the tendency toward dual arrest—which is considered by many to be a poor outcome. Of concern to policymakers, victim advocates, legislators and academics 
alike is the influence of race and offender presence on the likelihood of arrest. Also troubling are the high rates of dual arrests of same-sex couples.

For many it may also be reassuring that intimate partner cases are in general treated more seriously than other types of cases. However, less than half of the intimate partner cases that were referred for prosecution resulted in conviction. In addition, although the existence of a mandatory or preferred warrantless arrest law increased the likelihood of arrest, prosecutorial decision-making and court outcome data indicate that cases in states with mandatory warrantless arrest provisions are more likely not to end up in conviction than cases that take place in states with discretionary arrest laws. This may be taken as an indication that more attention needs to be given to what happens to cases after arrest.

A significant issue raised by our examination of subsequent rearrest relates to the interrelationship between alcohol and drug use and battering. Although substance use was not significantly associated either with arrest or conviction, it was associated significantly with rearrest. For police, this means that more attention should be paid to this factor, and its documentation in incident reports. This finding would also appear to highlight the need for offenders to receive treatment for both problems. 


\section{Chapter 1 \\ Introduction}

As stated in the program narrative in the grant proposal, the goal of this project is "to further our understanding of the prevalence, context, and consequences of dual arrest in intimate partner violence” (Hirschel \& Buzawa, 2001, p. 1). Written in response to a National Institute of Justice solicitation for proposals to examine the issue of dual arrest in intimate partner violence cases, the proposal sought to place the issue in a broader context. This was to be achieved in two ways: (1) By examining the phenomenon of dual arrest in intimate partner cases in comparison to its use in other non intimate partner domestic and non-domestic (acquaintance and stranger) cases. And, (2) by investigating the use of dual arrest in relation to the other options available to responding police officers, namely arresting one of the involved parties or neither of them.

More specifically, as outlined in the grant proposal, the objectives of the project were:

- To describe the prevalence and context of dual arrest in the United States.

a To explain the variance in dual arrest rates throughout the United States.

- To describe dual arrest within the full range of the police response to intimate partner violence.

․ To analyze the factors associated with no arrest, single arrest and dual arrest.

a To examine the reasons why women are arrested in intimate partner cases. And,

- To describe how the criminal justice system treats women who have been arrested for domestic violence (Hirschel \& Buzawa, 2001, pp. 1-3).

The proposed methodology envisaged a two-phase research design. In Phase I we would examine all assault and intimidation cases in the year 2000 National IncidentBased Reporting System (NIBRS). Using this database and additional information on 
state law, we would investigate the circumstances in which police arrest one of the parties, arrest both parties, and arrest no one in all cases of assault and intimidation. This would provide an accounting of the extent to which dual arrest is occurring nationwide and would permit an investigation of the relationship between incident and offender characteristics, as well as the effect of state laws, on police handling of assault and intimidation cases involving intimate partners, other domestic relationships, acquaintances, and strangers.

While Phase I would provide comprehensive coverage of police department arrest practices, the NIBRS dataset does not contain a wide variety of variables that may help explain divergent arrest practices. To compensate for this deficiency we proposed to collect more detailed information on a subset of NIBRS cases in Phase II. As described in our original proposal, as modified by both our supplementary proposal (Hirschel \& Buzawa, 2003) and discussions with NIJ staff, we proposed to select between twenty and thirty police departments across four states for more intensive data collection. For this phase of the study we limited the focus to intimate partner and other domestic violence cases. This phase of the study would not only provide more detailed information about police arrest practices, but would also yield information on the processing of domestic violence cases and subsequent re-offending. Since the number of police departments selected for Phase II would not provide a large enough sample to investigate the extent to which department policy reflected state law, we proposed an additional survey of police departments to examine the degree of congruence between departmental policy and state law. 
This report is divided into four parts. In Part 1 (chapters two and three) we provide background information on prior research and state law. In Part 2 (chapters four through six) we present our Phase I findings. In Part 3 (chapters seven through twelve) we present our Phase II findings. Finally, in Part 4 (chapter 13) we discuss the policy implications of our research findings. 


\section{Chapter 2 \\ Prior Research}

In an effort to combat intimate partner violence, state laws governing police warrantless arrest powers in domestic violence cases have been greatly expanded over the past thirty years. All states have increased police authority by empowering the police to make warrantless arrests in cases of domestic violence and by increasing both the scope of relationships as well as the acts covered under these statutes. In addition, state statutes have sought to reduce police discretion by mandating specific actions be taken when responding to such incidents. The extent to which states have permitted the police to retain discretion in the decision to arrest varies considerably. While some states still allow police to retain flexibility, many states now require more aggressive intervention by stating that arrest is the preferred police response, or by mandating an arrest whenever there is probable cause to believe a crime of domestic violence offense has been committed.

Current research indicates that the passage of mandatory and preferred arrest domestic violence laws has resulted in an increased likelihood of arrest in cases of domestic violence (see, e.g., Chaney \& Saltzstein, 1998; Eitle, 2005; Ho, 2000; Lawrenz, Lembo \& Schade, 1988; Miller, 2001, 2005; Municipality of Anchorage, 2000: 8-9; Office of the A.G. California, 1999; Robinson \& Chandek, 2000; Simpson, Bouffard, Garner and Hickman, 2006; Wanless, 1996, pp. 558-9; and Zorza \& Woods, 1994, p.12). This research also suggests that the increased arrest rate is in part attributable to a disproportionate increase in arrests for females either as a single offender or as part of what is known as a "dual arrest," the situation that arises when both parties involved in an incident are arrested. These studies are, however, for the most part limited by their use of 
a single department, departments in a single state, and/or the size and composition of their sample. In addition, there are a number of important victim, incident, and offender variables that are not considered in the analyses.

The increase in domestic violence arrests may also be attributed to an expansion in the scope of relationships since domestic violence statutes were first implemented. While initial domestic violence statutes typically only addressed violence between married couples, definitions have been expanded in all states to encompass a far broader range of domestic relationships. To date, empirical research on the arrest of females has either addressed the impact of these laws only in intimate partner cases (see, e.g., Eitle, 2005; Simpson et al., 2006), or in domestic cases as a whole without differentiating the differences between the impact observed in intimate partner and other domestic violence cases (see, e.g. Office of the A.G. California, 1999; Zorza \& Woods, 1994). This is of significance since data from the 1990s indicate an increase in the volume of domestic violence cases reported to law enforcement involving relationships other than intimate partner (Buzawa \& Hotaling, 2006).

In addition, none of the studies has compared police arrest practices in intimate partner violence cases with what is occurring in non-domestic violence cases. Examining police arrest practices in intimate partner cases without reference to what is occurring both in other domestic and in non-domestic violence situations poses the risk of concluding that dual arrests constitute a problem that is unique to intimate partner violence. The salient issue with regard to non-domestic cases is whether the increased attention legislation gives to intimate partner violence has a similar impact on non- 
domestic assaults, or alternatively, limits the resources or willingness needed to provide a similarly aggressive response to non-domestic cases.

In the following sections we review existing research literature on the growing role of domestic violence legislation and examine the available data on changes in arrest practices following implementation. We also discuss the potential unanticipated consequences of domestic violence legislation, including an increase in both single and dual arrests of women. We conclude the review with unanswered questions that will be the focus of the current project.

\section{The Increase in Domestic Violence Arrests}

Beginning in the 1970s, political pressure exerted by women's groups, lawsuits brought against police departments for negligence and failure to provide equal protection to female victims in domestic violence situations (see, e.g., Bruno v. Codd (1977); Scott v. Hart (1976); Thurman v. City of Torrington (1984)), and the findings reported by the Minneapolis domestic violence experiment (Sherman \& Berk 1984a, 1984b), resulted in a nationwide movement toward arrest as the preferred response to domestic violence. ${ }^{1}$ At the core of this movement have been legislative mandates designed to influence and change police behavior. This expectation is supported by research on domestic violence legislation that reports increased rates of arrest, prosecution, and conviction as well as improved responsiveness toward victims (National Research Council, 2004).

Prior research indicates that the raw numbers of domestic violence arrests increased in many police departments after the implementation of mandatory or proarrest laws and policies (see, e.g., Chaney \& Saltzstein, 1998; Lawrenz, Lembo \& Schade, 1988; Zorza \& Woods, 1994, p.12; Wanless, 1996, pp. 558-9; Office of the A.G. 
California, 1999; Municipality of Anchorage, 2000: 8-9). Arrest rates from data collected in the 1970s and 1980s were generally in the 7\% to 15\% range: for example, 7.3\% (Dutton, 1984, based on the six observational studies he examined); 7.5\% (Holmes \& Bibel, 1988 in Massachusetts); 10\% (Worden and Pollitz, 1984 from an examination of police/citizen encounters in Rochester, N.Y., Tampa-St. Petersburg, Florida, and St. Louis); 13.9\% (Bayley, 1986 in Denver, Colorado). More recently, however, these rates have been observed to be 30\% or more: see, e.g., 29\% (Bourg \& Stock, 1994 in South Florida); 33\% (Mignon \& Holmes, 1995 in Massachusetts); 34\% (Buzawa \& Hotaling, 2000 in Massachusetts); 36\% (Robinson \& Chandek, 2000 in the Midwest and Ho, 2003 in Columbia, South Carolina); 39\% (Simpson et al., 2006 in Maryland); 48\%, 53\% and 76\% (Hall, 2005 in three cities in upstate New York); 49\% (Eitle, 2005 in 115 jurisdictions with one hundred or more officers); and 75\% (Jones \& Belknap, 1999 in Boulder, Colorado where an agency overseeing the actions of criminal justice officials had been in place for eight years and the pro-arrest policy contained a mandate that officers not only arrest batterers but also have them jailed).

There is an acknowledged need to determine how these changes impact police behavior both in intended and unintended ways. While legislative mandates can be expected to promote the desired change, compliance is likely to impact organizational behavior in unexpected ways (Applegate, 2006; Manning, 1997; National Research Council, 2004; Roots, 2004). One topic of primary concern has been research reporting an increase in female arrests after the implementation of domestic violence legislation.

\section{The Increase in Female Arrests}


Accompanying the general increase in arrests for domestic violence offenses after the implementation of a preferred or mandatory arrest law, there has been an increase in the arrest of females for assault overall. Chesney-Lind (2006) has observed that, while the FBI (2004) reports that the male arrest rate for assault fell approximately 5.8\% between 1994-2003, the female arrest rate increased by 30.8\%. Likewise, Greenfeld and Snell (1999) have noted an increase in female convictions for aggravated assaults, which they believe may be attributable to domestic assault.

An increase in female arrests for domestic assault specifically has also been found. Research conducted in Washington State after the enactment of a mandatory arrest law in 1984 showed that women were now being arrested in 50\% of all cases in which an arrest was made for domestic violence offense (Epstein, 1987, citing Kassel, 1985). In California, a state with a preferred arrest law, De Leon-Granados, Wells and Binsbacher (2006) observed that, while women constituted 5\% of felony domestic violence arrests in 1987, they made up $18 \%$ of such arrests in 2000 . In Delaware, where police departments tend to operate under pro-arrest policies, Miller (2005) found that the proportion of female arrests for domestic assault grew from 5\% in 1987 to 17\% in 1999. Finally, research conducted in Winnipeg, Manitoba, Canada between 1991 to 1995 shows that the implementation of a zero tolerance domestic violence policy in 1993 had a significant impact on the percentage of female violence arrests that were domestic violence related, with these arrests increasing from 23\% of such charges in 1991 to 58\% in 1995 (Comack, Chopyk, \& Wood, 2000).

Part of the increase in female arrests may be the result of the increase in cases where the police have arrested both parties (see, e.g., Epstein, 1987; Martin, 1997; 
Saunders, 1995; Victim Services Agency, 1988; Zorza \& Woods, 1994). Thus, after the state of Washington enacted its mandatory arrest law in 1984, dual arrests increased and constituted one third of all arrests made for domestic violence offenses (Victim Services Agency, 1988). When New York enacted its mandatory arrest law in 1995, dual arrests were reported to have had similar increases (Haviland, Frye, Rajah, Thukral, \& Trinity, 2001).

\section{Possible Explanations for the Increase in Female Arrests}

There are several possible explanations for why domestic violence legislation may have produced an increase in the arrest of females. First, police may find themselves in a situation where the admissions of the involved parties, evidence, and/or witnesses identifies the female as the primary aggressor. Thus, while officers may be inclined to assume that adult male against female violence typically involves a male primary aggressor, they believe the evidence necessitates an arrest of the female. Research by Moffit, Caspi, Rutter, and Silva (2001) suggests that women do in fact commit a considerable number of violent acts in intimate relationships that do not constitute self defense, although the researchers do emphasize that the women's rates of violence are considerably lower, and their acts are less severe, than those perpetrated by males.

Therefore, women may not be the sole victims of domestic violence.

Second, officers may be attempting to implement a gender-neutral policy and believe that in order to implement the law fairly, they must arrest all violent parties (Buzawa \& Buzawa, 2003; Renzetti, 1999; Miller, 2006). Thus, the officer makes a decision regarding an assault in the context of a specific incident, rather than in the context of the victim-offender relationship (Buzawa \& Buzawa, 2003; Miller, 2001). 
Third, legislation directed at changing an organization's response can be expected to limit the influence of non-organizational variables (Black, 1976; Mastrofski, et. al., 1987; \& Wilson, 1968). Specifically, domestic violence legislation directed at limiting discretion in the decision to arrest can be expected to limit the influence of situational variables and result in a more legalistic response.

Fourth, police may be more likely to arrest women as part of an overall increase in arrests out of concern for the perceived or real threat of lawsuits (Buzawa \& Buzawa, 2003; Miller, 2005). The increased concern by departments to reduce liability and officer perceptions about civil liability may result in a decreased likelihood to use discretion (Hughes, 2001; Kappeler, 2001). In the case of domestic violence, this may create an unwillingness to attempt the identification of a primary aggressor and result simply in the arrest of “any and all violent parties.”

Fifth, there has been historic concern regarding the police propensity to arrest in cases of domestic assault compared to incidents of non-domestic assaults. In domestic violence cases, arrest has generally been infrequent and considered a last resort (Bittner, 1974; Black, 1976; Buzawa \& Buzawa, 2003; Elliott, 1989; Manning, 1997; Parnas, 1967; Skolnick, 1966; Wilson, 1968). Statutes mandating arrest in cases of domestic assault are likely to result in an increase in a more "legalistic" approach to domestic assault resulting in a greater likelihood for arrest in a domestic compared to a nondomestic assault. Since the vast majority of domestic violence incidents involve a female as one of the parties while the majority of non-domestic assaults involve males only, there may be a disproportionate increase in the proportion of females arrested for assault overall as a result. 
Research regarding leniency toward domestic violence compared to non-domestic violence cases has resulted in mixed findings. While some studies indicate that the police are less likely to arrest in domestic violence cases (see, e.g., Buzawa, Austin, \& Buzawa, 1995; Eigenberg, Scarborough \& Kappeler, 1996; Fyfe, Klinger \& Flavin, 1997; Avakame \& Fyfe, 2001; Felson \& Ackerman, 2001), other studies show a consistent police response to domestic and non-domestic violence cases (see, e.g. Oppenlander, 1982; Klinger, 1995; Feder, 1998). While a critique of this research is beyond the scope of this report, there are major differences in methodological strategies that make it difficult to draw any conclusive results. Further, research to date that has attempted to examine data nationally has relied on National Crime Victimization Survey data (Avakame \& Fyfe, 2001; Felson \& Ackerman, 2001), an approach that cannot account for potentially major, and possibly conflicting, practices among police departments.

\section{Nature and Extent of Dual Arrest}

In the first detailed study of dual arrests, Martin (1997) examined the disposition of domestic violence cases handled by the criminal courts in Connecticut just after implementation of a mandatory arrest policy in 1988 and found the dual arrest rate in adult intimate family violence cases to be 33\%. Compared to incidents resulting in single arrest, dual arrest cases were more likely to involve young white women who were unmarried and living with the co-defendant. Drugs and alcohol were more likely to be involved in dual arrest cases, although there was no information on who was actually under the influence of drugs and/or alcohol.

More recent research has shown wide variations in dual arrest rates in domestic violence cases. Where statewide data are available for domestic violence cases, dual 
arrest rates are as high as 23\% in Connecticut (Peng, personal communication, July 10, 2002), as low as 4.9\% in neighboring Rhode Island (Domestic Violence Training and Monitoring Unit, 2001a), and are 8\% in Arizona (Governor's Division for Prevention of Family Violence, 2001). The overall rate of women arrested for domestic violence also varies. In these three jurisdictions, it is 30.8\% (Connecticut Department of Public Safety, 2000), 17.4\% (Domestic Violence Training and Monitoring Unit, 2001b), and 28\% respectively (Governor’s Division for Prevention of Family Violence, 2001).

In some cases, dual arrests may be the result of legislation and/or department policies failing to require officers to identify the primary aggressor. As indicated in the next chapter, a majority of states do not have primary aggressor statutes on the books. In addition, when such provisions are present, there may be a lack of sufficient police training and/or a lack of information needed when responding to a domestic assault in order to identify the primary aggressor. This situation may be compounded by the allegation that batterers have become increasingly adept at manipulating the criminal justice system in an effort to further control or retaliate against their victim and may make efforts to “pre-empt” victims from notifying police (Buzawa \& Buzawa; 2003; Klein, 2004; Chesney-Lind, 2006).

Even in those cases where officers are asked to select a primary aggressor, current political and/or organizational pressure, and cultural norms may discourage officers from identifying women as “aggressors,” and, unsure what to do, the officers may arrest both parties. This observation is supported by some of the existing research. Jones and Belknap (1999:265-6) found in their Boulder study, where there was a strong pro-arrest policy, that male victim/female aggressor pairs were three times more likely to constitute 
a dual arrest than were female victim/male aggressor pairs. Likewise, Buzawa and Hotaling (2000) found in their study of three Massachusetts towns operating under a state pro-arrest law that when a male was a victim, the female was five times less likely to be arrested than was a male (p. 103). Prior research (see, e.g. Buzawa \& Hotaling, 2000) also suggests that dual arrest may occur less frequently in intimate partner relationships than in other types of domestic violence situations (e.g. siblings, parent/child).

Some research has suggested that the dual arrest of a female may be the result of specific behaviors and traits. Females who were unmarried cohabitants were reported to have higher rates of dual arrest than females in other intimate relationships (Houry, et. al., 2006). However, this may be a result of an increased likelihood that the police could not determine the primary aggressor (a possibility acknowledged by the researchers), especially if the incident did not occur in the residence. In addition, female use of alcohol and possession of a weapon has been reported to increase the likelihood of dual arrest (Houry, et. al., 2006). This substantiates Meda Chesney-Lind’s $(1988,2006)$ longstanding position regarding the more punitive treatment of women who deviate from the “good woman” image. The male failure to conform to expected social norms and behavior is more likely to be tolerated than is similar behavior by females.

\section{The Need for Current Research}

The question of when a single, dual, or no arrest is appropriate in cases of domestic assault cannot always be easily determined. The research that has been performed has been limited to a single site or jurisdiction with a limited set of variables. Martin's (1997) work is a single site study providing a retrospective account of the police response to a limited percentage of intimate partner cases that reached the courts. 
Research considering the full range of police responses to domestic and non-domestic assaults (no arrest, single arrest and dual arrest), and examining the legislative, organizational, incident, victim, and offender variables associated with those responses, would clearly provide a better understanding of dual arrest. Research may find that not only are observed variations real, but that there is no one set of variables that works as a constant among all departments both within and between states.

In sum, there are several explanations suggested for the increase in domestic arrests observed in the literature. Most hinge on changes in domestic violence legislation. However, to some extent, the variation in arrest rates reported by researchers to date is the result of differing methodologies and data sets.

In this report, we expand on prior research by undertaking a more intensive examination of domestic violence legislation. There is a need for a large-scale national empirical analysis of police arrest practices to determine the nature and extent of variation in the law enforcement response both within and among the states. This can help us better understand how the structure of domestic violence arrest laws impacts the decision to arrest as well as its limitations in influencing police practices. Of concern too is the extent to which police policies interact with legislative mandates and impact arrest decisions. Hopefully, this research will contribute to our growing understanding of the types of assaults reaching police attention and the reasons behind their decisions to arrest.

\footnotetext{
${ }^{1}$ For a more detailed history of the law enforcement response to intimate partner violence see e.g. Buzawa \& Buzawa (2003), Hirschel and Dawson (2000), Hirschel, Hutchison, Dean \& Mills (1992), and Pleck (1989).
} 


\section{Chapter 3 \\ The Parameters of State Law}

By prescribing general police powers and duties, state law provides the outside parameters within which the police must operate within a particular state. In order to understand the variations that exist among states in police policy and police practice, it is important to examine the guidelines provided by individual state laws. In this chapter we first examine state statutory warrantless arrest provisions, then look at actions that state statutes proscribe responding officers undertake, and finally review state primary aggressor laws.

\section{State Statutes Governing Warrantless Arrest}

As described in chapter 2, there has been since the 1980s a major move toward states enacting mandatory and preferred arrest laws in domestic violence cases. These laws seek to govern police practice in responding to domestic violence calls and enforcing suspected violations of restraining orders. In calendar year 2000, the year on which this study focuses, there were, including the District of Columbia, 23 states with mandatory arrest, and six states with preferred arrest, statutory provisions. ${ }^{1}$ As shown in Table 3.1, the states with mandatory arrest provisions vary both with regard to the circumstances in which arrest is mandated and the relationships those arrest provisions cover. While some states, such as Colorado and Kansas, have mandatory arrest provisions that apply to all crimes of domestic violence, others such as Maine and Ohio limit their provisions to felonies, while still others limit their provisions to offenses committed within a specified timeframe (e.g. Washington within past 4 hours, Alaska within past 12 hours, and both Mississippi and Nevada within past 24 hours). One state, Missouri, limits its mandatory arrest provisions to "any law enforcement officer subsequently called to the same address within a twelve-hour period, who shall find probable cause to believe 
the same offender has again committed a violation ....against the same or any other family or

household member”(Mo. Rev. Stat. § 455-085).

Table 3.1

States with Mandatory Arrest Provisions

\begin{tabular}{|c|c|c|c|}
\hline State & Mandatory Arrest for Crime & Circumstances & $\begin{array}{c}\text { Coded } \\
\text { Relationships } \\
\end{array}$ \\
\hline Alaska & Alaska Stat. § 18.65.530(a) & $\begin{array}{l}\text { Probable cause to believe that a crime of domestic } \\
\text { violence was committed within past } 12 \text { hours. }\end{array}$ & A,B,C,D,E, \\
\hline Arizona & Ariz. Rev. Stat. Ann. § 13-3601(B) & $\begin{array}{l}\text { Domestic violence involving infliction of physical } \\
\text { injury or use/threatening use deadly weapon. }\end{array}$ & A, B, C, E \\
\hline Colorado & Colo. Rev. Stat. § 18-6-803.6(1) & $\begin{array}{l}\text { Probable cause to believe a crime of domestic } \\
\text { violence was committed. }\end{array}$ & A, B, C \\
\hline Connecticut & Conn. Gen. Stat. § 46b-38b(a) & $\begin{array}{l}\text { Speedy information that family violence was } \\
\text { committed in jurisdiction. }\end{array}$ & $A, B, C, E$ \\
\hline $\begin{array}{l}\text { District Of } \\
\text { Columbia }\end{array}$ & D.C. Code Ann. § 16-1031 & $\begin{array}{l}\text { Probable cause to believe that an intrafamily offense } \\
\text { was committed that resulted in physical injury } \\
\text { including pain or illness or caused or was intended to } \\
\text { cause reasonable fear of imminent serious physical } \\
\text { injury or death. }\end{array}$ & A, B, C, D, E \\
\hline Iowa & Iowa Code $\S 236.12(2)$ & $\begin{array}{l}\text { Probable cause to believe that domestic abuse assault } \\
\text { committed that resulted in bodily injury, or was } \\
\text { committed with intent to inflict serious injury, or } \\
\text { with use or display of dangerous weapon. }\end{array}$ & A, B, C, E \\
\hline Kansas & Kan. Stat. Ann. § 22-2307(b)(1) & $\begin{array}{l}\text { Probable cause to believe a crime has been } \\
\text { committed. }\end{array}$ & A,B, C, E \\
\hline Louisiana & $\begin{array}{l}\text { La. Rev. Stat. Ann. § 46:2140 ; Ch. C. Art. } \\
1573(1)\end{array}$ & $\begin{array}{l}\text { Reason to believe family or household member has } \\
\text { been abused and (1) probable cause exists to believe } \\
\text { that aggravated/second degree battery was committed } \\
\text { or (2) aggravated or simple assault or simple battery } \\
\text { committed and reasonable belief in impending danger } \\
\text { to abused. }\end{array}$ & $\mathrm{A}, \mathrm{B}, \mathrm{E}$ \\
\hline Maine & Me. Rev. Stat. Ann. tit. 19-A, § 4012(5) & $\begin{array}{l}\text { Probable cause to believe there has been a violation } \\
\text { of title 17-A, section } 208 \text { (aggravated assault statute) } \\
\text { between members of same family or household. }\end{array}$ & A, B, C, D, E \\
\hline Mississippi & Miss. Code Ann. § 99-3-7(3) & $\begin{array}{l}\text { Probable cause to believe that within } 24 \text { hours } \\
\text { offender knowingly committed a misdemeanor act of } \\
\text { domestic violence. }\end{array}$ & A, B, E \\
\hline Missouri & Mo. Rev. Stat. § 455.085 & $\begin{array}{l}\text { Called to same address within } 12 \text { hours and probable } \\
\text { cause to believe same offender has committed abuse } \\
\text { or assault against same or other family/household } \\
\text { member. }\end{array}$ & $\mathrm{A}, \mathrm{B}, \mathrm{E}$ \\
\hline Nevada & Nev. Rev. Stat. Ann. § 171.137(1) & $\begin{array}{l}\text { Probable cause to believe that within } 24 \text { hours battery } \\
\text { was committed. }\end{array}$ & A, B, C, D, E \\
\hline New Jersey & N.J. Stat. Ann. § 2C:25-21(a) & $\begin{array}{l}\text { Probable cause to believe that domestic violence has } \\
\text { occurred and either victim shows signs of injury or } \\
\text { probable cause that a weapon was involved. }\end{array}$ & A, B, C, D, E \\
\hline New York & N.Y. Crim. Proc. Law § 140.10(4)(a) & $\begin{array}{l}\text { Probable cause to believe a felony has been } \\
\text { committed against a member of the same family or } \\
\text { household or, unless victim requests otherwise, a } \\
\text { misdemeanor family offense committed. }\end{array}$ & A, C, E \\
\hline
\end{tabular}




\begin{tabular}{|c|c|c|c|}
\hline State & Mandatory Arrest for Crime & Circumstances & $\begin{array}{c}\text { Coded } \\
\text { Relationships } \\
\end{array}$ \\
\hline Ohio & $\begin{array}{l}\text { Ohio Rev. Code Ann. } \S \\
\text { 2935.032(A)(1)(a)(i) }\end{array}$ & $\begin{array}{l}\text { Reasonable cause to believe that offender committed } \\
\text { felonious assault. }\end{array}$ & A,B.C, E \\
\hline Oregon & Or. Rev. Stat. § 133.055(2)(a) & $\begin{array}{l}\text { Probable cause to believe that a felonious assault or } \\
\text { an assault resulting in injury occurred or action has } \\
\text { placed another to reasonably fear imminent serious } \\
\text { bodily injury or death. }\end{array}$ & A, B, C, D, E \\
\hline $\begin{array}{l}\text { Rhode } \\
\text { Island }\end{array}$ & R.I. Gen. Laws § 12-29-3(c)(1) & $\begin{array}{l}\text { Probable cause to believe the following: felonious } \\
\text { assault: assault resulting in injury: action was } \\
\text { intended to cause fear of imminent serious bodily } \\
\text { injury or death. }\end{array}$ & A, B, C, D, E \\
\hline $\begin{array}{l}\text { South } \\
\text { Carolina }\end{array}$ & S.C. Code Ann. § 16-25-70(B) & $\begin{array}{l}\text { If physical injury is present and probable cause to } \\
\text { believe person is committing or has freshly } \\
\text { committed a misdemeanor/felony assault or battery. }\end{array}$ & A, B, C, E \\
\hline $\begin{array}{l}\text { South } \\
\text { Dakota }\end{array}$ & S.D. Codified Laws § 23A-3-2.1 & $\begin{array}{l}\text { Probable cause to believe that within previous } 4 \\
\text { hours*, there has been an aggravated assault, an } \\
\text { assault resulting in bodily injury, or an attempt by } \\
\text { physical menace to place in fear of imminent serious } \\
\text { bodily injury. }\end{array}$ & A, B, C, E \\
\hline Utah & Utah Code Ann. § 77-36-2.2(2)(a) & $\begin{array}{l}\text { Probable cause to believe that an act of domestic } \\
\text { violence was committed and there will be continued } \\
\text { violence or evidence perpetrator has recently caused } \\
\text { serious bodily injury or used a dangerous weapon. }\end{array}$ & $A, B, C, E$ \\
\hline Virginia & Va. Code Ann. § 19.2-81.3(B) & $\begin{array}{l}\text { Probable cause to believe assault or battery on family } \\
\text { or household member. }\end{array}$ & A, B, C, E \\
\hline Washington & Wash. Rev. Code $\S 10.31 .100(2)(c)$ & $\begin{array}{l}\text { Probable cause to believe a person } 16 \text { years or older } \\
\text { within the previous } 4 \text { hours assaulted a family or } \\
\text { household member and believes (1) felonious assault } \\
\text { occurred, or (2) assault resulting in bodily injury } \\
\text { occurred whether injury is visible or not, or (3) any } \\
\text { physical action occurred which was intended to cause } \\
\text { reasonable fear of imminent serious bodily injury or } \\
\text { death. }\end{array}$ & A, B, C, D, E \\
\hline Wisconsin & Wis. Stat. § 968.075 (2)(a) & $\begin{array}{l}\text { Reasonable cause to believe that offender committing } \\
\text { or has committed domestic abuse and either evidence } \\
\text { of physical injury or reasonable basis for believing } \\
\text { continued abuse is likely. }\end{array}$ & A, B, E \\
\hline \multicolumn{4}{|c|}{$\begin{array}{l}\text { Coded Relationships: (A) current/former spouse, (B) current/former cohabitant, (C ) child in common, (D) Dating relationship, } \\
\text { (E) related by marriage or blood }\end{array}$} \\
\hline \multicolumn{4}{|c|}{ * Amended in 2001 to 24 hours } \\
\hline
\end{tabular}

All 23 states with mandatory arrest provisions have these provisions apply to current or

former spouses. All of the states except New York have these provisions apply to current or

former cohabitants, and 19 of the 23 states cover couples with a child in common. All of the

states except for Colorado cover those related by blood or marriage. Finally, 8 states include

those with some type of a dating relationship. ${ }^{2}$ 
A pictorial representation of the distribution of the states with mandatory arrest provisions is given in Exhibit 3.1. As can be seen from an examination of that exhibit, no clear pattern emerges though both the North East and the West are somewhat over-represented among the states with mandatory arrest provisions.

\section{Exhibit 3.1}

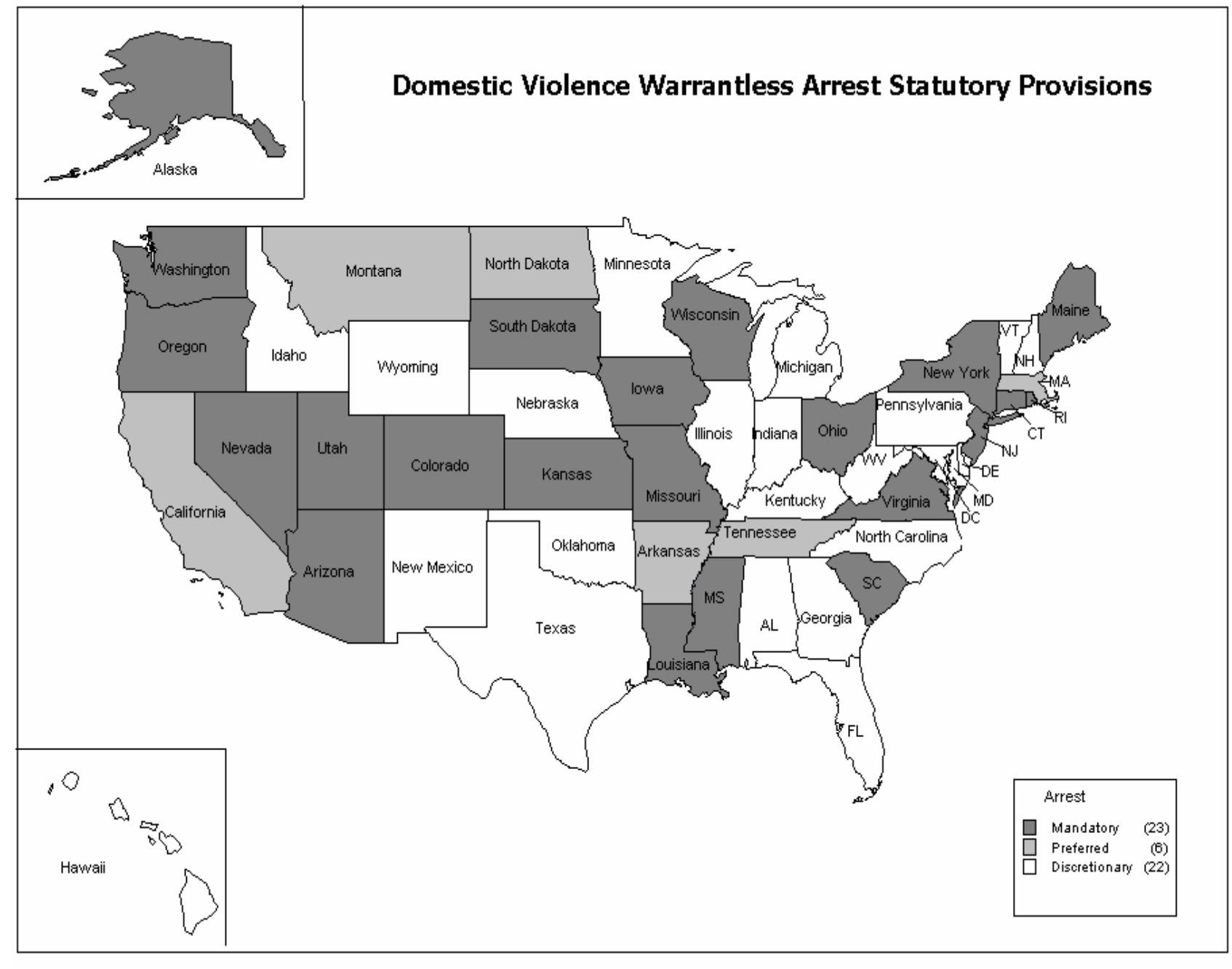

A total of six states have preferred arrest provisions (see Table 3.2). All of the statutory provisions in these states are explicit about arrest being the preferred response, using expressions such as arrest is "the preferred response” (e.g. Arkansas, Massachusetts, Montana and Tennessee) and “encouraging arrest” (e.g. California). 
Table 3.2

States with Preferred Arrest Provisions

\begin{tabular}{|c|c|c|}
\hline State & Statute & Circumstances \\
\hline Arkansas & Ark. Code Ann.§ 16-81-113 & $\begin{array}{l}\text { Preferred action when evidence indicates that domestic abuse has } \\
\text { occurred. }\end{array}$ \\
\hline California & Cal. Penal Code $\S 13701$ (b) & $\begin{array}{l}\text { The written policies shall encourage the arrest of domestic violence } \\
\text { offenders if there is probable cause that an offense has been committed. }\end{array}$ \\
\hline Massachusetts & $\begin{array}{l}\text { Mass. Gen. Laws Ann. ch. 209A } \\
\S 6 \text { (7) }\end{array}$ & $\begin{array}{l}\text { Preferred response whenever the officer has witnessed or has probable } \\
\text { cause to believe that a person has committed a felony, a misdemeanor } \\
\text { involving abuse, or an assault and battery. }\end{array}$ \\
\hline Montana & $\begin{array}{l}\text { Mont. Code Ann.§ 46-6-311 } \\
\text { (2)(a) }\end{array}$ & $\begin{array}{l}\text { Preferred response in partner or family member assault cases involving } \\
\text { injury to the victim, use or threatened use of a weapon, ... or other } \\
\text { imminent danger to the victim. }\end{array}$ \\
\hline North Dakota & N.D. Cent. Code § 14-07.1-10(1) & $\begin{array}{l}\text { If probable cause to believe that a person has committed a crime involving } \\
\text { domestic violence, whether the offense is a felony or misdemeanor, and } \\
\text { whether or not the crime was committed in the presence of the officer, } \\
\text { then the law enforcement officer shall presume that arresting the person is } \\
\text { the appropriate response. }\end{array}$ \\
\hline Tennessee & Tenn. Code Ann.§ 36-3-619 & $\begin{array}{l}\text { Preferred response when probable cause to believe that a crime committed } \\
\text { involving domestic abuse within or outside presence of the officer }\end{array}$ \\
\hline
\end{tabular}

The remaining 22 states have discretionary arrest provisions. These provisions differ in terms of the authority they entrust to officers to make warrantless arrests (see Table 3.3). While most of these 22 states permit the police to make warrantless arrests whenever there is probable cause to believe that a domestic violence offense has been committed, some states limit this power to the commission of specific domestic violence offenses (see, e.g. Indiana) or where there is evidence of physical injury (see, e.g. Kentucky, Texas), and others require that the suspected offense have been committed within a specified time period (see, e.g. New Hampshire (6 hours), Wyoming (24 hours)). Maryland and Oklahoma require both the existence of physical injury and that the suspected offense has been committed within a specified time period (within 48 hours in the case of Maryland, 72 hours in the case of Oklahoma). 
Table 3.3

\section{States with Discretionary Arrest Provisions}

\begin{tabular}{|c|c|c|}
\hline State & Discretionary Statute & Circumstances \\
\hline Alabama & Ala. Code § 15-10-3 (a)(8) & $\begin{array}{l}\text { An officer may arrest a person without a warrant, on any day and at any time in } \\
\text { any of the following instances: When an offense involves domestic violence as } \\
\text { defined by this section, and the arrest is based on probable cause, regardless of } \\
\text { whether the offense is a felony or misdemeanor. }\end{array}$ \\
\hline Delaware & $\begin{array}{l}\text { Del. Code Ann. tit. } \\
11 \S 1904(\mathrm{a})(4) \\
\end{array}$ & $\begin{array}{l}\text { Whenever a law enforcement officer has reasonable grounds to believe a person } \\
\text { has committed a misdemeanor involving physical injury or the threat thereof or } \\
\text { any misdemeanor involving illegal sexual contact or attempted sexual contact. }\end{array}$ \\
\hline Florida & Fla. Stat. ch. 741.29 (3) & $\begin{array}{l}\text { Whenever a law enforcement officer determines upon probable cause that an act } \\
\text { of domestic violence has been committed within the jurisdiction the officer may } \\
\text { arrest the person or persons suspected of its commission and charge such person } \\
\text { or persons with the appropriate crime. The decision to arrest and charge shall not } \\
\text { require consent of the victim or consideration of the relationship of the parties. }\end{array}$ \\
\hline Georgia & Ga. Code Ann. § 17-4-20 (a) & $\begin{array}{l}\text { An arrest for a crime may be made by a law enforcement officer either under a } \\
\text { warrant or without a warrant if the offense is committed in such officer's } \\
\text { presence or within such officer's immediate knowledge if the officer has probable } \\
\text { cause to believe that an act of family violence has been committed. }\end{array}$ \\
\hline Hawaii & Haw. Rev. Stat §709-906 (2) & $\begin{array}{l}\text { Any police officer, with or without a warrant, may arrest a person if the officer } \\
\text { has reasonable grounds to believe that the person is physically abusing, or has } \\
\text { physically abused, a family or household member and that the person arrested is } \\
\text { guilty thereof. }\end{array}$ \\
\hline Idaho & Idaho Code §19-603 (6) & $\begin{array}{l}\text { A peace officer may make an arrest when upon immediate response to a report of } \\
\text { a commission of a crime there is probable cause to believe that the person } \\
\text { arrested has committed a violation of section 18-902 (assault), 18-903 (battery), } \\
18-918 \text { (domestic assault or battery). }\end{array}$ \\
\hline Illinois & $\begin{array}{l}725 \text { Ill. Comp. Stat. 5/112A- } \\
30\end{array}$ & $\begin{array}{l}\text { Whenever a law enforcement officer has reason to believe that a person has been } \\
\text { abused by a family or household member, the officer shall immediately use all } \\
\text { reasonable means to prevent further abuse, including arresting the abusing party, } \\
\text { where appropriate. }\end{array}$ \\
\hline Indiana & $\begin{array}{l}\text { Ind. Code Ann. § 35-33-1-1 } \\
\text { (a)(5)(C ) }\end{array}$ & $\begin{array}{l}\text { A law enforcement officer may arrest a person when the officer has probable } \\
\text { cause to believe the person has committed a domestic battery under IC 35-42-2- } \\
\text { 1.3. }\end{array}$ \\
\hline Kentucky & $\begin{array}{l}\text { Ky. Rev. Stat. Ann. § } 431.005 \\
(2)(\mathrm{a})\end{array}$ & $\begin{array}{l}\text { Any peace officer may arrest a person without a warrant when he has probable } \\
\text { cause to believe that the person has intentionally or wantonly caused physical } \\
\text { injury to a family member or member of an unmarried couple. }\end{array}$ \\
\hline Maryland & Md. Code Ann. § 2-204 & $\begin{array}{l}\text { A police officer without a warrant may arrest a person if (s)he has probable cause } \\
\text { to believe that:(i) the person battered the person's spouse or another person with } \\
\text { whom the person resides; (ii) there is evidence of physical injury; and, (iii) unless } \\
\text { the person is arrested immediately, the person: } 1 \text {. may not be apprehended; } 2 \text {. } \\
\text { may cause physical injury or property damage to another; or } 3 \text {. may tamper with, } \\
\text { dispose of, or destroy evidence; and a report to the police was made within } 48 \\
\text { hours of the alleged incident. }\end{array}$ \\
\hline Michigan & Mich. Comp. Laws § 764.15a & $\begin{array}{l}\text { A peace officer may arrest an individual regardless of whether (s)he has a } \\
\text { warrant or whether the violation was committed in presence of the peace officer } \\
\text { has or receives positive information that another peace officer has reasonable } \\
\text { cause to believe both of the following: (a) The violation occurred or is } \\
\text { occurring. (b) The individual has had a child in common with the victim, resides } \\
\text { or has resided in the same household as the victim, has or has had a dating } \\
\text { relationship with the victim, or is a spouse or former spouse of the victim. }\end{array}$ \\
\hline
\end{tabular}




\begin{tabular}{|c|c|c|}
\hline State & Discretionary Statute & Circumstances \\
\hline Minnesota & Minn. Stat. § 629.341 (1) & $\begin{array}{l}\text { A peace officer may arrest a person anywhere without a warrant, including at the } \\
\text { person's residence, if (s)he has probable cause to believe that within the } \\
\text { preceding } 12 \text { hours the person has committed domestic abuse. The arrest may be } \\
\text { made even though the assault did not take place in the presence of the peace } \\
\text { officer. }\end{array}$ \\
\hline Nebraska & $\begin{array}{l}\text { Neb. Rev. Stat. § 29-404.02 } \\
(3)\end{array}$ & $\begin{array}{l}\text { A peace officer may arrest a person without a warrant if (s)he has reasonable } \\
\text { cause to believe that such person has committed one or more of the following } \\
\text { acts to one or more household members: (a) Attempting to cause or intentionally, } \\
\text { knowingly, or recklessly causing bodily injury with or without a deadly weapon; } \\
\text { or (b) Threatening another in a menacing manner. }\end{array}$ \\
\hline New Hampshire & $\begin{array}{l}\text { N.H. Rev. Stat. Ann. § 173- } \\
\text { B:9 \& N.H. Rev. Stat. Ann. § } \\
\text { 594:10 (I)(b) }\end{array}$ & $\begin{array}{l}\text { An arrest for abuse may be made without a warrant upon probable cause, } \\
\text { whether or not the abuse is committed in the presence of the peace officer. An } \\
\text { arrest by a peace officer without a warrant on a charge of a misdemeanor or a } \\
\text { violation is lawful whenever there is probable cause to believe that the person to } \\
\text { be arrested has within the past } 6 \text { hours committed abuse as defined in RSA 173- } \\
\text { B:1, I against a person eligible for protection from domestic violence. }\end{array}$ \\
\hline New Mexico & $\begin{array}{l}\text { N.M. Stat. Ann § 40-13-7 } \\
\text { (B)(5) }\end{array}$ & $\begin{array}{l}\text { A local law enforcement officer responding to the request for assistance shall be } \\
\text { required to take whatever steps are reasonably necessary to protect the victim } \\
\text { from further domestic abuse, including: arresting the abusing household member } \\
\text { when appropriate and including a written statement in the attendant police report } \\
\text { to indicate that the arrest of the abusing household member was, in whole or in } \\
\text { part, premised upon probable cause to believe that the abusing household } \\
\text { member committed domestic abuse against the victim. }\end{array}$ \\
\hline North Carolina & $\begin{array}{l}\text { NC Gen. Stat. § 15A-401 } \\
\text { (b)(2) }\end{array}$ & $\begin{array}{l}\text { An officer may arrest without a warrant any person whom (s)he has probable } \\
\text { cause to believe has committed a misdemeanor, and will not be apprehended } \\
\text { unless immediately arrested, or may cause physical injury to himself or others, or } \\
\text { damage to property unless immediately arrested, or has committed one of the } \\
\text { following (listed) misdemeanors. }\end{array}$ \\
\hline Oklahoma & Okla. Stat. tit. 22, § 40.3 (B) & $\begin{array}{l}\text { A peace officer may arrest without a warrant a person anywhere, including his } \\
\text { place of residence, if the peace officer has probable cause to believe the person } \\
\text { within the preceding seventy-two (72) hours has committed an act of domestic } \\
\text { abuse as defined by Section } 60.1 \text { of this title, although the assault did not take } \\
\text { place in the presence of the peace officer. Officer must observe a recent physical } \\
\text { injury to, or an impairment of the physical condition of, the alleged victim. }\end{array}$ \\
\hline Pennsylvania & 18 Pa. Cons. Stat. § 2711(A) & $\begin{array}{l}\text { A police officer shall have the same right of arrest without a warrant as in a } \\
\text { felony whenever (s)he has probable cause to believe the defendant has violated } \\
\text { section } 2504 \text { (relating to involuntary manslaughter), } 2701 \text { (relating to simple } \\
\text { assault), 2702(a)(3), (4) and (5) (relating to aggravated assault), } 2705 \text { (relating to } \\
\text { recklessly endangering another person), } 2706 \text { (relating to terroristic threats) or } \\
\text { 2709(b) (relating to harassment and stalking) against a family or household } \\
\text { member although the offense did not take place in the presence of the police } \\
\text { officer. An officer may not arrest a person pursuant to this section without first } \\
\text { observing recent physical injury to the victim or other corroborative evidence. }\end{array}$ \\
\hline Texas & $\begin{array}{l}\text { Tex. Code Crim. P. Ann. art. } \\
14.03(\mathrm{a})(4)\end{array}$ & $\begin{array}{l}\text { Any peace officer may arrest, without a warrant persons whom the peace officer } \\
\text { has probable cause to believe have committed an assault resulting in bodily } \\
\text { injury to a member of the person's family or household. }\end{array}$ \\
\hline Vermont & Vt .R. Cr. P. 3(a)(C) & $\begin{array}{l}\text { An officer may also arrest a person without warrant in the following situations: } \\
\text { that a person has committed a misdemeanor which involves an assault against a } \\
\text { family member, or against a household member as defined in } 15 \text { V.S.A. } \S \\
1101(2) \text {, or a child of such a family or household member. }\end{array}$ \\
\hline West Virginia & W.Va. Code $\S$ 48-27-1002(a) & $\begin{array}{l}\text { A law-enforcement officer has authority to arrest that person without first } \\
\text { obtaining a warrant if (s)he has observed credible corroborative evidence that an } \\
\text { offense has occurred and either the law-enforcement officer has received, from } \\
\text { the victim or a witness, an oral or written allegation of facts constituting a } \\
\text { violation of section twenty-eight, article two, chapter sixty-one of this code } \\
\text { (domestic violence offense) or the law-enforcement officer has observed credible } \\
\text { evidence that the accused committed the offense. }\end{array}$ \\
\hline
\end{tabular}




\begin{tabular}{|c|l|l|}
\hline State & \multicolumn{1}{|c|}{ Discretionary Statute } & \multicolumn{1}{c|}{ Circumstances } \\
\hline & & $\begin{array}{l}\text { In addition to arrests specified in W.S. 7-2-102, any peace officer who has } \\
\text { probable cause to believe that a violation of W.S. 6-2-501(a), (b), (e) or (f), 6-2- } \\
502(a) \text { or 6-2-504(a) or (b) has taken place within the preceding twenty-four (24) } \\
\text { hours or is taking place and that the person who committed or is committing the } \\
\text { violation is a household member as defined by W.S. 35-21-102(a)(iv), may arrest } \\
\text { the violator without a warrant for that violation, regardless of whether the } \\
\text { violation was committed in the presence of the peace officer. }\end{array}$ \\
Wyoming & Wyo. Stat. Ann. § 7-20-102 (a)
\end{tabular}

A larger number of states (33) mandate arrest when there is probable cause to believe that there has been a violation of a restraining order (See Table 3.4). While 17 of these 33 states are states that have mandatory on-scene arrest provisions, and four are states that have preferred arrest provisions, 12 of these states have discretionary arrest provisions. A total of five states and/or territories (Arizona, Connecticut, Nevada, Ohio, and Washington D.C.) have mandatory on-scene arrest provisions, but do not mandate arrest when there is probable cause to believe that there has been a violation of a restraining order. ${ }^{3}$

Table 3.4

\section{States with Mandatory Arrest for Violation of a Protection Order}

\begin{tabular}{|c|c|}
\hline State & Mandatory Arrest for Violation of Protection Order \\
\hline Alaska & Alaska Stat. $\S 18.65 .530(\mathrm{a})(2)$ \\
\hline California & Cal. Penal Code § 836 (c)(1) \\
\hline Colorado & Colo. Rev. Stat. 18-6-803.5(3)(b) \\
\hline Delaware & Del. Code Ann. tit. 10, § 1046(c) \\
\hline Iowa & Iowa Code $\S 236.11$ \\
\hline Kansas & Kan. Stat. Ann. § 22-2307 \\
\hline Kentucky & Ky. Rev. Stat. Ann. § 403.760(2) \\
\hline Louisiana & LA. Rev. Stat. Ann. § 14:79(E) \\
\hline Maine & Me. Rev. Stat. Ann. tit. 19-A, § 4012(5) \\
\hline Maryland & Md. Fam. Law Code Ann. § 4-509(b) \\
\hline Massachusetts & Mass. Gen. L. ch. 209A, § 6(7) \\
\hline Minnesota & Minn. Stat. § 518B.01(14)(e) \\
\hline Mississippi & Miss. Code Ann. § 99-3-7(3) \\
\hline Missouri & Mo. Rev. Stat $\S 455.085(2)$ \\
\hline
\end{tabular}


This document is a research report submitted to the U.S. Department of Justice. This report has not been published by the Department. Opinions or points of view expressed are those of the author(s) and do not necessarily reflect the official position or policies of the U.S. Department of Justice.

\begin{tabular}{|c|c|}
\hline State & Mandatory Arrest for Violation of Protection Order \\
\hline Nebraska & Neb. Rev. Stat. § 42-928 \\
\hline New Hampshire & N.H. Rev. Stat. Ann. § 173-B:9 \\
\hline New Jersey & N.J. Rev. Stat. § 2C:25-31 \& 2C:25-21(a)(3) \\
\hline New Mexico & N.M. Stat. Ann. § 40-13-6(C) \\
\hline New York & N.Y.Crim Proc. Law $\S 140.10(4)(b)$ \\
\hline North Carolina & N.C. Gen. Stat. § 50B-4.1(b) \\
\hline North Dakota & N.D. Cent. Code § 14-07.1-11(1) \\
\hline Oregon & Or. Rev. Stat. § 133.310(3)(a) \\
\hline Pennsylvania & 23 PA. Cons. Stat. § 6113(A) \\
\hline Rhode Island & R.I. Gen. Laws § 12-29-3(c )(1)(iv) \\
\hline South Carolina & S.C. Code Ann. § 16-3-1800 \\
\hline South Dakota & S.D. Codified Laws § 23A-3-2.1 \\
\hline Tennessee & Tenn. Code Ann. § 36-3-611 \\
\hline Texas & Tex. Crim. Proc. Code Ann. art. 14.03(b) \\
\hline Utah & Utah Code Ann. § 77-36-2.4(1) \\
\hline Virginia & Va. Code Ann. § 19.2-81.3(B) \\
\hline Washington & Wash. Rev. Code § 10.31.100(2)(a) \& 26.50.110(2) \\
\hline West Virginia & W. Va. Code $\S 48-2 A-10 c(a)^{*}$ \\
\hline Wisconsin & Wis. Stat. § 813.12(7) \\
\hline
\end{tabular}

\section{Statutory Reporting Requirements}

The ability of researchers to track domestic violence incidents comes from reports filed by law enforcement. An analysis of state statutes reveals that most states (30) require a written report in "all incidents" of domestic violence (see Table 3.5). This entails not only arrests, but also all family abuse situations investigated by police regardless of whether an arrest ensues. These mandated written reports take the form of either state designated reports made specifically for domestic violence incidents, or regular police reports that are required to be labeled as a domestic incident. $^{4}$ 
Table 3.5

Statutory Mandates for Reports by Law Enforcement in Domestic Violence Situations

\begin{tabular}{|c|c|c|c|c|c|}
\hline State/Territory & Statute & No Arrest & All Arrests & All Incidents & Dual Arrest \\
\hline Alabama & Ala. Code § 15-10-3 (c ) & & & $\sqrt{ }$ & \\
\hline Alaska & Alaska Stat. § 18.65.530 (e) & $\sqrt{ }$ & & & $\sqrt{ }$ \\
\hline \multicolumn{6}{|l|}{ Arizona } \\
\hline \multicolumn{6}{|l|}{ Arkansas } \\
\hline California & Cal. Penal Code § 13730 (a) \& (c ) & & & $\sqrt{ }$ & \\
\hline \multicolumn{6}{|l|}{ Colorado } \\
\hline Connecticut & Conn. Gen. Stat. § 46b-38d (a) & & & $\sqrt{ }$ & \\
\hline \multicolumn{6}{|l|}{ Delaware } \\
\hline \begin{tabular}{|l} 
District Of \\
Columbia
\end{tabular} & D.C. Code Ann. § 16-1032 & & & $\sqrt{ }$ & \\
\hline Florida & Fla. Stat. § $741.29(2)^{* * *}$ & $\sqrt{ }$ & & $\sqrt{ }$ & $\sqrt{ }$ \\
\hline Georgia & Ga. Code Ann. § 17-4-20.1 (c ) & $\sqrt{ }$ & & $\sqrt{ }$ & \\
\hline Hawaii & Haw. Rev. Stat. \& 709-906 (3) & & & $\sqrt{ }$ & \\
\hline Idaho & Idaho Code § 39-6316 (4) & & & $\sqrt{ }$ & \\
\hline Illinois & 725 Ill. Comp. Stat. 5/112A-29 & & & $\sqrt{ }$ & \\
\hline \multicolumn{6}{|l|}{ Indiana } \\
\hline \multicolumn{6}{|l|}{ Iowa } \\
\hline Kansas & Kan.Stat. Ann. § 22-2307 (b)(9) & & & $\sqrt{ }$ & \\
\hline Kentucky & Ky. Rev. Stat. Ann. § 403.785 (1) & & & $\sqrt{ }$ & \\
\hline Louisiana & La. Rev. Stat. Ann. § 46:2141 & & & $\sqrt{ }$ & \\
\hline Maine & Me. Rev. Stat. Ann. tit. 19-A § 4012 (1) & & & $\sqrt{ }$ & \\
\hline \multicolumn{6}{|l|}{ Maryland } \\
\hline Massachusetts & Mass. Gen. Laws Ann. ch. 209A § 6 & & & $\sqrt{ }$ & $\sqrt{ }$ \\
\hline Michigan & Mich. Comp. Laws § 764.15c (2) & & & $\sqrt{ }$ & \\
\hline Minnesota & Minn. Stat. § 629.341 (sub. 4) & & & $\sqrt{ }$ & \\
\hline \multicolumn{6}{|l|}{ Mississippi } \\
\hline Missouri & Mo. Rev. Stat. § 455.085 (1) & $\sqrt{ }$ & & & \\
\hline Montana & Mont. Code Ann. § 46-6-601 & $\sqrt{ }$ & & & \\
\hline \multicolumn{6}{|l|}{ Nebraska } \\
\hline Nevada & Nev. Rev. Stat. Ann. § 171.1227 (1) \& (3) & $\sqrt{ }$ & & $\sqrt{ }$ & \\
\hline \multicolumn{6}{|l|}{ New Hampshire } \\
\hline New Jersey & N.J. Stat. Ann. § 2C:25-24 (a) & & & $\sqrt{ }$ & \\
\hline New Mexico & N.M. Stat. Ann. § 40-13-7 (B)(5) & & $\sqrt{ }$ & & \\
\hline New York & N.Y. Crim. Proc. Law § 140.10 (5) & & & $\sqrt{ }$ & \\
\hline \multicolumn{6}{|l|}{ North Carolina } \\
\hline North Dakota & N.D. Cent. Code § 14-07.1-12 & & & $\sqrt{ }$ & \\
\hline Ohio & Ohio Rev. Code Ann.§ 2935.032 (C )(1), (D) & $\sqrt{ }$ & & $\sqrt{ }$ & \\
\hline \multicolumn{6}{|l|}{ Oklahoma } \\
\hline \multicolumn{6}{|l|}{ Oregon } \\
\hline Pennsylvania & 23 Pa. Cons. Stat. § 6105 (C) & $\sqrt{ }$ & $\sqrt{ }$ & $\sqrt{ }$ & \\
\hline Rhode Island & R.I. Gen. Laws § 12-29-3 (g) & & & $\sqrt{ }$ & \\
\hline
\end{tabular}




\begin{tabular}{|l|l|c|c|c|c|}
\hline State/Territory & \multicolumn{1}{|c|}{ Statute } & No Arrest & All Arrests & All Incidents & Dual Arrest \\
\hline South Carolina & S.C. Code Ann. § 16.25-70 (F) & & & & $\sqrt{ }$ \\
\hline South Dakota & S.D. Codified Laws § 25-10-36 & & $\sqrt{ }$ & & \\
\hline Tennessee & Tenn. Code Ann. § 36-3-619 (c ) & $\sqrt{ }$ & $\sqrt{ }$ & $\sqrt{ }$ \\
\hline Texas & Tex. Code Crim. Proc. Art 5.05 (a)*** & & & $\sqrt{ }$ & $\sqrt{ }$ \\
\hline Utah & Utah Code Ann. § 77-36-2.2 (5)(a) \& (6)(a) & $\sqrt{ }$ & & $\sqrt{ }$ \\
\hline Vermont & & & & $\sqrt{ }$ & \\
\hline Virginia & Va. Code Ann. § 19.2-81.3 (c ) & $\sqrt{ }$ & $\sqrt{ }$ \\
\hline Washington & Wash. Rev. Code Ann. § 10.99.030 (6)(b) & & & & \\
\hline West Virginia & W.Va. Code § 48-27-801 (a) & & & & $\sqrt{ }$ \\
\hline Wisconsin & Wis. Stat. § 968.075 (4) & $\sqrt{ }$ & & & \\
\hline Wyoming & Wyo. Stat. Ann. § 7-20-107 (a) & & & & \\
\hline
\end{tabular}

More germane to the issue of mandatory and preferred arrest laws are statutory provisions that require the filing of special reports when certain actions are taken by police after responding to the scene of a domestic disturbance call. A minority of states require officers to fill out extra paperwork when they either make no arrest ( $\mathrm{N}=12$ - see Table 3.6) or make dual arrests $(\mathrm{N}=6)$ in domestic violence cases. In states mandating reports in situations of no arrest or dual arrest, officers are required to document the reasons why they had either made no arrest or dual arrests. Four states (Alaska, Florida, Tennessee, and Utah) require reports be filed in both when no arrest or dual arrests are made. Seven of the 12 states that mandate reports in situations of no arrest are states with mandatory warrantless arrest provisions, while three of the six states that mandate reports in situations of dual arrest are states with mandatory warrantless arrest provisions.

\section{Proscribed Police Actions}

States also differ in terms of whether they describe in their state statutes the actions that they would like police to undertake when responding to the scene of a domestic incident. To enhance victim safety, most states (41) have implemented statutory provisions that detail what officers should consider doing when dealing with victims of domestic violence (see Table 3.6). A review of these statutory provisions reveals eight categories of assistance officers should 
consider rendering to victims. These are: stay on scene; get medical treatment; arrange for transport to safety; provide notice of victims’ rights; assist in filing a protection order; give information on available community resources, such as shelters and victim assistance programs; seize weapons; and, help with the removal of personal items. It should be noted that these categories are not mutually exclusive. Most states with statutory provisions proscribing police actions at the scene of a domestic call list several options for law enforcement to choose from dependant on the situation.

Table 3.6

Summary of Victim Helping Actions Mandated by State Statutes

\begin{tabular}{|c|c|c|c|c|c|c|c|c|c|}
\hline State/Territory & Statute & $\begin{array}{c}\text { Officer } \\
\text { Stay on } \\
\text { Scene } \\
\end{array}$ & \begin{tabular}{|c|} 
Get \\
Medical \\
Treatment \\
\end{tabular} & $\begin{array}{c}\begin{array}{c}\text { Arrange } \\
\text { for/ }\end{array} \\
\text { Transport } \\
\text { to Safety } \\
\end{array}$ & $\begin{array}{c}\text { Notice of } \\
\text { Victims } \\
\text { Rights } \\
\end{array}$ & \begin{tabular}{|c|} 
Assist in \\
Filing \\
Protection \\
Order \\
\end{tabular} & $\begin{array}{c}\begin{array}{c}\text { Community } \\
\text { Resource } \\
\text { Info }\end{array} \\
\end{array}$ & $\begin{array}{c}\text { Seize } \\
\text { Weapons }\end{array}$ & \begin{tabular}{|c} 
Removal \\
of \\
Personal \\
Items
\end{tabular} \\
\hline Alabama & Ala. Code § 30-6-9 & & & & & & $\sqrt{ }$ & & \\
\hline Alaska & Alaska Stat. § 18.65.515 (a) & & $\sqrt{ }$ & $\sqrt{ }$ & $\sqrt{ }$ & & & $\sqrt{ }$ & $\sqrt{ }$ \\
\hline Arizona & Ariz. Rev. Stat. § 13-3601 (J) & & & & $\sqrt{ }$ & & $\sqrt{ }$ & & \\
\hline \multicolumn{10}{|l|}{ Arkansas } \\
\hline California & Cal. Penal Code § 13701 (c ) & & $\sqrt{ }$ & $\sqrt{ }$ & $\sqrt{ }$ & $\sqrt{ }$ & $\sqrt{ }$ & & $\sqrt{ }$ \\
\hline Colorado & Colo. Rev. Stat. § 18-6-803.6 (3) & & & $\sqrt{ }$ & & & & & \\
\hline Connecticut & Conn. Gen. Stat. § 466-38b(d) & $\sqrt{ }$ & $\sqrt{ }$ & & $\sqrt{ }$ & & $\sqrt{ }$ & & \\
\hline \multicolumn{10}{|l|}{ Delaware } \\
\hline \multicolumn{10}{|l|}{$\begin{array}{l}\text { District Of } \\
\text { Columbia }\end{array}$} \\
\hline Florida & Fla. Stat. Ann. § 741.29 (1) & & $\sqrt{ }$ & & $\sqrt{ }$ & & $\sqrt{ }$ & & \\
\hline \multicolumn{10}{|l|}{ Georgia } \\
\hline Hawaii & Haw. Rev. Stat. § 709-906(4)(b) & & $\sqrt{ }$ & $\sqrt{ }$ & & & & $\sqrt{ }$ & \\
\hline Idaho & Idaho Code § 39-6316 & & $\sqrt{ }$ & $\sqrt{ }$ & $\sqrt{ }$ & & $\sqrt{ }$ & & \\
\hline Illinois & \begin{tabular}{|l}
725 Ill. Comp. Stat. 5/112A-30 \\
$(4,5,6,7)$
\end{tabular} & & $\sqrt{ }$ & $\sqrt{ }$ & $\sqrt{ }$ & $\sqrt{ }$ & $\sqrt{ }$ & $\sqrt{ }$ & \\
\hline \multicolumn{10}{|l|}{ Indiana } \\
\hline Iowa & Iowa Code $\S 236.12$ (1)(b) & $\sqrt{ }$ & $\sqrt{ }$ & $\sqrt{ }$ & $\sqrt{ }$ & & $\sqrt{ }$ & & \\
\hline Kansas & Kan. Stat. Ann. § 22-2307 (b)(8) & & & & $\sqrt{ }$ & & $\sqrt{ }$ & & \\
\hline Kentucky & $\begin{array}{l}\text { Ky. Rev. Stat. Ann. § } 403.785 \text { (a), } \\
\text { (b), (c ) }\end{array}$ & $\sqrt{ }$ & $\sqrt{ }$ & & $\sqrt{ }$ & & & & \\
\hline Louisiana & La. Rev. Stat. Ann. § $1573(3)^{* * *}$ & & $\sqrt{ }$ & $\sqrt{ }$ & $\sqrt{ }$ & & & & \\
\hline Maine & $\begin{array}{l}\text { Me. Rev. Stat. Ann. tit 19-A § } \\
4012 \text { (6) }\end{array}$ & $\sqrt{ }$ & $\sqrt{ }$ & & $\sqrt{ }$ & & & & \\
\hline Maryland & $\begin{array}{l}\text { Md. Code Ann., Fam. Law § 4- } \\
502 \text { (2)(ii) \& § 4-503 }\end{array}$ & & & & $\sqrt{ }$ & & & & $\sqrt{ }$ \\
\hline
\end{tabular}




\begin{tabular}{|c|c|c|c|c|c|c|c|c|c|}
\hline State & Statute & $\begin{array}{c}\text { Officer } \\
\text { Stay on } \\
\text { Scene }\end{array}$ & $\begin{array}{c}\text { Get } \\
\text { Medical } \\
\text { Treatment } \\
\end{array}$ & \begin{tabular}{|c|}
$\begin{array}{c}\text { Arrange } \\
\text { for/ }\end{array}$ \\
Transport \\
to Safety \\
\end{tabular} & $\begin{array}{c}\text { Notice of } \\
\text { Victims } \\
\text { Rights } \\
\end{array}$ & \begin{tabular}{|c|} 
Assist in \\
Filing \\
Protection \\
Order \\
\end{tabular} & $\begin{array}{c}\text { Community } \\
\text { Resource } \\
\text { Info }\end{array}$ & $\begin{array}{c}\text { Seize } \\
\text { Weapons }\end{array}$ & \begin{tabular}{|c|}
$\begin{array}{c}\text { Removal } \\
\text { of } \\
\text { Personal } \\
\text { Items }\end{array}$ \\
\end{tabular} \\
\hline Massachusetts & Mass. Gen. ch. 209A § 6 & $\sqrt{ }$ & $\sqrt{ }$ & $\sqrt{ }$ & $\sqrt{ }$ & & & & \\
\hline Michigan & Mich. Comp. Laws § 764.15c (1) & & & & $\sqrt{ }$ & & $\sqrt{ }$ & & \\
\hline Minnesota & Minn. Stat. § 629.341 (sub.3) & & & & $\sqrt{ }$ & & $\sqrt{ }$ & & \\
\hline Mississippi & Miss. Code Ann. § 93-21-28 (1) & & & $\sqrt{ }$ & & & $\sqrt{ }$ & & $\sqrt{ }$ \\
\hline Missouri*** & $\begin{array}{l}\text { Mo. Rev. Stat. § } 455.080 \text { (4) \& } \\
\text { (5) }\end{array}$ & & $\sqrt{ }$ & $\sqrt{ }$ & $\sqrt{ }$ & & $\sqrt{ }$ & & \\
\hline Montana & Mont. Code Ann. § 46-6-602 & & & & $\sqrt{ }$ & & $\sqrt{ }$ & & \\
\hline Nebraska & Neb. Rev. Stat. § 42-907 & & $\sqrt{ }$ & $\sqrt{ }$ & & & $\sqrt{ }$ & & \\
\hline Nevada & Nev. Rev. Stat. Ann. § 171.1225 & & & & $\sqrt{ }$ & & $\sqrt{ }$ & & \\
\hline New Hampshire & N.H. Rev. Stat. Ann. § 173-B:10 & & $\sqrt{ }$ & $\sqrt{ }$ & $\sqrt{ }$ & $\sqrt{ }$ & & $\sqrt{ }$ & $\sqrt{ }$ \\
\hline \multicolumn{10}{|l|}{ New Jersey } \\
\hline New Mexico & N.M. Stat. Ann. § 40-13-7 (B) & & $\sqrt{ }$ & $\sqrt{ }$ & $\sqrt{ }$ & & $\sqrt{ }$ & & $\sqrt{ }$ \\
\hline \multicolumn{10}{|l|}{ New York } \\
\hline North Carolina & N.C. Gen. Stat. § 50B-5(a) & & $\sqrt{ }$ & $\sqrt{ }$ & & & $\sqrt{ }$ & & $\sqrt{ }$ \\
\hline North Dakota & N.D. Cent. Code § 14-07.04 & & & & & & $\sqrt{ }$ & & \\
\hline Ohio & $\begin{array}{l}\text { Ohio Rev. Code. Ann. } 2935.032 \\
\text { (C )(3) }\end{array}$ & & & & $\sqrt{ }$ & & $\sqrt{ }$ & & \\
\hline Oklahoma & Okla. Stat. tit. $22 \S 40.3$ (c )(1) & & & & & $\sqrt{ }$ & & & \\
\hline Oregon & Or. Rev. Stat. § 133.055 (3) & & & & $\sqrt{ }$ & & $\sqrt{ }$ & & \\
\hline Pennsylvania & $\begin{array}{l}18 \text { Pa. Cons. Stat. § } 2711 \text { (D) \& } \\
23 \text { Pa. Cons. Stat. § 6105(B) }\end{array}$ & & & & $\sqrt{ }$ & $\sqrt{ }$ & $\sqrt{ }$ & $\sqrt{ }$ & \\
\hline Rhode Island & R.I. Gen. Laws § 12-29-3 (f) & $\sqrt{ }$ & $\sqrt{ }$ & & $\sqrt{ }$ & & $\sqrt{ }$ & & \\
\hline \multicolumn{10}{|l|}{ South Carolina } \\
\hline \multicolumn{10}{|l|}{ South Dakota } \\
\hline Tennessee & Tenn. Code Ann. § 36-3-619 (g) & & & $\sqrt{ }$ & $\sqrt{ }$ & & $\sqrt{ }$ & & \\
\hline Texas & $\begin{array}{l}\begin{array}{l}\text { Tex Crim. P. Code Ann. § } 5.04 \\
\text { (b) }\end{array} \\
\end{array}$ & & & & $\sqrt{ }$ & $\sqrt{ }$ & $\sqrt{ }$ & & \\
\hline Utah & Utah Code Ann. § 30-6-8 (2) & $\sqrt{ }$ & $\sqrt{ }$ & & $\sqrt{ }$ & & & & \\
\hline \multicolumn{10}{|l|}{ Vermont } \\
\hline Virginia & Va. Code Ann. § 19.2-81.3 (E) & & $\sqrt{ }$ & $\sqrt{ }$ & & $\sqrt{ }$ & & & \\
\hline Washington & $\begin{array}{l}\text { Wash. Rev. Code § } \\
10.99 .030(6)(a) \&(7)\end{array}$ & & $\sqrt{ }$ & & $\sqrt{ }$ & & $\sqrt{ }$ & & \\
\hline West Virginia & $\begin{array}{l}\text { W. Va. Code § 48-26-1101 \& § } \\
48-27-702 \text { (b) }\end{array}$ & & & $\sqrt{ }$ & & & $\sqrt{ }$ & & \\
\hline \multicolumn{10}{|l|}{ Wisconsin } \\
\hline Wyoming & $\begin{array}{l}\text { Wyo. Stat. Ann. § 7-20-104 \& } \\
\text { Wyo. Stat. Ann. § 35-21-107 (b) }\end{array}$ & & $\sqrt{ }$ & $\sqrt{ }$ & $\sqrt{ }$ & & $\sqrt{ }$ & & $\sqrt{ }$ \\
\hline
\end{tabular}

The majority of states (31) require officers to give victims notice of their rights. In some states, such as Florida and Idaho, these rights come in paper form to be given to the victim on the 
scene. Giving notice of rights also often involves the officer reading from a prescribed statement taken directly from the statute. Encompassed in the notice of victim's rights are several of the other categories, such as requesting transportation from the officer. Most state statutes (29) also require officers to give victims “community resource information.” This entails officers notifying victims of shelters, advocates and legal representation available in their communities. The category of "get medical treatment," which is to be found in 23 state statutes, refers to situations where there has been a physical assault and gives the officer permission to either transport the victim personally or to arrange for transport for medical treatment. A total of 20 states explicitly provide for officers to “arrange for transport to safety,” allowing officers to personally take a victim to another location like a shelter or a friend or family home or to arrange for another officer or agency official to transport the victim away from harm.

A smaller number of states explicitly cover the remaining four categories. A total of 9 states give officers the option of assisting victim in the "removal of personal items." This allows for the officer to act as a barrier between the victim and abuser as the victim gathers personal items such as medication and personal hygiene items needed from the home to assist her in leaving the situation. Seven states explicitly provide an “officer stay on scene” category giving the officer the authority to remain on the scene to ensure the victim’s safety. “Assist in filing protection order" consists of the officer physically helping the victim fill out the paperwork required to obtain a protection order $(\mathrm{N}=8)$. It can also involve the officer taking the necessary steps required to obtain an emergency order of protection, including contacting judges at night or on weekends and holidays to hasten the process. In order to protect the victim further, a few states required officers to "seize weapons" in domestic violence incidents $(\mathrm{N}=5)$. Offenders often have a prescribed amount of time that they had to wait before they can regain their weapons. 


\section{Primary Aggressor Laws}

The first explanation for the existence of high dual arrest rates was that police were unable or refused to distinguish ongoing victims of abuse from batterers. Given this view, states, beginning with Washington in 1985, started enacting "primary" or "predominant aggressor" laws. These laws seek to ensure that police officers receive guidance in assessing who is the "real" offender both in the relationship and in a particular situation, and encourage them to use information about the history of abuse to assist them in distinguishing between defensive and offensive injuries.

A total of 24 states had primary aggressor laws in effect in 2000 (see Table 3.7). While a few states, such as Florida, Ohio, Rhode Island and Virginia, merely instruct officers to "make attempts to determine the primary aggressor,” most states outline the factors officers should employ in making that determination. These factors generally include: comparative extent of injuries; prior domestic violence history; self-defensive actions; and, likelihood of future injury.

Table 3.7 States with Primary Aggressor Statutes

\begin{tabular}{|c|c|c|}
\hline State & Primary Aggressor Law & Instructions for Applying the Law \\
\hline Alabama & Ala. Code § 13A-6-134 & $\begin{array}{l}\text { Upon receipt of complaint of DV from } 2 \text { or more persons, each complaint } \\
\text { shall be evaluated separately to determine the PA. The officer shall } \\
\text { consider:1) prior complaints of DV, 2) severity of injuries, 3) likelihood } \\
\text { of future injury, 4) self defensive actions. }\end{array}$ \\
\hline Alaska & Alaska Stat. § 18.65.530(b) & $\begin{array}{l}\text { Upon receipt of complaint of DV from more than one person from the } \\
\text { same incident, evaluation of each individual's conduct to determine the } \\
\text { primary physical aggressor. The officer shall consider:1) prior complaints } \\
\text { of DV, 2) severity of injuries, 3) likelihood of future injury, 4) self } \\
\text { defensive actions. }\end{array}$ \\
\hline California & Cal. Penal. Code § 13701(b) & $\begin{array}{l}\text { Shall make reasonable efforts to determine the dominant aggressor. Shall } \\
\text { consider: 1) intent of law to protect victims of domestic violence, 2) } \\
\text { threats causing fear of physical injury, 3) history of domestic violence } \\
\text { with persons involved, and 4) self defensive actions. }\end{array}$ \\
\hline Colorado & Colo. Rev. Stat. § 18-6-803.6(2) & $\begin{array}{l}\text { Upon receipt of complaint of domestic violence from two or more } \\
\text { opposing persons, shall evaluate each complaint separately to determine if } \\
\text { crime was committed by one or the other. Shall consider: 1) prior } \\
\text { complaints of domestic violence, 2) relative severity of injury inflicted, 3) } \\
\text { likelihood of future injury, 4) self defensive actions. }\end{array}$ \\
\hline
\end{tabular}




\begin{tabular}{|c|c|c|}
\hline State & Primary Aggressor Law & Instructions for Applying the Law \\
\hline Florida & Fla. Stat. ch. 741.29 (4)(b) & $\begin{array}{l}\text { If probable cause to believe that } 2 \text { or more persons have committed a } \\
\text { misdemeanor or felony, or if } 2 \text { or more persons make a complaint, } \\
\text { attempts shall be made to determine the PA. }\end{array}$ \\
\hline Georgia & Ga. Code Ann. § 17-4-20.1 (b) & $\begin{array}{l}\text { Upon complaints of family violence from } 2 \text { or more parties shall evaluate } \\
\text { each complaint separately and attempt to determine PA. Shall consider: } 1 \text { ) } \\
\text { prior family violence, 2) severity of injuries, 3) potential for future injury, } \\
\text { 4) self defensive actions. }\end{array}$ \\
\hline Iowa & Iowa Code § 236.12(3) & $\begin{array}{l}\text { Shall arrest the person whom the officer believes to be the primary } \\
\text { physical aggressor. Shall consider: 1) need to protect victims, 2) relative } \\
\text { degree of injury or fear inflicted, 3) history of domestic abuse. }\end{array}$ \\
\hline Maryland & Md. Ann. Code art. 27§ 594B (d)(2) & $\begin{array}{l}\text { If probable cause to believe that mutual battery occurred and arrest is } \\
\text { necessary, officer shall consider if one party acted in self defense to } \\
\text { determine the PA. }\end{array}$ \\
\hline Missouri & Mo. Rev. Stat. § 455.085(3) & $\begin{array}{l}\text { Officer shall attempt to identify and arrest the party believed to be the } \\
\text { primary physical aggressor, most significant aggressor. Shall consider: 1) } \\
\text { intent of law to protect victims from further abuse, 2) comparative extent } \\
\text { of injuries inflicted or serious threats creating fear of physical injury, 3) } \\
\text { history of DV between parties. }\end{array}$ \\
\hline Montana & Mont. Code Ann. § 46-6-311(2)(b) & $\begin{array}{l}\text { In cases of mutual aggression, to evaluate the situation to determine PA } \\
\text { can consider: 1) prior history of violence, 2) relative severity of injuries, } \\
\text { 3) whether an act of or threat of violence was in self defense. }\end{array}$ \\
\hline Nevada & Nev. Rev. Stat. Ann.§171.137(2) & $\begin{array}{l}\text { If probable cause to believe that mutual battery occurred, shall attempt to } \\
\text { determine the primary physical aggressor. Shall consider: 1) prior DV } \\
\text { involving either person, 2) relative severity of injuries inflicted, 3) } \\
\text { potential for future injury 4) self defensive actions, 5) other factors that } \\
\text { may help make the determination. }\end{array}$ \\
\hline New Hampshire & N.H. Rev. Stat. Ann. § 173-B:10(II) & $\begin{array}{l}\text { When an officer has probable cause to believe that the persons have } \\
\text { committed abuse against each other, officers should arrest the person } \\
\text { believed to be the primary aggressor. Shall consider: 1) intent of chapter } \\
\text { to protect DV victims; 2) relative degree of injury or fear inflicted, and 3) } \\
\text { history of DV between persons. }\end{array}$ \\
\hline New Jersey & N.J. Rev Stat. § 2C:25-21 (c)(2) & $\begin{array}{l}\text { In determining the victim in a domestic violence incident where both } \\
\text { parties exhibit signs of injury, the officer should consider: 1) comparative } \\
\text { extent of injuries, 2) history of domestic violence between parties, and 3) } \\
\text { any other relevant factors. }\end{array}$ \\
\hline New York & $\begin{array}{l}\text { N.Y. Crim. Proc. Law § } 140.10 \\
(4)(c)\end{array}$ & $\begin{array}{l}\text { When reasonable cause to believe that more than one family or household } \\
\text { member has committed a misdemeanor, the officer shall attempt to } \\
\text { identify and arrest the primary physical aggressor. Must consider: 1) } \\
\text { comparative extent of injuries, 2) threats of future harm by perpetrator, 3) } \\
\text { prior history of DV, 4) self defensive actions. }\end{array}$ \\
\hline Ohio & $\begin{array}{l}\text { Ohio Rev. Code Ann. § } \\
\text { 2935.032(A)(1)(a)(ii) \& } \\
\text { 2935.03(B)(3)(d) }\end{array}$ & $\begin{array}{l}\text { If reasonable cause to believe that one or more persons committed } \\
\text { offenses against each other, the officer shall determine who is the primary } \\
\text { physical aggressor. Shall consider in addition to any other relevant } \\
\text { circumstance, 1) history of DV or other violent acts by either person, 2) } \\
\text { self defensive actions, 3) fear of physical harm resulting from threatened } \\
\text { use of force or use or history of use of force against any person and } \\
\text { reasonableness of that fear, 4) comparative severity of injuries. }\end{array}$ \\
\hline
\end{tabular}




\begin{tabular}{|c|c|c|}
\hline State & Primary Aggressor Law & Instructions for Applying the Law \\
\hline Oregon & Or. Rev. Stat. § 133.055(2)(c) & $\begin{array}{l}\text { Not specifically called "primary aggressor." the officer shall make } \\
\text { every effort to determine the assailant by considering: 1) comparative } \\
\text { extent of injuries and seriousness of threats creating fear of injury, 2) } \\
\text { history of DV between persons involved, 3) self defensive actions, 4) } \\
\text { potential for future assaults. }\end{array}$ \\
\hline Rhode Island & R.I. Gen. Laws § 12-29-3 (d)(2) & $\begin{array}{l}\text { When probable cause to believe that family/household members have } \\
\text { assaulted each other, shall arrest person who is believed to be the primary } \\
\text { physical aggressor. }\end{array}$ \\
\hline South Carolina & S.C. Code Ann. § 16-25-70 (D) & $\begin{array}{l}\text { If conflicting complaints of domestic or family violence from } 2 \text { or more } \\
\text { household members involving an incident of domestic or family violence, } \\
\text { officer shall evaluate each separately to determine PA. Shall consider: 1) } \\
\text { prior complaints of DV, 2) relative severity of injuries inflicted, 3) } \\
\text { likelihood of future injury, 4) self defensive actions, 5) individual } \\
\text { accounts regarding history of DV. }\end{array}$ \\
\hline South Dakota & S.D. Codified Laws § 23A-3-2.2* & $\begin{array}{l}\text { If probable cause to believe there has been mutual assaults, the officer } \\
\text { shall arrest the person whom the officer believes to be the primary } \\
\text { physical aggressor. The officer shall make every reasonable effort to } \\
\text { consider: (1) intent to protect the victims of DV, (2) comparative extent of } \\
\text { injuries inflicted or serious threats creating fear of physical injury, (3) } \\
\text { prior history of DV between persons. }\end{array}$ \\
\hline Tennessee & $\begin{array}{l}\text { Tenn. Code Ann. § 36-3-619 } \\
\text { (b)\&(c) }\end{array}$ & $\begin{array}{l}\text { If probable cause to believe that } 2 \text { or more persons committed a } \\
\text { misdemeanor or felony or if } 2 \text { or more make complaints, the officer shall } \\
\text { try to determine the PA. Shall consider: 1) history of DV, 2) relative } \\
\text { severity of injuries, 3) evidence from persons involved with DV, 4) } \\
\text { likelihood of future injury, 5) self defensive actions, 6) witnesses. }\end{array}$ \\
\hline Utah & Utah Code Ann. § 77-36-2.2 & $\begin{array}{l}\text { If complaints of DV from } 2 \text { or more opposing persons, the officer shall } \\
\text { evaluate each complaint separately to determine the predominant physical } \\
\text { aggressor. Shall consider: 1) prior complaints of DV, 2) relative severity } \\
\text { of injuries inflicted, 3) likelihood of future injury, 4) self defensive } \\
\text { actions. }\end{array}$ \\
\hline Virginia & Va. Code Ann. § 19.2-81.3 (B) & $\begin{array}{l}\text { The person the officer has probable cause to believe, based on the totality } \\
\text { of circumstances was the primary physical aggressor. }\end{array}$ \\
\hline Washington & Wash. Rev. Code $\S 10.31 .100(2)(c)$ & $\begin{array}{l}\text { When probable cause to believe that family/household members have } \\
\text { assaulted each other, the officer shall arrest the person believed to be the } \\
\text { primary physical aggressor. Shall make every reasonable effort to } \\
\text { consider: 1) intent to protect victims of domestic violence, 2) comparative } \\
\text { injuries inflicted or serious threats creating fear of physical injury, 3) } \\
\text { history of DV between persons involved. }\end{array}$ \\
\hline Wisconsin & Wis. Stat. § 968.075(3)(1)(b) & $\begin{array}{l}\text { When reasonable grounds to believe that domestic abuse was committed } \\
\text { against each other, the officer should determine the primary physical } \\
\text { aggressor. Shall consider 1) the intent of the section to protect victims of } \\
\text { DV, 2) the relative degree of injury or fear inflicted, and 3) any history of } \\
\text { domestic abuse between the persons. }\end{array}$ \\
\hline
\end{tabular}


${ }^{1}$ It is acknowledged that some subjectivity is involved in classifying states as having "mandatory," "preferred," or "discretionary" arrest provisions. The states, themselves, do not in general explicitly designate the classification of their arrest provisions, but indicate through their terminology the nature of the provisions. Thus, in general, terms like "shall," "will" and "must" signify a mandatory provision, while terms such as "may" and "can" signify a discretionary provision. Occasionally, a state may give the appearance of having a mandatory arrest provision, but then so dilute it as to make it in essence a discretionary provision. The Illinois statutory provision, for example, states that "Whenever a law enforcement officer has reason to believe that a person has been abused by a family or household member, the officer shall immediately use all reasonable means to prevent further abuse, including (1) arresting the abusing party, where appropriate...” (725 ILCS 5/112A-30: cf. New Mexico (NM Stat. Ann. § 40-13-7(B)(5)). In this summary the arrest provisions of both Illinois and New Mexico have been classified as discretionary.

The Tennessee Code explicitly states that: “. . . the preferred response of the officer is arrest” (Tenn. Code Ann. §36-3-619). However, in defining “preferred response," the code states that "preferred response means that law enforcement officers shall arrest a person committing domestic abuse unless there is a clear and compelling reason not to arrest” (Tenn. Code Ann. §36-3-601(6)). Thus, a case could be made that the Tennessee law constitutes, in reality, a mandatory arrest provision. We have, however, opted to abide by the explicit wording of the statute and classify the law as signifying a preferred arrest response.

The element of subjective assessment involved in classifying states as having "mandatory," "preferred," or "discretionary" arrest provisions in this matter can lead to different writers classifying the same statute in different categories. Thus, the astute reader may notice that whereas Wanless (1996) classifies Hawaii as having a mandatory arrest statute (see p. 577), we classify the statute as being "discretionary.” Our rationale for classifying the statute as "discretionary" is that the statute (Haw. Rev. Stat. § 709-906(2)) simply empowers officers to make arrests. Though the statute also empowers officers to order an abuser to leave the premises for twenty-four hours, and then mandates arrest should the abuser refuse to leave or return before 24 hours have passed (Haw. Rev. Stat. § 709-906(4)), this mandatory arrest is contingent on the officer having made a decision over which (s)he exercises discretion.

${ }^{2}$ The relationship categories covered by the various statutory provisions are not always as clear-cut as they may appear from reading the statutory summaries presented in this chapter. For example with regard to dating relationships, while some states (e.g. Alaska, Nevada, New Jersey and Washington) explicitly cover those in a current or former dating relationship, other states, such as Massachusetts and Rhode Island, limit coverage to those who are or were in a "substantial dating relationship." Still others do not refer to those in a dating relationship, but use terms whose exact overlap with a dating relationship is subject to debate. Maine, for example, does not mention including those in a dating relationship, but instead covers "those who are or were sexual partners" (19-A.M.R.S. § 4012.4). Oregon covers "persons who have been involved in a sexually intimate relationship with each other within two years immediately preceding the filing by one of them of a petition under ORS 107.710" (ORS $\S 107.705 .3(\mathrm{e})$ ). Interestingly, Alaska covers in separate provisions (a) those in a current or former dating relationship (Alaska Statute 18.66.990.5(C)) and (b) those in a prior or current sexual relationship (Alaska Statute 18.66.990.5(D)). In this chapter all of the above relationships are counted as dating relationships.

${ }^{3}$ The relevant Ohio statute states that arrest is the preferred response in these circumstances (ORC. Ann. § 2935.03(B)(3).

${ }^{4}$ In Kentucky, Maine, and West Virginia state statutes require "reporting” incidents of domestic violence, but the report is not defined as being paperwork as in most other states specifically requiring a written report. This ambiguity makes analysis difficult. 


\section{Chapter 4 \\ Descriptive Data from the National Incident Based Reporting System 2000 Assault Dataset}

Phase I involved an extensive analysis of year 2000 NIBRS data. This chapter will first examine how the National Incident Based System (NIBRS) data are collected and describe the different units of analysis that are available for data analysis. The chapter will also outline how cases were selected for analysis from the NIBRS dataset used in this study. This will be followed by a detailed description of the incidents selected for the study, including the manner in which police resolved the incident.

\section{NIBRS Data}

In the mid-1980s the FBI undertook a revision of the existing summary Uniform Crime Reporting system. The outcome of the FBI's work is the NIBRS. The NIBRS breaks away from the summary level reporting by requiring local law enforcement to report incident level details for 44 different offenses. This change in reporting requirements has the potential to revolutionalize our understanding of crime in the U.S.A.

Several factors differentiate NIBRS from the summary UCR data. First, unlike the UCR, which provides only summary counts of victims, the NIBRS provides individual level details on victims and offenders in all incidents reported to the police. The NIBRS provides 53 unique data elements for all crimes against the person, with details on the circumstances, the offense and other characteristics of the incident. Second, the NIBRS incorporates an extensive set of quality control standards throughout the data entry and submission processes. These types of data quality controls are not required for the summary UCR. For example, a common problem with the summary level UCR data is a general inconsistency in the way aggravated assaults are defined between jurisdictions. What one jurisdiction considers an aggravated assault another may define 
as a simple-assault or some other offense. The NIBRS data submission guidelines require that for an incident to include an aggravated assault offense, certain definitional criteria must be included, such as victim injury or weapon used. The inclusion of these quality control standards improves the overall reliability and inferential capabilities of the NIBRS data for examining crime issues across jurisdictions. Third, the NIBRS allows for frequent updates to all incident information for up to two years beyond the date of the incident. There are no such mechanisms for updating the summary UCR. Finally, the NIBRS includes information on all victims, offenders, arrests, and offenses in the incident. This additional information can be critical in identifying the prevalence and context of dual arrest in intimate partner violence.

The data elements necessary to address the research questions posed in this study are contained in various data segments of the hierarchical NIBRS structure. The nested structure of NIBRS allows up to six segments (administrative, offense, property, victim, offender, and arrestee) of information on each incident reported to the police. The hierarchical structure of NIBRS allows for analysis of different units of count. For example, it is possible to examine victims at a different unit of analysis from offenders. It is also possible to examine the interaction between victims and offenders. The nested structure of the NIBRS dataset lends itself to the use of HLM (Hierarchical Linear Modeling) for multivariate analysis, an issue which is discussed in more detail in the next chapter.

In the NIBRS data, a single incident can also have multiple records in each of the segments except the administrative data segment. For example, the offense data segment can contain up to 10 types of offenses, each of which will have a separate offense segment record. The FBI’s Uniform Crime Reporting hierarchy rule for selecting only the most serious offense in an incident for summary reporting is not used in the NIBRS. Therefore, in NIBRS, for each 
crime incident all offenses (up to a maximum of the 10 most serious) are reported. The victim data segment in an incident report can contain up to 999 victim records wherein each record contains detailed information pertinent to each victim. Similarly, the offender segment can contain up to 99 unique offender records per incident and the arrestee segment can have up to 99 unique arrestee records.

As with any relational database, the hierarchical structure of NIBRS permits linkages between segments. For instance, victim, offender and incident variables can be linked for analysis. These links are important for developing a better understanding of the circumstances associated with intimate partner violence. For example, incident circumstance information, contained within the offense segment, can be linked with the victim-offender relationship details in the victim segment. The victim segment also provides details on race, injury, and specific offenses committed against each victim in the incident. For dual arrest incidents this becomes important for examining the different types of offenses committed, injuries inflicted, and weapons used by one partner against the other. The linkages between all segments within the NIBRS data also provide details on additional victims and additional offenses within the incident that can help in defining a typology of intimate partner dual arrest incidents.

\section{Cases Selected from the NIBRS Dataset}

To facilitate compatibility among the incidents examined, and to make the project more manageable, it was decided not to include all criminal offenses, but instead to limit the study to incidents involving acts, or threats of acts, of physical violence to the person, regardless of the legal definition. Since prior research (see e.g. Durose, Harlow, Langan, Motivans, Rantala, \& Smith, 2005; Hirschel et al., 1991; Rennison 2003; Greenfeld, Rand, Craven, Klaus, Perkins, Ringel, Warchol, Maston, \& Fox 1998) has revealed that the majority of criminal incidents 
between intimate partners involve minor acts of violence such a limitation seems well justified.

The NIBRS categorization of assaults into "aggravated assaults," "simple assaults,” (common law simple battery) and “intimidation” (common law simple assault) provides the appropriate framework.

As we have discussed earlier in this report, examining dual arrest in intimate partner cases without reference to what is occurring in both other domestic (e.g. parent-child and sibling) and non-domestic violence situations poses the risk of concluding that dual arrests constitute a problem that is unique to intimate partner violence. Thus, the cases selected for this study comprise all assault and intimidation reported to the NIBRS no matter what the relationship between the victim and offender. In order to allow for a sufficiently lengthy follow-up without going back too far in time, we decided to focus on the calendar year 2000. Thus, the NIBRS dataset examined in this study includes all assault and intimidation cases reported to the NIBRS in the calendar year 2000.

\section{Identifying Dual Arrest Incidents in NIBRS}

The victim segment of the NIBRS data was used to identify the existence of a potential dual arrest situation. The NIBRS structure requires that offender to victim relationship information be included for all crimes against a person, including aggravated assault, simple assault, and intimidation. Up to ten victim-offender relationship codes can be reported for each victim. Included among the response categories in each of the victim-offender relationship variables is a value that indicates whether the victim has also been identified as an offender in the incident. When this code is used in one of the victim-offender variables, a second victimoffender relationship variable helps indicate the actual relationship between the offender and the victim. 
Consequently, identifying dual arrest intimate partner incidents involves selecting those incidents where the "victim was offender" code is used in combination with one of several codes that define intimate partners. A multi-step process was employed to define and select such cases from the dataset. First, all victims with a "victim was offender" value in one of the victimoffender relationship variables were selected out of the entire victim segment file for the year 2000 national dataset. In all, the 2000 NIBRS data contained 2,913,414 victim records. Of these, 650,849 victims included an assault or intimidation charge as one of the victimization offenses. Of the 650,849 assault and intimidation victims, 42,949 had a victim was offender code.

A new variable was required to define the closest relationship between each victim and all of the offenders in the incident. The first step in this process was to define the closest victim to offender relationship code for all 650,849 assault and intimidation victim records. The original victim-offender relationship variable was recoded into 5 general groups: “Intimate partner,” “other domestic,” "non-domestic but known to victim,” "stranger” and finally, "relationship unknown or missing.” Then, a series of recode statements was used to define the closest victim to offender relationship in the incident with intimate partner defined as the closest victimoffender relationship followed by other domestic, non-domestic but known to victim, stranger and finally, relationship unknown or missing.

\section{The Unit of Analysis}

The different segments in the NIBRS dataset provide several possible units of analysis. Since the major focus of this study is on the police response to incidents of intimidation and assault, it was decided to use the incident as the major unit of analysis.

\section{Contributing Jurisdictions}


A total of 2,819 jurisdictions (police reporting agencies) from 19 states contributed cases to the dataset (see Table 4.1). While jurisdictions in some of the contributing states, such as Idaho, Iowa, Michigan, South Carolina, Tennessee, Virginia, and West Virginia are well represented in the dataset, other states, such as Arkansas, Kentucky, and Nebraska have only a very small number of jurisdictions supplying cases. As previously discussed, Western and

\section{Table 4.1: Number of Jurisdictions Contributing to} NIBRS Dataset by State ${ }^{a}$

\begin{tabular}{lcc}
\hline \hline & Frequency & Percent \\
\hline Arkansas & 2 & .1 \\
Colorado & 131 & 4.6 \\
Connecticut & 37 & 1.3 \\
Idaho & 112 & 4.0 \\
lowa & 196 & 7.0 \\
Kentucky & 7 & .2 \\
Massachusetts & 187 & 6.6 \\
Michigan & 571 & 20.3 \\
Nebraska & 9 & .3 \\
North Dakota & 59 & 2.1 \\
Ohio & 85 & 3.0 \\
South Carolina & 261 & 9.3 \\
South Dakota & 59 & 2.1 \\
Tennessee & 373 & 13.2 \\
Texas & 51 & 1.8 \\
Utah & 53 & 1.9 \\
Vermont & 40 & 1.4 \\
Virginia & 340 & 12.1 \\
West Virginia & 246 & 8.7 \\
Total & 2819 & 100.0 \\
\hline \hline aeporting jurisdiction unit of analysis & & \\
\hline
\end{tabular}

Northeastern states are not well represented in the dataset. While 1,280 (45.4\%) of the jurisdictions in the dataset are from Southern states and 979 (34.7\%) are from North Central States, only 296 (10.5\%) are from Western and 264 (9.4\%) are from Northeastern states (Table 
4.2). In addition, smaller jurisdictions are more heavily represented than the larger jurisdictions. Excluding the 443 (15.7\%) of the jurisdictions that comprise state police, college/university, and other types of law enforcement agencies, nearly $60 \%$ of the jurisdictions in the dataset served populations of less than 10,000; and, only $2.5 \%$ of the jurisdictions served populations of 100,000 or more (Table 4.3). As the descriptive statistics in Table 4.4 indicate, the population of the jurisdictions ranged widely from 168 to 936,498. The mean population of these jurisdictions was 18,030 with a stand deviation of 42,211 .

\begin{tabular}{|c|c|c|}
\hline & Frequency & Percent \\
\hline North East & 264 & 9.4 \\
\hline North Central & 979 & 34.7 \\
\hline South & 1280 & 45.4 \\
\hline West & 296 & 10.5 \\
\hline Total & 2819 & 100.0 \\
\hline
\end{tabular}

Table 4.3: Number of Jurisdictions within Population Groups

\begin{tabular}{lccc}
\hline \hline & Frequency & Percent & Valid Percent \\
\hline Under 10,000 & 1413 & 50.1 & 59.5 \\
10,000 to 24,999 & 542 & 19.2 & 22.8 \\
25,000 to 49,999 & 251 & 8.9 & 10.6 \\
50,000 to 99,999 & 109 & 3.9 & 4.6 \\
100,000 to 249,999 & 48 & 1.7 & 2.0 \\
250,000 and over & 13 & .5 & .5 \\
Total & 2376 & 84.3 & 100.0 \\
State Police, universities and other agencies & & & \\
Total & 443 & 15.7 & \\
\hline \hline
\end{tabular}

a. Reporting jurisdiction unit of analysis

b. Other agencies include: state tobacco and alcohol control departments, state mental health agencies, airport authorities and other state, county and local agencies not directly covering an identified population. 


\section{Table 4.4: Descriptive Statistics of Served Populations ${ }^{a}$}

\begin{tabular}{lccccc}
\hline \hline & $\mathrm{N}$ & Minimum & Maximum & Mean & $\begin{array}{c}\text { Std. } \\
\text { Deviation }\end{array}$ \\
\hline Population & 2376 & 168 & 936,498 & 18030 & 42211 \\
Valid N (listwise) & 2376 & & & & \\
\hline \hline & & & & \\
${ }^{\text {a }}$ Reporting jurisdiction unit of analysis
\end{tabular}

As previously discussed, there are a variety of possible units of analysis and the sample size varies depending upon which unit of analysis is selected. Using jurisdiction as the unit of analysis, the sample size is 2,819 (see, e.g. Table 4.1). These 2,819 jurisdictions generated a total of 577,862 incidents of aggravated assault, simple assault, and intimidation in calendar year 2000. In these 577,862 incidents there were 650,849 victims, 622,258 offenders, and 235,690 arrests. As noted previously, because the primary focus of the study is on assessing the police response to incidents, incident was chosen as the primary unit of analysis. The remainder of this chapter describes these 577,862 incidents in greater detail.

\section{Descriptive Overview: The Incidents}

In slightly over $65 \%$ of the 577,862 incidents simple assault was reported as the most serious offense in the incident (Table 4.5). The rest were equally divided between cases of aggravated assault and intimidation. Most (61.6\%) of the incidents took place in a home or residence while $11.8 \%$ took place on a road or highway, or in an alley (Table 4.6).

Table 4.5: Most Serious Offense Against the Victim ${ }^{\text {a }}$

\begin{tabular}{lcc}
\hline \hline & Frequency & Percent \\
\hline Aggravated Assault & 99990 & 17.3 \\
Simple Assault & 378010 & 65.4 \\
Intimidation & 99862 & 17.3 \\
Total & 577862 & 100.0 \\
\hline \hline
\end{tabular}

a. Incident unit of analysis 
Table 4.6: Reported Incident Location ${ }^{\text {a }}$

\begin{tabular}{lcc}
\hline \hline & Frequency & Percent \\
\hline Air/Bus/Train Terminal & 967 & .2 \\
Bank/Savings and Loan & 553 & .1 \\
Bar/Night Club & 13643 & 2.4 \\
Church/Synagogue/Temple & 778 & .1 \\
Commercial/Office Building & 11436 & 2.0 \\
Construction Site & 539 & .1 \\
Convenience Store & 5697 & 1.0 \\
Department/Discount Store & 3491 & .6 \\
Drug Store/Doctor's Office/Hospital & 3583 & .6 \\
Field/Woods & 3254 & .6 \\
Government/Public Building & 4383 & .8 \\
Grocery/Supermarket & 2933 & .5 \\
Highway/Road/Alley & 67976 & 11.8 \\
Hotel/Motel/Etc. & 5886 & 1.0 \\
Jail/Prison & 3002 & .5 \\
Lake/Waterway & 457 & .1 \\
Liquor Store & 268 & .0 \\
Parking Garage & 23755 & 4.1 \\
Rental Storage Facility & 360 & .1 \\
Residence/Home & 355883 & 61.6 \\
Restaurant & 7748 & 1.3 \\
School/College & 21508 & 3.7 \\
Service/Gas Station & 3141 & .5 \\
Specialty Store & 2946 & .5 \\
Other/Unknown & 33675 & 5.8 \\
Total & 577862 & 100.0 \\
\hline \hline & & \\
\hline a.ncidenting & 5.0 \\
\hline
\end{tabular}

a. Incident unit of analysis 
Incidents are reported at all times of the day and night. They are at their lowest between five and six a.m., when about $1 \%$ of the incidents occur, and then steadily climb until the peak rate of a little over $6 \%$ is reached at about 9 p.m. (See Figure 4.1). ${ }^{1}$

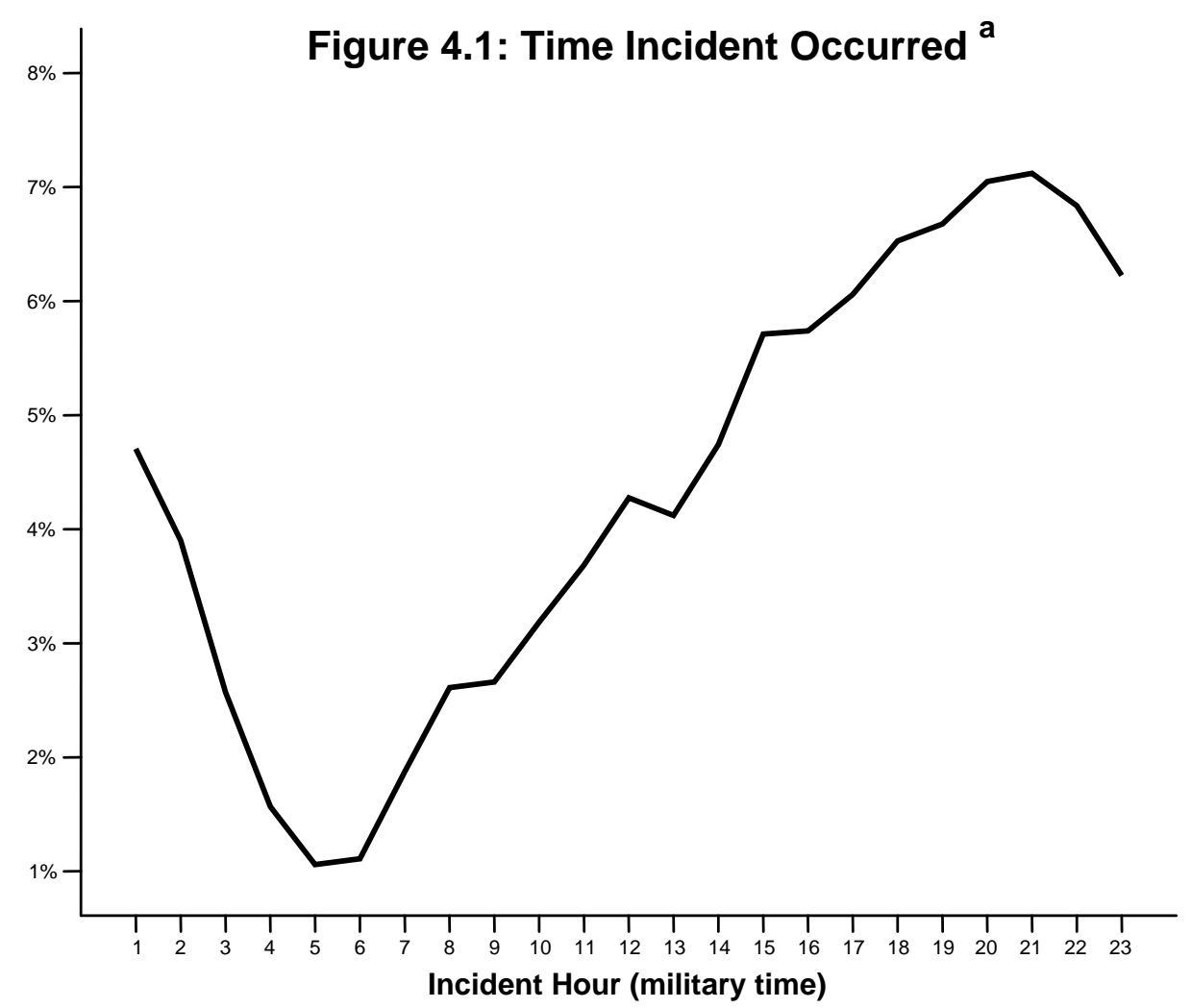

a. Incident unit of analysis

b. Due to a recording inconsistency in NIBRS Midnight (coded as 0 ) is excluded from the above chart.

c. Includes only those incidents where the actual incident time is reported. 
Most incidents have one victim (87.4\%: Table 4.7) and one offender (89.0\%: Table 4.8). Over four-fifths (82.2\%) of the incidents involved one victim and one offender, 3.8\% involved one victim and two offenders, 5.6\% two victims and one offender, and 4.5\% two victims and two offenders. When combining the rates for all incidents either with more than two victims or more than two offenders, this group comprises $3.8 \%$ of the total (Table 4.9 ).

Table 4.7: Count of Victims in Incident ${ }^{a}$

\begin{tabular}{lcc}
\hline \hline & Frequency & Percent \\
\hline 1 & 504787 & 87.4 \\
2 & 61407 & 10.6 \\
3 & 8543 & 1.5 \\
4 & 2091 & .4 \\
5 & 610 & .1 \\
6 & 233 & .0 \\
7 & 94 & .0 \\
8 & 42 & .0 \\
9 & 28 & .0 \\
10 & 14 & .0 \\
11 & 5 & .0 \\
13 & 5 & .0 \\
14 & 1 & .0 \\
18 & 1 & .0 \\
37 & 1 & .0 \\
Total & 577862 & 100.0 \\
\hline \hline
\end{tabular}

a. Incident unit of analysis 
Table 4.8: Count of offenders in incident ${ }^{a}$

\begin{tabular}{lcc}
\hline \hline & Frequency & Percent \\
\hline 1 & 514342 & 89.0 \\
2 & 50367 & 8.7 \\
3 & 8653 & 1.5 \\
4 & 2788 & .5 \\
5 & 982 & .2 \\
6 & 387 & .1 \\
7 & 152 & .0 \\
8 & 78 & .0 \\
9 & 57 & .0 \\
10 & 34 & .0 \\
11 & 5 & .0 \\
12 & 7 & .0 \\
13 & 1 & .0 \\
14 & 1 & .0 \\
15 & 2 & .0 \\
16 & 4 & .0 \\
17 & 1 & .0 \\
21 & 1 & .0 \\
Total & 577862 & 100.0 \\
\hline \hline
\end{tabular}

a. Incident unit of analysis

Table 4.9: Number of Victims by Number of Offenders in Each Incident ${ }^{\text {a }}$

\begin{tabular}{lllcccc}
\hline \hline & & \multicolumn{3}{c}{ Number of Offenders } & \\
\cline { 3 - 5 } & & & 1 & 2 & 3 or more & Total \\
\hline \multirow{2}{*}{$\begin{array}{l}\text { Number of } \\
\text { Victims }\end{array}$} & 1 & Count & 475278 & 22091 & 7418 & 504787 \\
& & \% of Total & $82.2 \%$ & $3.8 \%$ & $1.3 \%$ & $87.4 \%$ \\
\cline { 2 - 5 } & 2 & Count & 32496 & 25803 & 3108 & 61407 \\
& & \% of Total & $5.6 \%$ & $4.5 \%$ & $.5 \%$ & $10.6 \%$ \\
\cline { 2 - 5 } & \multirow{2}{*}{3 or more } & Count & 6568 & 2473 & 2627 & 11668 \\
& & \% of Total & $1.1 \%$ & $.4 \%$ & $.5 \%$ & $2.0 \%$ \\
\hline Total & Count & 514342 & 50367 & 13153 & 577862 \\
& & \% of Total & $89.0 \%$ & $8.7 \%$ & $2.3 \%$ & $100.0 \%$ \\
\hline \hline
\end{tabular}

a. Incident unit of analysis 
In $58.0 \%$ of the incidents the offender used a personal weapon (hands, fists, feet etc.: See Table 4.10). In $26.0 \%$ of the cases (which constitute the intimidation cases) no weapon of any kind was used. ${ }^{2}$ In $1.9 \%$ of the cases a handgun, and in a further $1.1 \%$ of the cases another type of firearm was used. A knife, cutting instrument, or blunt object was used in $6.3 \%$ of the cases.

Table 4.10: Weapon Used in Incident ${ }^{a}$

\begin{tabular}{lccc}
\hline \hline & Frequency & Percent & Valid Percent \\
\hline Firearm & 3013 & .5 & .5 \\
Handgun & 10563 & 1.8 & 1.9 \\
Rifle & 1067 & .2 & .2 \\
Shotgun & 1596 & .3 & .3 \\
Other Firearm & 673 & .1 & .1 \\
Knife/Cutting Instrument & 18998 & 3.3 & 3.4 \\
Blunt Object & 16492 & 2.9 & 2.9 \\
Motor Vehicle & 6269 & 1.1 & 1.1 \\
Personal Weapons & 325352 & 56.3 & 58.0 \\
Poison & 61 & .0 & .0 \\
Explosives & 70 & .0 & .0 \\
Fire/Incendiary Device & 189 & .0 & .0 \\
Drugs/Narcotics/Sleeping Pills & 47 & .0 & .0 \\
Asphyxiation & 69 & .0 & .0 \\
Other & 30537 & 5.3 & 5.4 \\
No Weapon & 145870 & 25.2 & 26.0 \\
Total & 560866 & 97.1 & 100.0 \\
Missing & 16996 & 2.9 & \\
Total & 577862 & 100.0 & \\
\hline \hline
\end{tabular}

a. Incident unit of analysis

In over half (55.2\%) of the incidents the victim suffered no injury, in $40.3 \%$ of the cases there was apparent minor injury, and in $4.5 \%$ of the cases there was serious physical injury (Table 4.11). 
Table 4.11: Most Serious Victim Injury ${ }^{a}$

\begin{tabular}{lcc}
\hline \hline & Frequency & Percent \\
\hline Serious Physical Injury & 25948 & 4.5 \\
Apparent Minor Injury & 233118 & 40.3 \\
No Injury & 318796 & 55.2 \\
Total & 577862 & 100.0 \\
\hline \hline a. Incident unit of analysis & &
\end{tabular}

\section{Descriptive Overview: The Victims}

As previously indicated, the 577,862 incidents generated 650,849 victims. A total of $57.3 \%$ of the victims were female (Table 4.12 ), $71.6 \%$ were White, $27.6 \%$ were Black, and $0.8 \%$ were from other racial groupings (Table 4.13). Only 6.1\% of the victims were identified as being of Hispanic origin (Table 4.14). Almost nine-tenths were residents of the jurisdiction (see Table 4.15). The mean age of the victims was $29.2($ s.d. $=12.8)$. The distribution of victim ages is depicted in Figure 4.2.

Table 4.12: Victim Gender ${ }^{\text {a }}$

\begin{tabular}{lccc}
\hline \hline & Frequency & Percent & Valid Percent \\
\hline Female & 370679 & 57.0 & 57.3 \\
Male & 275777 & 42.4 & 42.7 \\
Total & 646456 & 99.3 & 100.0 \\
Unknown/missing & 4393 & .7 & \\
Total & 650849 & 100.0 & \\
\hline \hline
\end{tabular}

a. Victim unit of analysis 
Table 4.13: Victim Race ${ }^{a}$

\begin{tabular}{lccc}
\hline \hline & Frequency & Percent & Valid Percent \\
\hline White & 452831 & 69.6 & 71.6 \\
Black & 174442 & 26.8 & 27.6 \\
Asian/Pacific Islander & 3375 & & .5 \\
American Indian/Alaskan Native & 2118 & .3 & .3 \\
Total known & 632766 & 97.2 & 100.0 \\
NA/Unknown & 18083 & 2.8 & \\
Total & 650849 & 100.0 & \\
\hline \hline
\end{tabular}

a. Victim unit of analysis

Table 4.14: Victim Ethnicity ${ }^{\mathrm{a}}$

\begin{tabular}{lccc}
\hline \hline & Frequency & Percent & Valid Percent \\
\hline Non-Hispanic & 433471 & 66.6 & 93.9 \\
Hispanic & 27992 & 4.3 & 6.1 \\
Total known ethnicity & 461463 & 70.9 & 100.0 \\
NA/Unknown & 91543 & 14.1 & \\
Missing & 97843 & 15.0 & \\
Total missing/unknown & 189386 & 29.1 & \\
Total & 650849 & 100.0 & \\
\hline \hline
\end{tabular}

a. Victim unit of analysis

Table 4.15: Victim Residency ${ }^{a}$

\begin{tabular}{lccc}
\hline \hline & Frequency & Percent & Valid Percent \\
\hline Resident & 441532 & 67.8 & 87.7 \\
Non-resident & 62167 & 9.6 & 12.3 \\
Total known residency & 503699 & 77.4 & 100.0 \\
NA/Unknown & 82035 & 12.6 & \\
Missing & 65115 & 10.0 & \\
Total missing/unknown & 147150 & 22.6 & \\
Total & 650849 & 100.0 & \\
\hline \hline
\end{tabular}

a. Victim unit of analysis 


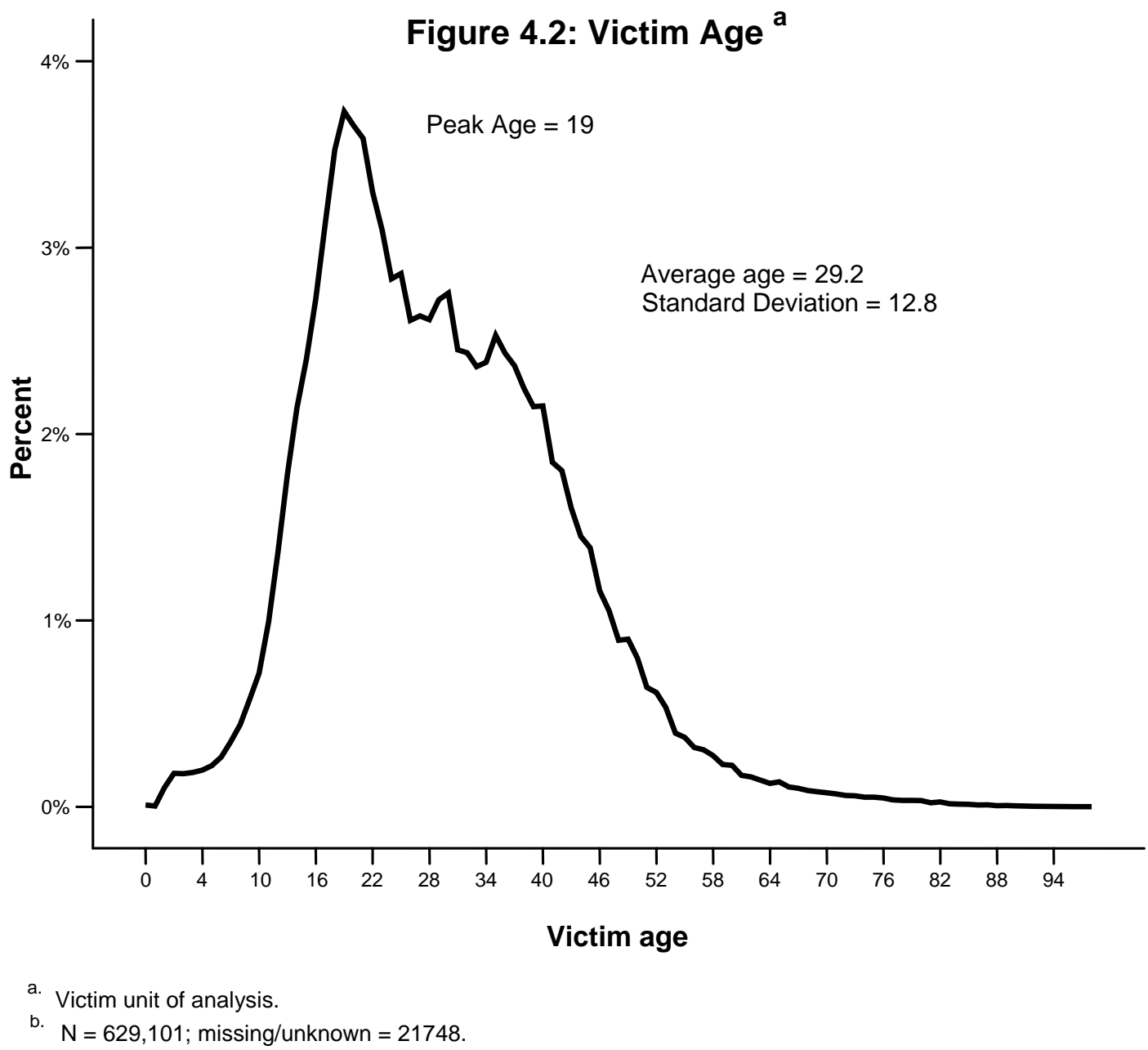

A key variable in this project is victim-offender relationship. Responding officers are instructed to record the closest victim-offender relationship. Thus, for example, if the victim is a parent or sibling who was babysitting, the category of parent or sibling is recorded in preference to babysitter. The NIBRS provides the victim-offender relationship for up to 10 offenders for each victim. The 2000 assault and intimidation data set used in this study has up to 37 victims in a single incident. The data set allows for victim-offender relationship information for up to 999 victims in an incident. 
In Table 4.16 we present the victim-offender relationship for the first victim. ${ }^{3}$ In $22.4 \%$ of the incidents the victim was an acquaintance, in $16.7 \%$ a boyfriend or girlfriend and in $14 \%$ a spouse. In only $10 \%$ of the cases were the victim and offender identified as strangers.

In $3.5 \%$ of the cases the victim was identified as an offender. In these cases we have situations in which two or more people have been identified by the responding officers as being both victims and offenders in the incident. Such cases constitute the potential dual arrest cases in this study. These are potential dual arrest cases because the officer has documented that both parties have committed an offense, and thus can be arrested. In cases where there are two people who have been identified as victims and offenders, if victim \#1 is identified as the offender in the variable depicting the victim-offender relationship for the first victim (i.e. in Table 4.16), then victim \#1's relationship to the offender (e.g. spouse) will be identified in the variable depicting the victim-offender relationship for the second victim (i.e. in Table 4.17).

In Table 4.17 we present the victim-offender relationship for the second victim. As can be seen from that table, the victim was an acquaintance in $26.2 \%$ of the $3.4 \%$ of the cases in which there was an identified victim-offender relationship for a second victim. In $13.9 \%$ of the cases the victim and offender were strangers and in $24.5 \%$ of the cases the victim was identified as an offender. In $86.6 \%$ of the cases there was no second victim. For those cases in Table 4.17 where the victim was identified as the offender, the relationship between the two parties can be found by looking at the victim-offender relationship reported for victim \#1 (i.e. in the data used to produce Table 4.16). 
Table 4.16: Victim-Offender Relationship for First Victim ${ }^{\text {a }}$

\begin{tabular}{|c|c|c|c|c|}
\hline & Frequency & Percent & $\begin{array}{c}\text { Valid } \\
\text { Percent }\end{array}$ & $\begin{array}{c}\text { Cumulative } \\
\text { Percent }\end{array}$ \\
\hline Victim was Spouse & 77989 & 12.0 & 14.0 & 14.0 \\
\hline Victim was common-law Spouse & 15341 & 2.4 & 2.7 & 16.7 \\
\hline Victim was Ex-Spouse & 8580 & 1.3 & 1.5 & 18.2 \\
\hline Victim was Boyfriend/Girlfriend & 93523 & 14.4 & 16.7 & 35.0 \\
\hline Homosexual Relationship & 1296 & .2 & .2 & 35.2 \\
\hline Victim was Parent & 18795 & 2.9 & 3.4 & 38.6 \\
\hline Victim was Sibling & 17210 & 2.6 & 3.1 & 41.7 \\
\hline Victim was Child & 17717 & 2.7 & 3.2 & 44.8 \\
\hline Victim was Grandparent & 994 & .2 & .2 & 45.0 \\
\hline Victim was Grandchild & 565 & .1 & .1 & 45.1 \\
\hline Victim was in-law & 4404 & .7 & .8 & 45.9 \\
\hline Victim was Stepparent & 3182 & .5 & 6 & 46.5 \\
\hline Victim was Stepchild & 3729 & .6 & .7 & 47.1 \\
\hline Victim was Stepsibling & 629 & .1 & .1 & 47.2 \\
\hline Other Family Member & 13809 & 2.1 & 2.5 & 49.7 \\
\hline Victim was Acquaintance & 125066 & 19.2 & 22.4 & 72.1 \\
\hline Victim was Friend & 17016 & 2.6 & 3.0 & 75.2 \\
\hline Victim was Neighbor & 11787 & 1.8 & 2.1 & 77.3 \\
\hline Victim was Babysitter & 334 & .1 & .1 & 77.3 \\
\hline Victim was Child of Boyfriend/Girlfriend & 1810 & .3 & .3 & 77.6 \\
\hline Victim was Employee & 2014 & .3 & .4 & 78.0 \\
\hline Victim was Employer & 1522 & .2 & .3 & 78.3 \\
\hline Victim was Otherwise Known & 46076 & 7.1 & 8.2 & 86.5 \\
\hline Victim was Stranger & 55937 & 8.6 & 10.0 & 96.5 \\
\hline Victim was Offender & 19328 & 3.0 & 3.5 & 100.0 \\
\hline Total & 558653 & 85.8 & 100.0 & \\
\hline Relationship Unknown & 64874 & 10.0 & & \\
\hline Relationship missing or not reported & 27322 & 4.2 & & \\
\hline Total & 92196 & 14.2 & & \\
\hline Total & 650849 & 100.0 & & \\
\hline
\end{tabular}

${ }^{\text {a. }}$ Victim unit of analysis 
Table 4.17: Victim-Offender Relationship for Second Victim ${ }^{\text {a }}$

\begin{tabular}{|c|c|c|c|c|}
\hline & Frequency & Percent & $\begin{array}{l}\text { Valid } \\
\text { Percent }\end{array}$ & $\begin{array}{c}\text { Cumulative } \\
\text { Percent }\end{array}$ \\
\hline Victim was Spouse & 4083 & .6 & 4.7 & 4.7 \\
\hline Victim was common-law Spouse & 736 & .1 & .8 & 5.5 \\
\hline Victim was Ex-Spouse & 323 & .0 & .4 & 5.9 \\
\hline Victim was Boyfriend/Girlfriend & 5023 & .8 & 5.7 & 11.6 \\
\hline Homosexual Relationship & 185 & .0 & .2 & 11.8 \\
\hline Victim was Parent & 1114 & .2 & 1.3 & 13.1 \\
\hline Victim was Sibling & 2050 & .3 & 2.3 & 15.5 \\
\hline Victim was Child & 1667 & .3 & 1.9 & 17.4 \\
\hline Victim was Grandparent & 51 & .0 & .1 & 17.4 \\
\hline Victim was Grandchild & 82 & .0 & .1 & 17.5 \\
\hline Victim was in-law & 660 & .1 & .8 & 18.3 \\
\hline Victim was Stepparent & 224 & .0 & .3 & 18.5 \\
\hline Victim was Stepchild & 305 & .0 & .3 & 18.9 \\
\hline Victim was Stepsibling & 62 & .0 & .1 & 18.9 \\
\hline Other Family Member & 2150 & .3 & 2.5 & 21.4 \\
\hline Victim was Acquaintance & 22907 & 3.5 & 26.2 & 47.6 \\
\hline Victim was Friend & 2376 & .4 & 2.7 & 50.3 \\
\hline Victim was Neighbor & 1700 & .3 & 1.9 & 52.3 \\
\hline Victim was Babysitter & 23 & .0 & .0 & 52.3 \\
\hline Victim was Child of Boyfriend/Girlfriend & 125 & .0 & .1 & 52.4 \\
\hline Victim was Employee & 112 & .0 & .1 & 52.6 \\
\hline Victim was Employer & 78 & .0 & .1 & 52.6 \\
\hline Victim was Otherwise Known & 7849 & 1.2 & 9.0 & 61.6 \\
\hline Victim was Stranger & 12132 & 1.9 & 13.9 & 75.5 \\
\hline Victim was Offender & 21424 & 3.3 & 24.5 & 100.0 \\
\hline Total & 87441 & 13.4 & 100.0 & \\
\hline Relationship Unknown & 13044 & 2.0 & & \\
\hline Relationship missing or not reported & 550364 & 84.6 & & \\
\hline Total & 563408 & 86.6 & & \\
\hline Total & 650849 & 100.0 & & \\
\hline
\end{tabular}

${ }^{\text {a. }}$ Victim unit of analysis 
For analytic purposes we collapsed the categories of victim-offender relationship into four broader categories: (1) intimate partner; (2) other domestic; (3) non-domestic, but known to victim; and, (4) stranger. While “intimate partners” include spouses, common-law spouses, exspouses, homosexual relationships, and boyfriends/girlfriends, “other domestic” include parentchild, child-parent, siblings, grandparents, grandchildren, child of boyfriend/girlfriend, in-laws, and “other family members.” Included in “non-domestic, but known to victim” are relationships categorized as involving acquaintances, friends, neighbors, employer/employee, babysitters, and “otherwise known.” Since our primary unit of analysis is the incident, we created a new variable to identify the closest offender-victim relationship in the incident. Thus, for example, if a man assaulted his wife, his mother-in-law and a friend, the closest victim-offender relationship in the incident would be spouse.

The distribution of the four broad victim-offender relationships is presented in Table 4.18. In 197,064 (39.7\%) of the 577,862 incidents, intimate partners constituted the closest victim-offender relationship. A total of 70,707 (14.2\%) of the incidents involved parties who had some other type of domestic relationship, 183,448 (36.7\%) parties who did not have a domestic relationship but were known to each other, and 46,254 (9.3\%) parties who were strangers.

Table 4.18: Closest Victim-Offender Relationship ${ }^{a}$

\begin{tabular}{lccc}
\hline \hline & Frequency & Percent & Valid Percent \\
\hline Intimate Partner & 197064 & 34.1 & 39.7 \\
Other Domestic & 70707 & 12.2 & 14.2 \\
Non Domestic - Known & 182448 & 31.6 & 36.7 \\
Stranger & 46254 & 8.0 & 9.3 \\
Total & 496473 & 85.9 & 100.0 \\
Missing/relationship unknown & 81389 & 14.1 & \\
Total & 577862 & 100.0 & \\
\hline \hline
\end{tabular}

a. Incident unit of analysis 


\section{Descriptive Overview: The Offenders}

As indicated above, there were 622,258 offenders in the 577,862 assault and intimidation incidents in the dataset. While there was one offender in 514,342 (89\%) of the incidents, there were two or more offenders in 63,520 (11.0\%) of the incidents (see Table 4.8). The vast majority (75\%) of the 622,258 offenders were male (Table 4.19). While 65\% of the offenders were White, 34\% were Black. Only 0.6\% were Asian and 0.4\% Native American (Table 4.20). The mean age of the offenders was 29.3 (s.d. $=11.9$ ). ${ }^{4}$ The age distribution of offenders is depicted in Chart 4.3.

Table 4.19: Offender Gender ${ }^{a}$

\begin{tabular}{lccc}
\hline \hline & Frequency & Percent & Valid Percent \\
\hline Female & 155671 & 23.5 & 25.0 \\
Male & 466769 & 70.5 & 75.0 \\
Total known & 622440 & 94.0 & 100.0 \\
Missing & 24714 & 3.7 & \\
Unknown & 15104 & 2.3 & \\
Total missing/unknown & 39818 & 6.0 & \\
Total & 662258 & 100.0 & \\
\hline \hline
\end{tabular}

a. Offender unit of analysis

Table 4.20:Offender Race ${ }^{a}$

\begin{tabular}{lccc}
\hline \hline & & & Valid \\
& Frequency & Percent & Percent \\
\hline White & 395313 & 59.7 & 65.0 \\
Black & 206938 & 31.2 & 34.0 \\
Asian/Pacific Islander & 3389 & .5 & .6 \\
American Indian/Alaskan Native & 2640 & .4 & .4 \\
Total known & 608280 & 91.8 & 100.0 \\
NA/Unknown & 29264 & 4.4 & \\
Missing & 24714 & 3.7 & \\
Total missing/unknown & 53978 & 8.2 & \\
Total & 662258 & 100.0 & \\
\hline \hline
\end{tabular}

a. Offender unit of analysis 


\section{Figure 4.3: Age of Offender ${ }^{a}$}

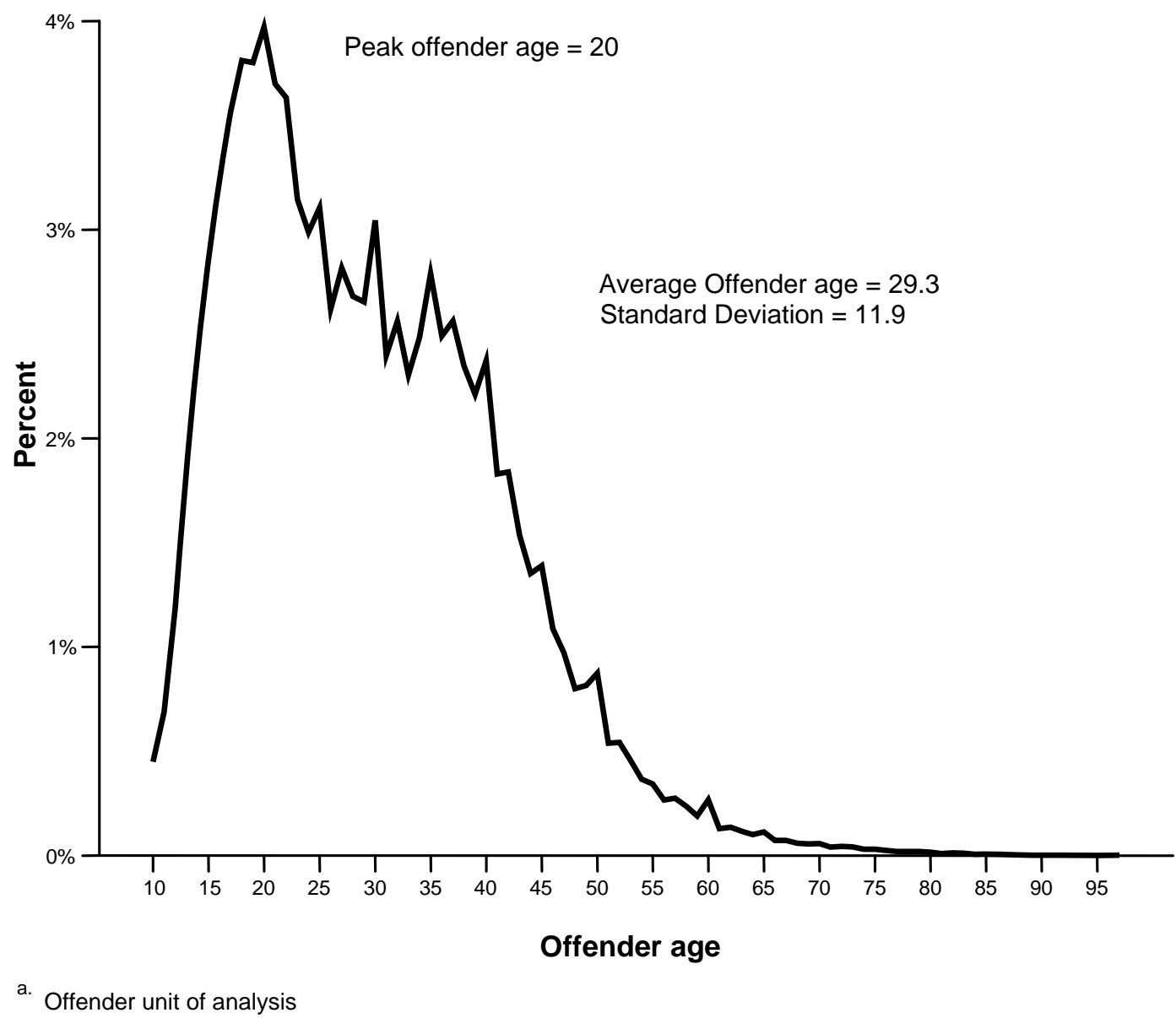

\section{Descriptive Overview: The Police Response}

In $213,598(37.0 \%)$ of the 577,862 cases of assault and intimidation to which the police responded an arrest was made (see Table 4.21$).^{5}$ In the vast majority (91.7\%) of the cases in which an arrest was made only one person was arrested (see Table 4.22). In 15,004 cases (7\% of the cases in which an arrest was made) two people were arrested and in 1,896 (0.9\%) of the arrest cases three people were arrested. Four or more people were arrested in $896(0.4 \%)$ of the cases in which an arrest was made. 


\section{Table 4.21: Police Disposition of Incident ${ }^{a}$}

\begin{tabular}{lcc}
\hline \hline & Frequency & Percent \\
\hline No arrest & 364264 & 63.0 \\
Arrest & 213598 & 37.0 \\
Total & 577862 & 100.0 \\
\hline \hline
\end{tabular}

a. Incident unit of analysis

\section{Table 4.22: Number Arrested ${ }^{a}$}

\begin{tabular}{ccc}
\hline \hline Count & Frequency & Percent \\
\hline 1 & 195802 & 91.7 \\
2 & 15004 & 7.0 \\
3 & 1896 & .9 \\
4 & 578 & .3 \\
5 & 179 & .1 \\
6 & 61 & .0 \\
7 & 40 & .0 \\
8 & 17 & .0 \\
9 & 9 & .0 \\
10 & 10 & .0 \\
11 & 2 & .0 \\
Total & 213598 & 100.0 \\
\hline \hline
\end{tabular}

a. Incident unit of analysis

The arrest cases generated a total of 235,690 arrestees. A total of 57,181 (15.7\%) of the 364,264 cases in which an arrest was not made were “cleared exceptionally.” (Table 4.23) In these cases "some reason outside the control of law enforcement” prevented a physical arrest (Federal Bureau of Investigation, 2000:70). ${ }^{6}$ The primary reasons for exceptional clearances were because "prosecution was declined' (43.2\%) and because the "victim refused to cooperate" (49.7\%: Table 4.24). 


\section{Table 4.23: Incident Disposition ${ }^{a}$}

\begin{tabular}{lcc}
\hline \hline & Frequency & Percent \\
\hline Cleared by arrest & 213598 & 37.0 \\
Cleared exceptionally & 57181 & 9.9 \\
Uncleared (at time of study) & 307084 & 53.1 \\
Total & 577862 & 100.0 \\
\hline \hline
\end{tabular}

a. Incident unit of analysis

Table 4.24: Reasons for Exceptional Clearance $^{a}$

\begin{tabular}{lcc}
\hline \hline & Frequency & Percent \\
\hline Death of Offender & 1179 & 2.1 \\
Prosecution Declined & 24693 & 43.2 \\
Extradition Denied & 153 & .3 \\
Victim Refused to Cooperate & 28445 & 49.7 \\
Juvenile/No Custody & 2711 & 4.7 \\
Total & 57181 & 100.0 \\
\hline \hline
\end{tabular}

a. Incident unit of analysis

\section{Descriptive Overview: The Arrestees}

As noted above the 213,598 arrest cases generated a total of 235,690 arrestees. Over

three-quarters (76.6\%) of the arrestees were male (see Table 4.25). While 68.6\% of the arrestees were White, 30.1\% were Black, $0.7 \%$ Asian or Pacific Islander, and $0.6 \%$ Indian or Alaskan Native (see Table 4.26). A total of 7.7\% were of Hispanic origin (see Table 4.27). Slightly over four-fifths (83.2\%) of the arrestees were residents of the jurisdiction (see Table 4.28). The average age of the arrestees was 29.8 (s.d. $=11.6){ }^{7}$ The age range of the arrestees is depicted in Figure 4.4. 
Table 4.25: Arrestee Gender ${ }^{a}$

\begin{tabular}{lcc}
\hline \hline & Frequency & Percent \\
\hline Female & 55066 & 23.4 \\
Male & 180624 & 76.6 \\
Total & 235690 & 100.0 \\
\hline \hline
\end{tabular}

a. Arrestee unit of analysis

Table 4.26: Race of Persons Arrested ${ }^{a}$

\begin{tabular}{lccc}
\hline \hline & Frequency & Percent & Valid Percent \\
\hline White & 160415 & 68.1 & 68.6 \\
Black & 70366 & 29.9 & 30.1 \\
Asian/Pacific Islander & 1548 & .7 & .7 \\
American Indian/Alaskan Native & 1434 & .6 & .6 \\
Total & 233763 & 99.2 & 100.0 \\
NA/Unknown & 1927 & .8 & \\
Total & 235690 & 100.0 & \\
\hline \hline
\end{tabular}

a. Arrestee unit of analysis

Table 4.27: Ethnicity of Persons Arrested ${ }^{a}$

\begin{tabular}{lccc}
\hline \hline & Frequency & Percent & Valid Percent \\
\hline Non-Hispanic & 168432 & 71.5 & 92.3 \\
Hispanic & 14027 & 6.0 & 7.7 \\
Total known & 182459 & 77.4 & 100.0 \\
NA/Unknown & 25006 & 10.6 & \\
Missing & 28225 & 12.0 & \\
Total Missing/Unknown & 53231 & 22.6 & \\
Total & 235690 & 100.0 & \\
\hline \hline
\end{tabular}

a. Arrestee unit of analysis 
Table 4.28: Residency of Persons Arrested ${ }^{a}$

\begin{tabular}{lccc}
\hline \hline & Frequency & Percent & Valid Percent \\
\hline Resident & 154450 & 65.5 & 83.2 \\
Non-resident & 31207 & 13.2 & 16.8 \\
Total known & 185657 & 78.8 & 100.0 \\
NA/Unknown & 24894 & 10.6 & \\
Missing & 25139 & 10.7 & \\
Total Missing/Unknown & 50033 & 21.2 & \\
Total & 235690 & 100.0 & \\
\hline \hline
\end{tabular}

a. Arrestee unit of analysis

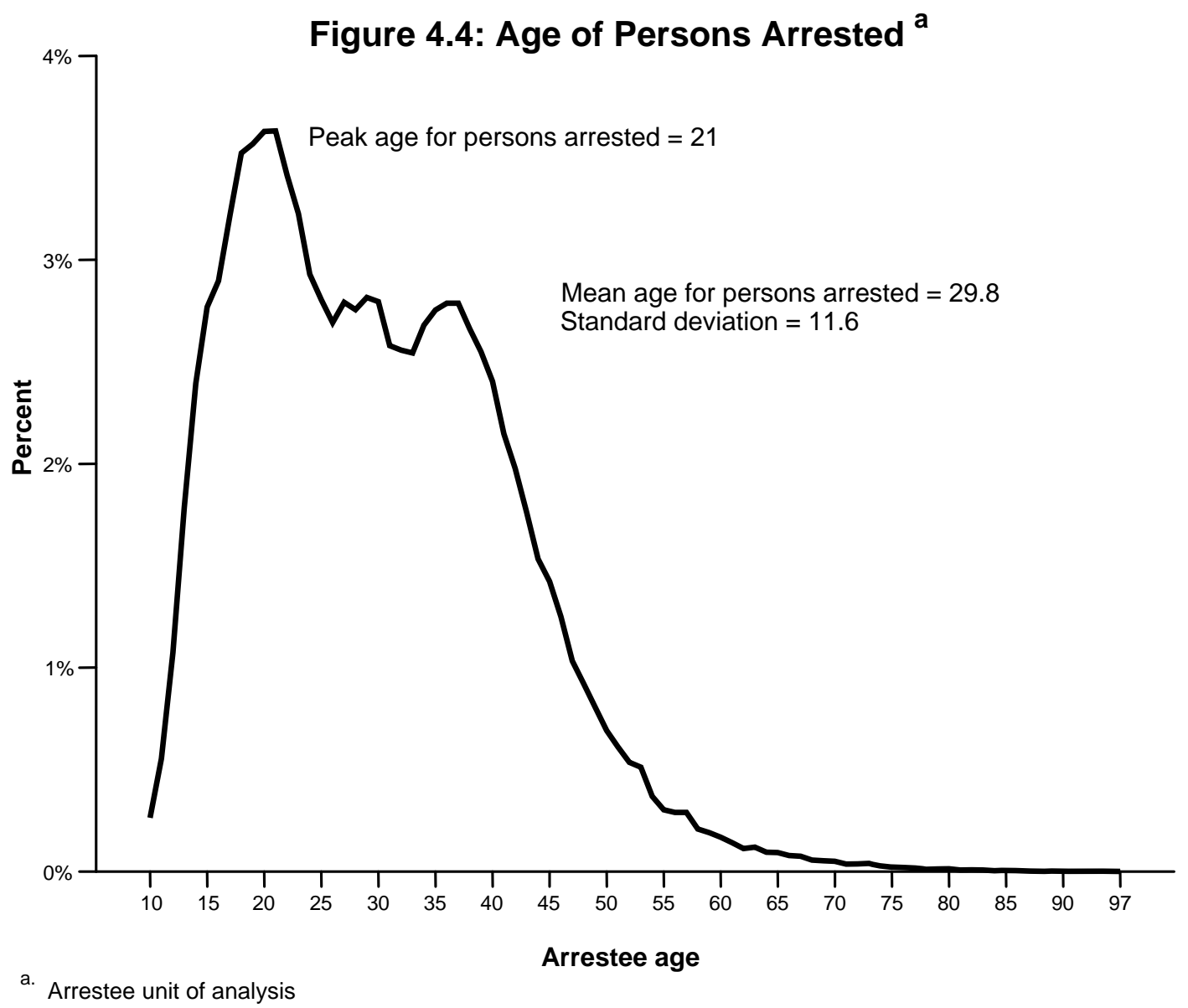


The NIBRS provides a "type of arrest” indicator with three types of arrest. "On-view arrest" indicates that the offender was taken into custody without a warrant or previous incident report. "Summoned/cited" implies that the offender was not arrested in the sense of being handcuffed and taken downtown for booking, but rather issued a summons or a citation to appear in court to face charges. The final category "taken into custody" implies that the offender was taken into custody based upon a warrant and/or a previous incident report. While just over half of the arrests (50.9\%) were on-view arrests, 35.0\% were arrests based on the issuance of a warrant or a previous incident report, and $14.1 \%$ were cases in which a summons or citation was issued (see Table 4.29). As would be expected, given the nature of the sample, the most common arrest offenses were simple assault (69.1\%), aggravated assault (19.7\%) and intimidation (4.8\%; see Table 4.30). A small minority was arrested for disorderly conduct (1.0\%), damage to property (0.7\%), drug offenses (0.6\%), weapons violations (0.4\%), larceny $(0.4 \%)$, kidnapping $(0.3 \%)$, burglary/breaking and entering (0.3\%), and drunkenness (0.3\%).

Table 4.29: Type of Arrest ${ }^{a}$

\begin{tabular}{lcc}
\hline \hline & Frequency & Percent \\
\hline On-view arrest & 119954 & 50.9 \\
Taken into custody & 82458 & 35.0 \\
Summoned/cited & 33278 & 14.1 \\
Total & 235690 & 100.0 \\
\hline \hline a. Arrestee unit of analysis & &
\end{tabular}


Table 4.30: Offense at Arrest ${ }^{a}$

\begin{tabular}{lccc}
\hline \hline & & & Valid \\
& Frequency & Percent & Percent \\
\hline Aggravated assault & 46392 & 19.7 & 19.7 \\
Simple assault & 162744 & 69.1 & 69.1 \\
Intimidation & 11424 & 4.8 & 4.8 \\
Forcible sexual assaults & 148 & .1 & .1 \\
Murder and nonnegligent manslaughter & 151 & .1 & .1 \\
Robbery & 290 & .1 & .1 \\
Kidnapping/abduction & 614 & .3 & .3 \\
Burglary/breaking and entering & 689 & .3 & .3 \\
Destruction, damage, vandalism of property & 1736 & .7 & .7 \\
Larceny & 870 & .4 & .4 \\
Weapons law violations & 842 & .4 & .4 \\
Disorderly conduct & 2283 & 1.0 & 1.0 \\
Drug/narcotics offenses & 1520 & .6 & .6 \\
Drunkeness, DUI, Liquor law violations & 1439 & .6 & .6 \\
Trespass & 342 & .1 & .1 \\
All other offenses & 4206 & 1.8 & 1.8 \\
Total & 235690 & 100.0 & 100.0 \\
\hline \hline a. Arrestee unit of analysis & & &
\end{tabular}

\section{Descriptive Overview: Dual Arrests}

A total of 213,598 (37.0\%) of the 577,862 assault and intimidation incidents to which the police responded resulted in arrest (Table 4.31). While $49.9 \%$ of the incidents involving intimate partners and $44.5 \%$ of the incidents involving other domestics resulted in arrest, the comparative figures for acquaintance and stranger cases were $29.1 \%$ and $35 \%$ respectively (Table 4.32 ). Of the 213,598 incidents with an arrest, 7,228 (3.4\%) were situations in which the responding officers had indicated that they had arrested both of the involved parties. Dual arrest rates were higher for intimate partner (1.9\%) and other domestic cases (1.5\%) than for cases involving acquaintances (1.0\%) or strangers ( $0.4 \%$; Table $4: 32)$. 
Table 4.31: Arrest Categories ${ }^{a}$

\begin{tabular}{lcc}
\hline \hline & Frequency & Percent \\
\hline No arrest & 364264 & 63.0 \\
One or more arrests & 206370 & 35.7 \\
Dual arrest & 7228 & 1.3 \\
Total & 577862 & 100.0 \\
\hline \hline
\end{tabular}

a. Incident unit of analysis

Table 4:32: Police Disposition by Victim-Offender Relationship ${ }^{\text {a }}$

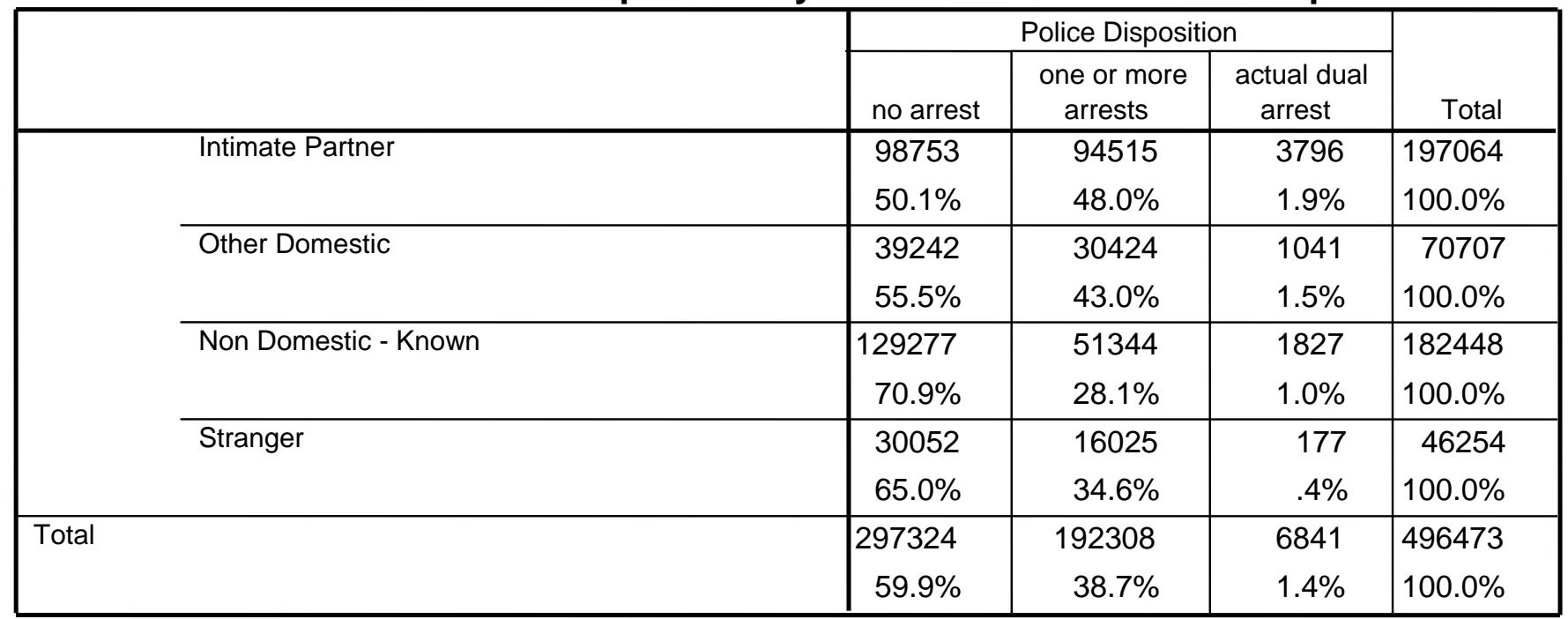

a. Incident unit of analysis

\section{Descriptive Overview: Legal Variables}

Three legal variables were added to the NIBRS dataset. First, a variable depicting state law warrantless arrest provisions in domestic violence cases. Following the analysis presented earlier in Chapter 3, state laws were coded as: (a) mandating arrest when responding officers had probable cause to believe a suspect had committed an offense; (b) indicating a preference for arrest when such circumstances existed; or (c) leaving arrest to the discretion of the responding police officers. Second, we constructed a variable that indicated whether state law mandated 
arrest when there was probable cause to believe there had been a violation of a restraining order. And, third, we created a variable indicating whether the state had a primary aggressor law.

A total of 174,477 (30.2\%) of the 577,862 cases in the dataset came from jurisdictions with mandatory state arrest laws in domestic violence cases, 131,516 (22.8\%) from jurisdictions with preferred arrest laws, and 271,869 from jurisdictions with discretionary arrest laws (see Table 4.33). Nearly three-quarters (72.4\%) of the cases were generated by jurisdictions that mandated arrest when there was probable cause to believe that there had been a violation of a restraining order (see Table 4.34). Finally, just under two-thirds (62.8\%) of the cases came from jurisdictions with primary aggressor statutes (see Table 4.35).

Table 4.33: Domestic Violence Warrantless Arrest Laws ${ }^{a}$

\begin{tabular}{lcc}
\hline \hline & Frequency & Percent \\
\hline Mandatory & 271869 & 47.0 \\
Preferred & 131516 & 22.8 \\
Discretionary & 174477 & 30.2 \\
Total & 577862 & 100.0 \\
\hline \hline
\end{tabular}

a. Incident unit of analysis

Table 4.34: Law Regulating Arrest for Violation of Restraining Order $^{a}$

\begin{tabular}{lcc}
\hline \hline & Frequency & Percent \\
\hline Not mandatory & 159699 & 27.6 \\
Mandatory & 418163 & 72.4 \\
Total & 577862 & 100.0 \\
\hline \hline
\end{tabular}

a. Incident unit of analysis 
Table 4.35: Existence of Primary Aggressor Law a

\begin{tabular}{lcc}
\hline \hline & Frequency & Percent \\
\hline No & 214823 & 37.2 \\
Yes & 363039 & 62.8 \\
Total & 577862 & 100.0 \\
\hline \hline a. Incident unit of analysis &
\end{tabular}

${ }^{1}$ Midnight is not included in Figure 4.1. The FBI indicates that zero (0) is to be used to represent midnight. Due to misinterpretation many departments also use a value of zero (0) to represent both missing/unknown time information and midnight. As a result the data representing midnight are likely to be unreliable.

${ }^{2}$ By definition intimidation does not include the use of a weapon. Therefore no weapon should be reported. See NIBRS Data Collection Guidelines Volume 1 (Federal Bureau of Investigation, 2000).

${ }^{3}$ As noted above (see Table 4.6), 87.4\% of the 577,862 incidents in the dataset had only one victim.

${ }^{4}$ This variable is one of the least robust in the NIBRS dataset. Because some agencies use 97, 98, or 99 to denote missing values, values of 97,98 , and 99 were coded as missing. Because of concerns about the accuracy of age values less than 10, all ages 0 through 9 were likewise coded as missing.

${ }^{5}$ Cases in which citations or summons to appear in court were issued are included as arrest cases.

${ }^{6}$ The NIBRS guidelines indicate that a case should be cleared in this fashion when: (1) the offender dies; (2) prosecution is declined for reasons other than lack of probable cause; (3) extradition of the offender is denied; (4) the victim refuses to cooperate in the prosecution of the case; and, (5) the case involves a juvenile who is not taken into custody (Federal Bureau of Investigation, 2000: 70).

${ }^{7}$ As with the variable depicting the offender's age, this variable is one of the least robust in the NIBRS dataset. Because some agencies use 97, 98, or 99 to denote missing values, values of 97, 98, and 99 were coded as missing. Also because of concerns about the accuracy of age values of less than 10, ages 0 through 9 were likewise coded as missing. These procedures resulted in 1,137 (0.5\%) of the cases being reclassified as missing. 


\section{Chapter 5 \\ The Role and Impact of Preferred and Mandatory Domestic Violence Arrest Laws}

In this chapter we investigate the impact of domestic violence legislation on arrest practices in the police agencies in the 19 states. For these analyses our database includes 412,065 single offender and single victim incidents of intimidation, simple assault and aggravated assault nested in 2,357 police agencies jurisdictions nested in 19 states. ${ }^{1}$ First, we review our NIBRS dataset analysis strategy. We then present our findings about the impact of independent variables on arrest and dual arrest.

\section{NIBRS Dataset Analysis Strategy}

It is becoming a standard practice to use hierarchical modeling statistical techniques when using nested data to estimate multilevel effects on outcomes. Hierarchical linear modeling (HLM) is desirable with nested data since each level in the structure can be represented by its own sub-model. Moreover, HLM modeling allows for examining how variables at one level affect relationships occurring at another level (Bryk and Raudenbush, 1992).

A major challenge for hierarchical model building is determining the appropriate groups to include in the analysis. This process must be guided by theoretical, practical, and methodological considerations. Since our identification of arrest laws in cases of domestic violence was determined through examination of state level statutes, we initially considered the state as a group-level variable in the model. Our preliminary analysis revealed that there was no significant variation in arrest levels for our selected incidents across states. ${ }^{2}$ There may be several explanations for this finding. The first may have to do with our limited number of states $(n=19)$. While there is no agreement on the number of groups necessary for reliable hierarchical analyses, a study by Kreft (1996) suggests a rule of thumb of 30 groups or higher to ensure accurate results. 
A second explanation is that mandatory and preferred arrest laws are not having the impact that one might expect. For example, domestic violence laws are intended to increase the likelihood of arrest in intimate partner cases. The expected outcome in this case is that the overall level of arrests should be higher in those states if all else remains equal. If this were the case, then we would have expected there to be significant variation in overall arrests across states when mandatory and discretionary states are examined. It is possible, however, that domestic violence laws are having an impact in more subtle ways. For example, although arrest estimates may not vary significantly across states, domestic violence laws may influence the circumstances under which arrests are likely to occur.

A third possibility is that our original consideration of state as our level-two group may not be reliable, both from the statistical standpoint described earlier, and from a more practical consideration of policy variation that may exist at the agency level. Preliminary survey work being conducted on this issue suggests that police agency policies with respect to arrest in domestic violence incidents do not always align with state laws. For example, in some cases agency policies have stricter standards than state laws. Given these methodological, theoretical, and practical issues associated with using state as our group two level, we chose to use police agency as our group-two level for the analysis.

The independent variables reflect the legal context (as indicated in state domestic violence warrantless arrest laws); agency characteristics; victim and offender demographics; and incident characteristics. At the agency, or level two for our analysis, we included a dichotomous variable indicating if the police agency was in a state with a mandatory state arrest law for domestic violence incidents (coded 1 for yes) or if the agency was in a preferred arrest state (code 1 for yes). Discretionary state laws are the reference category. We also included other 
agency level measures to reflect agency characteristics, namely the number of officers per 1000 population, a female to male officer ratio, and the total number of assault, simple assault and intimidation cases reported in the jurisdiction.

At the incident level, level one, we included the following victim and offender demographic variables: victim and offender age (coded 0 for under 21 and 1 for 21 and over); victim and offender sex (coded 0 for female, 1 for male; and victim and offender race (coded 0 for white and 1 for minority). Additional incident-level data included the incident characteristic of offense seriousness, measured as aggravated assault and intimidation offense dummy variables with simple assault serving as the reference category. These offenses are categorized in this way by the officers who responded to the incident. Two other indicators of seriousness, use of weapon (coded as weapon, personal weapon and no weapon) and injury (coded as serious physical injury, apparent minor injury, and no injury) were also initially considered for the multivariate analysis but were found to covary significantly with most serious offense. ${ }^{3}$

The location of incident was also included as an incident characteristic, indicating whether the offense occurred in a home or residence (coded as 1) or in a public/other place (coded as 0). The logic for including a location variable is that offenses occurring in public may be significantly different from those occurring in a residence in terms of police response. Incidents occurring in public places may have more witnesses and may make arrest more likely. This is a proxy measure of potential for witnesses since NIBRS does not include information on whether witnesses were present.

Using hierarchical modeling, we explored the extent to which the observed variation in our variables of interest is influenced by domestic violence laws in terms of arrest odds. By estimating hierarchical models separately for each victim offender relationship category, we 
were able to examine the extent to which domestic laws affect arrest levels among agencies, as well as the effects domestic violence laws have on the relationships that exist between offense circumstances, offense seriousness, and victim and offender demographics and arrest outcomes within agencies. Given that our outcome variable is dichotomous, we used hierarchical generalized linear model (HGLM) analysis, which is a variation of HLM (Raudenbush et al., 2005) that adjusts for dichotomous dependent variables.

We constructed preliminary models including only a random intercept for each victimoffender relationship category. There was significant random variation in the log-odds of arrest at the agency level for each victim offender relationship category. To examine the impact of laws on the relationship between individual level characteristics and arrest in each victim offender category, we employed an intercept and slopes-as-outcomes model. A slopes-asoutcomes model allows for the slopes of the independent variable effects on arrest at the individual level to vary across agencies net of other model effects.

For each victim offender relationship category, the following model was estimated for case $i$ in agency $j$ :

\section{Level 1 Model}

Prob $($ arrest $=1 / \beta)=\varphi$

$\log [\varphi /(1-\varphi)]=\eta$

$\eta=\beta_{o j}+\beta_{1 j}$ (offender age) $+\beta_{2 j}$ (offender sex) ${ }_{i j}+\beta_{3 j}$ (offeder race) ${ }_{j j}+\beta_{4 j}$ (location) ${ }_{j j}+$ $\beta_{5 j}$ (agg. assault) $_{i j}+\beta_{6 j}$ (intimidation) ${ }_{i j}$

\section{Level 2 Model}

$$
\begin{aligned}
& \beta_{\mathrm{o} j}=\gamma_{00}+\gamma_{01} \text { (mandatory) }_{j}+\gamma_{02} \text { (preferred) }_{j}+\gamma_{03} \text { (officers) }_{j}+\gamma_{04} \text { (incidents }_{j}+\gamma_{05}(\mathrm{f} / \mathrm{m} \\
& \text { officer ratio })_{j} \mu_{0 j}
\end{aligned}
$$

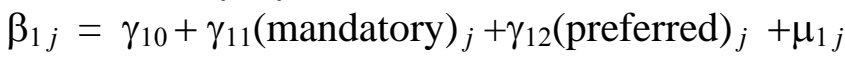

$$
\begin{aligned}
& \beta_{2 j}=\gamma_{20}+\gamma_{21} \text { (mandatory) }{ }_{j}+\gamma_{22} \text { (preferred) }_{j}+\mu_{2 j}
\end{aligned}
$$

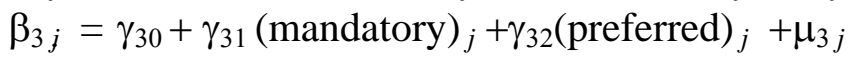




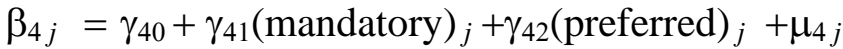

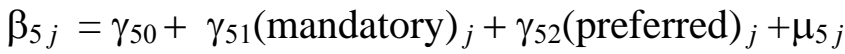

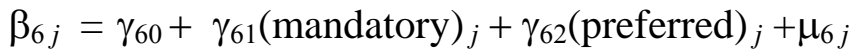

We initially considered both victim and offender characteristics. However, there were significant bivariate correlations among the victim and offender characteristics, particularly in the intimate partner group. Out of concern that multicollinearity might influence model estimation, we included offender characteristics for this analysis. All of the level one variables were centered around their group means.

\section{Findings: Descriptive Statistics}

Descriptive statistics are presented in Table 5.1. Across relationship categories, there is variation in the percentage of arrests made. In intimate partner cases, $49 \%$ of the cases resulted in an arrest, compared to $44 \%$ in other domestic incidents, $28 \%$ in acquaintance cases and 31\% in stranger cases. Offender characteristics and offense characteristics also show variation across victim-offender relationship categories.

Table 5.1 Descriptive Statistics

\begin{tabular}{lcc} 
Individual level & Mean & Std. Dev. \\
\cline { 2 - 3 } Arrest & 0.49 & 0.5 \\
Dual Arrest* & 0.04 & 0.19 \\
Offender Sex & 0.83 & 0.37 \\
Offender Age & 0.91 & 0.28 \\
Offender Race & 0.33 & 0.47 \\
Location & 0.82 & 0.37 \\
Aggravated Assault & 0.12 & 0.32 \\
Simple Assault & 0.76 & 0.42 \\
Intimidation & 0.11 & 0.31 \\
& $(\mathrm{n}=176084)$ \\
& & \\
Agency Level & Mean & Std. Dev. \\
Mandatory & 0.4 & 0.49 \\
Preferred & 0.24 & 0.42 \\
Discretionary & .36 & .48 \\
Officers per 1000 & 22 & 21 \\
Female/Male Officers & 0.07 & 0.11 \\
No. Cases & 202 & 651 \\
& \multicolumn{2}{c}{$(\mathrm{n}=2357)$}
\end{tabular}

\begin{tabular}{|c|c|c|c|c|c|c|c|}
\hline \multicolumn{2}{|c|}{ Intimate Partner } & \multicolumn{2}{|c|}{ Other Domestic } & \multicolumn{2}{|c|}{ Acquaintance } & \multicolumn{2}{|c|}{ Stranger } \\
\hline Mean & Std. Dev. & Mean & Std. Dev. & Mean & Std. Dev. & Mean & Std. Dev. \\
\hline$\overline{0.49}$ & 0.5 & $\overline{0.44}$ & 0.49 & $\overline{0.28}$ & 0.44 & $\overline{0.31}$ & 0.46 \\
\hline 0.04 & 0.19 & 0.03 & 0.17 & 0.04 & 0.18 & 0.01 & 0.18 \\
\hline 0.83 & 0.37 & 0.69 & 0.46 & 0.72 & 0.44 & 0.81 & 0.38 \\
\hline 0.91 & 0.28 & 0.65 & 0.47 & 0.65 & 0.47 & 0.75 & 0.43 \\
\hline 0.33 & 0.47 & 0.29 & 0.45 & 0.36 & 0.48 & 0.75 & 0.47 \\
\hline 0.82 & 0.37 & 0.88 & 0.32 & 0.47 & 0.49 & 0.22 & 0.41 \\
\hline 0.12 & 0.32 & 0.14 & 0.35 & 0.16 & 0.37 & 0.22 & 0.41 \\
\hline 0.76 & 0.42 & 0.75 & 0.43 & 0.6 & 0.48 & 0.56 & 0.49 \\
\hline 0.11 & 0.31 & 0.1 & 0.29 & 0.23 & 0.42 & 0.2 & 0.4 \\
\hline \multicolumn{2}{|c|}{$(n=176084)$} & \multicolumn{2}{|c|}{$(n=56201)$} & \multicolumn{2}{|c|}{$(n=145178)$} & \multicolumn{2}{|c|}{$(n=32442)$} \\
\hline
\end{tabular}

* based on proportion of arrests 


\section{Findings: Impact of Independent Variables on Arrest (for Intimate Partner Cases)}

Table 5.2 includes the results of the full hierarchical model with intercept and slopes as outcomes using the offender measures. Model 1 presents the results for intimate partner cases.

Legal context. The intercept coefficient (B0) is the expected log odds for an arrest in an intimate partner incident occurring in a typical police agency with a discretionary law. This coefficient converts to an average arrest probability of .523. Domestic violence laws have a significant main effect on this outcome. The expected log-odds of arrest are higher in both mandatory and preferred agencies compared to discretionary agencies net of other model effects. In mandatory agencies, the odds of arrest are increased by $97 \%$ compared to discretionary and by about $177 \%$ in preferred law agencies compared to discretionary. The total number of cases has a small significant negative impact on the log odds of arrest for the typical agency as does the rate of officers per 1000 .

Offender demographics. Several offender characteristics also have significant effects on the log-odds of arrest. Offender age has a significant main effect on the log-odds of arrest. In the typical police agency with a discretionary arrest policy, an arrest is more likely to occur for offenders 21 and over controlling for other variables in the model. Since offenders 20 and under include juveniles, this finding could be a result of the historic increased police leniency and informal responses to juveniles (Black, 1980).

Offender race also significantly influences the log-odds of arrest. In the typical police agency with discretionary law, the log-odds of arrest for incidents involving a minority offender are -.175. This relationship is significantly weaker in preferred law agencies with the log-odds of arrest at -.036 or $[(-.175)+1(.139)]$. The odds ratio indicates that the odds of arrest of a minority offender in a preferred law agency is reduced by $15 \%$. 
Sex does not have an effect on the log-odds of offender arrest. Controlling for the other

variables in the model, females were no more likely than males to be arrested in cases of intimate

partner violence. This analysis does not provide support for the hypothesis that the increase in

both the number and proportion of female arrests for intimate partner violence cited in the earlier

literature review is attributable to a predisposition on the part of the police to arrest females

without taking other situational factors into account.

\begin{tabular}{|c|c|c|c|c|c|c|c|c|}
\hline \multirow[b]{4}{*}{ Arrest Intercept (B0) } & \multicolumn{6}{|c|}{ Table 5.2. HGLM Results Predicting Arrests } & \multirow{2}{*}{\multicolumn{2}{|c|}{ Model 4: Stranger }} \\
\hline & \multicolumn{2}{|c|}{$\underline{\text { Model 1:Intimate Partner }}$} & \multicolumn{2}{|c|}{ Model 2:Other Domestic } & \multicolumn{2}{|c|}{ Model 3: Acquaintance } & & \\
\hline & coefficient & odds ratio & coefficient & odds ratio & coefficient & odds ratio & coefficient & odds ratio \\
\hline & 0.093 & $1.097 *$ & -0.269 & $0.763 * *$ & -1.297 & $0.273 * *$ & -0.677 & 0.508 ** \\
\hline Mandatory Law & 0.671 & $1.966 * *$ & 0.484 & $1.62 * *$ & 1.075 & $2.931 * *$ & 0.589 & 1.803 ** \\
\hline Preferred Law & 1.019 & $2.771 * *$ & 0.949 & $2.583 * *$ & 1.154 & $3.171 * *$ & 0.808 & 2.244 ** \\
\hline Officers per 1000 & -0.004 & $0.997 *$ & -0.005 & $0.995 *$ & -0.002 & 0.998 & -0.001 & 0.999 \\
\hline No. Incidents & -0.0003 & $0.999 * *$ & -0.0002 & $0.999^{* *}$ & 0 & 1 ** & 0 & 1 ** \\
\hline Female/Male Officer Ratio & -0.506 & 0.602 & -0.232 & 0.792 & -0.29 & 0.748 & -1.237 & 0.29 * \\
\hline \multicolumn{9}{|l|}{ Offender Age $(1=21+)$} \\
\hline Intercept (B1) & 0.29 & $1.337 * *$ & -0.383 & $0.682 * *$ & 0.133 & $1.142 * *$ & 0.143 & 1.153 \\
\hline Mandatory Law & -0.035 & 0.965 & 0.239 & $1.271 * *$ & -0.227 & $0.797 * *$ & -0.086 & 0.917 \\
\hline Preferred Law & -0.078 & 0.925 & 0.019 & 1.019 & 0.058 & 1.059 & -0.195 & 0.823 \\
\hline \multicolumn{9}{|l|}{ Offender Sex (1=male) } \\
\hline Intercept (B2) & 0.06 & 1.059 & 0.28 & $1.312 * *$ & 0.1 & $1.105 *$ & -0.061 & 0.941 \\
\hline Mandatory Law & -0.09 & 0.914 & -0.116 & $0.89 *$ & -0.111 & $0.895 *$ & -0.027 & 0.973 \\
\hline Preferred Law & -0.112 & 0.894 & -0.222 & $0.8 * *$ & -0.115 & 0.891 & -0.045 & 0.956 \\
\hline \multicolumn{9}{|l|}{ Offender Race(1=minority) } \\
\hline Intercept (B3) & -0.175 & $0.839 * *$ & -0.086 & 0.917 & -0.022 & 0.978 & -0.117 & 0.89 \\
\hline Mandatory Law & -0.006 & 0.994 & -0.03 & 0.97 & 0.013 & 1.013 & 0.07 & 1.073 \\
\hline Preferred Law & 0.139 & $1.15 *$ & 0.113 & 1.12 & 0.224 & $1.251 * *$ & 0.184 & 1.202 \\
\hline \multicolumn{9}{|l|}{ Location (1=inside) } \\
\hline Intercept (B4) & 0.313 & $1.368 * *$ & 0.377 & $1.46 * *$ & 0.209 & $1.233 * *$ & 0.205 & 1.228 * \\
\hline Mandatory Law & -0.124 & $0.883 * *$ & -0.129 & 0.878 & -0.246 & $0.782 * *$ & -0.25 & 0.779 * \\
\hline Preferred Law & -0.198 & $0.82 * *$ & -0.189 & 0.828 & -0.264 & $0.768 * *$ & -0.226 & 0.798 \\
\hline \multicolumn{9}{|c|}{ Aggravated Assault ( $1=$ agg. assault) } \\
\hline Intercept (B5) & $\overrightarrow{0.161}$ & $1.175 *$ & 0.501 & $1.651 * *$ & 0.828 & $2.288 * *$ & 0.665 & 1.944 ** \\
\hline Mandatory Law & 0.226 & $1.254 * *$ & -0.076 & 0.926 & -0.393 & $0.675^{* *}$ & -0.488 & 0.614 ** \\
\hline Preferred Law & 0.278 & $1.32 * *$ & 0.035 & 1.035 & 0.066 & 1.068 & -0.169 & 0.844 \\
\hline \multicolumn{9}{|l|}{ Intimidation (1=intimidation) } \\
\hline Intercept (B6) & -2.291 & $0.101 * *$ & -1.64 & $0.194 * *$ & -1.257 & $0.285 * *$ & -1.002 & 0.367 ** \\
\hline Mandatory Law & 0.86 & $2.365 * *$ & 0.881 & $2.415 * *$ & 0.437 & $1.548 * *$ & 0.053 & 1.054 \\
\hline Preferred Law & 0.244 & 1.276 & -0.045 & 0.956 & 0.389 & $1.476 * *$ & -0.162 & 0.851 \\
\hline \multicolumn{9}{|l|}{ Variance Components } \\
\hline & variance & chi square & variance & chi square & variance & chi square & variance & chi square \\
\hline Arrest Intercept, Uo & 1.546 & $35479.216 * *$ & 0.998 & $7752.86 * *$ & 1.866 & 16579.534 ** & 1.091 & 3519.085 ** \\
\hline Offender Age,U1 & 0.012 & 682.154 & 0.378 & $938.309 * *$ & 0.465 & $2484.898 * *$ & 0.150 & 371.581 * \\
\hline Offender Sex,U2 & 0.119 & $1034.23 * *$ & 0.017 & 375.561 & 0.041 & 852.629 & 0.073 & 310.102 \\
\hline Offender Race, U3 & 0.034 & $769.507 * *$ & 0.008 & 338.432 & 0.026 & 806.924 & 0.045 & 328.168 \\
\hline Location,U4 & 0.046 & $788.555 * *$ & 0.061 & 395.162 & 0.109 & 1108.536 ** & 0.067 & 295.418 \\
\hline Aggravated Assault,U5 & 0.314 & $1210.57 * *$ & 0.126 & $443.039 *$ & 0.318 & $1390.593 * *$ & 0.407 & 484.050 ** \\
\hline Intimidation ,U6 & 0.785 & $1570.831 * *$ & 0.41 & $517.535 * *$ & 0.573 & $1579.034 * *$ & 0.569 & 455.209 ** \\
\hline
\end{tabular}


Incident characteristics. Offense location has significant level one effects on the log-odds of arrest. An arrest is more likely to occur for incidents occurring in residences versus public places in agencies with discretionary laws net of other model effects. The log-odds of arrest for incidents happening in a residence for discretionary law agencies are .313. This relationship is significantly weakened by domestic violence laws favoring arrest. In mandatory and preferred arrest agencies, the slopes are significantly weaker than in discretionary agencies. In mandatory agencies, the odds of arrest are reduced by about $12 \%$ and $18 \%$ in preferred law agencies.

Offense classification for aggravated assault compared to simple assault has a significant positive effect on the log-odds of arrest (.161). This relationship is significantly stronger in mandatory and preferred agencies compared to discretionary agencies. The odds of arrest for aggravated assaults occurring in mandatory agencies are $25 \%$ higher than agencies in discretionary agencies and 32\% higher in preferred agencies. Intimidation cases have a significant negative effect on the log-odds of arrest (-2.291), but the effects are significantly lower in mandatory agencies where the odds of arrest are reduced by 136\%. Though intimidation incidents are significantly less likely than simple assault to end in arrest, this effect is significantly weaker in mandatory arrest agencies.

In sum, domestic violence arrest laws have significant effects on agency level arrests in intimate partner cases. At the agency, or level two model, arrests are significantly more likely to occur in mandatory and preferred agencies independent of other agency and individual factors included in the model. At the incident level, domestic violence laws influence arrest practices for certain offense characteristics such as incident location and offense seriousness and to a lesser extent offender characteristics. However, these laws do not significantly increase the logodds of females being arrested. 


\section{Findings: Impact of Independent Variables on Arrest (for Non-Intimate Partner Cases)}

We were also interested in the extent to which there may be spillover effects of domestic violence laws on arrest in incidents involving other types of victim-offender relationships. The model intercepts (B0), when converted to probabilities suggest that the chances of being arrested are higher in other domestics (.433), followed by stranger (.337) and acquaintance cases (.216). This compares with an arrest probability of .523 in intimate partner violence cases.

Legal context. As with intimate partner violence cases, domestic violence laws have a significant main effect on this outcome. For all relationship categories the expected log-odds of arrest are significantly higher in both mandatory and preferred agencies compared to discretionary agencies net of other model effects (see Table 5.2).

Offender Demographics. The impact of arrest laws on outcomes for other relationship categories differs in some ways from the intimate partner model results. For other domestics, offenders 21 and over are significantly less likely to be arrested in these types of incidents. In mandatory agencies, this effect is significantly reduced by 27\%. For acquaintances, those 21 and over are at higher risk for arrest, but the effect is significantly smaller in mandatory agencies. Mandatory laws serve to create more equity in the impact of age on arrest outcomes for other domestics and acquaintances.

A similar effect is observed for offender sex. For both other domestics and acquaintances, males are at significantly higher log-odds of arrest than females. Again in both models, mandatory arrest laws significantly reduce these effects. Preferred arrest laws significantly reduce these effects for other domestics. No such effects are observed for strangers. Incident Characteristics. Offense characteristics also reveal important differences in effects across relationship categories. While the main effects for location, aggravated assault, and 
intimidation for the other relationship categories are significant and in the same direction as those for intimate partner cases, differences emerge when the cross-level interactions between these effects and domestic violence laws are considered. For other domestics, the only significant cross-level interaction was for intimidation cases, where the existence of mandatory laws tempered the negative main effect these cases had on the likelihood of arrest.

For acquaintances, there were significant cross-level interaction effects for location, and for aggravated assault and intimidation. For location and intimidation these effects operated in a direction similar to that observed in the intimate partner cases, again where the effects were mitigated in mandatory and preferred agencies. For aggravated assault, mandatory arrest effects also mitigated the main effects. For stranger cases, these mitigating effects were observed for location and aggravated assaults in mandatory law agencies.

In sum, these results suggest several noteworthy findings. First, mandatory and preferred arrest statutes have significant effects on the expected log-odds of arrest at the agency level for all relationship categories net of other model effects. For intimate partner cases, the effects of domestic violence laws (both mandatory and preferred) appear to have more of an impact on arrest practices involving offense characteristics (location, aggravated assault, and intimidation) than those involving offender characteristics (only race). They enhance arrest odds for cases involving aggravated assaults and weaken the effects on arrest for intimidation and location incidents.

For acquaintances, cross level interactions are also observed for both preferred and mandatory laws for the offense characteristics, but here offender characteristics (age and sex) are also significantly influenced by mandatory arrest laws. Other domestics also reveal cross-level interactions for offender characteristics including age and sex, but the offense characteristics are 
less affected by arrest laws with the exception of intimidation incidents. Stranger cases have important cross-level interactions only for mandatory laws and location and aggravated assault.

According to the variance components section of Table 5.2, there is still significant unexplained variance in the agency or level two random intercepts. This suggests that there are other important factors that may help to explain arrests. Variance components for many of the level one slopes also suggest that there is significant unexplained variation. Future research could further attempt to account for this variation by including other sources of data.

\section{Findings: Impact of Independent Variables on Dual Arrest (for All Relationship Types)}

We also examined the impact of domestic violence laws on the log-odds of dual arrest. This variable was coded 1 for dual arrest and 0 for single arrest. The difference in model specification from the arrest analysis reported in Table 5.2 is that the level one effects are treated as fixed across agencies. This decision was made after a preliminary analysis revealed no significant random variation in the slopes for these variables across models. Under these circumstances a more parsimonious model specification was appropriate. Given the lack of dual arrest cases in instances of offenses involving strangers, this group was omitted from this analysis.

The results are reported in Table 5.3. The intercept indicates the expected odds of dual arrest for a typical police agency with discretionary arrest law. The probability equivalents for models 1 through 3 are .018, .018, and .014 respectively suggesting that there are only minor differences in the probability of dual arrest across relationship categories. Mandatory arrest laws show a significant positive association with log-odds of arrest for each of the relationship categories meaning that, the log-odds of dual arrest increase in mandatory compared to discretionary agencies. 
Level 2

Dual Arrest Intercept (B0)

Mandatory Law

Preferred Law

Officers per 1000

No. Incidents

Female/Male Officer Ratio

Level 1

Offender Age (1=21+)

Offender Sex (1=male)

Offender Race(1=minority)

Location (1=inside)

Aggravated Assault (1=agg. assault)

Intimidation (1=intimidation)

Variance Components

Dual Arrest Intercept, Uo

${ }^{*} p<.05,{ }^{* *} p<.01$

Table 5.3. HGLM Results Predicting Dual Arrest

Model 1:Intimate Partner

coefficient odds ratio

$-3.997 \quad 0.018$ **

$0.628 \quad 1.874$ **

$-0.247 \quad 0.781$

$0.003 \quad 1.003$

$0.000 \quad 1.000$

$-0.389 \quad 0.678$

$-0.184 \quad 0.832$ **

$-1.435$

0.045

0.149

$-0.292$

$-1.904$

variance chi square

1.26

0.238 *

1.046

1.161 *

0.747 *

0.149 *

6379
Model 2:Other Domestic

coefficient odds ratio

-4.0190 .018 *

$0.674 \quad 1.962$ **

$-0.135 \quad 0.874$

$0.013 \quad 1.013$ *

$0.000 \quad 1.000$

$-0.170 \quad 0.843$
0.246

$-0.555$

0.058

0.260

$-0.158$

$-2.044$

1.279 *

0.574 *

1.060

1.297

0.853

0.130 *

variance

1.169 chi square
2061

Model 3: Acquaintence

coefficient odds ratio

$-4.244 \quad 0.014$ **

$0.632 \quad 1.881$ **

$-0.301 \quad 0.740$

$0.010 \quad 1.010$ **

$0.000 \quad 1.000$

$0.122 \quad 1.130$

$-0.370 \quad 0.691$ *

$-0.581 \quad 0.560$ **

$-0.017 \quad 0.984$

$-0.257 \quad 0.774$ *

-0.6430 .526 **

$-2.3010 .100 * *$

In intimate partner cases, there are significant main effects for offender age and sex, where dual arrest is less likely if one of the involved offenders is identified as a male or over 21. Dual arrest is also less likely to occur in cases involving aggravated assaults or intimidation compared to simple assault. Dual arrest log odds are higher for incidents occurring in a residence. There are no cross-level interaction effects with arrest laws.

In other domestic cases, dual arrest is more likely if an offender is 21 or older and less likely if an offender is male. Intimidation incidents are less likely to result in arrest than simple assaults for this group. In cases involving acquaintances, dual arrest is less likely if an offender is male or under 21. A dual arrest is less likely to happen in a residence or if the offense is classified as either an aggravated assault or intimidation compared to simple assault.

\section{Summary of Findings}

Overall, domestic violence arrest laws have a significant impact on arrest practices for all relationship categories. Some of the effects are the same when comparing across relationship 
categories and others differ. Arrest laws appear to have more influence on the relationship between offense characteristics and arrest for intimate partner and stranger cases, offender characteristics for other domestics, and offender and offense characteristics for acquaintances.

Significant cross-level effects are also observed more often with mandatory law agencies than preferred law agencies. Interestingly, the direction of cross-level effects tends to remain constant across groups, where domestic violence laws mediate level one effects by working toward more equitable arrest practices through decreasing the strength of association for offender and offense characteristics. One exception to this pattern is in the case of aggravated assault for intimate partner cases, where the effect of arrest laws makes the association stronger.

Dual arrest results reveal that mandatory arrest laws do have an impact at the agency level, but they do not have any cross-level interaction with offender or offense characteristics for intimate partner and other domestic cases. There is also significant random variation remaining for intercept U0. It thus appears that there are other omitted factors that may explain the police decision to make a dual arrest. From these results, we can conclude that domestic violence laws have more impact on decision making for a single arrest compared to a dual arrest. It is apparent that police decision-making processes differ in the two situations, resulting in different arrest outcomes.

\section{Discussion}

In accordance with prior research conducted after the passage of mandatory and preferred arrest statutes for incidents of domestic violence, ${ }^{4}$ we found the overall arrest rate for assault and intimidation to be well in excess of 30\%: 49\% for intimate partner violence cases, and $44 \%$ for other domestic violence cases (Table 5.1). Most significantly, our HGLM analysis revealed that mandatory and preferred arrest laws are having the intended effect of producing higher domestic 
violence arrest rates in these states compared to states with discretionary arrest laws.

There are several possible explanations for the higher arrest rates observed in these jurisdictions. First, it can be expected that state legislation is reflective of public sentiment. States that are unwilling to declare that arrest is the preferred or required police response, may not place as high a priority on domestic violence as a societal problem when compared to states with preferred or mandatory legislation. At an aggregate level, this may help explain the overall higher rates.

Second, it is possible that states with more aggressive legislation also received additional state funding and resources for their implementation. A great deal of federal support has been provided under the Violence Against Women Act to jurisdictions with pro-active and innovative responses. As a result, many of these departments have been able to afford a dedicated domestic violence officer or establish a domestic violence unit, which would otherwise not have been possible. These added resources may not only increase arrests in cases of domestic assault, but free up other department resources that can be used to target other offenses more aggressively as well.

Third, there may have been concurrent inter-organizational effects of domestic violence legislation including changes in prosecutorial practices, judicial behavior, and programs for batterers. The increased probability of a police arrest going forward through the system is likely to positively impact police arrest practices.

These higher arrest rates are observed not only in intimate partner and other domestic violence cases, but in acquaintance and stranger cases as well. Thus, though the mandatory and preferred arrest provisions only apply to domestic violence cases, there appears to be a spillover effect with officers in these states more likely than their counterparts in the other states to arrest 
offenders in both domestic and non-domestic violence cases. Removing officer discretion and requiring mandatory arrest in domestic violence cases may have implications with regard to the manner in which officers perceive their role in general. Mandatory arrest may lead officers to believe there has been a shift both in their role, and their organization's role, conforming more with Wilson's (1968) definition of a legalistic department. Officers may believe it inappropriate (or unacceptable) to exercise discretion, instead following a legalistic, somewhat mechanistic, style in applying the law. In addition, increased concerns for both individual and organizational liability have also served as an impetus for increased arrest rates (Buzawa \& Buzawa, 2004).

The key incident variables in these analyses affecting the arrest decision are those relating to offense seriousness. As would be expected, we found that in all relationship categories aggravated assault cases are more likely than simple assault cases to result in arrest. However, when we considered the effect of state laws on arrest practices we uncovered some interesting variations. For cases involving intimate partners the existence of a mandatory or preferred arrest law enhanced even more the likelihood of arrest, while for acquaintance and stranger cases the existence of these laws diminished, though by no means negated, the positive association between aggravated assault and the likelihood of arrest. Thus, officers responding to intimate partner violence cases in mandatory and preferred arrest states seem to understand that the combination of seriousness of the offense and the existence of a mandatory or preferred arrest law leaves them little choice but to make an arrest. The message seems to be different when responding to acquaintance and stranger cases. This is not surprising, given that the mandatory and preferred arrest laws do not apply to these types of cases and that historically officers typically use low levels of authority with regard to assault. (Black, 1980; Klinger, 1996; Manning, 1997; Worden, 1989). 
Intimidation cases, conversely, were less likely than simple assault cases to result in arrest. Here the existence of a mandatory arrest law increased the likelihood of arrest in intimate partner, other domestic, and acquaintance cases, while the presence of a preferred arrest law also enhanced the likelihood of arrest in acquaintance cases. Clearly, officers understand that when the law instructs them to treat seemingly less serious cases in a serious manner, as by arresting the offender, they should do so.

As discussed, the results show that mandatory and preferred arrest laws are clearly producing the desired effect of encouraging arrest in intimate partner violence cases. For other domestics the effect is somewhat weaker. This may be a result of the wide range of relationship categories (parent-child, siblings etc.) and offense circumstances included in this relationship category. For acquaintances the effect is perhaps stronger than anticipated. This may reflect the inclusion of some important relationships in the "other domestic" category.

In all relationship categories offenses occurring in residences were more likely to result in arrest than those taking place in public. This result appears counterintuitive, and runs counter to what occurred prior to the development of the pro-arrest movement in intimate partner violence cases, when, because of public nuisance concerns, intimate partner violence cases occurring in public were more likely than those occurring in private to result in arrest. In addition, a historic criticism of the "classic" police response is that police do not want to become involved in incidents in residences, or "behind closed doors” (Black, 1980; Edwards, 1989; Manning 1997; Pagelow, 1984; Zorza, 1994). However, increasing public awareness and concern for domestic assault may result in increased reporting by neighbors or other bystanders (Cassidy, Nichol, Ross \& Lonsway, 2004; Robinson \& Chandek, 2000). For example, Klein (2006) reported that the vast majority of calls to the police for domestic assault in the State of 
Rhode Island did not come from the victim. The involvement of an external complainant may have increased officers' perceived need to “do something” to resolve the incident.

The increase in arrest rate for assaults in residential locations could be a function of the increased powers of police in all states to make warrantless misdemeanor arrests. Prior to these changes in the law police were unable to make warrantless misdemeanor arrests for offenses they did not witness. In addition, police may be more likely to have a suspect to arrest in incidents that occur in residences. Further research as to whether the suspect was present at the time police arrived and efforts made by police to locate and arrest suspects who had left the scene might provide a better understanding of variations in police response. This is, in fact, an issue that is investigated in Phase II of this study.

As noted above, the presence of mandatory and preferred arrest laws mediates the effect of offense location on the likelihood of arrest. In intimate partner and acquaintance cases the presence of both mandatory and preferred arrest laws, and in the case of stranger cases mandatory arrest laws, significantly equalize the likelihood of arrest. Thus, the existence of these laws results in more even application of the law whether the offense occurs in a residence or in public.

Cases involving intimate partners and acquaintances are more likely to result in arrest if the offender is over 21 . However, in other domestic cases, arrest is more likely if the offender is under 21. Clearly, there appear to be some dynamics shared by intimate partner and acquaintance cases that differ from those in other domestic cases. As discussed above, the wide range of relationships and accompanying age distributions of the involved parties in other domestic cases may explain this. Prior research conducted by Buzawa and Hotaling (2000) and Chesney-Lind (2004) supports the hypothesis of a disproportionate arrest rate of juveniles in domestic cases. 
For both other domestic and acquaintance cases the presence of a mandatory arrest law significantly mediates the effect of age on the likelihood of arrest.

Of great interest is the impact of sex on the odds for arrest. In these analyses sex had no significant effect on the response to intimate partner or stranger cases. Thus, no support is provided by these analyses for the hypothesis that the increase in the number of female arrests in intimate partner violence cases can be attributed to their disproportionate arrest rate for minor offenses. However, the fact that males and females are equally likely to be arrested may be evidence of an increase in female arrests, if in the past males were more likely to be arrested. No longer are females treated more leniently. Faced with similar circumstances responding officers are as likely to arrest a female offender, as they are a male offender. For both other domestic and acquaintance cases, arrest was, however, more likely if the offender was male. Thus, in these cases, there is some evidence that females are treated more leniently than males. Yet again, the presence of a mandatory arrest law had a mediating effect, equalizing to a great extent the response whether the offender was male or female. For other domestic cases the presence of a preferred arrest law had a similar effect.

Offender race had a significant effect on the response to intimate partner cases. Arrest was more likely if the offender was white. While this finding indicates that the police response is affected by the racial composition of the involved parties, it is unclear what factors account for this. Factors such as victim preference and the presence of the suspect may account for the observed difference in response. Yet again the presence of preferred arrest laws was observed to have a mediating effect. In intimate partner violence cases the existence of a preferred arrest law, helped provide more equal treatment of both black and white offenders.

These results show that mandatory and preferred arrest laws are having the desired effect 
of producing higher arrest rates in these states compared to states with discretionary arrest laws. This effect is to be observed not just in intimate partner and other domestic violence cases, but in acquaintance and stranger cases as well. Where significant main effects were observed at level one (the individual case) the presence of mandatory and preferred arrest laws tended to mediate these effects, such as by increasing the likelihood of arrest in intimidation cases and by making the likelihood of arrest less dependent on where the incident took place or on the race of the offender.

Prior research (see, e.g. Haviland et al., 2001; Martin, 1997; Victim Services Agency, 1988) has raised concerns that the enactment of mandatory and preferred arrest laws has produced high rates of dual arrest. However, until now there has been no large-scale study that has examined the extent of dual arrest. Our examination of police action in 2,819 jurisdictions in 19 states revealed a low overall dual arrest rate: 1.3\% (see Table 4.31). However, when considered as a proportion of all arrests, the dual arrest percentage was slightly higher for intimate partner compared to other relationship categories (Table 5.1).

Though the overall dual arrest rates were low, there was considerable variation in the dual arrest rates both among and within states (see post, Table 7.1). Our analyses of the effect of mandatory and preferred arrest laws on the likelihood of officers making dual arrests produced some striking results. First, the existence of a mandatory arrest law significantly increased the likelihood of arrest for all three of the relationship categories (intimate partner, other domestic, and acquaintance) examined. Thus, this study does provide support for the hypothesis that mandatory arrest laws produce higher rates of dual arrest in intimate partner and other domestic violence cases. They also have a spillover effect in acquaintance cases.

As noted above, mandatory arrest laws may lead officers to adopt a legalistic orientation 
(Wilson, 1968). Considering it inappropriate to use discretion, they apply the law in a mechanistic style. Thus, when faced with a situation that appears to involve two mutual combatants, they opt to arrest both, leaving it to the prosecutor, and perhaps the court, to determine culpability. The impact of primary aggressor legislation on the decision to arrest in such circumstances would appear to constitute an issue that merits further examination. However, since seven of the eight mandatory arrest states involved in this study had primary aggressor laws, the passage of a primary aggressor law clearly does not negate the relationship between mandatory arrest laws and higher dual arrest rates. However, it is important to note that the only mandatory state that did not have a primary aggressor provision at the time of the study (Connecticut) also had by far the highest dual arrest rate.

Interestingly, the existence of a preferred arrest law did not significantly increase the likelihood of dual arrest in any relationship category. While leaving the responding officers some discretion when responding to domestic calls is clearly associated with lower dual arrest rates, it is not totally clear what factors prompt officers to use this discretion.

With regard to this issue, the HGLM analysis produced one striking finding that was consistent among the three relationship categories examined: dual arrests were less likely in intimate partner, other domestic, and acquaintance cases when the first offender in the offender segment was male. Thus, in intimate partner violence cases, $98 \%$ of which in this study had heterosexual couples as the involved parties, a dual arrest was more likely if the female was designated as the first offender in the offender segment than if the male was designated as such. Though this suggests that females may be being treated more leniently than males, this conclusion hinges on the assumption that the designation by NIBRS of an offender as the first offender accurately depicts who has primary culpability for the incident. 
${ }^{1}$ We included only incidents with two parties involved as victims and offenders. Because of the different dynamics involved, and the added complexities presented for analysis, we excluded incidents with multiple victims and/or offenders.

${ }^{2}$ The preliminary analysis included an empty model including only an intercept with random effects.

${ }^{3}$ A bivariate analysis revealed that all of the incidents in which a weapon (gun, knife, blunt object etc.) was used were categorized as aggravated assaults. Similarly, no weapons, personal or otherwise, were reported in any intimidation incidents. Injuries (serious and minor) were reported in two thirds of the aggravated assault incidents and more than half of the simple assault incidents. No injuries were reported in close to $100 \%$ of the intimidation cases. Given the covariation in the measures of offense seriousness and our specific interest in examining official handling of intimate partner violence cases, we used offense seriousness as reported by the responding police officer for the multivariate analyses.

${ }^{4}$ Cf. Bourg \& Stock (1994, p. 181), Buzawa \& Hotaling (2000, p. 37), Eitle (2005), Hall (2005), Ho (2003), Jones \& Belknap (1999, pp. 263-264), Mignon \& Holmes (1995, p. 433), Robinson \& Chandek (2000, p. 27), and Simpson et al. (2006). 


\section{Chapter 6 \\ The Arrest of Women}

A major focus of this study is the role of sex in influencing a police officer's identification of victim and offender in the decision to arrest. In the previous chapter, we reported no significant relationship between sex of the offender and the general likelihood of arrest in cases of intimate partner or stranger violence. For both other domestic and acquaintance cases, arrest was, however, more likely if the offender was male. These analyses did not, however, take into account the sex of the victim and whether there were variations in the police response in incidents involving a male offender and a female victim, a female offender and a female victim, a female offender and a female victim, or a male offender and a male victim. In this chapter we examine how these gender variations in victim-offender relationship impact police arrest decisions.

A total of 252,110 (43.6\%) of the 577,862 incidents in the data set involved a female victim and a male offender. In 55,268 (9.6\%) of the cases, there was a male victim and a female offender. In 70,794 (12.3\%) of the incidents both the victim and offender were female, and in 158,012 (27.3\%) of the incidents, both parties were male. Information was missing for 41,678 (7.2\%) of the cases.

As Table 6.1 shows, however, the victim-offender sex distributions varied considerably when examining victim-offender relationship. While $80.9 \%$ of the intimate partner violence cases involved a male offender and a female victim, only $36.7 \%$ of the other domestic cases, $25.1 \%$ of the acquaintance, and $19.9 \%$ of the stranger cases did. Conversely, while cases involving male victims and male offenders comprised only $1.4 \%$ of the intimate partner violence cases, they comprised $31.3 \%$ of the other domestics, $46.6 \%$ of the acquaintance and $62.3 \%$ of the stranger cases. 
Table 6.1

Victim-Offender Sex by Victim Offender Relationship

$(\mathrm{N}=494,039)$

\begin{tabular}{|c|c|c|c|c|c|c|}
\hline & & \multicolumn{4}{|c|}{ Victim and Offender Sex } & \multirow[b]{2}{*}{ Total } \\
\hline & & $\begin{array}{l}\text { female victim } \\
\text { male offender }\end{array}$ & $\begin{array}{c}\text { male victim } \\
\text { female } \\
\text { offender }\end{array}$ & both female & both male & \\
\hline \multirow{8}{*}{$\begin{array}{l}\text { Victim-Offender } \\
\text { Relationship }\end{array}$} & Intimate Partner & 159216 & 31796 & 3028 & 2694 & 196734 \\
\hline & & $80.9 \%$ & $16.2 \%$ & $1.5 \%$ & $1.4 \%$ & $100.0 \%$ \\
\hline & Other Domestic & 25882 & 6155 & 16386 & 22091 & 70514 \\
\hline & & $36.7 \%$ & $8.7 \%$ & $23.2 \%$ & $31.3 \%$ & $100.0 \%$ \\
\hline & Acquaintance & 45554 & 11544 & 39725 & 84567 & 181390 \\
\hline & & $25.1 \%$ & $6.4 \%$ & $21.9 \%$ & $46.6 \%$ & $100.0 \%$ \\
\hline & Stranger & 9048 & 2955 & 5118 & 28280 & 45401 \\
\hline & & $19.9 \%$ & $6.5 \%$ & $11.3 \%$ & $62.3 \%$ & $100.0 \%$ \\
\hline \multirow[t]{2}{*}{ Total } & & 239700 & 52450 & 64257 & 137632 & 494039 \\
\hline & & $48.5 \%$ & $10.6 \%$ & $13.0 \%$ & $27.9 \%$ & $100.0 \%$ \\
\hline
\end{tabular}

Several striking findings emerged when we examined the police disposition of the case by victim and offender sex for each of the four relationship categories. First and foremost, was the high percentage of dual arrests in same sex intimate partner incidents. While the overall dual arrest rate for all intimate partner violence cases was $1.9 \%, 26.1 \%$ of the female same sex cases, and $27.3 \%$ of the male same sex cases, resulted in the arrest of both of the involved parties (Table 6.2). As noted earlier in this report, both the overall arrest rate (49.9\%) and the dual arrest rate $(1.9 \%)$ were higher for intimate partner violence cases than for any of the other three relationship categories. Within the intimate partner relationship category the overall arrest rates for the four victim-offender sex categories were extremely close, ranging from an overall arrest rate of $50.7 \%$ for cases involving either a male offender and a female victim or two female involved parties to $49.7 \%$ for cases with a female victim and a male offender. Thus, though the police were equally likely to resolve cases involving both heterosexual and same sex couples by making an arrest, cases involving same sex couples were substantially more likely to result in the 
arrest of both parties. The sex of the involved parties did not exert any influence on the

likelihood of arrest.

Table 6.2

Police Disposition by Victim-Offender Sex by Victim Offender Relationship

$(\mathrm{N}=494,039)$

\begin{tabular}{|c|c|c|c|c|c|c|}
\hline \multirow[b]{2}{*}{$\begin{array}{l}\text { Victim-Offender } \\
\text { Relationship }\end{array}$} & & & \multicolumn{3}{|c|}{ Police Disposition } & \multirow[b]{2}{*}{ Total } \\
\hline & & & no arrest & $\begin{array}{l}\text { one or more } \\
\text { arrests }\end{array}$ & $\begin{array}{c}\text { dual } \\
\text { arrest }\end{array}$ & \\
\hline \multirow[t]{5}{*}{ Intimate Partner } & \multirow{4}{*}{$\begin{array}{l}\text { Victim } \\
\text { and } \\
\text { Offender } \\
\text { Sex }\end{array}$} & $\begin{array}{l}\text { female victim } \\
\text { male offender }\end{array}$ & $50.3 \%$ & $48.9 \%$ & $.8 \%$ & \\
\hline & & $\begin{array}{l}\text { male victim } \\
\text { female offender }\end{array}$ & $49.3 \%$ & $47.7 \%$ & $3.0 \%$ & \\
\hline & & both female & $49.3 \%$ & $24.5 \%$ & $26.1 \%$ & \\
\hline & & both male & $49.9 \%$ & $22.8 \%$ & $27.3 \%$ & \\
\hline & Total & & $50.1 \%$ & $48.0 \%$ & $1.9 \%$ & $100.0 \%$ \\
\hline \multirow[t]{5}{*}{ Other Domestic } & \multirow{4}{*}{$\begin{array}{l}\text { Victim } \\
\text { and } \\
\text { Offender } \\
\text { Sex }\end{array}$} & $\begin{array}{l}\text { female victim } \\
\text { male offender }\end{array}$ & $53.4 \%$ & $46.2 \%$ & $.4 \%$ & \\
\hline & & $\begin{array}{l}\text { male victim } \\
\text { female offender }\end{array}$ & $59.1 \%$ & $39.8 \%$ & $1.1 \%$ & \\
\hline & & both female & $58.7 \%$ & $39.1 \%$ & $2.3 \%$ & \\
\hline & & both male & $54.7 \%$ & $43.1 \%$ & $2.3 \%$ & \\
\hline & Total & & $55.5 \%$ & $43.0 \%$ & $1.5 \%$ & $100.0 \%$ \\
\hline \multirow[t]{5}{*}{ Acquaintance } & \multirow{4}{*}{$\begin{array}{l}\text { Victim } \\
\text { and } \\
\text { Offender } \\
\text { Sex }\end{array}$} & $\begin{array}{l}\text { female victim } \\
\text { male offender }\end{array}$ & $72.9 \%$ & $26.8 \%$ & $.3 \%$ & \\
\hline & & $\begin{array}{l}\text { male victim } \\
\text { female offender }\end{array}$ & $70.6 \%$ & $28.6 \%$ & $.8 \%$ & \\
\hline & & both female & $73.5 \%$ & $24.9 \%$ & $1.6 \%$ & \\
\hline & & both male & $68.8 \%$ & $30.1 \%$ & $1.2 \%$ & \\
\hline & Total & & $71.0 \%$ & $28.0 \%$ & $1.0 \%$ & $100.0 \%$ \\
\hline \multirow[t]{5}{*}{ Stranger } & \multirow{4}{*}{$\begin{array}{l}\text { Victim } \\
\text { and } \\
\text { Offender } \\
\text { Sex }\end{array}$} & $\begin{array}{l}\text { female victim } \\
\text { male offender }\end{array}$ & $75.2 \%$ & $24.7 \%$ & $.2 \%$ & \\
\hline & & $\begin{array}{l}\text { male victim } \\
\text { female offender }\end{array}$ & $48.8 \%$ & $51.1 \%$ & $.1 \%$ & \\
\hline & & both female & $74.1 \%$ & $25.0 \%$ & $.9 \%$ & \\
\hline & & both male & $61.8 \%$ & $37.8 \%$ & $.4 \%$ & \\
\hline & Total & & $65.0 \%$ & $34.6 \%$ & $.4 \%$ & $100.0 \%$ \\
\hline
\end{tabular}


Analyses examining the effect of the seriousness of the case on the likelihood of arrest in intimate partner violence cases revealed a consistent pattern of more arrests in more serious cases, with aggravated assaults more likely than simple assaults, and simple assaults more likely than cases of intimidation, to result in arrest (Table 6.3). Same sex aggravated and simple assault cases were also substantially more likely than similar cases involving heterosexuals to result in arrest. There was little difference in the probability of arrest between female and male same sex couples for either aggravated or simple assault. However, female same sex couples (11.7\%) were twice as likely as male sex couples (5.7\%) to have cases of intimidation resolved by a dual arrest. Faced with an intimidation case involving male same sex partners, responding officers were more likely to resolve the case without resorting to arrest than they were when the case involved two female sex partners. Thus, in cases of intimidation, male same sex offenders appear to be receiving more lenient dispositions of cases than female same sex offenders. This may be a result of police viewing such behavior among males as "normal," whereas this behavior is more likely to be viewed negatively by police officers when it involves females (Renzetti, 1999; Swan \& Snow, 2006).

Interestingly, the converse situation appears to exist when comparing the likelihood of dual arrest in heterosexual cases for female victims or male victims. While $2.9 \%$ of the aggravated assault cases, and 3.3\% of the simple assault cases with a male victim and a female offender, ended in dual arrests, the comparative figures for aggravated and simple assaults with female victims and male offenders were 0.9 in both cases. ${ }^{1}$ This may be a result of the process by which officers attempt to determine the primary aggressor. Typically, the "potential to inflict greater harm” is attributed to males, given their (usual) size and strength relative to females (Buzawa \& Buzawa, 2003). Straus (2006:1093) takes this explanation further than is typical of 
researchers in the field. He believes that "there is a growing effort to avoid arresting female perpetrators under a policy of arresting the 'primary offender' .” However, data from other studies (see, eg., De Leon-Granados et al., 2006; Miller, 2005) indicating an increase in the percentage of women arrested for intimate partner violence appear to belie this position.

Table 6.3

Intimate Partner Violence Cases: Police Disposition by Victim-Offender Sex Controlling for Seriousness of Offense

$(\mathrm{N}=196,734)$

\begin{tabular}{|c|c|c|c|c|c|c|}
\hline \multirow[b]{2}{*}{$\begin{array}{l}\text { Victim and Offender } \\
\text { Sex }\end{array}$} & & & \multicolumn{3}{|c|}{ Police Disposition } & \multirow[b]{2}{*}{ Total } \\
\hline & & & no arrest & $\begin{array}{l}\text { one or more } \\
\text { arrests }\end{array}$ & $\begin{array}{c}\text { dual } \\
\text { arrest }\end{array}$ & \\
\hline \multirow{4}{*}{$\begin{array}{l}\text { female victim male } \\
\text { offender }\end{array}$} & \multirow{3}{*}{$\begin{array}{l}\text { Most serious } \\
\text { offense against } \\
\text { the victim }\end{array}$} & Aggravated Assaul & $39.6 \%$ & $59.4 \%$ & $.9 \%$ & \\
\hline & & Simple Assault & $47.3 \%$ & $51.8 \%$ & $.9 \%$ & \\
\hline & & Intimidation & $81.9 \%$ & $18.0 \%$ & $.1 \%$ & \\
\hline & Total & & $50.3 \%$ & $48.9 \%$ & $.8 \%$ & $100.0 \%$ \\
\hline \multirow{4}{*}{$\begin{array}{l}\text { male victim female } \\
\text { offender }\end{array}$} & \multirow{3}{*}{$\begin{array}{l}\text { Most serious } \\
\text { offense against } \\
\text { the victim }\end{array}$} & Aggravated Assaul & $41.4 \%$ & $55.8 \%$ & $2.9 \%$ & \\
\hline & & Simple Assault & $46.9 \%$ & $49.8 \%$ & $3.3 \%$ & \\
\hline & & Intimidation & $88.1 \%$ & $11.5 \%$ & $.4 \%$ & \\
\hline & Total & & $49.3 \%$ & $47.7 \%$ & $3.0 \%$ & $100.0 \%$ \\
\hline \multirow[t]{4}{*}{ both female } & \multirow{3}{*}{$\begin{array}{l}\text { Most serious } \\
\text { offense against } \\
\text { the victim }\end{array}$} & Aggravated Assaul & $40.6 \%$ & $34.8 \%$ & $24.6 \%$ & \\
\hline & & Simple Assault & $49.0 \%$ & $23.9 \%$ & $27.1 \%$ & \\
\hline & & Intimidation & $73.8 \%$ & $14.5 \%$ & $11.7 \%$ & \\
\hline & Total & & $49.3 \%$ & $24.5 \%$ & $26.1 \%$ & $100.0 \%$ \\
\hline \multirow[t]{4}{*}{ both male } & \multirow{3}{*}{$\begin{array}{l}\text { Most serious } \\
\text { offense against } \\
\text { the victim }\end{array}$} & Aggravated Assaul & $38.9 \%$ & $35.5 \%$ & $25.6 \%$ & \\
\hline & & Simple Assault & $49.9 \%$ & $21.3 \%$ & $28.8 \%$ & \\
\hline & & Intimidation & $82.8 \%$ & $11.5 \%$ & $5.7 \%$ & \\
\hline & Total & & $49.9 \%$ & $22.8 \%$ & $27.3 \%$ & $100.0 \%$ \\
\hline
\end{tabular}

Earlier in this report we presented findings indicating that arrest was more likely in intimate partner violence cases when the incident involved non-minority as opposed to minority couples. When we examined this finding in relation to the sex of the victim and offender, we observed that incidents with a minority female victim and a male offender (who was nearly always also a minority) were particularly likely not to result in an arrest (Table 6.4). 
Table 6.4

Intimate Partner Violence Cases: Police Disposition by Victim-Offender Sex Controlling for Victim Race

$(\mathrm{N}=194,338)$

\begin{tabular}{|c|c|c|c|c|c|c|}
\hline \multirow{2}{*}{\multicolumn{3}{|c|}{ Victim and Offender Se }} & \multicolumn{3}{|c|}{ Police Disposition } & \multirow{3}{*}{ Total } \\
\hline & & & \multirow{2}{*}{$\frac{\text { no arrest }}{58.6 \%}$} & \multirow{2}{*}{$\begin{array}{c}\text { one or more } \\
\text { arrests }\end{array}$} & \multirow{2}{*}{$\begin{array}{c}\begin{array}{c}\text { dual } \\
\text { arrest }\end{array} \\
1.0 \%\end{array}$} & \\
\hline female victim male & Victim & Minority & & & & \\
\hline offender & Race & Non-Minority & $46.8 \%$ & $52.4 \%$ & $.8 \%$ & \\
\hline & Total & & $50.3 \%$ & $48.8 \%$ & $.8 \%$ & $100.0 \%$ \\
\hline \multirow{3}{*}{$\begin{array}{l}\text { male victim female } \\
\text { offender }\end{array}$} & \multirow{2}{*}{$\begin{array}{l}\text { Victim } \\
\text { Race }\end{array}$} & Minority & $53.3 \%$ & $43.5 \%$ & $3.1 \%$ & \\
\hline & & Non-Minority & $47.6 \%$ & $49.5 \%$ & $3.0 \%$ & \\
\hline & Total & & $49.3 \%$ & $47.7 \%$ & $3.0 \%$ & $100.0 \%$ \\
\hline \multirow[t]{3}{*}{ both female } & \multirow{2}{*}{$\begin{array}{l}\text { Victim } \\
\text { Race }\end{array}$} & Minority & $53.1 \%$ & $23.2 \%$ & $23.7 \%$ & \\
\hline & & Non-Minority & $47.7 \%$ & $25.0 \%$ & $27.3 \%$ & \\
\hline & Total & & $49.4 \%$ & $24.5 \%$ & $26.2 \%$ & $100.0 \%$ \\
\hline \multirow[t]{3}{*}{ both male } & \multirow{2}{*}{$\begin{array}{l}\text { Victim } \\
\text { Race }\end{array}$} & Minority & $54.4 \%$ & $19.4 \%$ & $26.2 \%$ & \\
\hline & & Non-Minority & $48.1 \%$ & $23.9 \%$ & $28.0 \%$ & \\
\hline & Total & & $49.8 \%$ & $22.7 \%$ & $27.5 \%$ & $100.0 \%$ \\
\hline
\end{tabular}

Our earlier analyses also indicated that arrest was more likely in intimate partner violence cases when the incident took place in a home or residence as opposed to somewhere else. When this finding was examined in the light of victim-offender sex, a divergence from this pattern emerged for same sex couples. Cases involving same sex females were marginally more likely to result in arrest if the incident took place outside of the home or residence, and a trend in the same direction was seen for male same sex couples (Table 6.5). 
Table 6.5

Intimate Partner Violence Cases: Police Disposition by Victim-Offender Sex Controlling for Location of Incident

$(\mathrm{N}=190,776)$

\begin{tabular}{|c|c|c|c|c|c|c|}
\hline \multirow[b]{2}{*}{ Victim and Offender Sex } & & & \multicolumn{3}{|c|}{ Police Disposition } & \multirow[b]{2}{*}{ Total } \\
\hline & & & no arrest & $\begin{array}{l}\text { one or more } \\
\quad \text { arrests }\end{array}$ & $\begin{array}{c}\text { dual } \\
\text { arrest }\end{array}$ & \\
\hline \multirow{3}{*}{$\begin{array}{l}\text { female victim male } \\
\text { offender }\end{array}$} & & Home/Residence & $49.2 \%$ & $49.9 \%$ & $.8 \%$ & \\
\hline & & Elsewhere & $54.1 \%$ & $45.2 \%$ & $.8 \%$ & \\
\hline & Total & & $49.9 \%$ & $49.2 \%$ & $.8 \%$ & $100.0 \%$ \\
\hline \multirow{3}{*}{$\begin{array}{l}\text { male victim female } \\
\text { offender }\end{array}$} & & Home/Residence & $48.2 \%$ & $48.7 \%$ & $3.1 \%$ & \\
\hline & & Elsewhere & $53.5 \%$ & $43.7 \%$ & $2.8 \%$ & \\
\hline & Total & & $49.0 \%$ & $48.0 \%$ & $3.0 \%$ & $100.0 \%$ \\
\hline \multirow[t]{3}{*}{ both female } & & Home/Residence & $49.4 \%$ & $24.2 \%$ & $26.3 \%$ & \\
\hline & & Elsewhere & $47.4 \%$ & $27.3 \%$ & $25.4 \%$ & \\
\hline & Total & & $49.1 \%$ & $24.7 \%$ & $26.2 \%$ & $100.0 \%$ \\
\hline \multirow[t]{3}{*}{ both male } & & Home/Residence & $48.5 \%$ & $22.8 \%$ & $28.7 \%$ & \\
\hline & & Elsewhere & $55.5 \%$ & $24.0 \%$ & $20.5 \%$ & \\
\hline & Total & & $49.5 \%$ & $23.0 \%$ & $27.5 \%$ & $100.0 \%$ \\
\hline
\end{tabular}

The lack of large disparities in arrest rates between a home or residence compared to other locations is noteworthy. This was a source of historic concern to domestic violence advocates as females are much more likely to be victimized inside a home or residence compared to males (Straus et al., 1980). Historically, police were oriented to responding to crimes of public disorder, rather than events that occurred "behind closed doors” (Buzawa \& Buzawa, 2003; Manning, 1997). The current analysis suggests that there is less of a "location bias,” which may disproportionately increase the likelihood of female victims being arrested now than in the past.

A number of interesting findings thus emerge from examining the police response to intimate partner violence cases by the sex of the victim and offender. The most striking finding is the substantially higher dual arrest rates in incidents involving same sex couples. The dual arrest 
rates for same sex couples (both female and male) are almost ten times the rate for cases with male victims and female offenders and over 30 times the rate found in cases with female victims and male offenders (Table 6.2). For the most part, there was little difference in the likelihood of dual arrests occurring in female and male same sex cases.

However, although dual arrests were about equally likely in female and male same sex aggravated and simple assault cases, dual arrests were twice as likely to occur in intimidation cases involving female same sex couples as they were in cases involving male same sex couples. In addition, though in general arrest was more likely if the incident took place in a home or residence, cases involving same sex female victims were marginally more likely to result in arrest if the incident took place outside of the home or residence. Thus, same sex female couples who were involved in incidents that took place outside the home were more likely to be arrested than any of the other victim-offender sex categories.

With regard to heterosexual couples our analyses provided two findings that expanded on what we had found so far. First, the likelihood of dual arrest was about three times greater for cases with male victims and female offenders than for cases with female victims and male offenders (Table 6.2). Second, while arrest was less likely in cases involving minority couples, incidents with a minority female victim and a male offender were particularly likely not to result in an arrest. This supports Black’s (1976) theory that violence among minorities is more likely to be viewed as "normal behavior” and thus police are less likely to invoke their arrest powers.

Our examination of the police response to other domestic cases showed that a total of $43 \%$ of these cases resulted in the police making one or more arrests and an additional $1.5 \%$ of cases were resolved with dual arrests (Table 6.2). As with intimate partner violence cases, arrest was more likely when the incident involved two parties of the same sex, although for other 
domestics the disparity between the dual arrest rates of same sex and opposite sex participants was not as great as in intimate partner cases. Same sex non intimate partner domestic violence cases were about twice as likely to produce dual arrests as cases with opposite sex involved parties (Table 6.2). Our previous HGLM analyses had indicated that in these other domestic cases the sex of the offender did make a difference in the police response with male offenders being more likely than female offenders to be arrested when seriousness of the offense and other factors were held constant. Further analyses revealed that there were only marginal differences in female and male arrest rates when a weapon, such as a gun, knife, or object was used in the incident or when the incident involved minorities. ${ }^{2}$

Cases involving acquaintances were, as indicated above, the least likely to result in arrest with the police making an arrest in only $29 \%$ of those cases (Table 6.2). The HGLM analyses conducted in chapter 5 indicated that, controlling for seriousness of offense and other salient factors, incidents with acquaintances as the involved parties were in general more likely to result in arrest when the offender was a male. The data in Table 6.2 indicate that arrest was most likely when the incident involved two males (31.3\%) and least likely when it involved two females (26.5\%). Yet again, dual arrest was more likely when the incident involved same sex parties. Stranger cases were the most likely to have incidents with male involved parties $(62.3 \%$ : see Table 6.1). While $38.2 \%$ of these cases resulted in arrest compared to $25.9 \%$ of cases with female involved parties, $51.2 \%$ of stranger cases with a male victim and a female offender resulted in arrest compared to only $24.9 \%$ of incidents with a female victim and a male offender (Table 6.2). Despite the fact that cases with male victims and female offenders were comparatively rare (they comprised only $6.5 \%$ of stranger cases: see Table 6.1 ), they were markedly more likely to result in arrest. Our HGLM analyses had indicated that females were no 
more likely than males to be arrested in stranger cases. Further analyses examining arrest rates

by victim-offender sex, and controlling for offense seriousness and other salient factors, indicated that incidents with male victims and female offenders were consistently more likely to result in arrest. ${ }^{3}$ This finding supports research reporting an increased propensity to arrest women (Miller, 2005).

1 The other measures of offense seriousness, namely use of weapon and injury, yielded similar results. However, it should be noted that, when no injury was inflicted in the incident, cases involving same sex female couples were no more likely than cases with same sex male couples to end up in dual arrest (21.8\% v. 21.2\%).

${ }^{2}$ When a weapon was involved in the incident $65.5 \%$ of the incidents with a male offender and a female victim resulted in arrest compared to $64.7 \%$ of the incidents with a female offender and a male victim. When the incident involved minority opposite sex parties the arrest rate for female offenders was $41.5 \%$, for male offenders $43.7 \%$.

${ }^{3}$ While, for example, $41 \%$ of all stranger aggravated assault cases resulted in arrest, $54.2 \%$ of stranger incidents with a male victim and a female offender resulted in arrest. For simple assault and intimidation cases the overall stranger arrest rates were $37.3 \%$ and $18.5 \%$ while for incidents with a male victim and a female offender they were $55.7 \%$ and $25 \%$ respectively. 


\section{Chapter 7 \\ Phase II: Going Beyond NIBRS}

In Phase I, the National Incident Based Reporting System (NIBRS) enabled us to conduct a broad based examination of police arrest practices in the United States. However, while the NIBRS provides comprehensive coverage of police department arrest practices, it does not contain a wide variety of variables that help explain the divergent practices we observed in arrest patterns. Key variables that are not contained in the NIBRS dataset include: whether the offender was on the scene when the police arrived, who reported the incident, the exact nature of injuries suffered by the involved parties, victim and offender substance use, victim preferences, offender demeanor, and presence of children. All of these variables might be expected in some way to impact the decision to arrest.

As a consequence, for Phase II, the NIBRS dataset was supplemented by the addition of numerous variables from several different sources. Phase II is concerned with expanding the analyses presented in the preceding chapters in two significant ways. First, we surveyed a sample of police departments to examine the extent to which department policy reflects state law. As we have already noted, there is considerable within state, as well as among state, variation in both overall arrest and dual arrest rates. Although state law provides the outside parameters within which the police must operate within a particular state, it does not necessarily follow that department policy must reflect a mirror image of state law. Though required to adhere to the minimum requirements of state law, police departments are generally free to adopt policies that exceed those requirements.

What this means in terms of domestic violence arrest laws is that, while police departments in mandatory arrest states must require that police officers make arrests in the circumstances outlined in the statute, police departments in states with discretionary arrest laws 
do not necessarily leave the arrest decision to the discretion of the responding officers; they may implement a policy that either dictates a preference for arrest, or even mandates arrest, if certain stated conditions are met. Thus, it may well be a mistake to assume that all police departments in states with discretionary arrest laws have discretionary arrest policies. Similarly, a police department in a preferred arrest state may have implemented a mandatory arrest policy.

Second, we collected far more detailed information on a sample of cases taken from selected police departments to expand our analysis of factors that affect arrest decisions. For this phase of the project we focused on intimate partner and other domestic cases, and excluded acquaintance and stranger cases. We restricted our cases in this way because the primary focus of this study is domestic violence, in particular violence among intimates, and to collect sufficient data for the two additional populations would have added greatly to the expense and time required to carry out this project.

\section{Selecting Sites for Phase II Data Collection}

In selecting our sites for data collection, samples we utilized a stratified sampling approach. Maintaining our focus on the legislative framework under which police departments operate, we divided the states that contributed to the NIBRS year 2000 dataset into three strata: (1) those with mandatory warrantless arrest laws; (2) those with preferred warrantless arrest laws; and, (3) those with discretionary warrantless arrest laws. Using specified criteria, we selected first the states, and then the specific jurisdictions, we would use for additional data collection.

Our conceptual framework necessitated that we select at least one state from each of the three strata. We decided to sample two mandatory arrest states for Phase II data collection because higher rates of overall arrest and actual dual arrest were observed in mandatory arrest 
states, and within state variations in mandatory arrest states were more unexpected than in states with preferred or discretionary laws in domestic violence cases. The issue of cost precluded selecting a larger number of states.

Given the low percentage of cases that result in dual arrests, a primary concern in selecting states for these additional components of our study was that they generated a sufficient number of dual arrest cases for meaningful analysis. Thus state dual arrest rate was the primary criterion in selecting a state for inclusion in this phase of the study. In selecting the states we did, however, also consider overall arrest rate and a third measure that has the potential to contribute meaningfully to data analysis, potential dual arrest rate. This is an additional measure of police decision-making that is provided by the NIBRS dataset that focuses on whether the police identified an incident as potentially involving a dual arrest before they make an arrest decision. In these situations responding police officers have identified at least two parties involved as "mutual combatants" and consequently, these parties have the potential to be arrested. Whether both, one, or neither of the parties is arrested is, of course, an entirely different matter, and will depend on a variety of incident characteristics (or other factors) such as who is present upon police arrival, presence of a weapon, and the infliction of injuries.

In Table 7.1 we present the actual dual arrest rate, the potential dual arrest rate, and the overall arrest rate for each of the 19 states in the NIBRS dataset. Since Phase II focuses only on domestic violence cases, we did not include acquaintance or stranger cases in this analysis. Of the seven mandatory arrest states Connecticut has the by far the highest actual dual arrest rate (13.6\%) and thus was automatically selected for Phase II. South Carolina and Virginia presented as the main contenders for selection as the second mandatory arrest state because they generated a sufficient number of dual arrests despite their comparatively low dual arrest rates, and because 
we knew that they possessed high quality well established state data systems. After much discussion, Virginia was chosen as the second mandatory arrest state because of its proximity to the location of PERF, one of the partners in this study.

Table 7.1

Potential Dual Arrest Rate, Total Arrest Rate, and Actual Dual Arrest Rate for Domestic Violence Cases by State

\begin{tabular}{|l|l|c|c|c|c|}
\hline \multicolumn{1}{|c|}{ State } & $\begin{array}{l}\text { Police } \\
\text { Warrantless } \\
\text { Arrest Powers }\end{array}$ & $\begin{array}{l}\text { Potential } \\
\text { Dual } \\
\text { Arrest Rate }\end{array}$ & $\begin{array}{l}\text { Total } \\
\text { Arrest } \\
\text { Rate }\end{array}$ & $\begin{array}{l}\text { Actual } \\
\text { Dual } \\
\text { Arrest Rate }\end{array}$ & $\begin{array}{l}\text { \# of Dual } \\
\text { Arrest } \\
\text { Cases }\end{array}$ \\
\hline Arkansas* & Preferred & $1.0 \%$ & $45.9 \%$ & $0.0 \%$ & 0 \\
\hline Colorado & Mandatory & $4.1 \%$ & $76.5 \%$ & $2.9 \%$ & 239 \\
\hline Connecticut & Mandatory & $21.3 \%$ & $67.9 \%$ & $13.6 \%$ & 553 \\
\hline Idaho & Discretionary & $8.1 \%$ & $63.4 \%$ & $4.0 \%$ & 279 \\
\hline Iowa & Mandatory & $3.9 \%$ & $64.3 \%$ & $2.1 \%$ & 230 \\
\hline Kentucky & Discretionary & $2.6 \%$ & $48.3 \%$ & $1.4 \%$ & 13 \\
\hline Massachusetts & Preferred & $1.1 \%$ & $61.8 \%$ & $0.3 \%$ & 42 \\
\hline Michigan & Discretionary & $3.1 \%$ & $44.4 \%$ & $0.8 \%$ & 348 \\
\hline Nebraska & Discretionary & $9.2 \%$ & $66.2 \%$ & $5.5 \%$ & 32 \\
\hline North Dakota & Preferred & $8.1 \%$ & $50.7 \%$ & $2.5 \%$ & 29 \\
\hline Ohio & Mandatory & $2.3 \%$ & $44.5 \%$ & $1.1 \%$ & 121 \\
\hline $\begin{array}{l}\text { South } \\
\text { Carolina }\end{array}$ & Mandatory & $6.7 \%$ & $39.9 \%$ & $2.2 \%$ & 1001 \\
\hline South Dakota & Mandatory & $1.9 \%$ & $82.4 \%$ & $1.9 \%$ & 486 \\
\hline Tennessee & Preferred & $5.5 \%$ & $40.0 \%$ & $1.3 \%$ & 622 \\
\hline Texas & Discretionary & $4.5 \%$ & $39.7 \%$ & $1.2 \%$ & 148 \\
\hline Utah & Mandatory & $8.1 \%$ & $67.5 \%$ & $4.6 \%$ & 264 \\
\hline Vermont & Discretionary & $3.4 \%$ & $79.1 \%$ & $2.5 \%$ & 24 \\
\hline Virginia & Mandatory & $5.1 \%$ & $55.8 \%$ & $2.0 \%$ & 798 \\
\hline West Virginia & Discretionary & $1.6 \%$ & $42.8 \%$ & $0.7 \%$ & 85 \\
\hline \multirow{2}{*}{ Has only two jurisdictions reporting. } & & & & \\
\hline & & & & & \\
\hline
\end{tabular}

The choice of the preferred arrest state was simple. Of the four discretionary arrest states (Arkansas, Massachusetts, and North Dakota and Tennessee), only Tennessee generated a sufficient number of dual arrest cases for Phase II analysis. The selection of the discretionary arrest state was slightly more complicated. Both Michigan and Idaho were seriously considered as Phase II states. A number of factors influenced us to choose Idaho as our discretionary arrest 
state. First, Idaho had a higher dual arrest rate than Michigan and as a consequence there was greater variability in the dual arrest rates that existed among police jurisdictions in Idaho. Second, Idaho had been contributing data to NIBRS for more than 13 years, which gave us confidence that their data were valid and reliable. Third, Idaho and other largely rural states are underrepresented in the domestic violence literature and the selection of a rural state would allow us to focus on an underserved constituency.

\section{The Police Department Policy Component}

We used the same states for the police department policy component of the study, but added one more discretionary state (Michigan) since police departments within discretionary arrest states have the greatest latitude in diverging from state law. Since there were only 37 police departments in Connecticut and 112 in Idaho, we included all of these departments in this component of the project. The number of NIBRS jurisdictions in Virginia (342), Tennessee (373), and Michigan (571), precluded conducting a census of all the NIBRS jurisdictions in those states. In order to ensure representation of the large jurisdictions (operationally defined as those with a population of 50,000 or more), we selected all jurisdictions in those three states that had a population of 50,000 or more. We also obtained a random sample of 100 of the smaller jurisdictions in each of those three states. Our samples for Virginia, Tennessee and Michigan contained 93, 116, and 121 police departments respectively. The total sample size for this component of the study was 479.

\section{Phase II Data Collection}

We believe that a critical part of our task is to maximize the relevance of our findings and policy implications for other police departments. A frequent criticism of research on police arrest practices is that the focus is almost exclusively on large police departments that do not typify 
policing in the United States. With the dual goals of promoting diversity among the selected Phase II sites, and enhancing the generalizability of our findings, we used the following procedures for selecting police jurisdictions for Phase II data collection.

(1) We selected, in each of the four selected states, two medium to large jurisdictions that varied from each other in potential dual arrest, actual dual arrest, and overall arrest rates to serve as core sites. Medium to large jurisdictions were operationally defined as jurisdictions that had a population of at least 100,000 and had generated at least 300 domestic violence cases in 2000.

(2) We selected at least one additional satellite police jurisdiction that was located near each of the two core jurisdictions selected in each state. To qualify as a satellite jurisdiction, a jurisdiction could not qualify as a core site. "Being near” was operationally defined as being within a radius of 25 miles of the boundaries of the core site.

Since the success of Phase II of the project was dependent on the quality of the data that were obtained, an additional criterion for site selection focused on the extent and quality of the police and court data that were available. 


\section{Chapter 8 \\ The Role of Police Policies}

We have reported in our Phase I analyses of police arrest practices that domestic violence legislation has in general succeeded in its efforts to increase arrests in cases of domestic assault. In addition, states with mandatory and preferred warrantless arrest statutes have generated higher arrest rates than states with discretionary statutes. However, we have also noted great within state variation in arrest rates. While some of this variation has been explained by differences in the composition of the cases that individual police departments receive, there is still, as our HGLM analyses in chapter five have indicated, a great deal of unexplained variation in arrest practices. In this chapter we seek to explain some of this variation by investigating the interrelationships among statutory frameworks (e.g. mandatory, preferred or discretionary arrest), departmental policies, and actual arrests rates. To accomplish this objective we surveyed a sample of police departments in five states.

The variations in agency practices are likely due to a multitude of factors pertaining to the implementation of legislative mandates. As a result, domestic violence legislative reforms have resulted in markedly different policies and arrest practices even when departments operate under the same statutory framework or the "official" policies read similarly. This is often the result of differences in how individual departments respond to new legislative mandates as well as how officers within departments comply with legislative mandates that they may not personally support.

Policies are not only intended to restrict the discretion of members of the organization, but also to establish priorities when there are conflicting goals and procedures. Thus, policies are expected to reduce variability in personal decision-making and allow the focus of the decision to rest on the organization rather than the individual. Consequently, one would project 
that there would be variations among states in police policies that are reflective of statutes.

Further, one would also expect that in states with mandatory arrest requirements, there would be less flexibility in policy requirements and practice since those statutes provide for less discretion to be exercised by either the agency or the individual police officer.

Police agencies often develop specific policies that may be more restrictive than required by state statute. As previously discussed, states with mandatory laws require police compliance with their provisions, states with preferred laws indicate a preference for arrest, and states with discretionary laws leave the decision-making to the individual police departments. Clearly, agencies in states with discretionary arrest laws have the greatest freedom to choose to develop policies that provide additional limits on officer discretion.

In addition, policies are often used to directly address the goals of the organization and may therefore be indicative of organizational commitment to statutory requirements and represent a formalization of organizational rules and procedures that officers are expected to follow (see Hall, 1991). Police administrators have substantial discretion in their decisions to develop domestic violence policies. While many police administrators try to respond aggressively, others display lower levels of commitment at monitoring the implementation of domestic violence policies. Consequently, administrators can provide their officers with an unstated message regarding the relative importance of statutory mandates. Thus, merely imposing new (or any) policy may per se not prevent circumvention of legal mandates.

\section{Methodology}

To determine the nature and extent of discrepancies between agency policy and state law, we requested domestic violence policies from a sample of departments from five states for the year 2000. The sample states selected included two states (Connecticut and Virginia) where the 
legislative framework for the year 2000 was mandatory, one state with preferred arrest requirements (Tennessee), and two states with discretionary arrest statutes (Idaho and Michigan). Given that the number of participating agencies was relatively small for Idaho and Connecticut, we included in our sample all agencies from these states. From Virginia, Tennessee, and Michigan, we selected all agencies with a population over 50,000 and a random sample of about 100 of the remaining agencies. The final sample comprised a total of 479 departments.

Departments selected for the sample were sent letters requesting a copy of their domestic violence policy for the year 2000, and were asked to complete a brief survey. Self-addressed stamped envelopes were included for returning the responses. Follow-up calls were made to jurisdictions that failed to respond to the initial request for information and the final sample consisted of 282 agencies, a 59\% response rate.

Once policies were received, they were coded in order to examine variations in policy variations and requirements. We attempted to determine how many departments actually had policies and if so, whether they had developed their own policy, followed a state model policy, or that of another police agency. In addition, we coded specific police mandates under these policies regarding arrest, services for victims, and the identification of a primary aggressor. Finally, we examined policies to determine what instructions and/or guidelines were provided when making arrest decisions.

An initial decision was made to define as mandatory policies that stated that officers "must”, "shall”, or “will” make an arrest. Preferred was defined when the words "should” or "preferred” were used, while the word "may" was seen as discretionary. This interpretation obviously frames our findings. Achieving both accuracy and consistency in coding was hampered by the fact that departments were inconsistent in their wording. Some departments 
were identified as “mandatory" for some specific statutory requirements, but "preferred” and/or “deferred” for others. Accuracy was particularly problematic when words shifted when referring to the same statutory requirement. For example, in one policy, a subheading stated "arrest must be made when there is probable cause....," however, in the specific points under the subheading, it was stated that "officers may arrest if victims do not want an arrest made.” These considerations highlight the difficulty of relying on the wording of written policies.

The majority of departments surveyed did, in fact, have specific domestic violence policies in 2000. Only 6\% of respondents reported having no policy. The vast majority of departments with policies had developed their own policies (85\%), while 5\% of departments reported following their state's model policy. An additional 5\% stated that they copied their policy from another department, typically a neighboring and/or larger jurisdiction. Five percent declined to provide a copy of their policies.

\section{Relationship of Policies to State Statute}

One of the questions we addressed was the extent to which agency policy varied from statutory arrest requirements. Of the 282 departments included in the sample, 234 or $83 \%$, of the respondents were able to provide us with policy information for the year 2000. According to Table 8.1, the overwhelming majority of agencies in states with a mandatory arrest policy also have mandatory arrest policies in place. The consistency between state and agency policies in states with mandatory arrest statutes is expected, as a less restrictive policy could potentially create difficulties for departments failing to comply with such mandates as well as potential liability. While some agencies that indicate a discretionary or preferred arrest policy were in a state with mandatory arrest statutes, it is possible that this finding is a function of how the wording in the policy was interpreted for purposes of coding. In addition, departments may use 
flexible wording, but during police training on policies, explain that arrest is mandated. Several departments visited during site visits did in fact provide training curricula and course manuals that were far more rigid than state statute or policy requirements.

Table 8.1

Police Department Arrest Policy by State Warrantless Arrest Law

\begin{tabular}{|ll|r|r|r|r|}
\hline & & \multicolumn{3}{|c|}{ State Domestic Violence Law } & \\
\cline { 2 - 5 } & & Mandatory & Preferred & Discretionary & \multicolumn{1}{c|}{ Total } \\
\hline \multirow{2}{*}{$\begin{array}{l}\text { Agency } \\
\text { Policy }\end{array}$} & Mandatory & 70 & 5 & 20 & 95 \\
& & $94.6 \%$ & $12.5 \%$ & $16.7 \%$ & $40.6 \%$ \\
\cline { 2 - 5 } & Preferred & 3 & 29 & 66 & 98 \\
& & $4.1 \%$ & $72.5 \%$ & $55.0 \%$ & $41.9 \%$ \\
\cline { 2 - 5 } & Discretionar. & $1.4 \%$ & $15.0 \%$ & $28.3 \%$ & $17.5 \%$ \\
\hline Total & 74 & 40 & 120 & 234 \\
& & $100.0 \%$ & $100.0 \%$ & $100.0 \%$ & $100.0 \%$ \\
\hline
\end{tabular}

As expected, the less predictable results are for agencies in preferred and discretionary arrest states. Most agencies in preferred states indicated that they also followed a preferred arrest policy (72.5\%). The remaining agencies were closely divided between mandatory (12.5\%) and discretionary (15\%) policies.

Discretionary states showed the largest variation in agency policies. Only $28.3 \%$ of the agencies in discretionary law states indicated that they followed a discretionary arrest policy. The majority of agencies (55\%) claimed that they followed a preferred policy and an additional 16.7\% reported that they follow a mandatory arrest policy. These results suggest that in mandatory and preferred arrest states, most agencies follow policy similar to that prescribed by the state. For discretionary agencies, however, there was much less compatibility between state 
and agency defined policies, and the findings suggest that the vast majority of these departments adopt more pro-active arrest policies than mandated by statute.

\section{Relationship between State Statute and Policy Arrest Policies and Arrest Practices}

We also explored whether arrest levels differed based on whether we used the statute based arrest practice to define each agency as mandatory, preferred or discretionary or the agency defined policy (mandatory, preferred, discretionary) as indicated in the survey. A onesample t-test was conducted with the state law defined arrest proportions as the test value. This analysis provided further insight as to the relative significance of statutory requirements compared to agency policy requirements by determining if compatible definitions are reflected in arrest outcomes.

Table 8.2 compares the arrest proportions for mandatory agencies when defined by state law and agencies when defined as mandatory according to the agency survey. Arrest proportions are included for all arrests, female arrests, dual arrests, and female involved dual arrests. There was little variation in the means of arrest proportions for state law versus agency policy mandatory arrest practices and the one-sample t-test revealed no significant differences in arrest proportions. This may a result of the small number of agencies in preferred and discretionary states that indicated a mandatory arrest policy. There is significant overlap in the agencies included in each group, so it is not surprising that mandatory state law and agency defined mandatory arrest policies have similar arrest proportions. 
This document is a research report submitted to the U.S. Department of Justice. This report has not been published by the Department. Opinions or points of view expressed are those of the author(s) and do not necessarily reflect the official position or policies of the U.S. Department of Justice.

Table 8.2 Comparison of Arrest Proportions - Mandatory State Law with Agency Defined Mandatory Policy

\begin{tabular}{|c|c|c|c|c|c|c|}
\hline \multirow[b]{2}{*}{ Agg. Assault } & \multirow[b]{2}{*}{ Intimate Partner } & \multicolumn{2}{|c|}{ Mandatory Law } & \multicolumn{2}{|c|}{ Mandatory Agency } & \multirow[b]{2}{*}{$\left({ }^{\star} \mathrm{p}<.05\right)$} \\
\hline & & Mean & Agencies & Mean & Agencies & \\
\hline & All arrests & 0.76 & 67 & 0.76 & 74 & \\
\hline & Dual Arrests & 0.04 & 63 & 0.04 & 71 & \\
\hline & Female Arrests & 0.30 & 63 & 0.28 & 71 & \\
\hline & Female Dual Arrests & 0.97 & 19 & 0.98 & 21 & \\
\hline & Other Domestic & & & & & \\
\hline & All arrests & 0.69 & 58 & 0.66 & 61 & \\
\hline & Dual Arrests & 0.04 & 53 & 0.04 & 56 & \\
\hline & Female Arrests & 0.30 & 53 & 0.31 & 56 & \\
\hline & Female Dual Arrests & 0.70 & 12 & 0.71 & 11 & \\
\hline & Acquaintence & & & & & \\
\hline & All arrests & 0.62 & 72 & 0.61 & 80 & \\
\hline & Dual Arrests & 0.02 & 67 & 0.02 & 74 & \\
\hline & Female Arrests & 0.18 & 67 & 0.18 & 74 & \\
\hline & Female Dual Arrests & 0.57 & 15 & 0.63 & 10 & \\
\hline & Stranger & & & & & \\
\hline & All arrests & 0.54 & 46 & 0.55 & 54 & \\
\hline & Dual Arrests & 0.01 & 42 & 0.01 & 48 & \\
\hline & Female Arrests & 0.15 & 42 & 0.14 & 48 & \\
\hline & Female Dual Arrests & 0.00 & 2 & 0.00 & 2 & \\
\hline \multirow[t]{20}{*}{ Sim. Assault } & Intimate Partner & & & & & \\
\hline & All arrests & 0.70 & 84 & 0.70 & 93 & \\
\hline & Dual Arrests & 0.08 & 82 & 0.08 & 90 & \\
\hline & Female Arrests & 0.21 & 82 & 0.22 & 90 & \\
\hline & Female Dual Arrests & 0.99 & 48 & 0.99 & 56 & \\
\hline & Other Domestic & & & & & \\
\hline & All arrests & 0.60 & 79 & 0.60 & 87 & \\
\hline & Dual Arrests & 0.34 & 76 & 0.34 & 85 & \\
\hline & Female Arrests & 0.08 & 76 & 0.07 & 85 & \\
\hline & Female Dual Arrests & 0.61 & 35 & 0.63 & 33 & \\
\hline & Acquaintence & & & & & \\
\hline & All arrests & 0.51 & 83 & 0.50 & 92 & \\
\hline & Dual Arrests & 0.05 & 80 & 0.05 & 89 & \\
\hline & Female Arrests & 0.30 & 80 & 0.29 & 89 & \\
\hline & Female Dual Arrests & 0.15 & 10 & 0.08 & 10 & \\
\hline & Stranger & & & & & \\
\hline & All arrests & 0.47 & 69 & 0.48 & 78 & \\
\hline & Dual Arrests & 0.02 & 59 & 0.02 & 68 & \\
\hline & Female Arrests & 0.43 & 47 & 0.40 & 53 & \\
\hline & Female Dual Arrests & 0.51 & 10 & 0.36 & 10 & \\
\hline \multirow[t]{20}{*}{ Intimidation } & Intimate Partner & & & & & \\
\hline & All arrests & 0.45 & 65 & 0.40 & 71 & \\
\hline & Dual Arrests & 0.03 & 57 & 0.02 & 54 & \\
\hline & Female Arrests & 0.11 & 57 & 0.09 & 54 & \\
\hline & Female Dual Arrests & 1.00 & 8 & 1.00 & 7 & \\
\hline & Other Domestic & & & & & \\
\hline & All arrests & 0.45 & 53 & 0.42 & 54 & \\
\hline & Dual Arrests & 0.03 & 41 & 0.03 & 40 & \\
\hline & Female Arrests & 0.21 & 41 & 0.22 & 40 & \\
\hline & Female Dual Arrests & 0.33 & 4 & 0.33 & 4 & \\
\hline & Acquaintence & & & & & \\
\hline & All arrests & 0.34 & 72 & 0.30 & 78 & \\
\hline & Dual Arrests & 0.00 & 58 & 0.00 & 59 & \\
\hline & Female Arrests & 0.19 & 58 & 0.20 & 59 & \\
\hline & Female Dual Arrests & 0.67 & 4 & 0.56 & 3 & \\
\hline & Stranger & & & & & \\
\hline & All arrests & 0.31 & 50 & 0.29 & 56 & \\
\hline & Dual Arrests & 0.01 & 35 & 0.01 & 32 & \\
\hline & Female Arrests & 0.22 & 35 & 0.21 & 32 & \\
\hline & Female Dual Arrests & 0.00 & 1 & 0.00 & 1 & \\
\hline
\end{tabular}


Table 8.3 includes the results for the comparison of statute defined preferred arrest laws and agency defined preferred policies. For aggravated assaults, there were no differences in arrest proportions involving intimate partners. Other domestics reveal that dual arrest and female arrests are significantly lower in the preferred agency category. No differences were observed for acquaintances and strangers. For other domestics, dual arrests are significantly higher in legally defined preferred agencies.

Cases involving simple assaults show that dual arrests are slightly lower in preferred agencies for intimate partners. No significant differences were observed for other domestics. Acquaintance and stranger cases show that all arrests are lower in preferred agencies. Many of the t-test comparisons in this category could not be computed due to small cases or lack of variation. Several differences are worth noting. For intimate partner and acquaintance incidents, all arrests and female arrests are significantly lower in agencies with preferred arrest policies. No significant differences emerged in stranger cases. The finding that arrest rates are lower in agencies with preferred arrest policies may be a result of the number of agencies in discretionary states defining their local policy as preferred according to the survey. In discretionary arrest states, 55\% of the agencies in discretionary states defined their local policy as preferred and $16.7 \%$ as mandatory. Therefore, it is possible that these agencies still embrace less restrictive arrest practices resulting in lower arrest rates.

Table 8.4 includes the results for the arrest proportion comparison of state defined discretionary arrest law and agency defined discretionary policies. Few significant differences were observed. For aggravated assaults, the only significant difference is for all arrests involving other domestics. In this case, legally defined discretionary arrest proportions are lower than 
This document is a research report submitted to the U.S. Department of Justice. This report has not been published by the Department. Opinions or points of view expressed are those of the author(s) and do not necessarily reflect the official position or policies of the U.S. Department of Justice.

Table 8.3 Comparison of Arrest Proportions - Preferred State Law and Agency Defined Preferred Policy

\section{Preferred Law}

Agg.Ass.

Agg.Ass.

Sim. Ass.

Intimidation

Female Dual Arrests

38

38
33

33

11

11

29

29
27

27

6

Intimate Partner
All arrests
Dual Arrests
Female Arrests
Female Dual Arrests
Other Domestic

Dual Arrests

Female Arrests

Female Dual Arrests

Acquaintence

All arrests

Dual Arrests

Female Arrests

Stranger

All arrests

Dual Arrests

Female Arrests

Female Dual Arrests Intimate Partner

All arrests

Dual Arrests

Female Arrests

Female Dual Arrests

Mean

0.63

0.05

0.35

1.00

0.60

0.07

0.31

0.33

0.51

0.00

0.20

1.00

0.41

0.00

0.18

0.00

0.56

0.03

0.15

0.99

Other Domestic

All arrests

Dual Arrests

Female Arrests

Female Dual Arrests

Acquaintence

All arrests

Dual Arrests

Female Arrests

Female Dual Arrests

Stranger

All arrests

Dual Arrests

Female Arrests

Female Dual Arrests

Intimate Partner

All arrests

Dual Arrests

Female Arrests

Female Dual Arrests

Other Domestic

All arrests

Dual Arrests

Female Arrests

Female Dual Arrests

Acquaintence

All arrests

Dual Arrests

Female Arrests

Female Dual Arrests

Stranger

All arrests

Dual Arrests

Female Arrests

Female Dual Arrests

0.44

0.25

0.00

0.29

0.16

0.00

0.03

1.00
Agencies

Preferred Agency

Mean

0.57

0.03

0.31

1.00

0.56

0.03

0.23

0.15

Agencies $\quad \begin{aligned} & \text { T-test Sig. } \\ & \left({ }^{*} \mathrm{p}<<.05\right)\end{aligned}$

81

71

71

13

67

59

59

$$
9
$$

0.46

0.00

0.14

0.50

0.42

0.00

0.12

0.00

0.51

0.02

0.16

0.95

0.44

0.33

0.02

0.42

0.24

0.01

0.26

0.06

0.32

0.00

0.27

0.50

0.12

0.00

0.05

1.00

0.10

0.00

0.39

13

13

\section{7}

0.11

0.00

0.17

47

47

25
10
10
1

0.10

56

0.00

18

0.18

18 


\begin{tabular}{|c|c|c|c|c|c|c|}
\hline \multirow[b]{2}{*}{ Agg. Assault } & \multirow[b]{2}{*}{ Intimate Partner } & \multicolumn{2}{|c|}{ Discretionary Law } & \multicolumn{2}{|c|}{ Discretionary Policy } & \multirow{2}{*}{$\begin{array}{r}\text { t-test } \\
* \mathrm{p}<-05\end{array}$} \\
\hline & & Mean & Agencies & Mean & Agencies & \\
\hline & All arrests & 0.62 & 108 & 0.76 & 27 & \\
\hline & Dual Arrests & 0.02 & 96 & 0.01 & 23 & \\
\hline & Female Arrests & 0.28 & 96 & 0.24 & 23 & \\
\hline & Female Dual Arrests & 1.00 & 13 & 1.00 & 3 & \\
\hline & \multicolumn{6}{|l|}{ Other Domestic } \\
\hline & All arrests & 0.60 & 86 & 0.77 & 21 & * \\
\hline & Dual Arrests & 0.01 & 75 & 0.03 & 20 & \\
\hline & Female Arrests & 0.20 & 75 & 0.22 & 20 & \\
\hline & Female Dual Arrests & 0.07 & 5 & 0.50 & 1 & \\
\hline & \multicolumn{6}{|l|}{ Acquaintence } \\
\hline & All arrests & 0.51 & 117 & 0.57 & 30 & \\
\hline & Dual Arrests & 0.01 & 103 & 0.01 & 24 & \\
\hline & Female Arrests & 0.16 & 103 & 0.22 & 24 & \\
\hline & Female Dual Arrests & 0.25 & 4 & 0.00 & 1 & \\
\hline & \multicolumn{6}{|l|}{ Stranger } \\
\hline & All arrests & 0.49 & 78 & 0.49 & 15 & \\
\hline & Dual Arrests & 0.00 & 63 & 0.00 & 9 & \\
\hline & Female Arrests & 0.08 & 63 & 0.05 & 9 & \\
\hline & \multicolumn{6}{|l|}{ Female Dual Arrests } \\
\hline \multirow{20}{*}{ Simple Assault } & \multicolumn{6}{|l|}{ Intimate Partner } \\
\hline & All arrests & 0.61 & 138 & 0.68 & 37 & \\
\hline & Dual Arrests & 0.05 & 134 & 0.11 & 33 & * \\
\hline & Female Arrests & 0.21 & 134 & 0.25 & 33 & \\
\hline & Female Dual Arrests & 0.97 & 54 & 0.98 & 16 & \\
\hline & \multicolumn{6}{|l|}{ Other Domestic } \\
\hline & All arrests & 0.50 & 127 & 0.47 & 30 & \\
\hline & Dual Arrests & 0.32 & 116 & 0.40 & 23 & \\
\hline & Female Arrests & 0.01 & 116 & 0.02 & 23 & \\
\hline & Female Dual Arrests & 0.46 & 19 & 0.33 & 3 & \\
\hline & \multicolumn{6}{|l|}{ Acquaintence } \\
\hline & All arrests & 0.34 & 142 & 0.48 & 38 & * \\
\hline & Dual Arrests & 0.03 & 125 & 0.04 & 34 & \\
\hline & Female Arrests & 0.25 & 125 & 0.26 & 34 & \\
\hline & Female Dual Arrests & 0.14 & 4 & 0.06 & 1 & \\
\hline & \multicolumn{6}{|l|}{ Stranger } \\
\hline & All arrests & 0.41 & 109 & 0.51 & 26 & \\
\hline & Dual Arrests & 0.01 & 83 & 0.03 & 18 & \\
\hline & Female Arrests & 0.37 & 67 & 0.62 & 12 & * \\
\hline & Female Dual Arrests & 0.50 & 5 & 1.00 & 2 & \\
\hline \multirow[t]{19}{*}{ Intimidation } & Intimate Partner & & & & & \\
\hline & All arrests & 0.15 & 95 & 0.33 & 16 & \\
\hline & Dual Arrests & 0.01 & 46 & 0.00 & 10 & \\
\hline & Female Arrests & 0.03 & 46 & 0.20 & 10 & \\
\hline & Female Dual Arrests & 1.00 & 1 & & & \\
\hline & \multicolumn{6}{|l|}{ Other Domestic } \\
\hline & All arrests & 0.17 & 55 & 0.43 & 8 & \\
\hline & Dual Arrests & 0.00 & 16 & 0.00 & 6 & \\
\hline & Female Arrests & 0.18 & 16 & 0.17 & 6 & \\
\hline & Female Dual Arrests & & & & & \\
\hline & Acquaintence & & & & & \\
\hline & All arrests & 0.17 & 111 & 0.30 & 27 & \\
\hline & Dual Arrests & 0.00 & 62 & 0.00 & 13 & \\
\hline & Female Arrests & 0.14 & 62 & 0.12 & 13 & \\
\hline & Female Dual Arrests & & & & & \\
\hline & Stranger & & & & & \\
\hline & All arrests & 0.17 & 64 & 0.45 & 10 & \\
\hline & Dual Arrests & 0.00 & 22 & 0.00 & 6 & \\
\hline & Female Arrests & 0.18 & 22 & 0.08 & 6 & \\
\hline
\end{tabular}


policy defined discretionary agencies. For simple assaults, dual arrests were higher for intimate partner cases in discretionary policy agencies and for acquaintances all arrest proportions were higher in discretionary policy agencies. The findings from Table 8.4 should be interpreted with caution. Not only is the number of agencies small in our agency defined discretionary group, but many of the agencies had a very small numbers of cases. Small numbers of cases will heavily influence the proportion of arrests toward higher levels and may account for these findings.

These results suggest that for mandatory arrest practices, there is no difference in the proportion of arrests depending upon which agency definition is used. For preferred arrest practices, our results show that statute defined agencies were more favorable than policy defined agencies toward arrest for all arrests, female arrests and dual arrest in intimate partner cases involving simple assaults and intimidation, but not aggravated assault. Discretionary arrest practices revealed few significant differences, but tended to show higher arrests for agencydefined policy than state defined policy.

Although we did not identify a large number of significant differences in arrest proportions depending upon how the agency arrest practices are defined (statute vs. policy), it could be that there is significant variation within states depending upon how agencies document their arrest policies. To explore this possibility, we examined the variation in agency policies within discretionary states since that is where much of the variation in policies exists. As noted, there was little variation in policies for agencies within mandatory and preferred arrest states (see Table 8.1). To determine if observed differences were significant, we conducted an analysis of variance with post-hoc comparisons where variances were assumed to be unequal. In order to address the small number of cases observed in the prior analysis, we did not break out the arrest proportions by offense type. Instead, we compared the proportions of arrests, dual arrests, 
female arrests and female dual arrest controlling for victim-offender relationship (intimate partner, other domestic, acquaintance and strangers).

The results are reported in Table 8.5. For intimate partner cases there are some differences worth noting. For all arrests, arrest proportions for preferred agencies were significantly less than those in mandatory and discretionary agencies. For dual arrests, preferred agencies have significantly higher dual arrest proportions than mandatory and discretionary agencies. Female arrests in intimate partner incidents were significantly higher for mandatory agencies than preferred agencies. There were no significant differences for other domestic incidents. In the acquaintance category, mandatory and discretionary agencies had significantly higher overall arrest proportions than preferred agencies. Overall arrests were significantly

\begin{tabular}{|c|c|c|c|c|c|c|c|c|c|c|}
\hline & \multicolumn{10}{|c|}{ Table 8.5 Arrest Proportions For Agency Arrest Policies within Discretionary States } \\
\hline & \multicolumn{3}{|c|}{ Mandatory } & \multicolumn{3}{|c|}{ Preferred } & \multicolumn{3}{|c|}{ Discretionary } & \multirow[t]{2}{*}{ Post Hoc Comparisons* } \\
\hline & Mean & $\mathrm{N}$ & S.D. & Mean & $\mathrm{N}$ & S.D. & Mean & $\mathrm{N}$ & S.D. & \\
\hline \multicolumn{11}{|l|}{ Intimate Partner } \\
\hline All Arrests & 0.651 & 20 & 0.212 & 0.497 & 66 & 0.226 & 0.682 & 32 & 0.281 & \multirow{4}{*}{$\begin{array}{c}\text { mand./pref.* disc./pref.* } \\
\text { mand./pref.* disc./pref.* } \\
\text { mand./pref.* }\end{array}$} \\
\hline Dual Arrests & 0.085 & 20 & 0.085 & 0.011 & 65 & 0.022 & 0.093 & 29 & 0.123 & \\
\hline Female Arrests & 0.258 & 20 & 0.098 & 0.163 & 65 & 0.107 & 0.248 & 29 & 0.219 & \\
\hline Female Dual Arrest & 0.994 & 14 & 0.022 & 0.935 & 18 & 0.237 & 0.976 & 14 & 0.089 & \\
\hline \multicolumn{11}{|l|}{ Other Domestic } \\
\hline All Arrests & 0.529 & 20 & 0.269 & 0.448 & 63 & 0.249 & 0.598 & 26 & 0.321 & \\
\hline Dual Arrests & 0.004 & 20 & 0.012 & 0.013 & 59 & 0.031 & 0.016 & 24 & 0.053 & \\
\hline Female Arrests & 0.269 & 20 & 0.201 & 0.322 & 59 & 0.264 & 0.339 & 24 & 0.400 & \\
\hline Female Dual Arrest & 0.750 & 2 & 0.354 & 0.330 & 14 & 0.426 & 0.333 & 3 & 0.289 & \\
\hline \multicolumn{11}{|l|}{ Acquaintances } \\
\hline All Arrests & 0.403 & 20 & 0.249 & 0.210 & 65 & 0.207 & 0.490 & 33 & 0.315 & \multirow[t]{4}{*}{ mand./pref.* disc./pref.* } \\
\hline Dual Arrests & 0.035 & 20 & 0.077 & 0.008 & 59 & 0.021 & 0.036 & 31 & 0.067 & \\
\hline Female Arrests & 0.195 & 20 & 0.146 & 0.219 & 59 & 0.209 & 0.231 & 31 & 0.232 & \\
\hline Female Dual Arrest & 0.375 & 8 & 0.518 & 0.599 & 10 & 0.453 & 0.494 & 9 & 0.441 & \\
\hline \multicolumn{11}{|l|}{ Stranger } \\
\hline All Arrests & 0.372 & 20 & 0.334 & 0.303 & 55 & 0.295 & 0.533 & 24 & 0.390 & \multirow[t]{4}{*}{ disc./pref.* } \\
\hline Dual Arrests & 0.013 & 16 & 0.039 & 0.000 & 45 & 0.000 & 0.021 & 18 & 0.079 & \\
\hline Female Arrests & 0.145 & 16 & 0.172 & 0.159 & 45 & 0.200 & 0.166 & 18 & 0.224 & \\
\hline Female Dual Arrest & 0.000 & 2 & 0.000 & 0.000 & 0 & 0.000 & 1.000 & 2 & 0.000 & \\
\hline
\end{tabular}


higher in discretionary than preferred agencies for incidents involving strangers. The higher rates among the discretionary group may be a reflection of the small number of cases reported in many of these agencies, which may tend to drive up arrest proportions.

Primary aggressor instruction was also considered as a possible factor in explaining variation in agency arrest rates. Table 8.6 shows that state and agency policies regarding primary aggressor are not always consistent. In states that do not have primary aggressor instruction, $44.1 \%$ of the agencies reported that their agency did in fact have primary aggressor instruction. Interestingly, in states that do have statute based primary aggressor instruction, 19.3\% reported that their policies did not have primary aggressor instruction.

Table 8.6

Comparison of State v. Agency Primary Aggressor Instruction

\begin{tabular}{|ll|r|r|r|}
\hline & & \multicolumn{2}{|c|}{$\begin{array}{c}\text { State Primary Aggressor } \\
\text { Instruction }\end{array}$} & \\
\cline { 3 - 4 } & & \multicolumn{1}{|c|}{ No } & \multicolumn{1}{c|}{ Yes } & \multicolumn{1}{c|}{ Total } \\
\hline Agency Policy Instructs \\
on Primary Aggressor & Yes & 52 & 67 & 119 \\
& & $44.1 \%$ & $80.7 \%$ & $59.2 \%$ \\
\cline { 2 - 5 } & No & 66 & 16 & 82 \\
& & $55.9 \%$ & $19.3 \%$ & $40.8 \%$ \\
\hline Total & & 118 & 83 & 201 \\
& & $100.0 \%$ & $100.0 \%$ & $100.0 \%$ \\
\hline
\end{tabular}

According to Table 8.7, there are significant differences in the arrest proportions in states that have no primary aggressor instruction in the statute. In states without statutory mandates, agencies that reported no primary aggressor instruction had significantly higher arrest proportions and dual arrest proportions for intimate partner cases, other domestics, and acquaintances. All arrests were also higher for stranger cases. In contrast, there was only one significant difference observed for agencies in states that have statute based primary aggressor instruction. In these agencies, arrests for other domestic cases show lower arrest proportions in agencies that reported no agency based primary aggressor instruction. 
The differences in dual arrest rates in intimate partner violence cases are striking.

Agencies in states without primary aggressor laws that have policies with mandates to identify primary aggressors and specific instruction as to their identification reported a dual arrest rate of $2 \%$ in intimate partner violence cases (Table 8.7). This is a rate that is equal to that reported by agencies in states with primary aggressor laws and less than a quarter of the dual arrest rate of 9\% observed in jurisdictions that operated in states without primary aggressor laws and did not provide primary aggressor instruction.

\begin{tabular}{|c|c|c|c|c|c|c|c|c|c|c|}
\hline \multirow{3}{*}{ Agency primary aggressor $\mathrm{i}$} & \multicolumn{5}{|c|}{ No state primary aggressor instruction } & \multicolumn{5}{|c|}{ State primary aggressor instruction } \\
\hline & \multicolumn{2}{|c|}{ Yes } & \multicolumn{3}{|c|}{ No } & \multicolumn{2}{|c|}{ Yes } & \multicolumn{2}{|c|}{ No } & \\
\hline & Mean & $\mathrm{N}$ & Mean & $\mathrm{N}$ & & Mean & $\mathrm{N}$ & Mean & $\mathrm{N}$ & \\
\hline \multicolumn{11}{|l|}{ Intimate Partner } \\
\hline All Arrests & 0.50 & 52 & 0.65 & 64 & * & 0.58 & 64 & 0.55 & 14 & \\
\hline Dual Arrests & 0.02 & 51 & 0.09 & 63 & * & 0.03 & 62 & 0.02 & 12 & \\
\hline Female Arrests & 0.19 & 51 & 0.23 & 63 & & 0.19 & 62 & 0.19 & 12 & \\
\hline Female Dual Arrest & 1.00 & 12 & 0.95 & 41 & & 0.99 & 34 & 1.00 & 3 & \\
\hline \multicolumn{11}{|l|}{ Other Domestic } \\
\hline All Arrests & 0.43 & 50 & 0.58 & 61 & * & 0.52 & 61 & 0.35 & 13 & * \\
\hline Dual Arrests & 0.01 & 45 & 0.05 & 61 & * & 0.05 & 61 & 0.02 & 9 & \\
\hline Female Arrests & 0.34 & 45 & 0.33 & 61 & & 0.32 & 61 & 0.26 & 9 & \\
\hline Female Dual Arrest & 0.35 & 9 & 0.52 & 21 & & 0.57 & 25 & 0.50 & 1 & \\
\hline \multicolumn{11}{|l|}{ Acquaintances } \\
\hline All Arrests & 0.21 & 52 & 0.43 & 63 & * & 0.39 & 65 & 0.42 & 14 & \\
\hline Dual Arrests & 0.01 & 47 & 0.04 & 62 & * & 0.03 & 62 & 0.01 & 12 & \\
\hline Female Arrests & 0.22 & 47 & 0.22 & 62 & & 0.25 & 62 & 0.26 & 12 & \\
\hline Female Dual Arrest & 0.67 & 9 & 0.36 & 23 & & 0.69 & 26 & 1.00 & 1 & \\
\hline \multicolumn{11}{|l|}{ Stranger } \\
\hline All Arrests & 0.30 & 44 & 0.43 & 57 & * & 0.44 & 59 & 0.36 & 10 & \\
\hline Dual Arrests & 0.00 & 34 & 0.02 & 48 & & 0.01 & 55 & 0.02 & 8 & \\
\hline Female Arrests & 0.17 & 34 & 0.16 & 48 & & 0.17 & 55 & 0.25 & 8 & \\
\hline Female Dual Arrest & 0.02 & 1 & 0.08 & 5 & & 0.03 & 8 & 0.00 & 1 & \\
\hline
\end{tabular}

This suggests that the existence of department policies requiring officers to identify primary aggressors is of particular importance in preventing dual arrest in states where there are no statutory mandates. However, it is uncertain why there is a lower overall arrest rate in states with such a provision. It is possible that while officers are mandated to identify a primary 
aggressor, there is insufficient instruction as to how the primary aggressor is to be identified.

Therefore, officers concerned with complying with a policy requirement are hesitant to make an arrest in a situation where they are uncertain what criteria to follow. For example, in one department the researchers visited, a sergeant reported that officers were trained to arrest all violent parties, which meant anyone using violence, while at the same time, ensuring that they identify a primary aggressor.

In summary, it appears that police policies primarily reflect statutory intent for mandatory and preferred states. Agencies within discretionary states show a clear trend toward more restrictive arrest practices. The impact of definitional differences on arrest proportions are less clear. Arrest proportions were largely similar when state vs. agency comparisons are made for mandatory and discretionary definitions. However, given that many agencies within discretionary states reported a preferred policy, significant differences were observed when preferred state defined agencies were compared to agency defined preferred policies. Agency defined preferred agencies tended to have lower arrest proportions than state defined preferred agencies for certain groups.

There are limitations to what could be done with the policy data collected. It is very possible that departments sampled who declined to provide us with policy information may significantly impact findings. After all, they may be concerned about their failure to have a policy when mandated by statute or having a policy that might be questioned upon further examination. The researchers intend to further explore whether arrest rates among respondents compared to those not responding in the sample differed significantly for the criteria discussed.

The sample size limited the type of analysis that could be conducted, and enlarging the sample size could be helpful in order to further an understanding of how departments with 
similar policies in the same state differed in arrest practices. This is possible for several reasons. First, departments often fail to disseminate relevant policies, as well as legislative mandates. Second, the significance of these policies may be minimized through both pre-service and inservice training programs. Many officers in departments with differing policies attend the same in-service and/or pre-service domestic violence training programs. This may mask the potential impact of policy variations. Third, organizational variations including the implementation of policies and strategies for dissemination may cause variations among departments with similar policies. Fourth, political influences and the community culture may impact how officers are expected to interpret policies. Finally, police organizational culture and street level practices may allow police a variety of strategies to subvert policies that are not supported by officers such as call screening and downgrading or re-defining calls. As can be surmised, such practices would not be fully revealed in any size sample relying on official data as these cases would not become part of any data base. 


\section{Chapter 9 \\ Factors Impacting the Likelihood of Arrest: Phase II Data}

In chapter seven we indicated that some key variables were missing from the NIBRS dataset that might help explain the differences we observed in police arrest practices. These variables include whether the offender was on the scene when the police arrived, who reported the incident, the exact nature of injuries suffered by the involved parties, victim and offender substance use, offender demeanor, and presence of children. In this chapter we first describe how we selected the sites for Phase II and obtained the data we were seeking. We then present our descriptive findings and, using logistic regression, examine the effect these key variables had on the decision to arrest.

\section{Site Selection}

A critical part of our task was to maximize the relevance of our findings and policy implications for other police departments. A frequent criticism of research on police arrest practices is that the focus is almost exclusively on large police departments that do not typify policing in the United States. With the dual goals of promoting diversity among the selected Phase II sites, and enhancing the generalizability of our findings, we used the following procedures for selecting police jurisdictions for Phase II data collection.

(1) We selected, in each of the four selected states (Connecticut, Idaho, Tennessee and Virginia), two medium to large jurisdictions that varied from each other in potential dual arrest, actual dual arrest, and overall arrest rates to serve as "core” sites. Medium to large jurisdictions were operationally defined as jurisdictions that had a population of at least 100,000 and had generated at least 300 domestic violence cases in 2000.

(2) For each of the core jurisdictions (eight total), we then selected at least one additional police jurisdiction that was located near that jurisdiction to serve as "satellite" sites. To qualify as 
satellite jurisdiction, a jurisdiction could not also have qualified as a core site. "Being near” was operationally defined as being within a radius of 25 miles of the boundaries of the core site. When more than two sites qualified as a satellite, the project staff chose sites with the greatest number of dual arrests, or sites that maximized the diversity of the sites visited.

(3) Since the success of Phase II of the project was dependent on the quality of the data that were obtained, an additional criterion for site selection focused on the extent and quality of the police and court data that were available. Project staff conducted telephone interviews with informed people in each jurisdiction to assess the site's data quality.

\section{Case Sample Selection}

Since we wanted to be able to draw inferences about both medium to large (represented by the core) and small (represented by the satellite) jurisdictions we sampled cases from each of the participating core and satellite jurisdictions. Our analysis of Phase I data had clearly indicated that the jurisdictions were not producing large numbers of dual arrest cases. Consequently, we included all of the selected jurisdictions' dual arrest cases in both the core and satellite sites. Since there were far larger numbers of single and no arrest cases, we pooled the single and no arrest cases in each jurisdiction and, using the SPSS sampling program, produced a randomly generated sample of about 220 single and no arrest cases from each core jurisdiction and the satellite jurisdiction. To address potential difficulty locating files for all chosen cases, we over-sampled so that, unless there was a significant problem with missing cases, we would not have to construct a replacement sample. The proportion of cases sampled varied from jurisdiction to jurisdiction, but we kept the proportion of cases sampled from satellite sites within a particular jurisdiction constant. Because of the small number of cases in these jurisdictions we 
needed to include the full population of single and no arrest cases (as well as all dual arrest cases) in 8 of the 17 satellite jurisdictions.

\section{Site Recruitment}

Obtaining access to the selected police departments turned out to be a highly timeconsuming process. Initial contact with the departments was made by sending out letters to the police chiefs explaining the purpose of the study and what we were seeking from the police department. Follow up calls were then made and negotiations ensued. Confidentiality was a major concern. For the most part this concern was alleviated by providing appropriate documentation that included copies of both the Human Subjects Protection Assurance form that we filed with the original grant proposal and the most recent of the University of Massachusetts at Lowell’s IRB approval letters. Obtaining permission took from a few weeks in some jurisdictions to months in others. Once permission to obtain the required data had been obtained, arrangements were made for site visits.

Though obtaining permission from the individual police departments was complex and time consuming, most of the police departments that were contacted ultimately agreed to participate in the study. One department could not participate because it was moving location. A second department was not involved in the study because of confidentiality concerns. A third department cited time constraints. Ultimately, we sought and obtained permission to obtain police data in eight core sites and 17 satellite sites: five in Idaho and four each in Connecticut, Tennessee, and Virginia. An additional police department agreed to participate in the study, but provided reports with so much information blacked out that the reports could not be used for data analysis. 


\section{On Site Data Collection and Management}

Each site was sent a list of selected cases prior to the site visit and asked to make copies of all incident, arrest and supplemental case reports for our project staff. Sites were also asked to provide copies of training and policy documents, and to be interviewed to obtain background information on the department's approach to domestic violence. All of the information about the incident and the police response to the incident was obtained directly from the involved police departments. Data were abstracted from these forms to determine incident characteristics, criminal history, and court case processing.

We found that the police reports, which varied both in format and content across jurisdictions, contained detailed information on the selected cases. Some police departments also provided requested information about the court processing of the arrest cases as well as details of criminal histories. In some cases, this information was provided by other county agencies. In two of the four states, Connecticut and Virginia, there are well-established state criminal history record systems administered by the State Police and this information was obtained through these agencies.

Obtaining the court processing information and the criminal histories was, as had been the case with obtaining the police reports, highly complex and time consuming. Problems with obtaining access, and concerns about the quality of any data that might be obtained, resulted in a decision not to collect these data in most of the jurisdictions in Tennessee.

A lengthy codebook was constructed and pretested so that data could be captured consistently across jurisdictions and computerized for analysis. This codebook contains six principal segments, each incorporating an array of variables pertaining to the incident, the victims, the offenders, the responding officers' actions, prosecution and court case processing, 
and victim and offender criminal histories. A team of trained research assistants coded the reports and the data were entered into an SPSS file. Inter-rater reliability was assessed by having different coders code the same cases. The Phase II data were merged with the Phase I data.

The socioeconomic background of the core and satellite jurisdictions that participated in Phase II is presented in Table 9.1. Reflecting the manner in which the two samples had been drawn, six (75\%) of the eight core jurisdictions had populations of 100,000 or more while only one (5.9\%) of the 17 satellite jurisdictions did. A total of 14 (83.2\%) of the 17 satellite jurisdictions had a population of less than 50,000. Despite these differences in population size, there was still a great deal of variation within both the core and satellite jurisdictions in terms of land area encompassed by the jurisdiction and population per square mile. While three (37.5\%) of the core jurisdictions covered less than 20 square miles, an equal number covered between 200 and 499 square miles. While nine (52.9\%) of the satellite jurisdictions encompassed less than 20 square miles, two (11.8\%) covered more than 500 square miles. Though there was a fair mix within both the core and satellite jurisdictions in terms of population per square mile, the core jurisdictions tended to be more densely populated. While two (25\%) of the core jurisdictions had over 300,000 persons per square mile, only one (5.9\%) of the satellite jurisdictions did (Table 9.1).

Table 9.1

Socioeconomic Background of the Phase II Core and Satellite Sites

\begin{tabular}{|c|c|c|}
\hline & CORE JURISDICTIONS & SATELLITE JURISDICTIONS \\
\hline & $\mathrm{N}=8$ & $\mathrm{~N}=17$ \\
\hline Population, 2000 & & $14 \quad(83.2 \%)$ \\
\hline Under 50,000 & $1 \quad(12.5 \%)$ & $2 \quad(11.8 \%)$ \\
\hline $50,000-99,999$ & $1 \quad(12.5 \%)$ & 0 \\
\hline $100,000-299,999$ & $4 \quad(50.0 \%)$ & 1 \\
\hline 300,000 or more & $2 \quad(5.9 \%)$ & \\
\hline
\end{tabular}




\begin{tabular}{|c|c|c|}
\hline & CORE JURISDICTIONS & SATELLITE JURISDICTIONS \\
\hline \multicolumn{3}{|l|}{ Land area, 2000 (squares miles) } \\
\hline under 20 square miles & $3 \quad(37.5 \%)$ & $9 \quad(52.9 \%)$ \\
\hline 21 to 49 square miles & $1 \quad(12.5 \%)$ & $6 \quad(35.3 \%)$ \\
\hline 50 to 199 square miles & $1 \quad(12.5 \%)$ & $(5.9 \%)$ \\
\hline 200 to 499 square miles & $3 \quad(37.5 \%)$ & 0 \\
\hline 500 and over & 0 & $\begin{array}{ll}2 & (11.8 \%) \\
\end{array}$ \\
\hline \multicolumn{3}{|l|}{ Persons per square miles, 2000} \\
\hline under 1,000 per square mile & $\begin{array}{ll}1 & (12.5 \%) \\
\end{array}$ & $\begin{array}{ll}5 & (29.4 \%) \\
\end{array}$ \\
\hline 1,000 to 1,999 per square mile & $2 \quad(25.0 \%)$ & $5 \quad(29.4 \%)$ \\
\hline 2,000 to 2,999 per square mile & $3 \quad(37.5 \%)$ & $6 \quad(35.3 \%)$ \\
\hline 3,000 and over per square mile & $2 \quad(25.0 \%)$ & $1 \quad(5.9 \%)$ \\
\hline \multicolumn{3}{|l|}{$\begin{array}{l}\text { Population, percent change, } \\
1990 \text { to } 2000\end{array}$} \\
\hline loss of more than $10 \%$ & 0 & $2 \quad(11.8 \%)$ \\
\hline loss of less than $10 \%$ & $2 \quad(25.0 \%)$ & $1 \quad(5.8 \%)$ \\
\hline increase of less than $10 \%$ & $1 \quad(12.5 \%)$ & $4 \quad(23.5 \%)$ \\
\hline increase of $10 \%$ to $29.9 \%$ & $\begin{array}{ll}4 & (50.0 \%) \\
\end{array}$ & $\begin{array}{ll}6 & (35.3 \%) \\
\end{array}$ \\
\hline increase of $30 \%$ or more & $1 \quad(12.5 \%)$ & $4 \quad(23.5 \%)$ \\
\hline \multicolumn{3}{|l|}{$\begin{array}{l}\text { Living in the same house in } 1995 \\
\text { and 2000, pct age 5+, } 2000\end{array}$} \\
\hline less than $40 \%$ & $1 \quad(12.5 \%)$ & $2 \quad(11.8 \%)$ \\
\hline $40 \%$ to $49.9 \%$ & $4 \quad(50.0 \%)$ & $7 \quad(41.2 \%)$ \\
\hline $50 \%$ to $69.9 \%$ & $3 \quad(37.5 \%)$ & $5 \quad(29.4 \%)$ \\
\hline $70 \%$ and over & 0 & $3 \quad(17.6 \%)$ \\
\hline \multicolumn{3}{|l|}{ White persons, percent, 2000} \\
\hline less than $50 \%$ & $2 \quad(25.0 \%)$ & $1 \quad(5.9 \%)$ \\
\hline $50 \%$ to $69.9 \%$ & $3 \quad(37.5 \%)$ & $1 \quad(5.9 \%)$ \\
\hline $70 \%$ to $89.9 \%$ & $1 \quad(12.5 \%)$ & $7 \quad(41.2 \%)$ \\
\hline $90 \%$ and over & $2 \quad(25.0 \%)$ & $8 \quad(47.1 \%)$ \\
\hline \multicolumn{3}{|l|}{ Persons below poverty, 1999} \\
\hline less than $10 \%$ & $3 \quad(37.5 \%)$ & $10 \quad(58.8 \%)$ \\
\hline $10 \%$ to $19.99 \%$ & $1 \quad(12.5 \%)$ & $7 \quad(41.2 \%)$ \\
\hline $20 \%$ and over & $4 \quad(50.0 \%)$ & 0 \\
\hline \multicolumn{3}{|l|}{$\begin{array}{l}\text { High school graduates or higher, } \\
\text { percent of persons age } 25+, 2000\end{array}$} \\
\hline under $70 \%$ & 0 & $2 \quad(11.8 \%)$ \\
\hline $70 \%$ to $79.9 \%$ & $3 \quad(37.5 \%)$ & $2 \quad(11.8 \%)$ \\
\hline $80 \%$ to $89.9 \%$ & $4 \quad(50.0 \%)$ & $8 \quad(47.1 \%)$ \\
\hline $90 \%$ and over & $1 \quad(12.5 \%)$ & $5 \quad(29.4 \%)$ \\
\hline
\end{tabular}


There was also considerable variation within both the core and satellite jurisdictions with regard to population mobility. While two (25\%) of the core and three (17.6\%) of the satellite jurisdictions evidenced a decrease in their overall population between 1990 and 2000, one (12.5\%) of the core jurisdictions and four (23.5\%) of the satellite jurisdictions saw a population increase of $30 \%$ or more. Not surprisingly a lower percentage of those in the core cities were living in the same house in 1995 and 2000. While none of the core jurisdictions had 70\% or more of their inhabitants living in the same house, three (17.6\%) of the satellite jurisdictions did.

With regard to socioeconomic variables, while there was diversity within the core and satellite jurisdictions, satellite jurisdictions were more likely than the core areas to be essentially comprised of whites. While eight (47.1\%) of the satellite jurisdictions had a population that was $90 \%$ or more white, only two (25\%) of the core jurisdictions did. The satellite jurisdictions were also less likely to have a high percentage of their population below the poverty level. None of the 17 satellite jurisdictions had more than $20 \%$ of their population below the poverty line, while two (25\%) of the core jurisdictions did. Finally, there was more diversity within the satellite jurisdiction than the core jurisdictions in terms of the percentage of the population that had completed high school. While two (11.8\%) of these jurisdictions had less than $70 \%$ of their population completing high school and 5 (29.4\%) had 90\% or more doing so, the percentages for the core jurisdictions were $0 \%$ and $12.5 \%$ respectively.

\section{Offender Presence and the Decision to Arrest}

Prior research shows that about half of the offenders in domestic violence incidents have left the scene before the police arrive (Dunford, 1990; Feder, 1996; Hirschel \& Hutchison, 1992:894). From the perspective of the offender this is a good course of action to take since an offender who has left the scene is far less likely to be arrested than one who remains on the scene 
(Eigenberg et al., 1996; Feder, 1996; Robinson \& Chandeck, 2000). For victims and policymakers this is disconcerting, particularly since there is research indicating that offenders who have left the scene are more dangerous and more likely to reoffend than those who remain on the scene (Buzawa et al., 1999:142).

The findings from our sample show that in $59.7 \%$ of the incidents the offender was on the scene when the officers arrived (see Tables 9.2a and 9.2b). This is slightly higher than findings from previous research. In $76.2 \%$ of the incidents where the offender remained on the scene there was a single offender. Table 9.2c shows that in intimate partner incidents when the offender was on the scene $74.4 \%$ were arrested compared to only $42.4 \%$ of those who left before the police arrived. In other domestic incidents $63.5 \%$ of those offenders on the scene were arrested while only $40 \%$ of those who were not on the scene were arrested.

Table 9.2a: Number of Offenders on the Scene When the Police Arrived

\begin{tabular}{lccc}
\hline \hline & & & \\
& Frequency & Percent & Valid Percent \\
\hline 0 & 1656 & 37.7 & 38.7 \\
1 & 1996 & 45.5 & 46.7 \\
2 & 597 & 13.6 & 14.0 \\
3 & 23 & .5 & .5 \\
4 & 2 & .0 & .0 \\
number disputed & 1 & .0 & .0 \\
Total & 4275 & 97.4 & 100.0 \\
Missing & 113 & 2.6 & \\
Total & 4388 & 100.0 & \\
\hline \hline
\end{tabular}




\section{Table 9.2b: Offender(s) on Scene When Police Arrived}

\begin{tabular}{lccc}
\hline \hline & & & \\
& Frequency & Percent & Valid Percent \\
\hline Offender not on scene & 1769 & 40.3 & 40.3 \\
Offender on scene & 2619 & 59.7 & 59.7 \\
Total & 4388 & 100.0 & 100.0 \\
\hline \hline
\end{tabular}

\section{Table 9.2c: Crosstabulation of Offender on Scene by Police Disposition by Relationship}

$\%$ within Offender on scene

\begin{tabular}{lccccc}
\hline \hline \multirow{2}{*}{ Relationship } & & \multicolumn{3}{c}{ Police Disposition } \\
\cline { 3 - 5 } Intimate & & No arrest & Normal arrest & Dual arrest & Total \\
\hline partner & Offender not on scene & $57.6 \%$ & $40.8 \%$ & $1.6 \%$ & $100.0 \%$ \\
& Offender on scene & $25.6 \%$ & $53.7 \%$ & $20.7 \%$ & $100.0 \%$ \\
& Total & $38.8 \%$ & $48.4 \%$ & $12.8 \%$ & $100.0 \%$ \\
\hline Other & Offender not on scene & $60.0 \%$ & $39.3 \%$ & $.7 \%$ & $100.0 \%$ \\
domestic & Offender on scene & $36.5 \%$ & $49.2 \%$ & $14.3 \%$ & $100.0 \%$ \\
& Total & $45.3 \%$ & $45.5 \%$ & $9.2 \%$ & $100.0 \%$ \\
\hline \hline
\end{tabular}

\section{Presence of Children and the Decision to Arrest}

While there is research evidence to show that there is no association between the presence of children in the household and the victim's decision to call the police (Hutchison \& Hirschel, 2001), several research studies have found that officers are more likely to make an arrest if intimate partner violence is committed in the presence of children or if the children are possibly at risk for abuse or neglect (see, e.g., Buzawa \& Austin, 1993; Eigenberg et al., 1996). In terms of dual arrests, Houry et al. (2004) have found that the presence of a child decreases the likelihood of a victim being arrested in conjunction with the offender.

The data collection for this project included a count of the number of minors (ages 17 and younger) on the scene when the incident occurred. Table 9.3a shows that in the majority 
(56.7\%) of the incidents there were no minors on the scene when the incident occurred. The overriding question for the current analysis is the presence of minors and not so much the number of minors on the scene. To address this specific issue the count of minors on the scene was recoded to a dichotomous measure ( $0=$ not on scene, $1=$ present when incident occurred $)$. The results of this revised variable are shown in Table 9.3b. Overall, minors were present at the time of domestic violence in $43.3 \%$ of the incidents.

Table 9.3c indicates that intimate partner incidents had a slightly higher percentage (66.3\%) of minors present than other domestic incidents (59.3\%). A more detailed examination of this table indicates that there was a slightly higher percentage of arrests when a minor was present during the incident in all types of domestic violence incidents.

ger)

on the Scene When the Incident Occurred

\begin{tabular}{cccc} 
& Frequency & Percent & Valid Percent \\
\hline 0 & 2017 & 46.0 & 56.7 \\
1 & 945 & 21.5 & 26.6 \\
2 & 402 & 9.2 & 11.3 \\
3 & 128 & 2.9 & 3.6 \\
4 & 44 & 1.0 & 1.2 \\
Five or more & 21 & .5 & .6 \\
Total & 3557 & 81.1 & 100.0 \\
System & 831 & 18.9 & \\
Total & 4388 & 100.0 & \\
\hline \hline
\end{tabular}


Table 9.3b: Minor on Scene When Police Arrived

\begin{tabular}{lccc}
\hline \hline & & & \\
& Frequency & Percent & Valid Percent \\
\hline No minor present & 2017 & 46.0 & 56.7 \\
Yes & 1540 & 35.1 & 43.3 \\
Total & 3557 & 81.1 & 100.0 \\
Missing & 831 & 18.9 & \\
Total & 4388 & 100.0 & \\
\hline \hline
\end{tabular}
Table 9.3c: Crosstabulation of Minor on Scene by Police Disposition by
Relationship

$\%$ within Minor on scene

\begin{tabular}{llcccc}
\hline \hline \multirow{2}{*}{$\begin{array}{l}\text { Relationship } \\
\text { Intimate }\end{array}$} & \multicolumn{3}{c}{ Police Disposition } & \\
\cline { 3 - 5 } & & No arrest & Normal arrest & Dual arrest & Total \\
\hline & $\begin{array}{l}\text { Minor present at time } \\
\text { of incident }\end{array}$ & $38.2 \%$ & $48.5 \%$ & $13.3 \%$ & $100.0 \%$ \\
& $\begin{array}{l}\text { Total } \\
\text { Other }\end{array}$ & $36.6 \%$ & $51.9 \%$ & $14.4 \%$ & $100.0 \%$ \\
domestic & No minor present & $43.9 \%$ & $46.1 \%$ & $10.0 \%$ & $100.0 \%$ \\
& $\begin{array}{l}\text { Minor present at time } \\
\text { of incident }\end{array}$ & $40.8 \%$ & $50.8 \%$ & $8.5 \%$ & $100.0 \%$ \\
& \begin{tabular}{l} 
Total \\
\hline \hline
\end{tabular} & $41.9 \%$ & $49.1 \%$ & $9.0 \%$ & $100.0 \%$ \\
\hline
\end{tabular}

\section{Offender History and the Decision to Arrest}

The offender's previous history of abuse/violence has been noted by several researchers as a major factor that increases the likelihood of arrest in domestic violence cases (Buzawa \& Hotaling, 2000; Kingsnorth, 2006; Klinger, 1995; Worden \& Shepard, 1996).

While the assumption has been generally made in prior research studies that if the offender had a prior record the responding officers knew about it, we have in our dataset a variable, gleaned from the police reports, that actually taps the dimension of the responding officers' knowledge of the offender's history of abuse/violence. Table 9.4a shows that the 
responding officers were clearly aware of the offender's history of violence in only $31.4 \%$ of the incidents. While some of the offenders in the remaining $68.6 \%$ of the incidents had prior records of violent arrests, the arriving officers were not aware of this fact. Our analysis indicates that when the responding officers are aware that an offender has a history of violence there is a marginally higher percentage of arrests in both intimate partner (62.1\%) and other domestic violence incidents (60\%) as opposed to when the officers have no prior knowledge of the offender's violent history (60.6\% and 52.8\%: see Table 9.4b).

Table 9.4a: Officer Aware that Offender has a History of Violence

\begin{tabular}{lccc}
\hline \hline & & & \\
& Frequency & Percent & Valid Percent \\
\hline $\begin{array}{l}\text { No known history of } \\
\text { violence }\end{array}$ & 2984 & 68.0 & 68.6 \\
Known history of violence & 1364 & 31.1 & 31.4 \\
Total & 4348 & 99.1 & 100.0 \\
Missing & 40 & .9 & \\
Total & 4388 & 100.0 & \\
\hline \hline
\end{tabular}

\section{Table 9.4b: Crosstabulation of Officer Aware that Offender has a History of Violence by Police Disposition by Relationship}

$\%$ within Officer aware that offender has a history of violence

\begin{tabular}{|c|c|c|c|c|c|}
\hline \multirow[b]{2}{*}{ Relationship } & & \multicolumn{3}{|c|}{ Police Disposition } & \multirow[b]{2}{*}{ Total } \\
\hline & & No arrest & Normal arrest & Dual arrest & \\
\hline \multirow[t]{3}{*}{$\begin{array}{l}\text { Intimate } \\
\text { partner }\end{array}$} & $\begin{array}{l}\text { No known history of } \\
\text { violence }\end{array}$ & $39.4 \%$ & $46.0 \%$ & $14.6 \%$ & $100.0 \%$ \\
\hline & Known history of violence & $37.9 \%$ & $53.1 \%$ & $9.0 \%$ & $100.0 \%$ \\
\hline & tal & $38.9 \%$ & $48.4 \%$ & $12.8 \%$ & $100.0 \%$ \\
\hline \multirow[t]{3}{*}{$\begin{array}{l}\text { Other } \\
\text { domestic }\end{array}$} & $\begin{array}{l}\text { No known history of } \\
\text { violence }\end{array}$ & $47.3 \%$ & $42.2 \%$ & $10.6 \%$ & $100.0 \%$ \\
\hline & Known history of violence & $40.0 \%$ & $54.5 \%$ & $5.5 \%$ & $100.0 \%$ \\
\hline & tal & $45.3 \%$ & $45.5 \%$ & $9.2 \%$ & $100.0 \%$ \\
\hline
\end{tabular}




\section{Who Reported the Incident and the Decision to Arrest}

Police as a group tend to respond differently depending on who initiated the call for service in a domestic dispute (Buzawa \& Buzawa, 2003). Research shows that the police may not be as responsive as expected to incidents when it is the victim who initiated the call. (Berk \& Loseke, 1980-1981; Berk \& Newton, 1985; Buzawa \& Hotaling, 2000; Stanko, 1985). From their interviews with 498 women in a domestic violence shelter in Florida, Coulter et al. (1999) noted that $58 \%$ of the victims contacted the police to report some type of domestic abuse but less than one fourth of the offenders were arrested. Earlier Berk and Loseke (1980-1981) had found that the probability of an arrest declined significantly when the victim contacted the police, as opposed to a third party.

As we can see in Table 9.5a the findings from our analysis show that nearly two-thirds (66.1\%) of the calls to the police were from the victims in the incident. Also similar to prior research our analysis shows that there is a difference between intimate partner and other domestic incidents in arrests by who called the police. Table 9.5b indicates that in intimate partner incidents there is a lower percentage of arrests (56.9\%) when the victim initiates the call compared to $71.3 \%$ when someone other than the victim calls the police. In other domestic situations there appears to be little difference in the percentages of arrests by who initiated the call. $^{1}$ 
Table 9.5a: Victim Reported the Incident

\begin{tabular}{lccc}
\hline \hline & & & \\
& Frequency & Percent & Valid Percent \\
\hline Someone other than the & 1016 & 23.2 & 33.9 \\
victim reported the incident & & & 66.1 \\
Victim reported incident & 1981 & 45.1 & 100.0 \\
Total & 2997 & 68.3 & \\
Missing/not applicable & 1391 & 31.7 & \\
Total & 4388 & 100.0 & \\
\hline \hline
\end{tabular}

Table 9.5b: Crosstabulation of Victim Reported the Incident by Police Disposition by Relationship

$\%$ within Victim reported the incident

\begin{tabular}{|c|c|c|c|c|c|}
\hline \multirow[b]{2}{*}{ Relationship } & & \multicolumn{3}{|c|}{ Police Disposition } & \multirow[b]{2}{*}{ Total } \\
\hline & & No arrest & Normal arrest & Dual arrest & \\
\hline \multirow[t]{3}{*}{$\begin{array}{l}\text { Intimate } \\
\text { partner }\end{array}$} & $\begin{array}{l}\text { Someone other than the } \\
\text { victim reported the incident }\end{array}$ & $28.6 \%$ & $53.9 \%$ & $17.4 \%$ & $100.0 \%$ \\
\hline & Victim reported incident & $43.2 \%$ & $49.0 \%$ & $7.9 \%$ & $100.0 \%$ \\
\hline & Total & $38.8 \%$ & $50.5 \%$ & $10.7 \%$ & $100.0 \%$ \\
\hline \multirow[t]{3}{*}{$\begin{array}{l}\text { Other } \\
\text { domestic }\end{array}$} & $\begin{array}{l}\text { Someone other than the } \\
\text { victim reported the incident }\end{array}$ & $45.5 \%$ & $44.9 \%$ & $9.6 \%$ & $100.0 \%$ \\
\hline & Victim reported incident & $45.4 \%$ & $48.5 \%$ & $6.1 \%$ & $100.0 \%$ \\
\hline & Total & $45.4 \%$ & $46.9 \%$ & $7.6 \%$ & $100.0 \%$ \\
\hline
\end{tabular}

\section{Alcohol and the Decision to Arrest}

Many studies have investigated the association between intimate partner violence and the use of alcohol by the perpetrator, victim or both (see, e.g., Bushman, 1993; Heyman et al., 1995; Hutchison, 1999; Kantor \& Straus, 1989; Roizen, 1993; Schafer et al., 2004). However, research pertaining to the link between alcohol use, intimate partner violence and an officer’s decision to make an arrest is a topic that has not received much attention. A recent study conducted by Busch and Rosenberg (2004) found that both men and women were equally likely to be using 
drugs or alcohol at the time of their arrest, but it was not stated whether this directly influenced the officer's decision to make the arrest. Houry et al. (2004) found in their study of the frequency and characteristics of victims coarrested for intimate partner violence that $9 \%$ of female victims who utilized 911 for an intimate partner violence incident in Atlanta were arrested in conjunction with the perpetrator. One of the major characteristics that increased the likelihood of the victim being coarrested was alcohol use. Martin (1997) studied cases processed through the Connecticut court system after the implementation of a 1988 mandatory arrest law. In her examinations, she found a dual arrest rate of 33\% in the adult intimate partner violence cases. Martin's (1997) results revealed that drugs and alcohol were more likely to be involved in dual arrest cases compared to single arrest cases, but was unable to state whether the victim or the offender was under the influence.

Four data elements were used to create the measure to identify drug and/or alcohol involvement in the incident. Information on the officer's perception as to whether the victim and/or the offender had been using drugs or alcohol is included in the data collection. These four variables were combined to indicate the involvement of either alcohol or drugs in the incident. Table 9.6a indicates that according to the officer's perception only $37.1 \%$ of the incidents in our study involved the use of alcohol or drugs.

The crosstabulation in Table 9.6b runs somewhat counter to the prior research. The results indicate that, in both intimate partner and other domestic incidents, there were overall fewer arrests if drugs or alcohol were involved in the incident. However, a caution is necessary. These data reflect the officer's perception and are not based upon any drug or alcohol testing process. Therefore, these results must be interpreted with caution. ${ }^{2}$ 
Table 9.6a: Offender and/or Victim were Reported to have Used Drugs or Alcohol

\begin{tabular}{lccc}
\hline \hline & Frequency & Percent & Valid Percent \\
\hline $\begin{array}{l}\text { No drug or alcohol } \\
\text { involvement reported }\end{array}$ & 2081 & 47.4 & 62.9 \\
Drugs/alcohol involved & 1225 & 27.9 & 37.1 \\
Total & 3306 & 75.3 & 100.0 \\
Missing & 1082 & 24.7 & \\
Total & 4388 & 100.0 & \\
\hline \hline
\end{tabular}

\section{Table 9.6b: Crosstabulation of Use of Drugs or Alcohol by Police Disposition by Relationship}

$\%$ within Use drugs or alcohol

\begin{tabular}{llcccc}
\hline \hline \multirow{2}{*}{ Relationship } & & \multicolumn{3}{c}{ Police Disposition } \\
\cline { 3 - 5 } Intimate & & No arrest & Normal arrest & Dual arrest & Total \\
\hline partner & $\begin{array}{l}\text { No drug or alcohol } \\
\text { involvement reported }\end{array}$ & $26.4 \%$ & $56.5 \%$ & $17.2 \%$ & $100.0 \%$ \\
& Drugs/alcohol involved & $31.8 \%$ & $52.5 \%$ & $15.7 \%$ & $100.0 \%$ \\
& Total & $28.6 \%$ & $54.9 \%$ & $16.5 \%$ & $100.0 \%$ \\
\hline Other & No drug or alcohol & $37.0 \%$ & $49.6 \%$ & $13.4 \%$ & $100.0 \%$ \\
& $\quad$ involvement reported & & & $7.1 \%$ & $100.0 \%$ \\
& Drugs/alcohol involved & $40.2 \%$ & $52.7 \%$ & $11.7 \%$ & $100.0 \%$ \\
\hline \hline
\end{tabular}

\section{Offender's Demeanor and Decision to Arrest}

Research has suggested that the offender's demeanor, such as a lack of civility towards the police in a domestic violence situation, can affect the officer's decision to arrest (Bayley, 1996; Dolon, Hendricks \& Meagher, 1986; Smith \& Klein, 1984; Worden \& Pollitz, 1984).

Table 9.7a indicates that when the officer on the scene of a domestic violence incident records the offender's demeanor the two ends of an implied demeanor continuum stand out. 
Officers reported that about one-third of offenders displayed anger and slightly over one-third were calm. Of the remaining emotions officers indicated that $19.4 \%$ of the offenders cried, $2.9 \%$ were fearful and $7.7 \%$ were apologetic. Unfortunately, there are a large number of cases where the officer did not report the offender's demeanor or the offender was not on the scene.

Therefore, any further interpretation must proceed with caution. ${ }^{3}$

Generally, in both intimate partner and other domestic incidents when the offender displayed anger their percentage (70.9\% and 71\%) of arrests increased (see Table 9.7c).

Table 9.7a: Offender Demeanor at Time of Police Disposition

\begin{tabular}{lccc}
\hline \hline & & & \\
& Frequency & Percent & Valid Percent \\
\hline Angry & 279 & 6.4 & 33.7 \\
Fearful & 24 & .5 & 2.9 \\
Crying & 161 & 3.7 & 19.4 \\
Apologetic & 64 & 1.5 & 7.7 \\
Calm & 301 & 6.9 & 36.3 \\
Total & 829 & 18.9 & 100.0 \\
Demeanor not noted on & 2421 & 55.2 & \\
police report & 1110 & 25.3 & \\
Offender not at scene & 28 & .6 & \\
Missing & 3559 & 81.1 & \\
Total & 4388 & 100.0 & \\
Total & & & \\
\hline \hline
\end{tabular}


Table 9.7b: Offender Displayed Anger

\begin{tabular}{lccc}
\hline \hline & & & \\
& Frequency & Percent & Valid Percent \\
\hline Offender displayed other & 550 & 12.5 & 66.3 \\
emotion & 279 & 6.4 & 33.7 \\
Offender displayed anger & 829 & 18.9 & 100.0 \\
$\quad$ Total & 3559 & 81.1 & \\
$\quad \begin{array}{l}\text { Demeanor not reported, } \\
\text { missing, not applicable }\end{array}$ & 4388 & 100.0 & \\
Total &
\end{tabular}

\section{Table 9.7c: Crosstabulation of Offender Displayed Anger by Police} Disposition by Relationship

\begin{tabular}{|c|c|c|c|c|c|}
\hline \multirow[b]{2}{*}{ Relationship } & & \multicolumn{3}{|c|}{ Police Disposition } & \multirow[b]{2}{*}{ Total } \\
\hline & & No arrest & Normal arrest & Dual arrest & \\
\hline \multirow[t]{3}{*}{$\begin{array}{l}\text { Intimate } \\
\text { partner }\end{array}$} & $\begin{array}{l}\text { Offender displayed other } \\
\text { emotion }\end{array}$ & $32.5 \%$ & $57.9 \%$ & $9.6 \%$ & $100.0 \%$ \\
\hline & Offender displayed anger & $29.1 \%$ & $56.1 \%$ & $14.8 \%$ & $100.0 \%$ \\
\hline & Total & $31.4 \%$ & $57.4 \%$ & $11.2 \%$ & $100.0 \%$ \\
\hline \multirow[t]{3}{*}{$\begin{array}{l}\text { Other } \\
\text { domestic }\end{array}$} & $\begin{array}{l}\text { Offender displayed other } \\
\text { emotion }\end{array}$ & $51.6 \%$ & $41.8 \%$ & $6.6 \%$ & $100.0 \%$ \\
\hline & Offender displayed anger & $28.9 \%$ & $64.4 \%$ & $6.7 \%$ & $100.0 \%$ \\
\hline & Total & $42.0 \%$ & $51.4 \%$ & $6.6 \%$ & $100.0 \%$ \\
\hline
\end{tabular}

\section{Reported Injury}

Prior research indicates that $40 \%$ to $50 \%$ of victims in intimate partner violence incidents are injured in the incident (Department of Justice, 2005:33; Rennison \& Welchans, 2000) and that female victims are more likely than male victims to be injured (Straus \& Gelles, 1986; Tjaden \& Thoennes, 1998). Consistent with the fact that most of these incidents are misdemeanor assault, the injuries tend to be classified as minor with the prominent category of injury being scratches, bruises, or welts (Tjaden \& Thoennes, 1998). 
Research on the relationship between victim injury and the decision to arrest is somewhat mixed. Some studies that have found a positive relationship between victim injuries and arrest (see, e.g., Berk \& Sherman, 1998; Black, 1980; Buzawa \& Austin, 1993; Buzawa \& Hotaling, 2000; Eigenberg, 2001; Feder, 1996; Ferraro, 1989a; Hotaling and Buzawa 2001). However, other studies have found there to be no significant relationship between the two (see, e.g., Berk \& Loseke, 1980-1981; Eigenberg et al., 1996; Feder, 1998; D A. Jones \& Belknap, 1999; Klinger, 1995; Worden \& Pollitz, 1984). Despite the variation in research results, most studies conclude that "the degree of violence or threat of violence to the victim is often of only minimal significance in the arrest decision” (Buzawa \& Buzawa, 2003:146).

Table 9.8a provides a breakdown of the types of injuries reported by the victim in the incident. There were no injuries reported in almost $50 \%$ of the incidents. Overall, $46.8 \%$ of the incidents involved a minor injury while only 3.7\% of the incidents involved any sort of major injury to the victim. When an injury was reported $92.6 \%$ of the injuries were reported as minor. ${ }^{4}$

The crosstabulation table $9.8 \mathrm{~b}$ of reported injury by arrests shows that, compared to incidents where no injury was reported, incidents with an injury resulted in overall higher percentages of arrests for all domestic violence incidents. In intimate partner incidents if a serious injury was reported over $70 \%$ of the incidents resulted in an arrest. In other domestic incidents the percentage was slightly higher at $73.7 \%$. 
Table 9.8a: Victim Reported Being Injured

\begin{tabular}{lccc}
\hline \hline & Frequency & Percent & Valid Percent \\
\hline No reported injury & 2170 & 49.5 & 49.5 \\
Minor injury reported & 2054 & 46.8 & 46.8 \\
$\begin{array}{l}\text { Serious injury reported } \\
\text { Both serious and minor }\end{array}$ & 114 & 2.6 & 2.6 \\
$\begin{array}{l}\text { injury reported } \\
\text { Total }\end{array}$ & 50 & 1.1 & 1.1 \\
\hline \hline
\end{tabular}

\section{Table 9.8b: Crosstabulation by Victim Reported being Injured by Police Disposition by Relationship}

$\%$ within Victim reported being injured

\begin{tabular}{lccccc}
\hline \hline \multirow{2}{*}{ Relationship } & & \multicolumn{3}{c}{ Police Disposition } \\
\cline { 3 - 5 } Intimate & & No arrest & Normal arrest & Dual arrest & Total \\
\hline partner & No reported injury & $48.1 \%$ & $39.9 \%$ & $12.0 \%$ & $100.0 \%$ \\
& Minor injury reported & $30.7 \%$ & $56.0 \%$ & $13.3 \%$ & $100.0 \%$ \\
& Serious injury reported & $29.4 \%$ & $54.8 \%$ & $15.9 \%$ & $100.0 \%$ \\
& Total & $38.8 \%$ & $48.4 \%$ & $12.8 \%$ & $100.0 \%$ \\
\hline Other & No reported injury & $52.8 \%$ & $39.4 \%$ & $7.8 \%$ & $100.0 \%$ \\
& Minor injury reported & $36.7 \%$ & $52.3 \%$ & $11.0 \%$ & $100.0 \%$ \\
& Serious injury reported & $26.3 \%$ & $63.2 \%$ & $10.5 \%$ & $100.0 \%$ \\
& Total & $45.3 \%$ & $45.5 \%$ & $9.2 \%$ & $100.0 \%$ \\
\hline \hline
\end{tabular}

\section{Multivariate Analyses: The Model}

In this section we present the result of our multivariate analyses. Tables 9.9 and 9.10

provide the results of the logistic regression analyses for the dependent variables arrest and dual arrest. As is evident from the descriptive analysis above, there were several variables we would have liked to include in the final analysis but due to lack of variation or high numbers of missing cases (generally not reported by the police) these variables would detract from the quality of the 
multivariate model. Therefore, the following independent variables are included in the logistic regression models:

- Offender is white ( $1=$ white, $0=$ minority)

- $\quad$ Offender is male ( 1 = male, 0 = female)

- Incident occurred in the core city ( 1 = core city, $0=$ satellite jurisdiction)

- A minor was present when the incident occurred $(1=$ minor present, $0=$ no minor present)

- The officer is aware if the offender has a history of violence ( $1=$ officer aware of the offenders history of violence, $0=$ officer not aware)

- $\quad$ The primary victim reported an injury $(1=$ victim reported an injury, $0=$ no injury reported)

- The offender was on the scene of the incident $(1=$ offender on the scene when police arrived, 0 = offender not on scene)

- The incident took place in the victim's home (1 = incident occurred in the victim's home, 0 = incident occurred elsewhere)

- $\quad$ Type of relationship ( 1 = Intimate partner, 0 = Other domestic)

The model being tested is the impact of these eight independent variables on changes in both overall arrests for the incidents (Table 9.9) and dual arrests (Table 9.10).

\section{Multivariate Analyses: Arrest as the Outcome Variable}

Since the tested model is guided by prior research, the forced entry method is the most appropriate. The intent is to examine the contribution of each variable individually while controlling for other known or hypothesized predictors of arrest in domestic violence incidents. The Model Chi-square test for arrest as an outcome is statistically significant $(\mathrm{p}<.000)$ with a $X^{2}$ $=460.362$ at $\mathrm{df}=9$.

Since there is no direct goodness of fit measure available for logistic models we used one of two pseudo R-square measures provided in the SPSS logistic output. Neither has a direct interpretation to the R Square used in OLS models. However, the Nagelkerke R Square is used most frequently because, like the OLS model R-Square, this pseudo measure is also based on a range of 0 to 1 and therefore more closely approximates its OLS counterpart (Tabachnick and 
Fidell, 2007, p. 461). The Model Summary results show a Nagelkerke R Square value of 0.173.

As with the interpretation of the OLS R-Square, this indicates that the overall model has a

moderately weak association with the dependent variable arrest.

The results presented in Table 9.9 indicate that six of the nine independent measures are statistically significant in the model. All appear to have a positive effect on changes in overall arrests. With all other factors being equal, the odds of an arrest increase by 1.33 if the incident is between intimate partners. Also, after controlling for the effects of all the other factors in the model if the offender is on the scene when police arrive the odds of an arrest are 3.82 times higher than if the offender is not on the scene. Again controlling for all other factors, if the

Table 9.9: Likelihood of Arrest as an Outcome

\begin{tabular}{lcccccc}
\hline \hline & B & S.E. & Wald & df & Sig. & Exp(B) \\
\hline White Offender & .338 & .078 & 18.939 & 1 & .000 & 1.401 \\
Offender was male & .013 & .090 & .020 & 1 & .887 & 1.013 \\
Core City & .355 & .080 & 19.655 & 1 & .000 & 1.426 \\
Minor present & .180 & .080 & 5.006 & 1 & .025 & 1.197 \\
Offender has history of violence & .117 & .083 & 2.016 & 1 & .156 & 1.124 \\
Victim was injured & .825 & .077 & 114.840 & 1 & .000 & 2.283 \\
Offender on the scene & 1.340 & .080 & 281.808 & 1 & .000 & 3.818 \\
Incident occurred in victim's home & -.080 & .124 & .423 & 1 & .516 & .923 \\
Intimate partner relationship & .287 & .091 & 9.972 & 1 & .002 & 1.332 \\
Constant & -1.275 & .205 & 38.797 & 1 & .000 & .279 \\
\hline \hline
\end{tabular}

a. Variables entered on step 1 - Offender was white, Offender was male, Core city, Minor present during incident, Offender has a history of violence, Offender was on the scene, Incident occurred in victim's home, Intimate partner relationship.

$X^{2}=460.362$ at $\mathrm{df}=9, \mathrm{p}<.000$

Nagelkerke $\mathrm{R}^{2}=0.173$ 
victim reports an injury the likelihood of an arrest is 2.28 times higher than if no injury is reported. Incidents occurring in a core city have a slightly higher (1.4) odds ratio for an arrest than if the incident occurs outside the core city and if the offender is white there are also slightly higher odds (1.4) of being arrested. Finally, if a minor is present during the incident the likelihood of arrest is increased by a factor of 1.2 .

\section{Multivariate Analyses: Dual Arrest as the Outcome Variable}

As with the arrest as the outcome model discussed above, the Model Chi-square test is statistically significant $(\mathrm{p}<.000)$ with a $X^{2}=538.059$ at $\mathrm{df}=9$. The Model Summary results for dual arrest as the outcome show a Nagelkerke R Square value of 0.276 . As with the interpretation of the OLS R-Square, this indicates that the overall model has a moderate association with the dependent variable dual arrest. This is slightly higher than the pseudo RSquare achieved in the overall arrest model above.

The results displayed in Table 9.10 show that six of the nine independent measures are statistically significant. Three of these variables, the offender was on the scene of the incident, the incident involved intimate partners, and the incident occurred in the core city displayed a positive effect on dual arrests. The variables offender was male, the offender was white, and the police were aware of the offender’s violent history, have a negative effect. The remaining variables, minors present when the incident occurred, the victim reported an injury, and the incident occurred in the victim’s home, have non-significant effects in this model with minimum impact on the outcome.

With all other factors being equal, the odds of dual arrest increase by 1.8 if the incident is between intimate partners. The most telling effect is the presence of the offender on the scene when the police arrive. With all other factors controlled the odds of a dual arrest is nearly 20 
times that of no dual arrest. Also, when controlling for the effects of all the other factors in the model the odds of a dual arrest in the core city is 2.99 times that of the odds of dual arrest in the satellite areas surrounding the core city.

According to this model, with the other factors held constant, if the primary offender is white, the likelihood of a dual arrest occurring is about half (0.569) as likely as when the offender is a minority. Likewise, dual arrest is about half as likely $(0.42)$ if the offender is male. Finally, if the police are aware that the offender has a history of violence there is a lesser chance (0.59) of a dual arrest outcome.

Table 9.10: Likelihood of a Dual Arrest Outcome

\begin{tabular}{lcccccc}
\hline \hline & B & S.E. & Wald & df & Sig. & Exp(B) \\
\hline White offender & -.564 & .115 & 24.159 & 1 & .000 & .569 \\
Offender was male & -.862 & .117 & 54.268 & 1 & .000 & .422 \\
Core city & 1.097 & .115 & 91.141 & 1 & .000 & 2.996 \\
Minor was present & .022 & .118 & .035 & 1 & .852 & 1.022 \\
Offender has history of violence & -.521 & .132 & 15.625 & 1 & .000 & .594 \\
Victim was injured & .090 & .114 & .613 & 1 & .434 & 1.094 \\
Offender was on the scene & 2.992 & .261 & 131.777 & 1 & .000 & 19.919 \\
Incident occurred in victim's home & -.081 & .192 & .179 & 1 & .672 & .922 \\
Intimate partner relationship & .593 & .146 & 16.456 & 1 & .000 & 1.810 \\
Constant & -4.920 & .385 & 163.647 & 1 & .000 & .007 \\
\hline \hline
\end{tabular}

a. Variables entered on step 1 - Offender was non-white, Offender was male, Core city, Minor present during incident, Offender has a history of violence, Offender was on the scene, Incident occurred in victim's home, Intimate partner relationship.

$X^{2}=538.059$ at $\mathrm{df}=9, \mathrm{p}<.000$

Nagelkerke $\mathrm{R}^{2}=0.276$ 


\section{Discussion}

Through the inclusion of additional variables, such as offender on the scene and presence of children, and by shedding additional light on the variables included in the multivariate models in the Phase I analyses, these Phase II results contribute substantially to our understanding of the police response to domestic violence.

As all of our previous analyses have shown, the likelihood of an arrest being made was greater in intimate partner than in other domestic incidents. As in our Phase I multivariate analyses, arrest was more likely if the offender was white than if he/she was of minority status. Again, sex had no impact on the likelihood of any of the involved parties being arrested. A major difference between our Phase I and Phase II findings concerns the impact of the place in which the incident occurred. Our Phase I findings indicated that arrest was more likely if the incident took place in a residence as opposed to somewhere else. In our Phase II model location of the incident no longer exerts a significant impact on the likelihood of arrest. A new variable, offender on the scene, appears to have taken its place. If the offender remains on the scene, he/she is nearly four times more likely to be arrested than if he/she leaves the scene. Intuitively, it makes sense to believe that an offender who has committed an offense in a residence is less likely to take off than one who has committed the offense elsewhere.

New variables that manifest a significant effect on the likelihood of arrest are victim injury, presence of minors, and whether the incident took place in a core city or a satellite jurisdiction. In our Phase I multivariate analyses we used offense as a predictor variable and did not include victim injury because of the highly significant interrelationship between the two variables. In Phase II we substituted victim injury for seriousness of offense because of the richness of the data we have gathered on victim injury, data that will be fully explored in 
subsequent analyses. As would be expected, victim injury exerted in our Phase II model a similar effect to that exerted by seriousness of offense in our Phase I model.

The presence of minors also increased the likelihood of arrest. This may be taken as evidence that the police take seriously the well documented deleterious effects that children experience as a result of exposure to domestic violence (see, e.g. Buka, Stichick, Birdthistle \& Felton, 2001; Edleson, 1999; Henning, Leitenberg, Coffey, Turner \& Bennett, 1996; McNeal \& Amato, 1998; Graham-Bermann \& Levendosky, 1998). Finally, arrests were more likely to be made in the core cities, the larger more densely populated, generally less affluent and more racially mixed jurisdictions, than in the smaller satellite jurisdictions. More detailed analyses of the impact of these jurisdictional characteristics will be explored in subsequent work.

Most of these variables also impacted the likelihood of dual arrests. Dual arrests were more likely in intimate partner than in other domestic incidents. They were also more likely to occur in core cities than in satellite jurisdictions. The responding offers were also more likely to effect dual arrests if the offender remained on the scene, but were less likely to make dual arrests if the offender was White.

When the officers were aware that the offender had a history of violence they were less likely to arrest the other party involved in the incident, an indication that officers do take this factor into account when determining the primary aggressor in an incident. Finally, sex does appear to affect the likelihood of dual arrest. When the primary aggressor is male, the other party is less likely to be arrested. Since most of the incidents in this study involved parties of the opposite sex, this may be taken as evidence that, for a variety of reasons, the police are adopting a more lenient attitude toward females. However, as we cautioned in Chapter Five, this conclusion hinges on the assumption that the designation by NIBRS of an offender as the first 
offender accurately depicts who has primary culpability for the incident. Despite this, it should be noted that this finding with regard to sex and dual arrest is consistent with prior research on this issue. For example, Jones and Belknap (1999:265-6) found in their Boulder study, where there was a strong pro-arrest policy, that male victim/female aggressor pairs were three times more likely to constitute a dual arrest than were female victim/male aggressor pairs. Likewise, Buzawa and Hotaling (2000) found in their study of three Massachusetts towns operating under a state pro-arrest law that when a male was a victim, the female was five times less likely to be arrested than was a male (p. 103).

\footnotetext{
${ }^{1}$ Over $30 \%$ of the cases for the variable are missing or otherwise not reported. These findings must be interpreted with caution. Also, because of the large number of missing cases we have omitted this variable from the multivariate logistic regression models discussed later in this chapter.

${ }^{2}$ Approximately 25\% of the incidents for drug and/or alcohol involvement are missing data or no information was reported. These findings must be interpreted with caution. Also, because of the large number of missing cases we have omitted this variable from the multivariate logistic regression models discussed later in this chapter.

${ }^{3}$ Over $80 \%$ of the incidents for offender's demeanor are missing data or no information was reported. These findings must be interpreted with caution. Also, because of the large number of missing cases we have omitted this variable from the multivariate logistic regression models discussed later in this chapter.

${ }^{4}$ The dataset includes information about the type of action that appears to have produced the injury (e.g. striking, kicking, biting) and the location of the injury (e.g. face/neck, cranium, stomach, back). These data elements will be incorporated into subsequent analyses.
} 


\section{Chapter 10 \\ Beyond Arrest: The Prosecution and Conviction of Domestic Violence Offenders}

In addition to investigating the factors that impact the decision to arrest, we followed domestic violence cases in which the police had made an arrest through the criminal justice system to determine the likelihood of prosecution and conviction and the factors that affect the probability that the offender will be prosecuted and convicted. We also examined the sentences that are imposed on those convicted of domestic violence offenses. In this chapter we present our findings on these issues.

\section{The Sample}

As discussed in chapter nine, we were able to obtain court-processing information on domestic violence cases in 20 of the 25 jurisdictions. Problems with obtaining access to, and concerns about the quality of any data that might be obtained, had resulted in a decision not to collect these data in one of the core and all four of the satellite jurisdictions in Tennessee. The data that were gathered in the remaining Tennessee jurisdiction had, however, so much missing information that we decided to exclude that jurisdiction as well. Thus, this stage of the project examines case processing in Connecticut, Idaho, and Virginia and does not include any data from Tennessee.

The 19 jurisdictions included in this stage of the project generated 3,202 cases. A total of $1,198(37.4 \%)$ of these cases resulted in no arrest, $1,606(50.2 \%)$ in one or more arrests, and 398 $(12.4 \%)$ in dual arrests. ${ }^{1}$ Court processing information was thus sought for a total of 2,004 cases. We were unable to obtain information for 425 (21.2\%) of those cases because the offender was a juvenile, or because the record had been expunged or was missing for some other reason. The final sample size thus is 1,579 . 


\section{The Decision to Prosecute}

The prosecution went ahead, at least initially, with the vast majority of cases against the offender (87.8\%: See Table 10.1). The initial prosecution rate was higher for intimate partner cases (90.3\%) than for other domestic cases (77.4\%). In $83.1 \%$ of the intimate partner cases and $84 \%$ of other domestic cases the defendant faced one charge. While $55.1 \%$ of defendants in intimate partner cases were charged with simple assault, and $26.6 \%$ with breach of the peace, the comparative figures for defendants in other domestic cases were $39.4 \%$ and $29.1 \%$ respectively. Over a quarter (41 or 26.5\%) of the 155 defendants in intimate partner cases who faced more than one charge had violation of probation as their second charge. Three (9.7\%) of the 31 "other domestic violence” offenders with more than one charge were charged with probation violation as the second offense. Over two thirds of the defendants (68.5\%) had prior arrest records with just over two-fifths (40.3\%) having prior records that included a violent offense. ${ }^{2}$ Defendants in intimate partner violence cases were slightly more likely than those in other domestic cases to have either any prior record (69.2\% v. 65.5\%) or a prior record for a violent offense $(41.8 \% \mathrm{v}$. $34.0 \%)$.

Victims were slightly less likely than defendants to have their cases proceed. A total of 83.3\% of the victims were prosecuted (Table 10.1). The vast majority (93.1\%) had one charge against them. While $44.4 \%$ of those involved in intimate partner violence cases were charged with simple assault, and $41.0 \%$ with breach of the peace, the comparative figures for domestic violence cases were $28.6 \%$ and $55.1 \%$ respectively. None of these victims were charged with probation violation. Just under half (47.4\%) of the victims had prior arrest records, with a quarter (24.9\%) having a prior record with a violence offense. Victims in intimate partner cases were 
more likely than those in other domestics to have both any prior record (49.7\% v. $37.4 \%)$ and a record of a prior violent offense (26.1\% v. 19.5\%).

Table 10.1

The Initial Decision to Prosecute by Victim-Offender Relationship

\begin{tabular}{|c|c|c|c|}
\hline & $\begin{array}{l}\text { Intimate Partner } \\
\text { Cases }\end{array}$ & $\begin{array}{l}\text { Other Domestic } \\
\text { Cases }\end{array}$ & Total \\
\hline \multicolumn{4}{|l|}{ Offender } \\
\hline Prosecuted & $1,327(90.3 \%)$ & $270(77.4 \%)$ & $1,597(87.8 \%)$ \\
\hline $\begin{array}{l}\text { \# of Charges } \\
\text { One } \\
\text { Two } \\
\text { Three or more }\end{array}$ & $\begin{array}{c}764(83.1 \%) \\
104(11.3 \%) \\
51(5.5 \%)\end{array}$ & $\begin{array}{c}163(84.0 \%) \\
20(10.3 \%) \\
11(5.7 \%)\end{array}$ & $\begin{array}{c}927(83.3 \%) \\
124(11.1 \%) \\
62(5.6 \%)\end{array}$ \\
\hline $\begin{array}{l}\text { First Charge } \\
\text { Aggravated Assault } \\
\text { Simple Assault } \\
\text { Disorderly conduct/ } \\
\text { Breach of Peace } \\
\text { Other }\end{array}$ & $\begin{array}{r}59(7.1 \%) \\
457(55.1 \%) \\
220(26.6 \%) \\
93(11.2 \%) \\
\end{array}$ & $\begin{array}{l}12(6.8 \%) \\
69(39.4 \%) \\
51(29.1 \%) \\
43(24.6 \%)\end{array}$ & $\begin{array}{c}71(7.1 \%) \\
526(52.4 \%) \\
271(27.0 \%) \\
136(13.5 \%)\end{array}$ \\
\hline Any Prior Arrest & $1,032(69.2 \%)$ & $230(65.5 \%)$ & $1,262(68.5 \%)$ \\
\hline Violent Prior Arrest & $643(41.8 \%)$ & $128(34.0 \%)$ & $771(40.3 \%)$ \\
\hline \multicolumn{4}{|l|}{ Victim } \\
\hline Prosecuted & $210(83.7 \%)$ & $53(81.5 \%)$ & $264(83.3 \%)$ \\
\hline $\begin{array}{l}\text { \# of Charges } \\
\text { One } \\
\text { Two } \\
\text { Three or more }\end{array}$ & $\begin{array}{c}156(94.0 \%) \\
7(4.2 \%) \\
3(1.8 \%) \\
\end{array}$ & $\begin{array}{c}47(90.4 \%) \\
4(7.7 \%) \\
1(1.9 \%)\end{array}$ & $\begin{array}{c}203(93.1 \%) \\
11(5.0 \%) \\
4(1.8 \%) \\
\end{array}$ \\
\hline $\begin{array}{l}\text { First Charge } \\
\text { Aggravated Assault } \\
\text { Simple Assault } \\
\text { Disorderly conduct/ } \\
\text { Breach of Peace } \\
\text { Other }\end{array}$ & $\begin{array}{c}5(3.5 \%) \\
64(44.4 \%) \\
59(41.0 \%) \\
15(10.4 \%)\end{array}$ & $\begin{array}{r}2(4.1 \%) \\
14(28.6 \%) \\
27(55.1 \%) \\
6(12.2 \%) \\
\end{array}$ & $\begin{aligned} & 7(3.6 \%) \\
& 79(40.9 \%) \\
& 86(44.6 \%) \\
& 21(10.9 \%) \\
&\end{aligned}$ \\
\hline Any Prior Arrest & $671(49.7 \%)$ & $111(37.4 \%)$ & $782(47.4 \%)$ \\
\hline Violent Prior Arrest & $352(26.1 \%)$ & 58 (19.5\%) & $410(24.9 \%)$ \\
\hline
\end{tabular}

\section{Case Processing and Case Resolution}

Over a quarter (26.5\%) of the defendants had the charges amended (see Table 10.2). This was more likely in intimate partner (27.7\%) than in other domestic cases (20.6\%). Less than half 
(42.6\%) of the defendants were convicted. Conviction was more likely in intimate partner (44.1\%) than in other domestic (35.4\%) cases. Nearly all of the cases that did not result in conviction were dismissed: $98.6 \%$ of intimate partner and $98.8 \%$ of other domestic cases.

Defendants who were convicted tended to receive a combination of sentences. A majority of those convicted received custodial sentences (74.6\%), sometimes partially or fully suspended, and/or probation/parole (71.2\%), and/or fines (73.6\%: see Table 10.2). All of these sentencing dispositions were imposed more frequently in intimate partner than in other domestic cases. Close to half (46.7\%) of those convicted in intimate partner cases, and just over a third (36.9\%) of those convicted in other domestic cases, were ordered to participate in treatment programs, typically anger management, and in the case of intimate partner violence, also batterer treatment programs.

Table 10.2

Case Processing and Case Resolution by Victim-Offender Relationship

\begin{tabular}{|l|c|c|c|}
\hline & $\begin{array}{c}\text { Intimate Partner } \\
\text { Cases }\end{array}$ & $\begin{array}{c}\text { Other Domestic } \\
\text { Cases }\end{array}$ & Total \\
\hline Offender & & & \\
\hline First Charge Amended & $299(27.7 \%)$ & $45(20.6 \%)$ & $344(26.5 \%)$ \\
\hline Convicted & $567(44.1 \%)$ & $91(35.4 \%)$ & $658(42.6 \%)$ \\
\hline Custodial Sentence & $382(75.5 \%)$ & $56(69.1 \%)$ & $438(74.6 \%)$ \\
\hline Probation & $330(72.2 \%)$ & $48(64.9 \%)$ & $378(71.2 \%)$ \\
\hline Treatment Program & $200(46.7 \%)$ & $24(36.9 \%)$ & $224(45.4 \%)$ \\
\hline Fined & $349(75.7 \%)$ & $44(60.3 \%)$ & $393(73.6 \%)$ \\
\hline & & & \\
\hline Victim & & & \\
\hline First Charge Amended & $36(18.1 \%)$ & $4(8.0 \%)$ & $40(16.4 \%)$ \\
\hline Convicted & $73(35.8 \%)$ & $11(21.6 \%)$ & $84(32.9 \%)$ \\
\hline Custodial Sentence & $51(67.1 \%)$ & $6(54.5 \%)$ & $57(65.5 \%)$ \\
\hline Probation & $36(53.7 \%)$ & $4(50.0 \%)$ & $40(53.3 \%)$ \\
\hline Treatment Program & $24(40.7 \%)$ & $2(40 \%)$ & $26(40.6 \%)$ \\
\hline Fined & $47(70.1 \%)$ & $5(62.5 \%)$ & $52(69.3 \%)$ \\
\hline
\end{tabular}


Victims (16.4\%) were less likely than defendants (26.5\%) to have charges amended with victims in intimate partner cases (18.1\%) being more likely than those in other domestics (8.0\%) to have their charges amended (see Table 10.2). Only about one third (32.9\%) of the cases against victims resulted in conviction. As had been the situation with defendants, victims in intimate partner incidents (35.8\%) were more likely than victims in other domestics (21.6\%) to have their cases result in conviction. A majority of those who were convicted were likely to receive custodial sentences (65.5\%) and/or probation/parole (53.3\%) and/or fines (69.3\%) with these dispositions more likely to be handed out in intimate partner than in other domestic cases. In about $40 \%$ of both intimate partner and other domestic cases the convicted victim was ordered to participate in a treatment program.

\section{Factors Impacting Case Resolution}

Very little research has been conducted on the processing of domestic violence cases. Schmidt and Steury (1989) in their study of misdemeanor cases processed by the Milwaukee County District Attorney’s office found that a defendant's failure to appear at the charging conference and his use of drugs or alcohol at the time of the incident were the factors that were most highly associated with the decision to charge. Other factors affecting this decision included amount of injury, the defendant's prior record, and the defendant's prior abuse of the victim. Martin (1994), in her study of cases processed through the Connecticut court system after the implementation of the mandatory arrest law, found that seriousness of the offense, prior history of abuse or risk (as indicated by prior arrest, prior assault, or prior court order), and alcohol or drug use by offender or victim at the time of the incident were significantly associated with the decision to prosecute. Finally, Hirschel and Hutchison (2001) in their study of misdemeanor cases processed in Charlotte, North Carolina, found that victim injury was the only significant 
factor associated with the decision to prosecute. The fact that the victim had argued with the responding officers against the arrest of the offender or the issuance of a citation was, on the other hand, the only significant factor associated with the decision not to prosecute.

\section{Multivariate Analyses: The Model}

The choice of variables included in our logistic regression model was guided by the existing research literature. As in our previous analyses, we included offender race and sex, victim injury, the involvement of drugs or alcohol, the presence of children, and whether the incident occurred in a core city. Other variables in the model focus on the offender's prior history, the mode by which the case reached the prosecutor's office (warrantless on scene arrest, arrest with warrant, or issuance of a citation), and the type of warrantless arrest statute in effect in the state.

Our previous analyses have indicated that the type of warrantless arrest provision in effect in the state exerts a significant effect on the likelihood of arrest. We wanted to examine whether the arrest provision has a similar effect on the likelihood of conviction. As discussed above, we have three states, Connecticut, Idaho and Virginia, represented in the prosecution dataset. While Idaho has a discretionary warrantless arrest law, Connecticut and Virginia both have mandatory arrest provisions.

The mode by which a case reaches the prosecutor's office was included in the model because of prior research (Hirschel \& Dean, 1995) indicating that cases in which citations are issued tend to be treated less seriously than cases in which an arrest has been made. Because of the small number of cases in which the victim was arrested we generated a model only for the offender. The following predictor variables are included in the logistic regression model tested:

- The offender was issued a citation as a result of the incident (no arrest, warrant arrest, and warrantless arrest $=0$, citation issued $=1$ ) 
- The offender was arrested on a warrant after the incident (warrantless arrest, no arrest, citation $=0$, warrant arrest $=1$ )

- The offender was arrested on the scene (warrantless arrest) (no arrest or other type of arrest $=0$, warrantless arrest $=1$ )

- $\quad$ The offender has a prior arrest $(1=$ yes, $0=$ no $)$

- Offender is white ( $1=$ white, $0=$ minority)

- Offender is male $(1=$ male, 0 = female)

- Incident occurred in the core city ( $1=$ core city, $0=$ satellite jurisdiction)

- The responding officer indicated drugs or alcohol may have been involved in the incident ( 1 = drugs and/or alcohol involved, $0=$ no drug or alcohol involvement reported)

- A minor was present when the incident occurred $(1=$ minor present, $0=$ no minor present)

- $\quad$ The primary victim reported an injury $(1=$ victim reported an injury, $0=$ no injury reported)

- $\quad$ The state's arrest statute $(1=$ mandatory arrest statute, $0=$ discretionary arrest statute)

- $\quad$ Type of relationship ( 1 = Intimate partner, 0 = Other domestic)

\section{Multivariate Analysis: Conviction as the Outcome Variable}

The results of the logistic regression analysis for the dependent variable conviction are presented in Table 10.3. The model being tested is guided by prior research and therefore the forced entry method of logistic regression is the most appropriate. The initial Chi-square test shows that the overall model is statistically significant $(\mathrm{p}<.000)$ with a $X^{2}=539.293$ at $\mathrm{df}=12$. The Model Summary results show a Nagelkerke R Square value of 0.316. As with the interpretation of the OLS R-Square, this indicates that the overall model has a moderate association with the dependent variable conviction.

The Likelihood of Conviction Table (Table 10.3) below shows that eight of the twelve independent measures are statistically significant in the model. Six of the independent measures have a positive effect on the likelihood of conviction. Two of the independent measures have a negative effect. With all other factors held constant, the odds of a conviction increase by 5.85 if the offender was arrested through the warrant process. The impact of arrest through the warrantless arrest process is also significant with an odds ratio of 5.09. Thus, with all other 
factors held constant, the likelihood of conviction is 5.85 times higher is the offender was arrested through the warrant process and 5.09 time higher if the offender was arrested through the warrantless on scene arrest. If the offender is given a citation he/she is 2.14 times more likely to be convicted. Other factors such as if the offender has a history of prior arrests increases conviction by 2.55. If the victim reports an injury (minor or serious) the likelihood of conviction increases 1.45 times. Finally, if the incident involved intimate partners the likelihood of conviction increases by 1.67 .

Table 10.3: Likelihood of Conviction

\begin{tabular}{|c|c|c|c|c|c|c|c|}
\hline & & B & S.E. & Wald & df & Sig. & $\operatorname{Exp}(B)$ \\
\hline \multirow[t]{13}{*}{ Step $1^{a}$} & Offender cited & .762 & .199 & 14.642 & 1 & .000 & 2.143 \\
\hline & Offender warrant arrest & 1.767 & .268 & 43.373 & 1 & .000 & 5.852 \\
\hline & Offender warrantless arrest & 1.628 & .188 & 74.770 & 1 & .000 & 5.093 \\
\hline & $\begin{array}{l}\text { Offender history of prior } \\
\text { arrests }\end{array}$ & .936 & .123 & 58.130 & 1 & .000 & 2.550 \\
\hline & Offender was white & -.347 & .138 & 6.318 & 1 & .012 & .707 \\
\hline & Offender was male & .180 & .136 & 1.749 & 1 & .186 & 1.197 \\
\hline & Within core city & .193 & .127 & 2.319 & 1 & .128 & 1.213 \\
\hline & Drugs or alcohol involved & .049 & .116 & .179 & 1 & .672 & 1.050 \\
\hline & Minor on scene of incident & -.061 & .117 & .277 & 1 & .599 & .940 \\
\hline & Victim injury & .373 & .118 & 9.951 & 1 & .002 & 1.452 \\
\hline & Warrantless arrest statute & -.822 & .077 & 115.289 & 1 & .000 & .439 \\
\hline & Intimate partner & .513 & .151 & 11.580 & 1 & .001 & 1.671 \\
\hline & Constant & -1.878 & .359 & 27.291 & 1 & .000 & .153 \\
\hline \multicolumn{8}{|c|}{$\begin{array}{l}\text { a. Variable(s) entered on step 1: offcit, owarra, oscena, oprior1, off_white, off_male, core_city, da_ } \\
\text { involved, minor_present, v1injury, arrstatu, ip. }\end{array}$} \\
\hline
\end{tabular}


Both offender race and the state's arrest statutes have a negative effect on the likelihood of conviction. With all other factors controlled, there is a thirty percent reduction in the likelihood of conviction if the offender is white. If the state has a mandatory arrest provision the likelihood of conviction is more than halved (.439). Other factors such as offender was male, the location of the incident (core city or outside the core city), the involvement of drugs and/or alcohol, and the presence of a minor during the incident do not have a significant impact on conviction.

\section{Discussion}

When we examined the police decision to arrest, we saw that the existence of a mandatory or preferred warrantless arrest law increased the likelihood that the police would make an arrest. The above analysis of prosecutorial decision-making and court outcome indicates that at this stage of the criminal justice process the reverse occurs. Cases in states with mandatory warrantless arrest provisions are more likely not to end up in conviction than cases that take place in states with discretionary arrest laws. Thus, it appears that prosecutors in mandatory arrest states may be compensating for the increase in caseload generated by the higher number of police arrests by dismissing more cases. ${ }^{3}$ This finding should, however, be viewed with some caution since the analysis includes only two states with mandatory warrantless arrest provisions (Connecticut and Virginia) and only one (Idaho) with a discretionary arrest law. In addition, the analysis does not include any state with a preferred warrantless arrest law.

Measures of the seriousness of the current offense and the offender's criminal history are significantly associated with the likelihood of conviction. If injury was inflicted the case is about one a half times more likely to end up in conviction. If the offender had a prior criminal record the odds of conviction increase two and a half times. In deciding whether to proceed with a case, 
seriousness of the current offense and the offender's prior record are the factors on which

prosecutors traditionally focus (see, e.g. Hirschel \& Hutchison, 2001; Martin, 1994; Schmidt and Steury, 1989). The findings of this study merely echo this well-established fact.

Our analysis also indicates that, in line with previous research (Hirschel \& Dean, 1995), cases entering the court system through the issuance of a citation are likely to be treated less seriously than those where the offender has been arrested whether on the scene or with a warrant. In the current study cases in which a citation has been issued are about twice as likely to be dismissed as cases where the offender has been arrested. This is a factor that police officers may want to take into account when deciding between arresting an offender and issuing a citation.

Consistent with our previous finding that the police were more likely to arrest in intimate partner violence cases, our analysis of the court processing of cases shows that conviction is more likely to occur in intimate partner than in other domestic cases. This may be an indication that there is a system wide inclination to treat intimate partner violence cases more seriously. This is, however, an issue that requires further investigation.

In contrast to the police decision of whether to arrest, the type of jurisdiction in which the incident occurred (core city versus satellite jurisdiction) and whether there were children present on the scene had no significant effect on the outcome. In neither case is this unexpected. While policing is conducted at the local level, the prosecution and court processing of criminal cases are more centralized. Thus, one would expect a previous finding of an effect of the type of locale in which the offense took place to dissipate. One might expect, as we have suggested in chapter nine, that the presence of minors would increase the likelihood of arrest because the responding officers are taking seriously the well-documented deleterious effects that children experience as a result of exposure to domestic violence. However, when the focus turns to processing the 
criminal cases against the defendant, and the police intervention has triggered some system response to the needs of the children, typically by involving the Department of Social Services, it is also to be expected that this consideration would no longer feature so prominently.

While there was no significant association between the offender's sex and the likelihood of conviction, the offender's race did exert a significant effect on the likelihood of conviction. Whites were thirty percent more likely than minorities not to have the case result in conviction. This finding is inconsistent with what we saw at the police stage, where whites were more likely than minorities to be arrested. A number of factors, such as social status, type of legal representation, willingness of the victim to proceed with the prosecution, and access to diversion programs may explain why whites were more likely to be arrested, but less likely to be convicted. This is a significant issue that merits further investigation.

\footnotetext{
${ }^{1}$ The full population of dual arrest cases was taken in each jurisdiction, whereas only a random sample of the no arrest and single arrest cases was selected.

${ }^{2}$ Violent offenses primarily consisted of assault, but could include such offenses as rape and robbery. If the offense was not known to include an element of violence, as was the case with disorderly conduct and breach of the peace, it was treated as non-violent.

${ }^{3}$ A total of $98.6 \%$ of intimate partner violence cases that did not end up in conviction were dismissed by the prosecutor. For other domestic cases that percentage was $98.8 \%$.
} 


\section{Chapter 11 \\ Rearrest}

The final issue examined in this report concerns the impact of police intervention on the likelihood of reoffending as measured by rearrest. Of particular concern is whether there is a differential impact on males and females who are arrested for domestic violence offenses, particularly those who are arrested as part of a dual arrest.

As was the situation with our investigation of court processing of domestic violence cases, the sample for this aspect of the project comprises all Phase II cases from the states of Connecticut, Idaho, and Virginia $(\mathrm{N}=3,202)$. As discussed in the previous chapter, concerns about the quality of data in Tennessee led to the omission of cases from that state. All offenders and victims in these 3,202 cases were tracked through either the state or local record system to see if they were rearrested after the incident that brought them into the year 2000 NIBRS dataset. The follow up period was a minimum of three years, the maximum a little over five years.

\section{Rearrest}

Just over half (53.0\%) of the offenders were rearrested in the three or more years that they were tracked after entering the sample (see Table 11.1). Just over a quarter (27.9\%) had a violent offense in their subsequent arrest record. ${ }^{1}$ Offenders in intimate partner incidents were more likely than offenders in other domestic both to have any subsequent arrest (55.9\% v. 45.2\%) and a subsequent arrest for a violent offense (29.7\% v. $22.7 \%)$.

Involved parties who had been designated the primary victims in the incident were less likely than the offenders to be rearrested. Just over a third (34.3\%) were arrested for a subsequent offense with about one in six (14.0\%) arrested for a violent 
offense (Table 11.1). Victims in intimate partner incidents were more likely than victims in other domestic cases both to have any subsequent arrest (36.3\% v. 28.5\%) and a subsequent arrest for a violent offense (14.6\% v. 12.1\%).

Table 11.1

Rearrest by Victim-Offender Relationship

\begin{tabular}{|l|l|l|l|}
\hline & $\begin{array}{l}\text { Intimate Partner } \\
\text { Cases }\end{array}$ & $\begin{array}{l}\text { Other Domestic } \\
\text { Cases }\end{array}$ & Total \\
\hline Offender & & & \\
\hline Subsequent Arrest & $1228(55.9 \%)$ & $358(45.2 \%)$ & $1586(53.0 \%)$ \\
\hline $\begin{array}{l}\text { Subsequent Violent } \\
\text { Arrest }\end{array}$ & $653(29.7 \%)$ & $180(22.7 \%)$ & $833(27.9 \%)$ \\
\hline Victim & & & \\
\hline Subsequent Arrest & $748(36.3 \%)$ & $209(28.5 \%)$ & $957(34.3 \%)$ \\
\hline $\begin{array}{l}\text { Subsequent Violent } \\
\text { Arrest }\end{array}$ & $301(14.6 \%)$ & $89(12.1 \%)$ & $390(14.0 \%)$ \\
\hline
\end{tabular}

Prior to conducting multivariate analyses to determine the relative impact of involved party, incident, criminal justice system processing, and jurisdictional variables on the likelihood of rearrest, we considered it would be instructive to examine the bivariate relationships between these variables and rearrest. We decided to focus on subsequent arrest as the outcome variable for these analyses for both theoretical and methodological reasons. First, since abusive behavior in intimate partner relationships comprises acts such as emotional abuse and controlling behaviors that are not criminal, it appeared wise to use a measure that took into consideration the widest range of criminal offenses and was not limited to offenses that were overtly violent in nature. Second, using subsequent arrest, rather than subsequent arrest for a violent offense, provided a far more even distribution of cases in the two categories of the outcome variable. 
This document is a research report submitted to the U.S. Department of Justice. This report has not been published by the Department. Opinions or points of view expressed are those of the author(s) and do not necessarily reflect the official position or policies of the U.S. Department of Justice.

\section{Background Characteristics of the Involved Parties and Rearrest}

Both sex of the party and the existence of a prior arrest record, whether it was for a violent offense or any offense, highly impacted the likelihood of rearrest of both parties involved in the incident that brought the case into the sample. While $60.3 \%$ of the male offenders in intimate partner cases and $51.8 \%$ of the male offenders in other domestic cases were rearrested, the comparative figures for female offenders were $42.5 \%$ and 34.4\% respectively (see Table 11.2). The same pattern held true for victim recidivism rates with $52.2 \%$ of the male victims in intimate partner cases, and $34.9 \%$ of male victims in other domestics being rearrested, while the recidivism rates for female victims were $31.1 \%$ and $24.6 \%$ respectively. In contrast to sex, race had little effect on the likelihood of recidivism by either of the parties in the incident (see Table 11.2).

Table11.2

\section{Rearrest by Involved Party Characteristics and Victim-Offender Relationship}

\begin{tabular}{|c|c|c|c|c|}
\hline \multirow{2}{*}{\begin{tabular}{|l|} 
\\
Involved Party \\
Characteristics \\
\end{tabular}} & \multicolumn{2}{|c|}{$\begin{array}{c}\text { Percent Rearrested: Intimate } \\
\text { Partner Cases }\end{array}$} & \multicolumn{2}{|c|}{$\begin{array}{c}\text { Percent Rearrested: Other } \\
\text { Domestic Cases }\end{array}$} \\
\hline & Offender & Victim & Offender & Victim \\
\hline Sex & & & & \\
\hline Male & 996 (60.3\%) & 268 (52.2\%) & 254 (51.8\%) & 98 (34.9\%) \\
\hline Female & 233 (42.5\%) & 481 (31.1\%) & 104 (34.4\%) & $111(24.6 \%)$ \\
\hline Race & & & & \\
\hline Minority & 384 (54.3\%) & 229 (33.5\%) & 249 (44.5\%) & 144 (28.7\%) \\
\hline White & 837 (56.6\%) & 513 (37.9\%) & 106 (47.3\%) & $61(27.6 \%)$ \\
\hline Prior Arrest & & & & \\
\hline Yes & 985 (75.8\%) & 557 (63.1\%) & 248 (71.3\%) & 126 (59.7\%) \\
\hline No & $243(27.1 \%)$ & 192 (16.3\%) & 110 (24.8\%) & 83 (15.9\%) \\
\hline Prior Violent Arl & & & & \\
\hline Yes & $655(78.5 \%)$ & 307 (66.5\%) & $143(72.6 \%)$ & $70(63.6 \%)$ \\
\hline No & $573(42.0 \%)$ & 442 (27.6\%) & 215 (36.1\%) & 139 (22.3\%) \\
\hline Total & 1229 (55.9\%) & 749 (36.3\%) & $358(45.2 \%)$ & 209 (28.5\%) \\
\hline
\end{tabular}


Prior arrest record exerted an even greater impact than sex. While $75.8 \%$ of the offenders in intimate partner cases and $71.3 \%$ of the offenders in other domestic cases who had prior arrest records were rearrested, the comparative figures for offenders without prior arrest records were $27.1 \%$ and $24.8 \%$ respectively (see Table 11.2 ). The contrast between the rearrest records of victims with and without prior records was equally great. While $63.1 \%$ of the victims in intimate partner cases and $59.7 \%$ of the victims in other domestic cases who had prior arrest records were rearrested, the comparative figures for victims without prior arrest records were $16.3 \%$ and $15.9 \%$ respectively. Similar differences in the rearrest of those with and without prior arrest records were observed when prior arrest for a violent offense was taken as the predictor variable (see Table 11.2).

\section{Incident Characteristics and Rearrest}

The characteristics of the incident that brought the case into the sample did not exert as striking effects on the likelihood of recidivism as sex and prior record had been observed to produce. However, both the offenders and victims involved in incidents where drug and/or alcohol use had been a factor were consistently about 15\% more likely to recidivate than the parties in incidents where drug and/or alcohol use had not been a factor (see Table 11.3). While cases in which someone other than the victim had called the police were consistently more likely to result in subsequent arrest than incidents in which the victim had called the police, the differences in recidivism rates were small. No consistent patterns were to be observed with regard to either offense seriousness or victim injury, though both seriousness of offense and seriousness of injury tended to be associated with recidivism. 
Table11.3

Rearrest by Incident Characteristics and Victim-Offender Relationship

\begin{tabular}{|l|r|l|l|l|}
\hline & \multicolumn{2}{|c|}{$\begin{array}{r}\text { Percent Rearrested: Intimate } \\
\text { Partner Cases }\end{array}$} & $\begin{array}{r}\text { Percent Rearrested: Other } \\
\text { Domestic Cases }\end{array}$ \\
\hline $\begin{array}{l}\text { Incident } \\
\text { Characteristics }\end{array}$ & Offender & Victim & Offender & Victim \\
\hline $\begin{array}{l}\text { Who Called Police } \\
\text { Victim }\end{array}$ & $519(54.3 \%)$ & $281(31.1 \%)$ & $126(44.5 \%)$ & $72(26.1 \%)$ \\
Other & $710(57.1 \%)$ & $468(40.4 \%)$ & $232(45.6 \%)$ & $137(30.0 \%)$ \\
\hline $\begin{array}{l}\text { Offense } \\
\text { Aggravated Assault }\end{array}$ & $105(57.7 \%)$ & $23(48.9 \%)$ & $42(56.0 \%)$ & $6(33.3 \%)$ \\
Simple Assault & $1047(57.2 \%)$ & $169(39.8 \%)$ & $283(45.4 \%)$ & $58(35.2 \%)$ \\
Intimidation & $77(41.4 \%)$ & $6(33.3 \%)$ & $33(35.1 \%)$ & $2(16.7 \%)$ \\
\hline Injury & & & & \\
Serious & $33(58.9 \%)$ & $27(50.9 \%)$ & $10(58.8 \%)$ & $8(47.1 \%)$ \\
Minor & $609(58.8 \%)$ & $365(38.4 \%)$ & $137(46.3 \%)$ & $71(27.0 \%)$ \\
None & $510(55.4 \%)$ & $357(33.8 \%)$ & $178(46.2 \%)$ & $130(28.7 \%)$ \\
\hline Drug/Alcohol Use & & & & \\
Yes & $441(63.9 \%)$ & $165(47.8 \%)$ & $91(55.8 \%)$ & $23(43.4 \%)$ \\
No & $562(49.3 \%)$ & $561(34.5 \%)$ & $202(40.2 \%)$ & $173(27.5 \%)$ \\
\hline Total & $1229(55.9 \%)$ & $749(36.3 \%)$ & $358(45.2 \%)$ & $209(28.5 \%)$ \\
\hline
\end{tabular}

\section{Case Processing Characteristics and Rearrest}

Involved parties who had been arrested or cited in the incident were consistently somewhat more likely to recidivate than those who had not been arrested or cited (see Table 11.4). Though, as indicated in Chapter ten, the vast majority of cases in which citations had been issued or arrests made, were at least initially prosecuted, the offenders in the few cases in which prosecution did not ensue were far less likely to recidivate than those involved in cases where prosecution did proceed. Offenders who were prosecuted and convicted were more likely to be rearrested than offenders who were not convicted. 
The same patterns held for victims in intimate partner cases, but not for victims in other domestics. The numbers of victims in other domestic cases are, however, very small.

Table11.4

Rearrest by Case Processing Characteristics and Victim-Offender Relationship

\begin{tabular}{|l|r|r|r|r|}
\hline & $\begin{array}{r}\text { Percent Rearrested: Intimate } \\
\text { Partner Cases }\end{array}$ & $\begin{array}{r}\text { Percent Rearrested: Other } \\
\text { Domestic Cases }\end{array}$ \\
\hline $\begin{array}{l}\text { Case Processing } \\
\text { Characteristics }\end{array}$ & Offender & Victim & Offender & Victim \\
\hline $\begin{array}{l}\text { Arrested or Cited } \\
\text { Yes }\end{array}$ & $968(56.7 \%)$ & $167(44.2 \%)$ & $249(48.1 \%)$ & $38(36.5 \%)$ \\
No & $261(53.0 \%)$ & $582(34.6 \%)$ & $109(39.8 \%)$ & $171(27.2 \%)$ \\
Total & $1229(55.9 \%)$ & $749(36.3 \%)$ & $358(45.2 \%)$ & $209(28.5 \%)$ \\
\hline Prosecuted & & & & \\
Yes & $881(67.7 \%)$ & $139(66.8 \%)$ & $172(64.9 \%)$ & $31(59.6 \%)$ \\
No & $55(44.4 \%)$ & $15(48.4 \%)$ & $28(48.3 \%)$ & $5(100 \%)$ \\
Total & $936(65.7 \%)$ & $154(64.4 \%)$ & $200(61.9 \%)$ & $36(63.2 \%)$ \\
\hline Convicted & & & & \\
Yes & $403(72.3 \%)$ & $55(76.4 \%)$ & $60(67.4 \%)$ & $5(50.0 \%)$ \\
No & $451(63.7 \%)$ & $82(63.1 \%)$ & $105(63.3 \%)$ & $24(60.0 \%)$ \\
Total & $854(67.5 \%)$ & $137(67.8 \%)$ & $165(64.7 \%)$ & $29(58.0 \%)$ \\
\hline
\end{tabular}

\section{Jurisdictional Characteristics and Rearrest}

Three major issues affect our findings on recidivism. First, states differ greatly in the extent to which they allow offenders to have their criminal records expunged. Of the three states in this phase of the project, Connecticut has by far the most expansive expungement laws. Second, while some states have well established state record systems, in other states record checks on an offender have to be conducted at the local level.

While Connecticut and Virginia have well established state record systems that were used to provide the data on arrest both prior and subsequent to the incident that brought an offender into our sample, Idaho did not have such a state record system and record checks 
were conducted at the local level. Third, offender mobility affects the likelihood that an arrest will be captured either at the state or local level. In the subsequent analyses we are able to examine the potential effect of record expungement and type of record check conducted (state v. local) by taking the state into account. To tap the issue of offender mobility we use a jurisdictional variable we have in our dataset: population percentage change 1990 to 2000 .

All three of these issues appear to affect the likelihood of rearrest, though not necessarily in the direction that might be predicted. First, Connecticut, with its far more liberal expungement laws, had by far the lowest recidivism rates (see Table 11.5).

Table 11.5

Rearrest by Jurisdictional Characteristics and Victim-Offender Relationship

\begin{tabular}{|l|l|l|l|l|}
\hline & \multicolumn{2}{|c|}{$\begin{array}{r}\text { Percent Rearrested: Intimate } \\
\text { Partner Cases }\end{array}$} & \multicolumn{2}{|c|}{$\begin{array}{r}\text { Percent Rearrested: Other } \\
\text { Domestic Cases }\end{array}$} \\
\hline $\begin{array}{l}\text { Jurisdictional } \\
\text { Characteristics }\end{array}$ & Offender & Victim & Offender & Victim \\
\hline $\begin{array}{l}\text { State } \\
\text { Connecticut }\end{array}$ & $299(43.5 \%)$ & $157(23.0 \%)$ & $77(27.5 \%)$ & $45(15.9 \%)$ \\
$\begin{array}{l}\text { Idaho } \\
\text { Virginia }\end{array}$ & $527(70.5 \%)$ & $342(57.8 \%)$ & $156(67.5 \%)$ & $94(58.0 \%)$ \\
\hline Record Check & $403(52.7 \%)$ & $250(31.8 \%)$ & $125(44.5 \%)$ & $70(24.3 \%)$ \\
State & $702(48.3 \%)$ & $407(27.7 \%)$ & $202(36.0 \%)$ & $115(20.1 \%)$ \\
Local & $527(70.5 \%)$ & $342(57.8 \%)$ & $156(67.5 \%)$ & $94(58.0 \%)$ \\
\hline Jurisdiction & & & & \\
Satellite Jurisdiction \\
Core city
\end{tabular}


Second, far higher recidivism rates were observed for jurisdictions in which local record searches were conducted. Clearly the inclusion of Connecticut as one of the two states where state record checks were conducted affects this finding. However, it should be noted that the other state in which state record checks were undertaken (Virginia) consistently had lower recidivism rates than the one state (Idaho) in which local record checks were conducted. Third, population mobility is highly associated with likelihood of recidivism. However, the association is a positive one. The greater the population change in the jurisdiction between 1990 and 2000, the greater the likelihood of recidivism. Since all the jurisdictions that had population changes of $30 \%$ or more were in Idaho, the associations found between both local record search and population mobility and likelihood of recidivism are interrelated.

\section{Multivariate Analysis}

The choice of variables included in our logistic regression model was guided by the existing research literature and the methodological concerns raised above.

Consequently, the forced entry method was used. The following predictor variables were included in the logistic regression model tested:

- The level at which record checks are conducted ( 1 = State level, 0 = local level)

- The offender has a prior arrest $(1=$ yes, $0=$ no)

- The offender has a prior record of violence $(1=$ yes, 0 = no)

- Offender is male ( $1=$ male, $0=$ female)

- Offender is white ( 1 = white, $0=$ minority)

- $\quad$ The primary victim reported an injury ( 1 = victim reported an injury, 0 = no injury reported)

- Drugs and/or alcohol were involved in the incident $(1=$ yes, $0=$ no $)$

- The offender was convicted for the initial offense $(1=$ yes, $0=$ no)

- The offender was arrested or issued a citation as a result of the incident (no arrest $=0$; warrant arrest, and warrantless arrest, citation issued $=1$ )

- Incident occurred in the core city ( $1=$ core city, $0=$ satellite jurisdiction)

- The city experienced a population change between 1990 to 2000 (1 = Less than $10 \%, 2=10 \%$ to $29 \%, 3=30 \%$ or more) 
- $\quad$ Type of relationship ( 1 = Intimate partner, 0 = Other domestic)

The ensuing Model Chi-square test is statistically significant $(\mathrm{p}<.000)$ with a $X^{2}=$

716.37 with 12 degrees of freedom. The Model Summary results for subsequent arrests show a Nagelkerke R Square value of 0.359 (Table 11.6). As with the interpretation of the OLS R-Square, this indicates that the overall model has a moderate association with the dependent variable rearrest.

Table 11.6: Likelihood of Subsequent Arrest

\begin{tabular}{|c|c|c|c|c|c|c|c|}
\hline & & B & S.E. & Wald & $d f$ & Sig. & $\operatorname{Exp}(B)$ \\
\hline \multirow[t]{13}{*}{$\bar{a}$} & State & .307 & .185 & 2.759 & 1 & .097 & 1.359 \\
\hline & Prior record & 1.965 & .176 & 124.814 & 1 & .000 & 7.135 \\
\hline & Prior record of violence & .000 & .002 & .008 & 1 & .930 & 1.000 \\
\hline & Offender was male & .690 & .112 & 37.885 & 1 & .000 & 1.994 \\
\hline & Offender was white & -.125 & .115 & 1.177 & 1 & .278 & .883 \\
\hline & Victim reported injury & .043 & .103 & .172 & 1 & .679 & 1.044 \\
\hline & Drugs/alcohol involved & .233 & .104 & 5.052 & 1 & .025 & 1.262 \\
\hline & $\begin{array}{l}\text { Offender convicted for } \\
\text { initial offense }\end{array}$ & .230 & .129 & 3.190 & 1 & .074 & 1.259 \\
\hline & Offender arrested or cited & .100 & .138 & .523 & 1 & .470 & 1.105 \\
\hline & Core city location & .138 & .128 & 1.150 & 1 & .284 & 1.148 \\
\hline & $\begin{array}{l}\text { City population change } \\
\text { between } 1990 \text { to } 2000\end{array}$ & .395 & .108 & 13.262 & 1 & .000 & 1.484 \\
\hline & Intimate partner incident & .077 & .117 & .429 & 1 & .512 & 1.080 \\
\hline & Constant & -2.578 & .324 & 63.485 & 1 & .000 & .076 \\
\hline
\end{tabular}

a. Variable(s) entered on step 1: state, oprior1, oprivio1, off_male, off_white, v1injury, da_ involved, offender_convicted, oarorc, core_city, ch9020, ip.

$X^{2}=716.37$ with $12 \mathrm{df}(\mathrm{p}<.000)$

Nagelkerke R Square $=0.359$ 
The results displayed in Table 11.6 "Likelihood of Subsequent Arrest” indicate that four of the twelve independent measures are statistically significant in the model. Four of these variables, the offender had a prior record, the offender was a male, drugs and/or alcohol were involved in the incident, and higher increases in population between 1990 and 2000 all displayed a positive effect on rearrest.

With all other factors being equal, the likelihood of an offender being rearrested increases by 7.135 if he/she has a prior record of offending. Male offenders have an increased likelihood (odds ratio $=1.994$ ) of rearrest. If drugs or alcohol were involved in the initial incident, the likelihood of rearrest increases by an odds ratio of 1.262. A one unit increase in percent population change between 1990 and 2000 for the jurisdiction where the incident occurred increases the likelihood of rearrest by 1.484 times.

\section{Discussion}

The results of this analysis are consistent with prior research that shows that prior behavior is the most significant predictor of subsequent behavior. Offenders with prior arrest records were over seven times more likely than those without prior records to be rearrested. Being arrested or cited for the incident that brought the case into the sample was not, however, a significant predictor of subsequent arrest. Nor was being convicted for that incident. For many of these offenders the current case was just one in a series of arrests.

The involvement of alcohol or drugs in the incident was, however, a significant predictor of subsequent arrest. This finding would appear to highlight the recognized interrelationship between alcohol/drug use and battering and highlight the need for offenders to receive treatment for both problems. 
Being male was also a significant predictor of rearrest. It is uncertain to what extent this finding is an indication of the intractability of the male psyche or is the result of other factors such as the lack of availability of, referral to, and successful usage of treatment options.

While the type of record search conducted (state versus local) did not produce any significant effect on the likelihood of a rearrest, there was a significant association between population mobility and rearrest. The more mobile the population, the greater the likelihood of a rearrest. This finding suggests an association between population mobility and the prevalence of battering. It may also indicate that population change constitutes a poor surrogate for offender mobility.

\footnotetext{
${ }^{1}$ Violent offenses primarily consisted of assault, but could include such offenses as rape and robbery. If the offense was not known to include an element of violence, as was the case with disorderly conduct and breach of the peace, it was treated as non-violent.
} 


\section{Chapter 12 Policy Implications}

The impact of widespread adoption of domestic violence arrest legislation on the police policies and practices has been monumental. Seldom has research, such as that of the arrest experiments, had such a profound impact on legislation, and seldom has legislation so fundamentally changed policing. To date, all states in the U.S. have enacted laws to specify clearly the conditions under which someone is to be arrested in a domestic violence situation. As noted previously, subsequent to the enactment of these laws, researchers have noted substantial increases in arrests for intimate partner violence, arrests of women, and the number of dual arrests.

Available research on the impact of these laws on dual arrest rates has shown wide variations in dual arrest rates, but this variation may result from differing methodologies and data sets. The current project aimed to overcome limitations of existing research and examine dual arrest for intimate partner violence cases in a large, multi-state sample, which took into consideration a wide range of incident and agency specific variables. Other domestics (parentchild, siblings etc.), acquaintances, and strangers comprised three separate comparison groups.

The findings of the two phases of this research, as detailed in the previous chapters, offer important implications for criminal justice system policies. These findings, and associated policy implications are discussed below.

\section{Phase I Findings}

Phase I analyzed year 2000 NIBRS data for all assault and intimidation cases to investigate the extent to which dual arrest is occurring nationwide, the relationship between incident and offender characteristics, and the effect of state laws on police handling of these 
cases for all relationship types. The following chart highlights important findings from this

phase.

\section{Phase I Findings}

\section{Arrest practices}

- A total of 213,598 (37.0\%) of the 577,862 assault and intimidation incidents to which the police responded resulted in arrest. Arrest rates were higher for intimate partner (49.9\%) and other domestics (44.5\%) than for acquaintance (29.1\%) and stranger (35\%) cases.

- The overall dual arrest rate was $1.3 \%$. Dual arrest rates were higher for intimate partner (1.9\%) and other domestics (1.5\%) than for acquaintance $(1.0 \%)$ and stranger $(0.8 \%)$ cases.

- Of the 213,598 incidents with an arrest, 206,370 (35.7\%) comprised incidents in which the police made one or more arrests and 7,228 (3.4\%) involved situations in which the responding officers had indicated that they had arrested both of the involved parties.

Impact of domestic violence legislation on arrest practices (for all relationship categories)

- States with mandatory and preferred arrest laws produced significantly higher domestic violence arrest rates compared to states with discretionary arrest laws.

- In mandatory arrest agencies, with other factors held constant, the odds of arrest in intimate partner incidents increase by $97 \%$ compared to discretionary arrest agencies. In preferred arrest agencies the increase is even higher: about $177 \%$.

- These higher arrest rates are observed in intimate partner, other domestic violence cases and in acquaintance and stranger cases as well, revealing an apparent spillover effect.

- Mandatory arrest laws significantly increased the likelihood of dual arrest for all three of the relationship categories examined (intimate partner, other domestic, and acquaintance).

- The existence of a preferred arrest law did not produce a similarly significant impact on the likelihood of dual arrest.

- The only mandatory state that did not have a primary aggressor provision at the time of the study (Connecticut) also had by far the highest dual arrest rate. 


\section{Impact of Incident and victim/offender characteristics on arrest practices (for all relationship} categories)

- Females were no more likely than males to be arrested in cases of intimate partner violence.

- For all relationship categories, aggravated assault cases were significantly more likely than simple assault cases to result in arrest.

- For all relationship categories, intimidation cases were significantly less likely than simple assault cases to result in arrest.

- For all relationship categories, offenses occurring in residences were significantly more likely to result in arrest than those taking place in public.

- Offender race had a significant effect on the response to intimate partner cases. Arrest was more likely if the offender was white.

- Cases involving intimate partners and acquaintances were more likely to result in arrest if the offender was over 21. However, in other domestic cases, arrest was more likely if the offender was under 21.

- The presence of mandatory and preferred arrest laws mediated the effect of offense location on the likelihood of arrest. In intimate partner and acquaintance cases the existence of both mandatory and preferred arrest laws, and in the case of stranger cases mandatory arrest laws, significantly equalized the likelihood of arrest.

- The presence of preferred arrest laws mediated the effect of race on the likelihood of arrest. In intimate partner violence cases, the existence of a preferred arrest law equalized treatment of black and white offenders.

Impact of victim and offender gender on arrest practices.

- Police were equally likely to resolve cases involving both heterosexual and same sex couples by making some arrests in the case.

- However, the dual arrest rates for same sex couples (both female and male) were almost ten times the rate for cases with male victims and female offenders and over 30 times the rate found in cases with female victims and male offenders.

- There was little difference in the probability of dual arrest between female and male same sex couples for offenses of aggravated and simple assault, but female same sex couples (11.7\%) were twice as likely as male sex couples $(5.7 \%)$ to have cases of intimidation resolved by a dual arrest.

- Same sex female couples who were involved in incidents that took place outside the home were more likely to be arrested than any of the other 


\begin{tabular}{|l|l|}
\hline victim-offender sex categories. \\
$\begin{array}{l}\text { - If the primary victim in a heterosexual incident was male the likelihood of } \\
\text { a dual arrest was three times greater than when the primary victim was a } \\
\text { female. }\end{array}$ \\
\hline
\end{tabular}

\section{Phase II Findings}

In Phase II, which focuses only on intimate partner and other domestic cases, the NIBRS dataset was supplemented by the addition of numerous variables from several different sources to explain more fully the divergent practices we observed in arrest patterns. First, we assessed the agency's domestic violence policy as it related both to the state statute and to the agency's arrest practices. Second, we added detailed incident-level variables not contained in NIBRS to understand their contribution to arrest patterns. During this phase, data were also collected on court case processing and criminal histories to determine the likelihood of conviction in the current case and subsequent offending. The following chart highlights important findings from this phase.

\section{Phase II Findings}

Policy Analysis

- The majority of responding departments had specific domestic violence policies in 2000; only $6 \%$ of respondents reported having no specific policy.

- The overwhelming majority of agencies in states with a mandatory arrest policy also had mandatory arrest policies in place.

- Less predictable results were found for agencies in preferred and discretionary arrest states, with the general trend being to have a stricter arrest policy than required by state law; for example, a police department in a discretionary arrest state reporting that it had a preferred or mandatory arrest policy.

- Department policies tended to correlate highly with the state statute, and 


\begin{tabular}{|c|c|}
\hline & $\begin{array}{l}\text { both correlated highly with arrest practices. } \\
\text { The existence of either a state statute or an agency policy mandating the } \\
\text { identification of a primary aggressor exerted a significant effect on the } \\
\text { dual arrest rate. Agencies in states without primary aggressor laws that } \\
\text { did not have policies mandating the identification of primary aggressors } \\
\text { reported a dual arrest rate in intimate partner violence cases that was four } \\
\text { times the dual arrest rate observed in the other jurisdictions. }\end{array}$ \\
\hline \multicolumn{2}{|c|}{ Impact of added incident-level variables on arrest practices } \\
\hline & $\begin{array}{l}\text { - Contrary to Phase I analysis, Phase II analysis showed that location of the } \\
\text { incident does not exert a significant impact on the likelihood of arrest. } \\
\text { The availability of the offender on the scene appears to have taken its } \\
\text { place. If the offender remains on the scene, he/she is nearly four times } \\
\text { more likely to be arrested than if he/she leaves the scene. } \\
\text { - Consistent with Phase I analyses, arrest was more likely in intimate } \\
\text { partner than in other domestic cases. } \\
\text { - Victim injury, presence of minors, and the incident taking place in a core } \\
\text { city manifested a significant positive effect on the likelihood of arrest. } \\
\text { - Dual arrests were more likely to occur in intimate partner cases and in } \\
\text { core cities as opposed to satellite jurisdictions. } \\
\text { - The responding offers were more likely to make dual arrests if the } \\
\text { offender remained on the scene. They were less likely to make dual } \\
\text { arrests if the offender was white. } \\
\text { - When the primary aggressor was male, the other party was significantly } \\
\text { less likely to be arrested with the primary aggressor. Since most of the } \\
\text { incidents in this study involved parties of the opposite sex, this could be } \\
\text { taken as evidence that police may be adopting a more lenient attitude } \\
\text { toward females. However, this finding may simply be an artifact of } \\
\text { reporting. }\end{array}$ \\
\hline \multicolumn{2}{|c|}{ Court processing of domestic violence cases } \\
\hline & $\begin{array}{l}\text { - Although the existence of a mandatory or preferred warrantless arrest law } \\
\text { increased the likelihood of arrest, prosecutorial decision-making and court } \\
\text { outcome indicated the reverse. } \\
\text { - Cases in states with mandatory warrantless arrest provisions were more } \\
\text { likely not to end up in conviction than cases that took place in states with } \\
\text { discretionary arrest laws. } \\
\text { - Significantly less than half of the cases in which an arrest had been made } \\
\text { or a citation issued resulted in conviction. Nearly all of these cases were }\end{array}$ \\
\hline
\end{tabular}




\begin{tabular}{|c|c|}
\hline & $\begin{array}{l}\text { dismissed by the prosecutor. } \\
\text { - Seriousness of the current offense and the offender's criminal history } \\
\text { were significantly associated with the likelihood of conviction. } \\
\text { - If injury was inflicted the case was about one and a half times more likely } \\
\text { to end up in conviction. } \\
\text { - Whites were thirty percent more likely than minorities not to have the } \\
\text { case result in conviction, a possible system effect of treating cases } \\
\text { involving minorities more seriously than those with non-minority } \\
\text { participants. } \\
\text { - Consistent with our previous finding that the police were more likely to } \\
\text { arrest in intimate partner violence cases, our analysis of the court } \\
\text { processing of cases showed that conviction was more likely to occur in } \\
\text { intimate partner than in other domestic cases. This may be an indication } \\
\text { that there is a system wide inclination to treat intimate partner violence } \\
\text { cases more seriously. This is, however, an issue that requires further } \\
\text { investigation. }\end{array}$ \\
\hline \multicolumn{2}{|l|}{ Reoffending } \\
\hline & $\begin{array}{l}\text { - Offenders with prior arrest records were over seven times more likely } \\
\text { than those without prior records to be rearrested. } \\
\text { - Arrest, citation or conviction for the incident that brought the case into the } \\
\text { sample were not significant predictors of subsequent arrest. } \\
\text { - The involvement of alcohol or drugs in the incident was a significant } \\
\text { predictor of subsequent arrest. } \\
\text { - Being male was a significant predictor of reoffending. }\end{array}$ \\
\hline
\end{tabular}

\section{Policy Implications of Study Findings}

The findings from this study provide evidence that mandatory and preferred arrest laws are producing the intended effect of increasing arrest rates in intimate partner and other domestic violence cases. The $49.9 \%$ and $44.5 \%$ arrest rates for all intimate partner and other domestic assault and intimidation cases are well above the arrest rates of $7 \%$ to $15 \%$ reported by research studies conducted prior to the advent of mandatory and preferred domestic violence laws (see, e.g., Bayley, 1986; Dutton, 1984; Holmes \& Bibel, 1988; Worden and Pollitz, 1984). In 
This document is a research report submitted to the U.S. Department of Justice. This report has not been published by the Department. Opinions or points of view expressed are those of the author(s) and do not necessarily reflect the official position or policies of the U.S. Department of Justice.

addition, our Phase I HGLM analysis indicated that arrests for domestic violence in agencies with mandatory and preferred arrest laws were significantly higher than those for departments in discretionary agencies. This would appear to show that police officers are following their department's arrest policy and state law on domestic violence closely.

States with mandatory and preferred domestic violence arrest laws were also observed to have significantly higher arrest rates for non-domestic acquaintance and stranger cases than states with discretionary arrest laws. This may indicate that domestic violence arrest laws are producing a significant spill-over effect. On the other hand, it may be argued that it was the states that already had more aggressive arrest policies that adopted mandatory and preferred domestic violence arrest laws. Longitudinal research is required to answer this question.

The overall dual arrest rate was low, 1.3\%, with dual arrest rates higher for intimate partner (1.9\%) and other domestics (1.5\%) than for acquaintance (1.0\%) and stranger (0.8\%) cases. This suggests that dual arrests are not occurring as frequently as prior more limited studies have suggested. Our analyses of the effect of mandatory and preferred arrest laws on the likelihood of officers making dual arrests did, however, provide support for the hypothesis that mandatory arrest laws produce higher rates of dual arrest. Mandatory arrest laws may lead officers to adopt a legalistic orientation (Wilson, 1968), because they consider it inappropriate to use discretion. Thus, when faced with a situation that appears to involve two mutual combatants, they opt to arrest both, leaving it to the prosecutor, and perhaps the court, to determine culpability. This eventuality is supported by our finding that arrests were less likely to result in conviction if made in a state with a mandatory arrest law as opposed to a state with a discretionary arrest law.

There is also evidence that the responding police officers are particularly likely to assign 
joint culpability for an incident that involves a same sex couple. The dual arrest rates for both female and male same sex couples was 10 times that for heterosexual couples with a male offender and a female victim and 30 times that for heterosexual couples with a female offender and a male victim. This finding could indicate that officers are unable, or unwilling, to assign primary responsibility to one of the parties involved in a same sex incident. The finding that female same sex couples were twice as likely as male sex couples to have cases of intimidation resolved by a dual arrest would appear to support the supposition that sex role stereotyping may play a part in the arrest decision; while some level of violence may be regarded as "normal" between two males, such violence is intolerable between two females. The factors that contribute to the far higher dual arrest rates observed when same sex couples are involved in an incident require more intensive examination. Whatever the outcome of such an examination, there would appear to be a need to train officers more intensively to recognize the special circumstances that exist in same sex incidents.

Interestingly, the existence of a preferred arrest law did not significantly increase the likelihood of dual arrest in either intimate partner or other domestic cases. Such an effect was observed only for cases involving acquaintances. Only one of the preferred arrest states involved in this study (Tennessee) had a primary aggressor law. While leaving the responding officers some discretion when responding to domestic calls is clearly associated with lower dual arrest rates, it is not totally clear what factors prompt officers to use this discretion.

Our data do, however, suggest that primary aggressor provisions are associated with fewer dual arrests, and thus, should be considered by policy-makers. It is notable that agencies in states without primary aggressor laws that had policies mandating the identification of primary aggressors reported a dual arrest rate in intimate partner violence cases that that was equal to that 
This document is a research report submitted to the U.S. Department of Justice. This report has not been published by the Department. Opinions or points of view expressed are those of the author(s) and do not necessarily reflect the official position or policies of the U.S. Department of Justice.

reported by agencies in states with primary aggressor laws, and less than a quarter of the dual arrest rate observed in jurisdictions that operated in states without primary aggressor laws and did not provide primary aggressor instruction. In addition, the only mandatory state that did not have a primary aggressor provision at the time of the study (Connecticut) also had by far the highest dual arrest rate.

Several of our findings indicate that officers appear to execute their duties without considering the extra-legal characteristic of the sex of the involved parties. We found that sex exerted no significant effect on the response to intimate partner cases. Thus, no support is provided by our analyses for the hypothesis that the increase in the number of female arrests in intimate partner violence cases can be attributed to their disproportionate arrest rate for minor offenses. However, the fact that males and females were equally likely to be arrested may be evidence of an increase in female arrests, if in the past males were more likely to be arrested. We did find that when the primary aggressor is male, the other party is less likely to be arrested. Since most of the incidents in this study involved parties of the opposite sex, this may be taken as evidence that, for a variety of reasons, the police are adopting a more lenient attitude toward females by being less inclined to impute shared culpability to a female than a male whom they have designated as the second party in a heterosexual incident. This finding, it should be noted, is consistent with prior research on this issue (Buzawa \& Hotaling, 2000; Jones \& Belknap, 1999). Indeed, our finding that male victim/female aggressor pairs were three times more likely to constitute a dual arrest than were female victim/male aggressor pairs parallels the ratio recorded by Jones \& Belknap (1999).

Our findings on the effect of race are somewhat perplexing. Officers appear to consider race in their arrest decisions and arrest white people more often. Incidents with a minority female 
victim and a male offender were particularly likely not to result in an arrest compared to similar incidents involving whites. This finding appears to support Black’s (1976) theory that violence among minorities is more likely to be viewed as "normal behavior" and thus police are less likely to invoke their arrest powers. Cases involving whites were, however, less likely than cases involving minorities to result in conviction. A number of factors, such as social status, type of legal representation, willingness of the victim to proceed with the prosecution, and access to diversion programs may explain why whites were more likely to be arrested, but less likely to be convicted. These constitute important issues that merit further investigation.

The presence of minors was also observed to increase the likelihood of arrest, but not the likelihood of conviction. This may be taken as evidence that the police take seriously the well documented deleterious effects that children experience as a result of exposure to domestic violence (see, e.g. Buka, Stichick, Birdthistle \& Felton, 2001; Edleson, 1999; Henning, Leitenberg, Coffey, Turner \& Bennett, 1996; McNeal \& Amato, 1998; Graham-Bermann \& Levendosky, 1998). When, however, the focus turns to processing the criminal cases against the defendant, and the police intervention has triggered some system response to the needs of the children, typically by involving the Department of Social Services, it is perhaps to be expected that this consideration would no longer feature so prominently.

A third circumstance in which an incident was more likely to result in arrest, but not in conviction, relates to the type of jurisdiction in which the incident occurred. Arrest, but not conviction, was more likely to occur if the incident took place in a core, as opposed to a satellite, jurisdiction. This finding suggests a contextual effect on police arrest practices which merits further investigation.

The significant association between an offender remaining on the scene and arrest is 
This document is a research report submitted to the U.S. Department of Justice. This report has not been published by the Department. Opinions or points of view expressed are those of the author(s) and do not necessarily reflect the official position or policies of the U.S. Department of Justice.

consistent with prior research (Eigenberg et al., 1996; Feder, 1996; Robinson \& Chandeck, 2000

) and indicates the need to conduct more intensive follow-up on offenders who have left the scene. This is particularly important in light of prior research (Buzawa et al., 1999) indicating that these offenders may, in fact, be more dangerous than those who remain on the scene.

Findings related to case prosecution and rearrest underscore the importance of policies designed to improve, and not simply increase, arrests and convictions in intimate partner violence cases. Officers were more likely to make arrests in cases with an injured victim, and those cases were more likely to result in conviction. Consistent with our previous finding that the police were more likely to arrest in intimate partner violence cases, we also observed that conviction was more likely to occur in intimate partner than in other domestic cases. This may be an indication that there is a system wide inclination to treat intimate partner violence cases more seriously than other domestics. However, considerably less than half of the cases that reached the prosecutor's office resulted in conviction. In addition, the increase in arrests for cases of intimate partner violence seen in mandatory arrest states is not supported by an increase in conviction. Prosecutors, faced with an increasing caseload that comes from implementation of mandatory arrest, may have to choose those cases with the best chance of conviction. These cases typically are those that are more serious and involve an offender with a criminal historyfactors that were in fact associated significantly with conviction in our data.

The data on rearrest make a clear argument for improving arrest policies with regard to accounting for the use of alcohol or drugs in incidents. Although substance use was not significantly associated either with arrest or conviction, it was associated significantly with reoffending. For police, this means that more attention should be paid to this factor, and its documentation in incident reports. This finding would also appear to highlight the recognized 
interrelationship between alcohol/drug use and battering, and the need for offenders to receive treatment for both problems.

Several limitations of our study must be noted. First, we rely solely on official data for our information on the police response to incidents, the court processing of those incidents, and subsequent reoffending. No information was obtained from the victims in these incidents. Second, both large police jurisdictions, and police jurisdictions from Western states, were underrepresented in the NIBRS dataset used for Phase I analyses. Third, police reports did not always contain the information we sought in our Phase II analyses and, as a result, some of the variables we intended to use could not be used in the ensuing multivariate analyses. Fourth, both the lack of availability of desired data elements, and concerns about the quality of the available data elements, led to the exclusion of some jurisdictions from certain aspects of Phase II analyses. Fifth, the expungement of criminal records, and uncertainty about the extent of expungement, throws some doubt on the validity of the rearrest data. While the results of this study must be viewed in the light of these limitations, we believe that our findings, particularly with regard to the police response, are sufficiently robust to withstand the concerns that these limitations raise.

These results should, in general, be reassuring to legislators and community members who supported the creation of mandatory arrest laws to improve the consistency and severity with which police treat domestic violence. However, those who sought to provide officers with somewhat greater decision-making authority, by enacting preferred arrest laws, will be pleased as well since these laws appear to mitigate the tendency toward dual arrest—which is considered by many to be a poor outcome-as well as the influence of race on the likelihood of arrest. The focus now, it appears, should be on what happens at the court stage. 


\section{REFERENCES}

Avakame, Edem F., \& James J. Fyfe. (2001). Differential police treatment of male-on-female spousal violence. Violence against Women, 7, 22-45.

Applegate, R.J. (2006). Changing local policy and practice towards the policing of domestic violence in England and Wales. Policing: An international journal of police strategies and management, 29:2, 368-383.

Bayley, David H. (1986). The tactical choices of police patrol officers. Journal of Criminal Justice, 14, 329-348.

Berk, Richard, \& Newton Phyllis. (1985). Does arrest deter wife battery? An effort to replicate the findings of the Minneapolis spouse abuse experiment. American Sociological Review, 50, 253-262.

Berk, Richard. A., \& Lawrence Sherman. (1988). Police responses to family violence incidences: An analysis of an experimental design with incomplete randomization. Journal of the American Statistical Association, 83, 70-76.

Berk, Sara. F., \& Donileen R Loseke. (1980-1981). “Handling” family violence: Situational determinants of police arrests in domestic disturbances. Law and Society Review, 15, 317-346.

Bittner, Egon. (1974). Florence Nightingale in pursuit of Willie Sutton: A theory of the police. In H. Jacob (Ed.), The potential for reform of criminal justice. Beverly Hills, CA: Sage.

Black, Donald. (1980). The manners and customs of the police. New York: Academic Press.

Bourg, Sherrie, \& Harley V. Stock. (1994). A review of domestic violence statistics in a police department using a pro-arrest policy: Are pro-arrest policies enough? Journal of Family Violence, 9, 177-189. 
Bruno v. Codd, 396 N.Y.S.2d 974, (Sup. Ct. 1977), rev’d, 64 A.D.2d 582 (N.Y. App. Div. 1978), aff'd, 393 N.E.2d 976 (N.Y. 1979).

Bryk, Anthony S., \& Stephen W. Raudenbush. (1992). Hierarchical Linear Models.

Sage Publications. CA.: Newbury Park.

Buka, Stephen L, Theresa L Stichick, Isolde Birdthistle, \& Felton J Earls. (2001 July). Youth

Exposure to Violence: Prevalence, Risks, and Consequences. American Journal or

Orthopsychiatry, 71:3, 298-310.

Busch, Amy L., \& Mindy S. Rosenberg. (2004). Comparing women and men arrested for domestic violence: A preliminary report. Journal of Family Violence, 19, 49-57.

Bushman, Brad J. (1993). Human aggression while under the influence of alcohol and other drugs: An integrative research review. Current Directions in Psychological Science, 2, 148-152.

Buzawa, Eve, \& Thomas Austin. (1993). Determining police response to domestic violence victims. American Behavioral Scientist, 36, 610-623.

Buzawa, Eve, Thomas Austin, \& Carl G. Buzawa. (1995). Responding to crimes of violence against women: Gender differences vs. organizational imperatives. Crime \& Delinquency, 41(4), 443466.

Buzawa, Eve. S., \& Carl G. Buzawa. (2003). Domestic violence: The criminal justice response (3rd ed.). Thousand Oaks, CA: Sage.

Buzawa, Eve, \& Gerald Hotaling. (2000). The police response to domestic violence calls for assistance in three Massachusetts towns: Final report. Washington, D.C.: National Institute of Justice.

Buzawa, Eve, Gerald Hotaling, Andrew Klein, \& James Byrne. (1999). Response to domestic violence in a pro-active court setting: Final Report. Washington, D.C.: National Institute of Justice.

Cassidy, M., Caroline G. Nicholl, Carmen R. Ross, \& Kimberly A. Lonsway. (2004). The Victim’s 
View: Domestic Violence and the Police Response. Law Enforcement Executive Forum, 4(1), $135-152$.

Chaney Carole K., \& Grace H. Salzstein. (1998). Democratic control and bureaucratic responsiveness:

The police and domestic violence. American Journal of Political Science, 42, 745-768.

Chesney-Lind, Meda. (1988 July-August). Doing feminist criminology. The Criminologist, 13, 16-17.

Chesney-Lind, Meda. (2006). Patriarchy, crime and justice: Feminist criminology in an era of backlash.

Feminist Criminology, 1(1), 6-26.

Chesney-Lind, Meda, \& Lisa J. Pasko. (2004). The female offender. Thousand Oaks: Sage Publications.

Comack, Elizabeth, Vanessa Chopyk, \& Linda Wood. (2000). Mean streets? The social locations, gender dynamics, and patterns of violent crime in Winnipeg. Ottawa, Ontario: Canadian Centre for Policy Alternatives.

Connecticut Department of Public Safety. (2000). Crime in Connecticut: 2000 Annual report. Middletown, CT: Connecticut State Police.

Coulter, Martha L., Kathryn Kuehnle, Robert Byers \& Moya Alfonso. (1999). Police-reporting behavior and victim-police interactions as described by women in a domestic violence shelter. Journal of Interpersonal Violence, 14, 1290-1298.

DeLeon-Granados, William, William Wells, \& Ruddyard Binsbacher. (2006). Arresting developments: Trends in female arrests for domestic violence and proposed explanations. Violence against Women, 12, 355-370.

Dolon, R., James Hendricks, \& Steven M. Meagher. (1986). Police practices and attitudes toward domestic violence. Journal of Police Science and Administration, 14, 187-192.

Domestic Violence Training and Monitoring Unit (2001a). "DV cases arrests, dual arrest \& multiple 
involvement. Domestic violence and sexual assault reports (from 01/01/99 -12/31/00), DV \#02,” http://courts.state.ri.us/domesticnew/dvsa/reports_dloads.htm (accessed 5 July 2002)

Domestic Violence Training and Monitoring Unit (2001b). “DV cases arrests by gender. Domestic violence and sexual assault reports (from 01/01/99 -12/31/00), DV\# 04,” http://courts.state.ri.us/domesticnew/dvsa/reports_dloads.htm (accessed 5 July 2002)

Dutton, Donald. (1984). The criminal justice response to wife assault. Law and Human Behavior, 11, 189-206.

Durose, Matthew R., Caroline W. Harlow, Patrick A. Langan, Mark Motivans, Ramona R. Rantala, \& Erica L. Smith. (2005). Family violence statistics. Washington, D.C.: Department of Justice. Edleson, Jeffrey L. (1999 August). Children's witnessing of adult domestic violence. Journal of Interpersonal Violence, 14:8, 839(3).

Edwards, Susan. M. (1989). Policing domestic violence: Women, law and the state. London: Sage.

Eigenberg, Helen M. (2001). Woman battering in the United States: Till death do us part. Prospect Heights, IL: Waveland.

Eigenberg, Helen. M., Kathryn E. Scarborough, \& Victor E. Kappeler. (1996). Contributory factors affecting arrest in domestic and non-domestic assaults. American Journal of Police, 15, 27-54.

Eitle, David. (2005). The influence of mandatory arrest policies, police organizational characteristics, and situational variables on the probability of arrest in domestic violence cases. Crime and Delinquency, 51, 573-597.

Elliott, Delbert S. (1989). Criminal justice procedures in family violence crimes. In Michael Tonry \& Norval Morris (Eds.), Family violence (pp. 427-480). Chicago: University of Chicago Press. 
Epstein, S. D. (1987). The problem of dual arrest in family violence cases. Meriden, CT: Connecticut Coalition Against Domestic Violence.

Feder, Lynette. (1996). The importance of offender's presence in the arrest decision when police respond to domestic violence calls. Journal of Criminal Justice, 12, 279-305.

Feder, Lynette. (1998). Police handling of domestic violence calls: Is there a case for discrimination? Crime \& Delinquency, 44(2), 139-153.

Federal Bureau of Investigation, U.S. Department of Justice. (2000). National incident based reporting system Volume 1: Data Collection Guidelines. Washington, D.C.

Felson, Richard B., \& Jeff Ackerman. (2001). Arrests for domestic and other assaults. Criminology, 39(3), 655-676.

Ferraro, Kathleen. (1989a). The legal response to women battering in the United States. In J. Hanmer, J. Radford, \& E. Stanko (Eds.), Women, policing, and male violence (pp. 155-184). London: Routledge \& Kegan Paul.

Fyfe, James.J., David Klinger, \& Jeanne M. Flavin. (1997). Differential police treatment of male-onfemale spousal violence. Criminology, 35, 455-473.

Governor’s Division for Prevention of Family Violence. (2001). Fiscal year 2001 annual report. Phoenix, AZ: Author.

Greenfeld, Lawrence A., \& Tracy L. Snell. (1999). Women offenders. Washington, D.C.: U.S. Department of Justice.

Greenfield, Lawrence A., Michael R. Rand, Diane Craven, Patsy A. Klaus, Craig A. Perkins, Cheryl Ringel, Greg Warchol, Cathy Maston, \& James A. Fox. (1998). Violence by intimates: Analysis of data on crimes by current or former spouses, boyfriends, and girlfriends. Washington, D.C.: Bureau of Justice Statistics. 
Graham-Bermann, Sandra A. and Alytia A Levendosky. (1998 February).Traumatic stress symptoms in children of battered women. Journal of Interpersonal Violence, 13:1, 111(18).

Greenfield, Lawrence A., Michael R. Rand, Diane Craven, Patsy A. Klaus, Craig A. Perkins, Cheryl Ringel, Greg Warchol, Cathy Maston, \& James A. Fox (1998). Violence by intimates: Analysis of data on crimes by current or former spouses, boyfriends, and girlfriends. Washington, D.C.: Bureau of Justice Statistics.

Hall, Donna. (2005). Domestic violence arrest decision making: The role of suspect availability in the arrest decision. Criminal Justice and Behavior, 32, 390-411.

Haviland, Mary, Victoria Frye, Valli Rajah, Juhu Thukral, \& Mary Trinity. (2001). The Family Protection and Domestic Violence Act of 1995: Examining the effects of Mandatory Arrest in New York City. New York: Urban Justice Center.

Henning, Kris, Harold Leitenberg, Patricia Coffey, Tonia Turner, \& Robert T. Bennett. (1996 March). Long-term psychological and social impact of witnessing physical conflict between parents. Journal of Interpersonal Violence, 11:1 35(17).

Heyman, Richard E., K. Daniel O’Leary, \& Ernest N. Jouriles (1995). Alcohol and aggressive personality styles: Potentiators of serious physical aggression against wives? Journal of Family Psychology, 9, 44-57.

Hirschel, David \& Eve Buzawa. (2001). Explaining the prevalence, context, and consequences of dual arrest in intimate partner cases. Proposal submitted to U.S. Department of Justice, National Institute of Justice.

Hirschel, J. David, \& Eva Buzawa. (2002). Understanding the context of dual arrest with directions for future research. Violence against Women, 8, 1449-1473. 
Hirschel, David \& Eva Buzawa. (2003). Explaining the prevalence, context, and consequences of dual arrest in intimate partner cases. Supplementary proposal submitted to U.S. Department of Justice, National Institute of Justice.

Hirschel, J. David, \& Charles W. Dean. (1995). The relative cost-effectiveness of citation and arrest. Journal of Criminal Justice, 23(1), 1-12.

Hirschel, J. David, \& D.J. Dawson. (2000). Violence against women: Synthesis of research for law enforcement officials. Washington, D.C.: U.S. Department of Justice.

Hirschel, J. David, \& Ira W. Hutchison. (2001). The relative effects of offense, offender, and victim variables on the decision to prosecute domestic violence cases. Violence against Women, 7, 4659.

Hirschel, J. David, \& Ira W. Hutchison. (2003). The voices of domestic violence victims: Predictors of victim preference for arrest and the relationship between preference for arrest and revictimzation. Crime and Delinquency, 49, 313-336.

Hirschel, J. David, Ira W. Hutchison, Charles W. Dean, \& Anne-Marie Mills. (1992). Review essay on the law enforcement response to spouse abuse: Past, present, and future. Justice Quarterly, 9, 247-283.

Ho, Taiping. (2000). Domestic violence in a southern city: The effects of a mandatory arrest policy on male-versus-female aggravated assault incidents. American Journal of Criminal Justice, 25, 107-118.

Ho, Truc-Nhu. (2003). The influence of suspect gender in domestic violence arrests. American Journal of Criminal Justice, 27, 183-195.

Holmes, William M., \& Daniel Bibel. (1988). Police response to domestic violence: Final report. Washington, D.C.: Bureau of Justice Statistics. 
Hotaling, Gerald T., \& Eve Buzawa. (June, 2001). An Analysis of Assaults in Rural Communities:

Final Report. Federal Grant \#MA0095-400, U.S. Department of Justice, Office of Community

Oriented Policing Services.

Houry, Debra, Sudha Reddy \& Constance Parramore. (2006). Characteristics of victims coarrested for intimate partner violence. Journal of Interpersonal Violence, 21, 1483-1492.

Hughes, Tom. (2001). Police officers and civil liability: "the ties that bind”? Policing: An international journal of police strategies \& management, 24:2, 240-262.

Hutchinson, Ira W. (1999). The influence of alcohol and drugs on women's utilization of the police for domestic violence: Final Report. Washington D.C.: National Institute of Justice.

Hutchison, Ira W., \& J. David Hirschel. (2001). The effects of children’s presence on woman abuse. Violence and Victims, 16, 3-17.

Jones, David A., \& Joanne Belknap. (1999). Police responses to battering in a progressive pro-arrest jurisdiction. Justice Quarterly, 15, 249-273.

Kantor, Glenda K., \& Murray A. Straus. (1989). Substance abuse as a precipitant of wife abuse victimizations. American Journal of Drug and Alcohol Abuse, 15:2, 173 (17).

Kassel, Philip. (1985). Ironic consequences of domestic violence law. National Lawyers Guild AntiSexism Newsletter, 1(2), 4.

Kingsnorth, Rodney. (2006). Intimate Partner Violence: Predictors of recidivism in a sample of arrestees. Violence Against Women, 12, 917-935.

Klein, Andrew R. (2004). The criminal justice response to domestic violence. Belmont, CA: Wadsworth/Thompson Learning. 
Klein, Andrew R. \& A. Crowe. (2006, May). Findings from an outcome examination of Rhode Island's specialized domestic violence probation supervision program: Do specialized supervision of batterers reduce reabuse? Paper presented at the NEACJS Annual Meeting.

Klinger, David. (1995). Policing spousal assault. Journal of Research in Crime and Delinquency, 32, 308-24.

Kreft, Ira G. (1996). Are Multilevel Techniques Necessary? An Overview, Including Simulation Studies. Obtained online Oct. 2005 at http://www.calstatela.edu/faculty/ikreft/quarterly.html

Lawrenz, Frances, James F. Lembo, \& Thomas Schade. (1988). Time series analysis of the effect of a domestic violence directive on the number of arrests per day. Journal of Criminal Justice, 16, 493-498.

Maltz, Michael. D. (1998). Visualizing homicide: A research note. Journal of Quantitative Criminology, 14, 387-410.

Manning, Peter. (1997). Police work: The social organization of policing. Prospect Heights, IL: Waveland.

Martin, Margret. (1997). Mandatory arrest for domestic violence: The courts’ response. Criminal Justice Review, 19, 212-227.

Martin, Margaret. (1997). Double your trouble: Dual arrest in family violence. Journal of Family Violence, 12, 139-157.

Mastrofski, Steven D., R..Richard Ritti, \& Debora Hoffsmaster. (1987). Organizational determinants of police discretion: The case of drinking-driving. Journal of Criminal Justice, 15, 387-402.

McNeal, Cosandra and Paul R. Amato. (1998 March). Parents’ marital violence: long-term consequences for children. Journal of Family Issues, 19:2, 123(17). 
Mignon, Sylvia I., \& William M. Holmes. (1995). Police response to mandatory arrest laws. Crime and Delinquency, 41, 430-443.

Miller, Susan. (2005). Victims as offenders: Women's use of violence in relationships. New Brunswick, NJ: Rutgers University Press.

Moffit, Terrie E., Avshalom Caspi, Michael Rutter, \& Phil A. Silva. (2001). Sex differences in antisocial behavior: Conduct disorder, delinquency, and violence in the Dunedin Longitudinal Study. Cambridge, England: Cambridge University Press.

Municipality of Anchorage. (2000). Analysis of police action and characteristics of reported domestic violence in anchorage, Alaska ten year study, 1989-1998. Anchorage, AK: Author.

National Research Council. (2004). Advancing the federal research agenda on violence against women. Washington, D.C.: The National Academic Press.

Office of the Attorney General, State of California. (1999). Report on arrest for domestic violence in California, 1998. Sacramento, CA: Author.

Oppenlander, Nan. (1982). Coping or copping out: Police service delivery in domestic disputes. Criminology, 20, 449-465.

Pagelow, Mildred D. (1984). Family violence. New York: Praeger.

Parnas, Raymond I. (1967). The police response to intra-family violence. Wisconsin Law Review, 2, 914-960.

Peng, Yu-Kuei, \& Dennis C. Mitchell. (2001). Dual arrest among intimate partners for family violence offenses in Connecticut. Middletown, CT: Connecticut State Police, Crime Analysis Unit. 
Pleck, Elizabeth. (1989). Criminal approaches to family violence 1640-1980. In L. Ohlin \& M. Tonry (Eds.), Crime and justice: A review of research (pp. 19-58). Chicago: University of Chicago Press.

Raudenbush, Stephen, Anthony Bryk, Yuk Fai Cheong, Richard Congdon, \& Mathilda DuToit. (2005). HLM6: Hierarchical Linear \& Non Linear Modeling. Lincolnwood, IL: Scientific Software International.

Rennison, Callie M. (2003). Intimate partner violence 1993-2001. Washington, D.C.: Bureau of Justice Statistics.

Rennison, Callie M., \& Welchans Sarah. (2000). Intimate partner violence. Washington D.C.: U.S. Department of Justice.

Renzetti, Claire M. (1999). The challenge to feminism posed by women’s use of violence in intimate relationships. In S. Lamb (Ed.), New versions of victims (pp. 42-56). New York: New York University Press.

Robinson, Amanda L., \& Meghan S. Chandek. (2000). Philosophy into practice? Community policing units and domestic violence victim participation. Policing: An International Journal of Police Strategies and Management, 23, 280-302.

Roots, Roger I. (2004). When laws backfire: Unintended consequences of public policy. American behavioral scientist, 47:11, 1376-1394.

Roizen, J. (1993). Issues in the epidemiology of alcohol and violence. In S. E. Martin (Ed), Alcohol and interpersonal violence: Fostering multidisciplinary perspectives (pp 3-36). Rockville, MD: National Institute on Alcohol Abuse and Alcoholism.

Saunders, Daniel. G. (1995). The tendency to arrest victims of domestic violence. Journal of Interpersonal Violence, 10, 147-158. 
Schafer, John, Raul Caetano, \& Carol B. Cunradi. (2004). A path model of risk factors for intimate partner violence among couples in the United States. Journal of Interpersonal Violence, 19, 127142.

Schmidt, J., \& E. H. Steury. (1989). Prosecutorial discretion in filing charges in domestic violence cases. Criminology, 27, 487-510.

Scott v. Hart, No. 6-76-2395, N.D. Cal. (1976).

Sherman, Lawrence W., \& Richard. A. Berk. (1984a). The Minneapolis domestic violence experiment. Washington, D.C.: Police Foundation.

Sherman, Lawrence W., \& Richard. A. Berk. (1984b). The specific deterrent effects of arrest for domestic assault. American Sociological Review, 49, 261-272.

Simpson, Sally S., Leana A. Bouffard, Joel Garner, \& Lauara Hickman. (2006). The influence of legal reform on the probability of arrest in domestic violence cases. Justice Quarterly, 23, 297-316.

Skolnick, Jerome H. (1966). Justice without trial. New York: John Wiley.

Smith, D. A., \& J. Klein. (1984). Police control of interpersonal disputes. Social Problems, 31, 468-481.

Stanko, Elizabeth. A. (1985). Would you believe this women? In N.H. Rafter \& E.A.

Stanko (Eds.), Judge, lawyer, victim, thief: Women, gender roles and criminal justice. Boston: Northeastern University Press.

Straus, Murray A. (2006). Future research on gender symmetry in physical assaults on partners. Violence against women, 12:11, 1086-1097.

Straus, Murray A., Richard J. Gelles, \& Suzanne Steinmetz. (1980). Behind closed doors: Violence in the American family. Newbury Park, CA: Sage.

Swan, Suzanne C. \& David L. Snow. (2006). The development of a theory of women's use of violence in intimate relationships. Violence Against Women, 12, 1026-1045) 
Thurman et al. v. City of Torrington, 595 F. Supp. 1521 (D. Conn. 1984).

Tjaden, Patricia, \& Nancy Thonness. (1998). Prevalence, incidence and consequences of violence against women: Findings from the National Violence against Women Survey. Washington D.C.: U.S. Department of Justice.

U.S. Department of Justice, Bureau of Justice Statistics. (2005). Family violence statistics. Washington, D.C.

Van Wyk, Judy A., Michael L Benson, Greer L. Fox, \& Alfred DeMaris. (2003). Detangling individual, partner, and community-level correlates of partner violence. Crime and Delinquency, 49(3), $412-438$

Victim Services Agency. (1988). The law enforcement response to family violence: A state by state guide to family violence legislation. New York: Author.

Wanless, Marion. (1996). Mandatory arrest: A step towards eradicating domestic violence, but is it enough? University of Illinois Law Review, 2, 533-587.

Wilson, James Q. (1968). Varieties of police behavior: The management of law and order in eight communities. Cambridge, MA.: Harvard University Press.

Worden, Robert E. (1989). Situational and attitudinal explanations of police behavior: A theoretical reappraisal and empirical assessment. Law \& Society Review, 23, 667-711.

Worden, Robert E., \& Alissa A. Pollitz. (1984). Police arrests in domestic disturbances: A further look. Law and Society Review, 18, 105-119.

Worden, Robert E., \& Robin Shepard. (1996). Demeanor, crime and police behavior: A reexamination of the Police Services Study data. Criminology, 34, 83-105.

Zorza, Joan. (1994). Woman battering: High costs and the state of the law (Special issue). Clearinghouse Review, 28, 383-395. 

been published by the Department. Opinions or points of view expressed are those of the author(s) and do not necessarily reflect the official position or policies of the U.S. Department of Justice.

Zorza, Joan, \& Laurie Woods. (1994). Mandatory arrest: Problems and possibilities.

Washington, D.C.: Center on Women and Family Law. 